\title{
WHO IS THE IDEAL WORKER? \\ HOW GENDERED ORGANIZATIONS ADVERSELY IMPACT WOMEN'S \\ PROMOTABILITY AND DEVELOPMENT
}

A Dissertation
presented to
the Faculty of the Graduate School
at the University of Missouri-Columbia
In Partial Fulfillment
of the Requirements for the Degree
Doctor of Philosophy
CLARISSA R. STEELE
Dr. Daniel Turban, Dissertation Supervisor
MAY 2020


The undersigned, appointed by the dean of the Graduate School, have examined the dissertation entitled

\section{WHO IS THE IDEAL WORKER? HOW GENDERED ORGANIZATIONS ADVERSELY IMPACT WOMEN'S PROMOTABILITY AND DEVELOPMENT}

presented by Clarissa Steele, a candidate for the degree of Doctor of Philosophy of Business Administration, and hereby certify that, in their opinion, it is worthy of acceptance.

\section{Professor Daniel Turban}

Professor Christopher Robert

Professor Karen Schnatterly

Professor Amanda Rose 


\section{ACKNOWLEDGEMENTS}

I would like to thank my dissertation advisor and my committee members for their feedback and support in preparing this dissertation. I would like to thank Professor Daniel Turban for his dedication in mentoring me throughout my dissertation program, and particularly through the dissertation process. I have learned so much about how to be a better researcher and a better colleague through his words of wisdom and advice based on his own experiences as a scholar. I would also like to thank Professors Christopher Robert, Karen Schnatterly, and Amanda Rose for their help in crafting my research questions and testing my ideas throughout the dissertation process. I have found it useful to work with researchers who have expertise on different topics and have experience with

different methods in their own research. My committee helped me to brainstorm creative solutions to challenges I encountered as I developed my dissertation research. 
TABLE OF CONTENTS

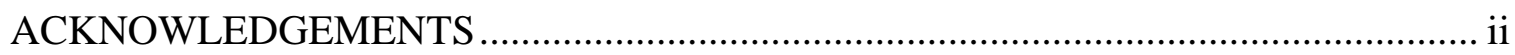

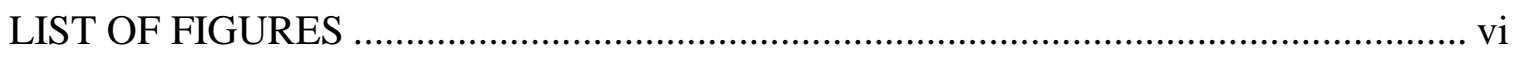

LIST OF TABLES ………………….................................................................. vii

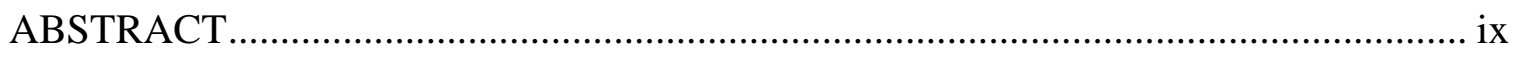

Chapter

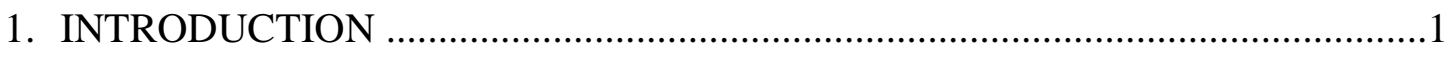

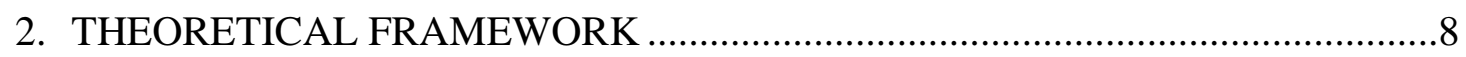

Gender Role Stereotypes

The Theory of Gendered Organizations

The Ideal Worker Stereotype

The Gendered Ideal Worker

Promotability and Development

The Effect of Stereotypes on Decision Making in Work Contexts

Individual Sexism Beliefs as a Moderator of the Association between Ideal Worker Attributes and Gender Role Stereotypes

The Dual Process Model of Stereotyping: Systematic vs. Automatic Associations

Overview of Studies

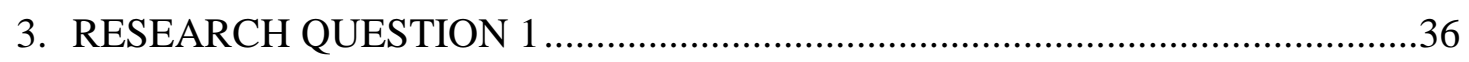

Method

Results

Discussion

4. RESEARCH QUESTION 2

Method

Results 
Discussion

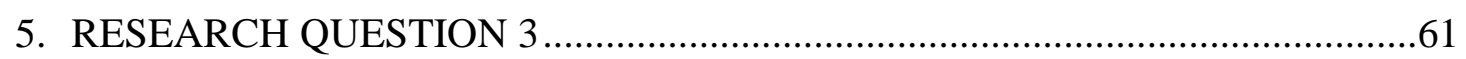

Method

Results

Discussion

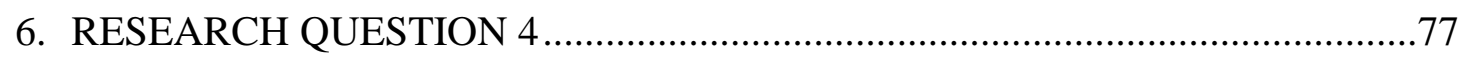

Method

Results

Discussion

7. RESEARCH QUESTION 5

.88

Method

Results

Discussion

8. GENERAL DISCUSSION

The Ideal Worker as a Stereotype

Unconscious Associations between Ideal Worker and Gender Role Stereotypes

Individual Differences and the Ideal Worker Stereotype

Limitations and Future Research Directions

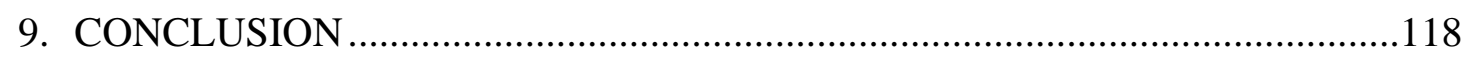

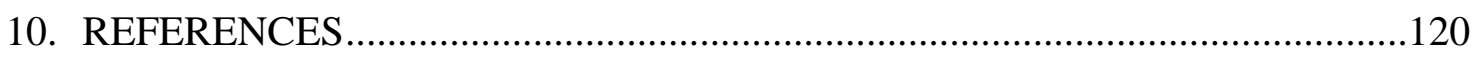

APPENDIX

1. RESEARCH QUESTION 1 SURVEY (SAMPLE 1) .......................................130

2. RESEARCH QUESTION 1 RESULTS FOR IDEAL WORKER ITEM

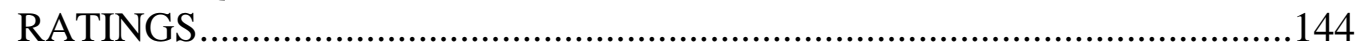

3. RESEARCH QUESTION 2 SURVEY (SAMPLE 4) .....................................158 
4. RESEARCH QUESTION 2 RESULTS FOR IDEAL WORKER ITEM

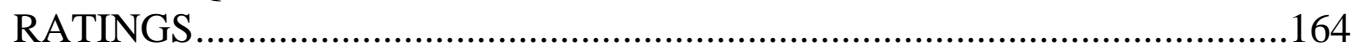

5. RESEARCH QUESTIONS 3 AND 4 SURVEY ...........................................171

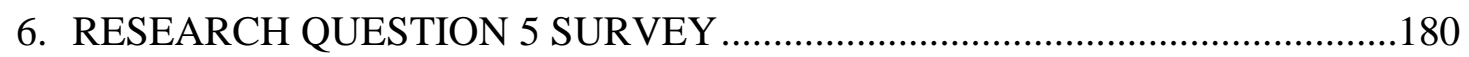

7. RESEARCH QUESTION 5 STUDY IMPLICIT ASSOCIATION PRE-TEST

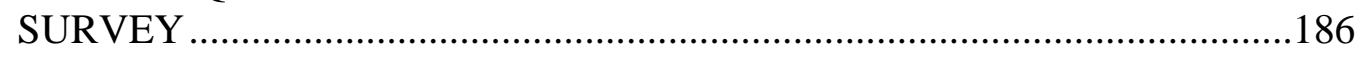

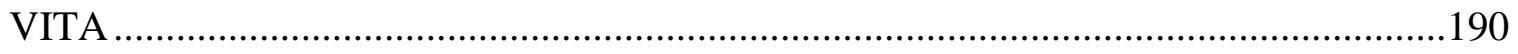




\section{LIST OF FIGURES}

Figure

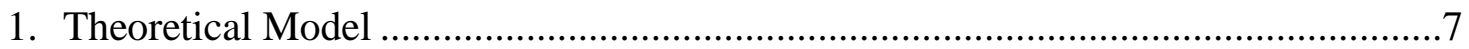

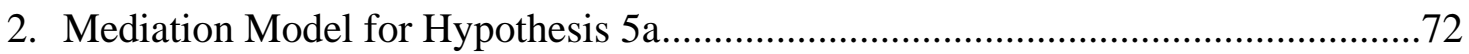

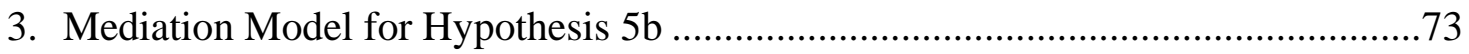

4. Two-Way Interaction between Employee Gender and Rater's Benevolent Sexism Beliefs Predicting Ideal Worker Rating (Hypothesis 6a) .................................83

5. Two-Way Interaction between Employee Gender and Rater's Modern Sexism Beliefs Predicting Ideal Worker Rating (Hypothesis 6b) ..................................84

6. Two-Way Interaction between Employee Gender and Rater's Benevolent Sexism Beliefs Predicting Recommended Development (Hypothesis 7b)

7. Two-Way Interaction between Employee Gender and Rater's Modern Sexism Beliefs Predicting Recommended Development (Hypothesis 6b) .....................86

8. Two-Way Interaction of Highly Characteristic IAT D-Score and Employee Gender Predicting Recommended Development (Hypothesis 9b)..... 


\section{LIST OF TABLES}

Table

1. Proposed Hypothesis for Each Research Question .34

2. Description of Samples and Procedures for All Research Questions .38

3. Participant-Generated Ideal Worker Descriptors from Samples 1 and 2 (in Order of Number of Mentions)

4. Ideal Worker Rated Items with Means of 4.25 and Above across All Four Samples Ranked by Mean (Ordered by Mean of Sample 4, then Sample 3) ......45

5. Significant Differences in Ideal Worker Ratings by Gender for Samples 3 and 4 ..49

6. Intraclass Correlation Coefficient Comparisons for Hypothesis 1 .57

7. Differences between Participants Whose Data Were Included and Not Included in Analysis

8. Means, Standard Deviations, and Correlations of Variables for Hypothesis 2 .......67

9. Means and Standard Deviations of Employee Outcomes by Employee Gender for Hypothesis 2

10. Means, Standard Deviations, and Correlations of Variables for Hypotheses 3 and 4

11. Means and Standard Deviations of Ideal Worker Rating by Employee Gender for Hypothesis 3

12. Regression Results for Hypothesis $4 \ldots$

13. Mediation Analysis Results for Hypothesis 5a .72

14. Mediation Analysis Results for Hypothesis $5 \mathrm{~b}$

15. Means, Standard Deviations, and Correlations of Variables for Hypotheses 5 and 6

16. Regression Results for Hypotheses 5 and 6

17. Means, Standard Deviations, and Correlations of Variables for Hypothesis 8 and 9

18. Regression Results for Hypothesis $9 \mathrm{a}$ and $9 \mathrm{~b}$ 
19. Hypotheses and Results for Each of the Research Questions ..............................104 


\begin{abstract}
Women tend to earn fewer promotions (Roth et al., 2012) and receive fewer developmental opportunities (King et al., 2012) than men, but little research explains why. I explore the stereotype of the ideal worker, someone who meets their supervisor's expectations and has the potential to be promoted to the top levels of their organization over their career, as one reason for this disparity. I propose that supervisors use this stereotype to assess employee promotability and developmental opportunities. I explore the attributes of the ideal worker stereotype using the theory of gendered organizations (Acker, 1990, 1992), which suggests that firms operate from a masculine perspective because men tend to create and lead organizations. I find that the attributes of the ideal worker are broader than suggested by the theory of gendered organizations and past research on the ideal worker, but that these attributes are not perceived as masculine. In addition, I find no differences between how men and women are rated in terms of promotability, recommended development, and the extent to which they exemplify the attributes of the ideal worker. However, the extent to which employees exemplify ideal worker attributes predicts promotability ratings and development recommended for them. Sexism, an individual difference among raters, moderates the relationship between employee gender and outcomes such that women receive lower ideal worker ratings and less recommended development when raters have high sexism beliefs. I also find that the implicit (unconscious) associations between ideal worker attributes and gender role stereotypes affects recommended development such that those with masculine implicit associations give more development to female employees. My dissertation presents future research opportunities to further investigate the ideal worker stereotype and its impact in the workplace.
\end{abstract}




\section{Introduction}

As modern economies switch from predominantly production to service, organizations increasingly rely on their human capital. To be competitive, firms must use their human capital to its fullest potential, including promoting the best employees into management, where they can have a larger impact on others. However, research on promotions shows that organizations may not always promote and develop the most qualified candidates for leadership. For instance, although women earn more than 50 percent of all college degrees and comprise 48.1 percent of the workforce in entry-level jobs, women only make up 39.8 percent of all managers in the United States (Catalyst, 2019). At the top of the organizational hierarchy, women make up less than a quarter of top leaders (Catalyst, 2019; Thomas et al., 2019), and in the Fortune 500, less than 5 percent of chief executive officers (Zarya, 2018). In addition, not only are women promoted to leadership positions at a slower rate than men, they also receive fewer developmental opportunities than their male colleagues (Lyness \& Schrader, 2006). These developmental opportunities, such as challenging work assignments and international assignments, allow employees to develop and demonstrate leadership skills and are key to promotions to leadership (Boak \& Crabbe, 2019; Day, 2000; Hezlett, 2016).

Research has focused on promotion and development decision making as a function of performance evaluations (Joshi et al., 2015). However, the higher rate of promotions and development for men is not due to men performing better than women at work. Studies of performance evaluations show that women perform as well as men (Joshi, 2014; Pazy \& Oron, 2001), and sometimes even outperform men (Lyness \& 
Heilman, 2006; Roth et al., 2012), across organizational levels. Since performance evaluations do not predict promotions and development recommended to employees, it seems these decisions hinge on information beyond that provided in an employee's performance evaluation. One piece of information that is likely important in these decision-making processes, but that has been little researched in the management literature, is promotability. Promotability is a supervisor's perception of how successful an employee will be at the next organizational level, often a position in management (De Pater et al., 2009; Greenhaus et al., 1990; London \& Stumpf, 1983). Promotability is a prediction about an employee's future performance and is different from the employee's past performance, which is assessed in the performance evaluation process. Although little research has investigated the relationship between promotability and development, they are likely related. When employees are considered highly promotable, they are offered more developmental opportunities such as challenging tasks because supervisors believe these employees are most likely to succeed (Harris et al., 2006). These opportunities help employees to develop additional skills and knowledge, which may make them more promotable in the future. Even though promotability is important to all employees in their careers, women are usually considered less promotable than men (Hoobler et al., 2009; Lynesss \& Heilman, 2006; Post et al., 2009; Roth et al., 2012), but this research provides little insight into the mechanisms that explain the disparities between men's and women's promotability.

Current performance may be an imprecise measure for how well an employee will perform at the next hierarchical level of the organization because the knowledge, skills, and abilities may be so different between these job roles that current performance 
inadequately assesses an employee's ability to take on a new role. Because of this ambiguity, information such as stereotypes may influence promotion and development decision making, even when decision-makers are unaware of its influence. One stereotype that may be important in the workplace is the ideal worker stereotype, which describes the attitudes and behaviors of an employee who fulfills supervisor expectations and has the ability to move up to the top of the organizational hierarchy over their career. The ideal worker stereotype may influence promotion and development decision making because the ideal worker seems like the kind of employee any supervisor would want to rise in the organization. The drawback of this stereotype is that it may introduce bias into the decision-making process. According to the theory of gendered organizations, being an ideal worker requires that an employee prioritize work over all other aspects in life, which includes being available for work when needed and willing to make sacrifices for work such as relocating and traveling (Acker, 1990, 1992). I propose this stereotype influences employee promotability ratings through assessments of the extent to which employees display the characteristics of the ideal worker, consistent with role congruity theory (Eagly \& Karau, 2002). The more an employee is perceived to exemplify the attributes of the ideal worker, the higher the employee's promotability. As posited by the theory of gendered organizations (Acker, 1990, 1992), the ideal worker stereotype is gendered masculine such that its attributes align with the male gender role stereotype. This gendering is important because of the social roles that men and women tend to hold in society (Eagly, 1987) such that women are generally perceived as being less able to prioritize work above other responsibilities like taking care of children. A gendered standard of comparison to assess promotability and development would introduce bias 
into the promotion and development decision-making process and hurt women's chances of being perceived as highly promotable as supervisors may be less likely to give women developmental opportunities and promote them into higher levels in the organization (Breaugh, 2011). For female employees, not being perceived as highly promotable, despite meeting high performance expectations, can stunt their careers due to fewer promotions and less development over time (Harris et al., 2006).

Although Acker $(1990,1992)$ suggests that an ideal worker stereotype exists, little research has focused on describing the attributes of this stereotype, testing whether the stereotype is masculine, and studying how the stereotype may affect employees in the workplace. Therefore, to study these ideas, I organize my dissertation around five research questions:

1. What are the attributes of the ideal worker?

2. Are these attributes gendered masculine?

3. Does the extent to which employees exemplify ideal worker attributes predict ratings of promotability and development recommended for them?

4. Do individual differences in rater sexism beliefs moderate the relationship between employee gender and employee outcomes (ideal worker rating, promotability, and recommended development) for male and female employees?

5. Do implicit associations between the ideal worker stereotype and gender role stereotypes predict promotability and recommended development for male and female employees? 
This research contributes to the theory of gendered organizations in many ways. First, by uncovering the attributes of the ideal worker stereotype, I provide one mechanism to explain the differential rates of promotion and development between male and female employees. I show that the ideal worker stereotype exists and provide attributes of the stereotype. Expanding our understanding of stereotyping to include stereotypes about employees helps us to better understand how they affect leaders and employees in the workplace. In this study, I show how these assessments affect important outcomes for employees, specifically promotability and recommended development. Second, I assess whether the ideal worker is a gendered stereotype. I test the conscious and unconscious associations between the attributes of the ideal worker stereotype and gender role stereotypes. By testing whether the ideal worker stereotype is associated with gender role stereotypes, I may show how the masculine gendering of organizations affects the expectations placed on employees and the influence of those perceptions in organizational decision making. Third, I will investigate how individual differences, as measured by sexism beliefs, influence the relationship between employee gender and perceptions of the extent to which employees exemplify the ideal worker attributes as well as employee outcomes such as promotability and recommended development. These individual differences in raters lead to different perceptions of male and female employees, even when employees have similar attributes and performance, affecting employees' careers over the short and long term.

To explore whether and how the ideal worker stereotype is gendered, I first explain the pervasiveness of gender role stereotypes in society and how these stereotypes create expectations about how men and women should behave. I then discuss how these 
gender role stereotypes seep into organizations according to the theory of gendered organizations. The gendering of organizations explains the predominance of the male gender role stereotype at work, which may influence the masculine gendering of the ideal worker stereotype. Further, I define the attributes of the ideal worker as suggested by theory and past qualitative research and describe how these attributes may be more closely related to the male gender role stereotype, as hypothesized by the theory of gendered organizations. I examine whether the extent to which an employee exemplifies the attributes of an ideal worker predicts ratings of employee promotability and development recommended to male and female employees. Because research shows that stereotypes may be influenced by individual differences, I also test whether raters' sexism beliefs moderate the relationship between the extent to which the rater perceives an employee as having the attributes of the ideal worker with promotability and recommended development decisions. Finally, I also study whether the implicit association of the ideal worker stereotype with gender role stereotypes moderates the relationship between employee gender and promotability ratings and development recommendations. Figure 1 presents my theoretical model. In the next section, I discuss why gender role stereotypes are important in society and specifically at work. 


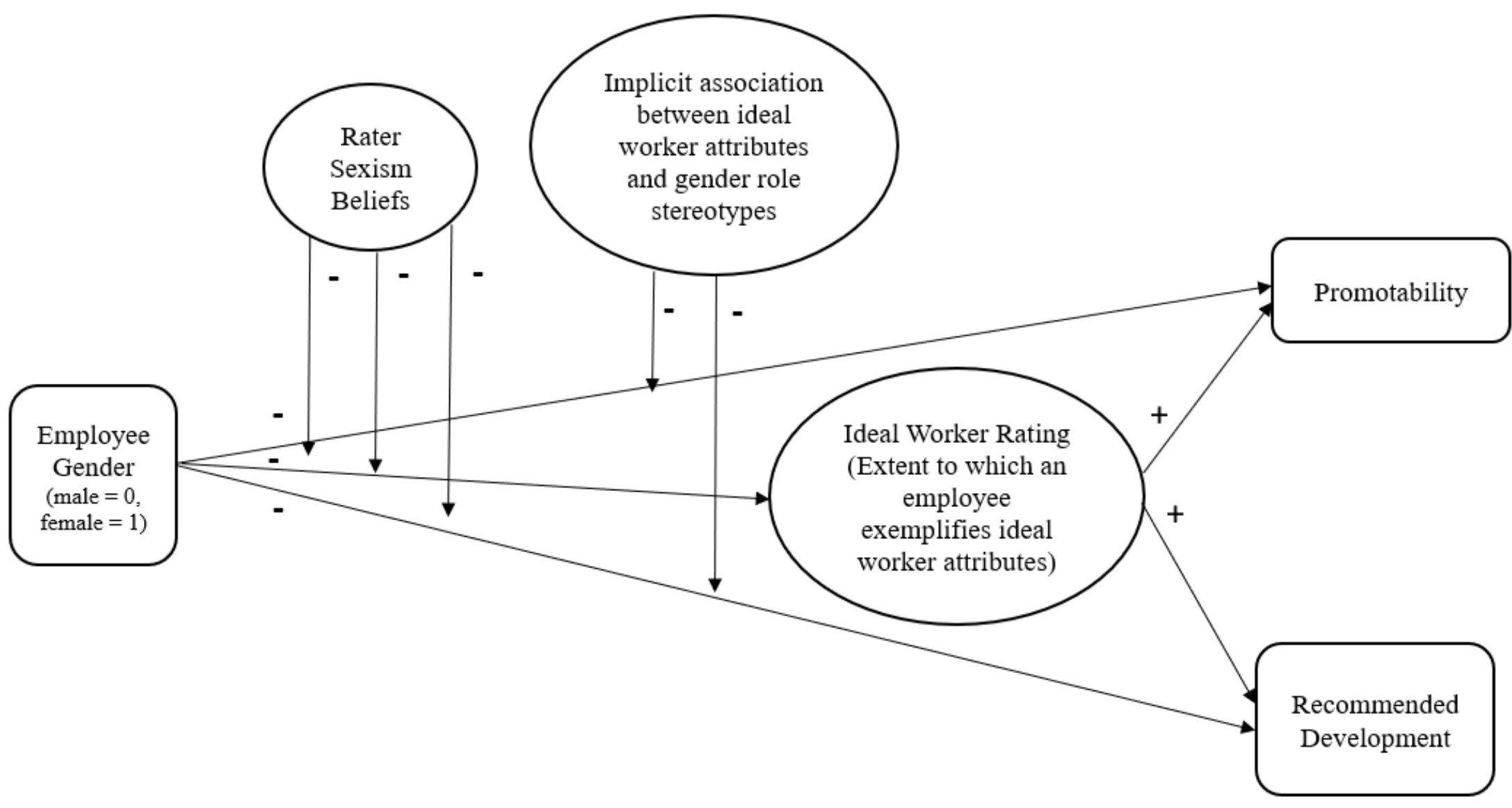




\section{Theoretical Framework}

\section{Gender Role Stereotypes}

As social beings, individuals navigate a complex world. Social situations provide people with a lot of information, but individuals are limited in how much information they can process at any moment. Due to the high cognitive load required by social interactions, cognitive schema, including stereotypes, often (unknowingly) influence people's perceptions (Fiske, 1998; Lord et al., 1984; Macrae et al., 1994; Shondrick et al., 2010). Stereotypes are beliefs about the attributes associated with people who are members of specific social groups (Hilton \& Von Hippel, 1996). They provide a schema that allows individuals to quickly infer the attributes of another person simply by identifying the social groups that person belongs to. By simplifying information about the other person, individuals can focus on aspects of the context that are new and different as well as elements of the situation that are important for determining how the person should behave in the interaction.

One of the first characteristics that people notice when they interact with others is gender (Fiske et al., 1991; Stephan, 1989). Although stereotypes vary across cultures, every culture has stereotypes about gender. From an early age, children can distinguish between males and females, and they associate specific attitudes and behaviors with each gender (Maccoby, 1988), known as gender role stereotypes. For example, in Western cultures, males are associated with being decisive, ambitious, and capable, whereas females are associated with being warm, social, and caring (Phelan et al., 2008). Since individuals learn gender role stereotypes at an early age, gender role stereotypes become a means to simplify complex social interactions throughout life. 
According to social role theory, people associate social groups with specific attributes because they see many examples of individuals from a social group fulfilling a specific role, and therefore, associate the group with the attributes of that role (Diekman \& Eagly, 2000; Eagly, 1987). Traditionally men have played the breadwinner role in their households, providing financial support to their families (Marsiglio et al., 2000). Consequently, in order to provide for their families, men are perceived as work-oriented (Rudman et al., 2012). Because women are often seen taking care of children, and because many children grow up with their mother as their primary caregiver, women are perceived as caring and warm (Ely \& Meyerson, 2000). Although these roles may be changing in society (Diekman \& Eagly, 2000), women are still predominantly responsible for childcare and other household tasks (Yavorsky et al., 2015). Thus, gender role stereotypes continue to be prevalent today.

Gender role stereotypes can describe the attributes of men and women and create expectations of how they should be. Descriptive stereotypes define what an individual is like based on a person's social category membership, while prescriptive and proscriptive stereotypes create expectations about what a person should or should not be like, respectively (Correll, 2004; Eagly \& Karau, 2002; Rudman et al., 2012). Often descriptive and prescriptive stereotypes are similar (Heilman, 2001; Prentice \& Carranza, 2002). Because of the oppositional nature of gender role stereotypes, the stereotypes associated with each gender are different from one another and mutually exclusive (Ely $\&$ Meyerson, 2000). For example, a descriptive and prescriptive stereotype for women is that they help others. For men, helping others is considered proscriptive. Instead, the 
descriptive and prescriptive stereotype for men suggests that they should be focused on their own success, which is proscriptive for women since they should be other-oriented.

Despite being aware of these stereotypes, individuals are often unaware of using them to make assumptions about others because stereotypes are automatic and unconscious (Macrae et al., 1994). Due to the primacy of gender, gender role stereotypes are automatically accessed, usually without the individual's awareness (Banaji et al., 1993). This automaticity can be useful in complex situations with a lot of new social information and in situations where the individual's cognitive resources are taxed, when it may be difficult to pay attention to every piece of information (Macrae et al., 1994). These conditions are especially likely in highly ambiguous situations, which describes the context supervisors experience when they make promotion and development decisions. At work it is difficult to see how others are performing their job roles and what other tasks they are doing around the workplace that contribute to the organization but that are not part of their job description (e.g., organizational citizenship behaviors). This ambiguity renders the workplace a cognitively demanding context, making the influence of cognitive schema, like stereotypes, stronger (Brewer, 1988, Fazio \& Olson, 2003; Shondrick et al., 2010).

Part of the reason that gender role stereotypes persist is that they are not only useful for describing others, they also set expectations about what others should be like and how they should behave. People create expectations about the members of a social group that are consistent with the descriptive, prescriptive, and proscriptive stereotypes for that group (Jones \& McGillis, 1976). According to role congruity theory, when individuals behave consistently with the stereotypes associated with their social group, 
they are said to be "role congruent." But when they do not behave consistently with these stereotypes, they are described as "role incongruent" (Eagly \& Karau, 2002). For instance, the female gender role stereotype describes women as passive, so women who are ambitious at work are perceived as role incongruent (Eagly \& Karau, 2002). A gap exists between the female gender role stereotype that women are expected to fulfill - that they be passive - and the ambition they show at work, which is consistent with the male gender role stereotype. This example demonstrates how gender role stereotypes can be limiting for employees at work. They create expectations for men and women without regard to the jobs they have, the organizations they work for, and what they need to do to be successful at work. Because of the blanket expectations gender role stereotypes create, behaving consistently with these stereotypes and doing what is needed to be successful at work may conflict with one another, leading employees to violate gender role stereotypes.

Individuals who violate gender role stereotypes may face punishment from others. When women try to act more agentically, a characteristic attributed to the male gender role stereotype, they may experience backlash (Eagly \& Karau, 2002). They are liked less, often actively disliked, are evaluated more harshly, and receive few, if any, rewards for their work (Eagly \& Karau, 2002; Heilman, 2001; Heilman \& Parks-Stamm, 2007). Women are more likely to face situations at work in which they are role incongruent because the female gender role stereotype is incompatible with the masculine expectations of the workplace. In the next section, I discuss how organizations came to be masculine as described by the theory of gendered organizations.

\section{The Theory of Gendered Organizations}


Gender role stereotypes not only apply to people, they also apply to organizations. The theory of gendered organizations posits that important aspects of the way organizations structure and reward work, as well as the way individuals interact at work, are related to gender (Acker, 1990). Acker $(1990,1992)$ proposes that because most organizations have been developed by men and have mostly male leadership, organizations operate from the point-of-view of male leaders who structure and govern the organization and the work employees do (Acker, 1992). This masculine gendering can be seen within and across organizations. For example, pay is differentiated across industries, which are segregated between genders such that industries and job roles that are dominated by men (in terms of proportion of employees) pay more than fields and positions that are dominated by women (Jarman et al., 2012). Indeed, recent research shows that as women enter professions that were traditionally dominated by men, the average pay in the industry decreases as the proportion of women overtakes the proportion of men in the field (Mandel, 2013). Likewise, this segregation occurs within organizations as well. Women often work in and are promoted to positions such as Chief Human Resources Officer or Chief Diversity Officer, positions that work with people but that are less likely to lead to the Chief Executive Officer role (DeSilver, 2018; Fuhrmans, 2020). Men, however, are more often promoted into positions such as Chief Financial Officer and Chief Operations Officer, positions that deal with firm strategy and that often directly lead to the CEO position.

Generally, the gendering of organizations can be difficult to perceive because organizations are presented as gender neutral (Acker, 1990, 1998). Since organizational processes and structures are considered separate from the people who do the work 
(Acker, 1990), gender appears to be irrelevant to how tasks are organized, the expectations employees must meet, and the way decisions are made at work. However, gender influences organizational processes, even if individuals do not recognize it. For instance, leadership is often associated with the male gender role stereotype (Eagly \& Carli, 2003a, 2003b), what has been termed the "think manager-think male" paradigm by management scholars. Managers are considered decisive, powerful, and independent, attributes that are often used to describe men. Because of this association, men are often considered more suited for managerial roles than women.

The masculine gendering of organizations occurs through four processes that are reflected in the way work is constructed as well as the symbols and images related to, interactions at, and expectations that employees try to meet at work (Acker, 1992). The first process entails arranging work through gender divisions. Historically, in most organizations, top leadership has been mostly male, while women have often dominated lower-level positions that support those leadership positions. As the research on promotions shows (Hoobler et al., 2009; Lyness \& Heilman, 2006; Post et al., 2009; Roth et al., 2012), despite women making up about half of the entry-level workforce, they make up less than one-quarter of top managers (Thomas et al., 2018). This percentage decreases in the most elite organizations such as the Fortune 500, where fewer than 5 percent of top executives are women (Zarya, 2018).

Second, these gender divisions are supported by symbols and images related to work. The association between leadership and the attributes of the male gender role stereotype supports the higher status of men and the lower status of women at work. Not only are men perceived to have the attributes of a good leader more often than women 
(Eagly \& Karau, 2002), tying good leadership to male gender role stereotype attributes makes it difficult for women to be perceived as effective managers. Women are often seen as lacking leadership characteristics, or, if they are perceived as good leaders, they are often seen as less feminine (Phelan \& Rudman, 2010). Women often cannot be considered both good leaders and feminine women. Moreover, research demonstrates that individuals tend to prefer men to women for management positions, even when the candidates for those management positions are equally qualified (Eagly et al., 1992). Thus, it can be difficult for women to convince others in the organization that they would make good leaders, and they may be passed up for leadership opportunities more than equally qualified men.

Third, interactions at work tend to replicate the power structures found in society such that men tend to have more power in interactions at work than women, even when the individuals interacting are at the same hierarchical level in the organization (Acker, 1990). This power differential comes not only from more men holding leadership positions than women, but also from the relational dynamics between men and women. These dynamics are reinforced through gender role stereotypes in which men are expected to be assertive and women passive and can be seen in the behaviors of men and women in conversation. Studies on cross-gender interactions at work show that women are interrupted more often than men, and usually by men (Smith-Lovin \& Brody, 1989); men take more turns to talk during discussions; and men frequently determine the topics of discussion (Acker, 1990). Thus, in meetings at work, men tend to have more power than women by dominating conversations and minimizing the contributions of their female colleagues. 
Finally, because prescriptive and proscriptive gender role stereotypes create expectations for men and women, employees try to live up to others' expectations about what is considered "gender-appropriate" (Acker, 1992, p. 253), particularly in terms of behavior, dress, and image (Acker, 1990). Research on women at work demonstrates that women are aware that they need to fulfill the expectations of the female gender role stereotype, such as being pleasant and non-confrontational, but that these expectations conflict with those for being a successful employee, such as speaking up and being decisive (Biernat \& Fuegen, 2001; Foschi, 2000; Heilman, 1983).

The processes that gender organizations shape the standards that employees are held to at work. Acker $(1990,1992)$ suggests that one of these standards is the ideal worker. The ideal worker, according to the theory of gendered organizations, is dedicated to their work such that they prioritize work above other outside responsibilities. Because of gender role stereotypes and the typical social roles that men and women hold, men are assumed to be able to prioritize work and are more likely to be able to meet organizational expectations for employees than women can. The theory of gendered organizations (Acker, 1990,1992) and supervisors and employees across studies agree that four attributes are desired in employees (Kelly et al., 2010; Reid, 2015; Sallee, 2012). In the next section, I describe the four attributes of the ideal worker as suggested by the theory of gendered organizations and research on ideal workers. Although little research has studied these attributes in the context of the ideal worker, they demonstrate how employees prioritize work in their lives.

\section{The Ideal Worker Stereotype}


The theory of gendered organizations suggests that the ideal worker reflects the standards of gendered organizations (Acker, 1990, 1992), and employees and managers recognize attributes of the ideal worker stereotype as important in their jobs (Kelly et al., 2010; Reid, 2015; Sallee, 2012). The ideal worker stereotype developed after World War II, as industry evolved and the roles of married couples were firmly divided. After the war, women worked inside the home doing housework and caring for children while men worked outside of the home for pay (Acker, 1990). Since men were expected to financially support their families and had wives at home to take care of other responsibilities, employees were expected to prioritize work, including showing a willingness to work whenever needed and displaying dedication to the job.

Although most employees were men, when women had to work (e.g., women from lower socioeconomic classes), they often worked in positions that assisted others in the office. These positions offered few, if any, opportunities for promotion, paid low wages, and were intended to benefit other employees who did the primary work of the organization (Eagly \& Crowley, 1986). Since men did the principle work of the organization, they had more status in the workplace and more opportunities for promotion. Thus, it may be that the ideal worker stereotype became a standard for determining which (male) employees to develop and promote in organizations.

Research on gendered organizations and standards for employees has suggested four attributes of the ideal worker. First, ideal workers should prioritize time for work above other domains in their lives. Ideal workers are available to work outside of the regular work schedule and can work overtime and outside of traditional work hours (Kelly et al., 2010; Reid, 2015; Sallee, 2012). They are often able to drop everything to 
take care of a work emergency or stay late to finish a project, whether as part of their regular work or extra work they have been asked to do. By working non-traditional hours and overtime, ideal workers signal their productivity to supervisors and other employees (Kelly et al., 2010), and being available for work shows commitment to the job and the organization (Acker, 1990; Bailyn, 2006; Reid, 2015). Employees are often aware that they are expected to stay late for work, and that not working overtime or outside of regular work hours can hurt their career. In a study of Best Buy, a large retail corporation in the U.S., employees and managers often perceived employees negatively if they did not stay late at work (Kelly et al., 2010). This perception impacted employees who sought a promotion to store management as corporate leaders expected store managers to put in more hours at work than store employees.

Second, ideal workers should be willing to travel and relocate for work (Bailyn, 1993; Reid, 2015). Employees may need to travel or relocate to meet with customers and clients, work with colleagues in branch offices, and attend conferences and meetings. Work travel and relocation can be challenging for employees and their families. An employee who travels may need someone to take care of their household in their absence. An employee who relocates must deal with moving their family and household belongings, and when they arrive in their new home, the employee and their family need time to familiarize themselves with their new city and integrate into social groups in their new community (Noe \& Barber, 1993). These adjustments can conflict with time at work for employees. However, because traveling and relocating require a large sacrifice from employees, others perceive those who are willing to travel and relocate for work as dedicated to the organization (Landau et al., 1992). When employees are unwilling to 
travel or move for work, they may limit their careers by not accepting new opportunities or projects that require travel or relocation. When supervisors need to choose an employee to take on a new opportunity, they may be more likely to first consider employees who are eager and willing to travel and relocate for work.

Third, ideal workers should be visible at work. Being visible means being present in the office, being seen by supervisors and other employees at work, and appearing to be visibly busy while in the office. Being visible at work provides two important signals to employers. First, the perception of busyness at work signals hard work and productivity to others (Paustian-Underdahl et al., 2016), particularly for employees in jobs where productivity is difficult to measure, which is common in many workplaces today. Second, being visible at work shows dedication to the job and the organization, and supervisors are likely to interpret this dedication as a signal that employees desire a promotion within the organization (Carter \& Silva, 2011; Wayne et al., 1999). When employees are visible to supervisors in the workplace, leaders are more likely to give them opportunities and develop relationships with individual employees, which may lead to more promotional opportunities for employees visible at work.

The fourth characteristic of ideal workers is that they should be dedicated to work. Dedication goes above and beyond being available, willing to travel and relocate, and being visible at work, which all signal an employee's dedication. Dedication is defined as an employee's positive affect and loyalty toward their work and organization (Reid, 2015). Employees with a high commitment to their work agree with their organization's goals and values, are willing to exert high levels of effort when they work, and desire to stay with their organization (Mowday et al., 1979), even if a competing organization 
offers them more status, pay, or benefits (Hrebiniak \& Allutto, 1973). Across studies in different organizations, supervisors rate employees higher in promotability when they perceive them to have high commitment to the organization and their job compared to other employees (Gurbuz et al., 2016; Shore et al., 1995).

Although scholars have found that employees recognize these characteristics as important in the workplace (Kelly et al., 2010; Reid, 2015; Sallee, 2012), no study has specifically investigated the attributes of the ideal worker nor how they may be perceived differently for male and female employees. In the next section, I describe how these attributes may disadvantage women at work because of their potential association with the male gender role stereotype.

\section{The Gendered Ideal Worker}

Although little research has studied the ideal worker stereotype specifically, scholars have begun to study how some of the attributes related to the ideal worker may be differentially perceived in male and female employees. For example, although being available to work long hours may appear to be a fair way to measure productivity and reward dedicated employees, not all employees may be perceived as being available to work long hours. In a study on employee work-life balance in a transportation firm, supervisors perceived that female employees had more work-life conflict than male employees (Hoobler et al., 2009). That is, supervisors perceived that female employees had fewer hours available to work because they had to take care of responsibilities like childcare outside of work. However, when employees were asked about their work-life conflict, male employees reported significantly more conflict than female employees. Not only were supervisors' perceptions incorrect about their female employees, but these 
perceptions had negative consequences for their female subordinates. Employees perceived as having more work-life conflict were also perceived as being less dedicated at work. Since women were perceived to have more work-life conflict than their male colleagues, they were perceived as less dedicated to work. Consequently, supervisors gave fewer promotions to women in the firm than men. Thus, these perceptions tended to advantage men while disadvantaging women at work, regardless of the actual availability and working hours of individual employees.

Likewise, the perception of who is available to travel and relocate for work may be affected by the gender of employees. Women tend to be offered fewer international opportunities because employers assume that their partners may be unwilling to uproot their families to live abroad for an extended period of time (Altman \& Shortland, 2008). Employers, however, do not perceive male employees as having the same constraints as their female colleagues. Partners of male employees are assumed to be willing to move abroad for their partner's work. These international opportunities are essential developmental opportunities for employees who want to be promoted into top management (Biemann \& Braakmann, 2013; Dragoni et al., 2014). If women are less likely to be offered international opportunities than men, they may, consequently, be less likely to earn a promotion later because they lack the international experience necessary for management positions at the top of the organizational hierarchy.

The visibility of employees at work is also thought to be an important aspect of the ideal worker stereotype. Busy workers appear to be productive, hardworking employees - those that deserve to receive promotions and development. However, being visible in the workplace may be perceived to be more difficult for female employees 
compared to male employees. When attorneys in a law firm were asked about why their male and female colleagues left work early, coworkers made different assumptions about men's and women's behavior (Rhode, 2003). Despite not knowing why their colleagues left the office early, men were assumed to be attending a meeting outside of the office, while women were assumed to be picking their kids up from school or attending an event for their children. If men are assumed to still be working when they leave the office, but women are not, men may be recognized for dedicating more time to their work and being willing to be more flexible for meetings with coworkers and clients, regardless of whether they were actually working when they left the office. Although by leaving early these attorneys were no longer visible at work, the reasons others assumed for why they left affected the employees' perceived commitment to work. Thus, visibility (and invisibility) at work may be gendered such that men are given the benefit of the doubt and perceived to be busier than women.

Similarly, supervisors may perceive the commitment of male and female employees to differ substantially. For instance, experimental studies find that mothers are perceived as less hard-working, less productive, and less reliable at work, even if they produce the same amount of work as they did before maternity leave (Cuddy et al., 2004; Etaugh \& Folger, 1998; Heilman \& Okimoto, 2008). Because women continue to take primary responsibility for children and household tasks (Yavorsky et al., 2015), others may perceive that women have outside obligations that compete with their commitment to work. Fathers, on the other hand, do not face these questions at work. Fathers are perceived as just as competent at work as they were before they had children (Cuddy et al., 2004; Heilman \& Okimoto, 2008; Okimoto \& Heilman, 2012). Because of their 
breadwinner role, men may be perceived as wanting to work more after they have children than before (Correll et al., 2007; Cuddy et al., 2004; Etaugh \& Folger, 1998; Fuegen et al., 2004), even when no evidence exists that fathers work harder than mothers or other employees without children (Kmec, 2011). Although these examples focus on mothers and fathers at work rather than men and women more generally, the dedication ideal workers are perceived to show toward their work may be gendered such that women may be perceived as less dedicated than men, even if they report being equally committed to their work. Therefore, I hypothesize that:

Hypothesis 1: The attributes of an ideal worker will be more associated with the attributes of the male than the female gender role stereotype.

\section{Promotability and Development}

The gendering of the ideal worker may have significant consequences for employees. Two outcomes that may be affected by the ideal worker stereotype are promotability and recommended development. Promotability is a perception of an individual employee's ability to fulfill a future job role, particularly in the next hierarchical level of the organization (De Pater et al., 2009; Greenhaus et al., 1990; London \& Stumpf, 1983), and is used to make promotion and development decisions (Breaugh, 2011; De Pater et al., 2009; Ng et al., 2005; Van Scotter et al., 2000). A supervisor may use promotability in the short term to decide whether an employee should be promoted to the next level of the organizational hierarchy, while higher-level leaders may use promotability in the long term in succession planning for the organization (Garman \& Glawe, 2004). 
Several studies have found that promotability and promotion decisions are correlated (Breaugh, 2011; London \& Stumpf, 1983; Ng et al., 2005; Stumpf \& London, 1981; Van Scotter et al., 2000). However, promotability and promotions are not perfectly correlated because of differences between an employee's current job role and the future job role they would be promoted to (Breaugh, 2011) and different managers making promotability and promotion decisions using different information (De Pater et al., 2009). Generally, employees who are perceived as highly promotable tend to receive more promotions and development than other employees. For example, archival data on district managers in the marketing department of a large retailer showed that promotability ratings were correlated 0.34 with promotion decisions (Breaugh, 2011). The district managers rated as having "high promotion potential" were four times more likely to be promoted than managers rated as simply "promotable." Similarly, when managers considered an employee lower in promotability, the employee was less likely to earn a promotion. Promotability is an important outcome to study because it is an important element of employees' careers since it is used in promotion and development decision making (Breaugh, 2011; De Pater et al., 2009; Ng et al., 2005; Van Scotter et al., 2000) and in succession planning within organizations (Breaugh, 2011; Garman \& Glawe, 2004).

In addition, because of limited resources, supervisors and other leaders use promotability to determine which employees should receive additional training, development, and support to prepare them for future leadership roles in the organization (Thacker \& Wayne, 1995). The talent management literature focuses on how organizations identify and develop their high-potential employees. High-potential 
employees are those that are classified by organizational leaders as employees who have the potential to move into organizational leadership in the future. The high-potential employee designation is useful for employers because it helps determine how resources should be distributed within the organization (Iles, 1997). Although all employees may be eligible for developmental opportunities such as training, the most visible and impactful development usually goes to high-potential employees. These valuable developmental opportunities go to high-potential employees because organizational leaders believe these employees can be successful in taking on challenging experiences and that these experiences will help employees to develop their knowledge, skills, and abilities to take on future leadership positions within the firm (Boak \& Crabbe, 2019; Day, 2000; Hezlett, 2016).

Although these outcomes are important for employees, male and female employees often differ in promotability and high-potential designations. Men are often considered more promotable than women (Hoobler et al., 2009; Lyness \& Heilman, 2006; Post et al., 2009; Roth et al., 2012) and receive more promotions than women, even at the lowest levels of the organization (Catalyst, 2019). Research from U.S. corporations shows that men make up over 60 percent of lower-level managers, and that the disparity between men and women has changed little since 2015 (Thomas et al., 2018). In some organizations, in lieu of a promotion to a position higher up in the organization, supervisors offer women lateral promotions (Ibarra et al., 2010). These promotions are at the same level of the organizational hierarchy as the employee's current role but are related to a different function of the organization's business. Although lateral promotions may be helpful for employees to develop new skills and to 
become familiar with different aspects of the organization's business, men are more likely to receive a promotion to a higher level of the organization than their female colleagues after a lateral promotion (Ibarra et al., 2010).

This disparity not only affects promotion decisions, including lateral promotions, but also other development offered to men and women in the workplace. Developmental work opportunities are important for employees to develop leadership skills and to demonstrate that they are ready for a leadership position higher up in the organization (Boak \& Crabbe, 2019; Day, 2000; Hezlett, 2016). Across organizations, men tend to receive more challenging work assignments (King et al., 2012), developmental job assignments (Lyness \& Schrader, 2006), and international assignments (Meier, 2017) than women. Organizations offer less development to women, and the opportunities given to women are of different quality than those that men receive. Men receive more opportunities that are visible to the organization's leadership (Kilian et al., 2005) and that lead to senior-level positions (De Pater et al., 2010) than women. In sum, men and women receive different support and resources for their professional development. Therefore, as a replication of research on gender differences in promotability ratings, I hypothesize that:

Hypothesis 2: Individuals will rate male employees higher on a) promotability and b) recommended development than female employees.

\section{The Effect of Stereotypes on Decision Making in Work Contexts}

One reason that men receive higher promotability ratings and development than women is that they may be more likely to be perceived as fulfilling the attributes supervisors look for in highly promotable employees such as ideal workers. I propose 
that supervisors and other leaders in organizations may use the ideal worker stereotype as a standard, often unknowingly, to compare employees to assess promotability and make promotion and development decisions. Some evidence from previous studies shows that leaders expect employees to fulfill some of the ideal worker attributes (e.g., working long hours) and that leaders expect managers to more strictly adhere to these standards as they move up through the organizational hierarchy (Kelly et al., 2010). Thus, it may be reasonable to expect that supervisors and other managers assess the extent to which an employee exemplifies the attributes of the ideal worker stereotype in making promotion and development decisions.

However, if the ideal worker stereotype is gendered masculine, this comparison may not be fair for employees. If attributes of the ideal worker stereotype are more closely associated with the male gender role stereotype, as hypothesized by the theory of gendered organizations (Acker, 1990, 1992), than employees who are perceived to display male gender role stereotype attributes will more likely be perceived as displaying the attributes of the ideal worker stereotype as well. Since women are expected to fulfill the female gender role stereotype, and as research shows, they face backlash when they are perceived as too masculine (Eagly \& Karau, 2002), it may be more difficult for female employees to be perceived as displaying the ideal worker stereotype attributes. A masculine ideal worker may put female employees in a bind. Female employees may have to choose whether to fulfill the female gender role stereotype at the expense of fulfilling the ideal worker stereotype or must deal with the backlash of trying to fulfill the ideal worker stereotype to the exclusion of the female gender role stereotype. The consequence is that women who try to exemplify attributes of the ideal worker may 
receive poorer evaluations and fewer rewards at work (Eagly \& Karau, 2002; Heilman, 2001; Heilman \& Parks-Stamm, 2007). Thus, I hypothesize that:

Hypothesis 3: Raters will rate male employees higher than female employees on the extent to which they exemplify ideal worker attributes.

Hypothesis 4: Ratings of the extent to which an employee exemplifies ideal worker attributes will predict a) promotability and b) recommended development.

Hypothesis 5: Ratings of the extent to which an employee exemplifies ideal worker attributes will partially mediate the relationship between employee gender and a) promotability and b) recommended development.

\section{Individual Sexism Beliefs as a Moderator of the Association between Ideal Worker Attributes and Gender Role Stereotypes}

Research on gender role stereotypes shows that although gender role stereotypes tend to be universal in their content - women are perceived as other-oriented and passive, while men are perceived as work-oriented and ambitious (Rudman et al., 2012) individual acceptance of the stereotypes differs based on attitudes and beliefs (Fiske, 1998). Individuals differ in their beliefs about how important it is that men and women adhere to gender role stereotypes (Glick \& Fiske, 2001). For example, a person who strongly believes in separate gender roles for men and women is more likely to expect men and women to adhere to gender role stereotypes. Within organizations, because supervisors tend to make promotion and development decisions, the beliefs supervisors have about gender role stereotypes may influence employee outcomes at work. In the U.S. culture, a supervisor with strong gender role beliefs may perceive men who are agentic at work as meeting the expectations of the male gender role stereotype, which can 
lead to more positive ratings for male employees. However, female employees who act agentic, as is often expected in the workplace, violate gender role stereotypes. A supervisor who strongly believes in gender role stereotypes may be more likely to see an agentic female as not fulfilling the expectations of the female gender role stereotype and may be more likely to punish her for her gender role stereotype violation with poor performance evaluations, low promotability scores, and fewer rewards for her work (Heilman et al., 2004; Rudman et al., 2012).

Two kinds of gender role beliefs that may affect perceptions of male and female employees are benevolent sexism and modern sexism. Individuals high in benevolent sexism assume that women are sensitive, should be protected from difficult tasks at work (Glick \& Fiske, 2001), and believe women should be confined to traditional female roles such as helping and seeking relationships with others (Glick \& Fiske, 1996). Benevolent sexism can be difficult to detect because it is often perceived positively (Glick \& Fiske, 1996) and includes behaviors such as avoiding assigning women international assignments because they are more difficult or being kinder to women than men (Kuchynka et al., 2018). Although some individuals may not see benevolent sexism as harmful, supervisors high in benevolent sexism beliefs are more likely to hold women back for fear that women are unable to take on challenging work or because they see their role as protecting women at work.

While benevolent sexism focuses on how individuals treat women, modern sexism measures how much individuals believe sexism exists in society. In general, sexist attitudes tend to be more subtle today than in the past (Campbell et al., 1997; Swim \& Cohen, 1997), and measuring subtle sexism is more difficult than measuring traditional 
(overt) sexism. To uncover subtle sexism, researchers ask individuals about their perceptions of societal attitudes about gender, rather than the individual's own attitudes and behaviors related to traditional gender roles (Swim \& Cohen, 1997; Swim et al., 2005). Modern sexism measures attitudes toward women's issues and can predict discrimination in terms of job segregation (Glick \& Fiske, 1996; Swim et al., 1995) as well as work atmosphere and promotional opportunities (Yoder \& McDonald, 1997). Thus, benevolent and modern sexism have been shown to predict how individuals perceive men and women and the effects of those perceptions on decision making at work. Therefore, I hypothesize that:

Hypothesis 6: Raters' sexism beliefs will moderate the relationship between employee gender and ideal worker attributes such that individuals with higher scores on the a) benevolent sexism and b) modern sexism scales will be more likely to perceive male employees as fulfilling ideal worker attributes than female employees.

Hypothesis 7: Raters'sexism beliefs (benevolent and modern sexism) will moderate the relationship between employee gender and a) promotability and b) recommended development such that individuals with higher scores on the sexism scales will be more likely to give male employees higher promotability ratings and more development than female employees.

\section{The Dual Process Model of Stereotyping: Systematic vs. Automatic Associations}

Stereotypes are complex and can influence individuals without their awareness.

The dual process model of stereotyping posits that stereotypes can comprise both systematic (conscious) and automatic (unconscious) processes, with many stereotypes 
having both components (Devine, 1989). With conscious associations between an attribute and a social group, individuals can identify the descriptive, prescriptive, and proscriptive stereotypes of a specific social group and are often aware of when they are stereotyping others (Fiske, 1998). However, unconscious or implicit associations are difficult to recognize, and individuals are often unaware of having them and using them in their social interactions (Banaji \& Hardin, 1996). Because of this lack of awareness, automatic stereotyping is usually not identified until it affects members of the stereotyped social group.

The ideal worker stereotype can have both systematic (conscious) and automatic (unconscious) components. It may be that individuals can describe what an ideal worker is like if asked (the conscious component). However, if the stereotype has an unconscious component, it may be difficult for individuals to comprehensively describe the ideal worker when prompted. The unconscious component of the ideal worker stereotype may have different unconscious (implicit) associations with other stereotypes (such as gender role stereotypes). Thus, it may be that the ideal worker stereotype is associated more with the male gender role stereotype implicitly, even if this association does not exist consciously. An unconscious or automatic component of the ideal worker stereotype would be consistent with the theory of gendered organizations. Acker (1990, 1992) explained that masculine gendering can be difficult to perceive because organizational processes are often presented as gender neutral. If individuals describe ideal worker attributes as gender neutral but have an implicit association between the attributes of the ideal worker stereotype and those of the male gender role stereotype, then this pattern may fit that proposed by the theory of gendered organizations. 
Additionally, as the dual model of stereotyping predicts (Devine, 1989), we may not see the automatic or unconscious components of a stereotype until it affects members of the stereotyped group. Thus, I hypothesize that:

Hypothesis 8: Ideal worker attributes will be more implicitly associated with the male than the female gender role stereotype.

Hypothesis 9: Implicit associations between the ideal worker stereotype and gender role stereotypes will moderate the relationship between employee gender and a) promotability and b) recommended development such that individuals with a stronger implicit association between ideal worker attributes and the male gender role stereotype will rate female, but not male, employees, lower in promotability and recommend less development for female employees than individuals with a weak or no association.

\section{Overview of Studies}

I organize my studies around my research questions. I examine the first research question - what are the attributes of the ideal worker? - by asking students and employees to describe an ideal worker using slightly different definitions. Participants provided attributes of an ideal worker in a free-list exercise as well as rated a variety of items that describe employees as to how characteristic or uncharacteristic they were of an ideal worker. I find many attributes describe the ideal worker, and I use the attributes collected in Research Question 1 to examine my other research questions in later studies.

My second research question addresses whether the attributes of the ideal worker, collected for Research Question 1, are related to gender role stereotypes. I hypothesize that the ideal worker attributes are masculine, as described by Acker $(1990,1992)$ in her 
theory of gendered organizations. I asked participants to rate how characteristic attributes are of an ideal worker as well as either a typical man or a typical woman. I then correlated the ratings given to the ideal worker with those given to the typical man or the typical woman to assess differences in the strength of these correlations. I find that ideal worker attributes are equally associated with the male and female gender role stereotypes for employees but more associated with the female gender role stereotype for students, contrary to my hypothesis.

With an understanding of whether and how the attributes of the ideal worker are gendered, I then explore how these attributes are related to important employee outcomes. My third research question asks whether the extent to which an employee exemplifies the attributes of an ideal worker predicts their promotability and the development recommended for them. I asked participants to rate an equally qualified male or female employee on the extent to which the employee exemplifies the attributes of an ideal worker and their potential for promotion as well as provide development recommendations for the employee. I find that ideal worker attributes are a significant and positive predictor of promotability and recommended development and that these ratings did not differ between male and female employees.

With the finding that ideal worker attributes predict promotability and recommended development, I study my fourth research question addressing whether sexism beliefs moderate this relationship. I asked participants about their sexism beliefs using the Benevolent Sexism Inventory and the Modern Sexism Scale, after rating either an equally qualified male or female employee on their promotability and development recommendations. I find that sexism moderates the relationship between employee 
gender and recommended development, but not promotability, even though in the previous research question, I find no differences in ratings between male and female employees.

Finally, my fifth research question asks about the implicit associations between the ideal worker stereotype and gender role stereotypes. In the previous research questions, I only focused on the conscious stereotype. However, because stereotypes can have conscious and unconscious associations with other social schema, I test whether implicit associations between the ideal worker and gender role stereotypes moderate the relationship between employee gender and employee outcomes such as promotability and recommended development. I find that implicit associations between some ideal worker attributes and the male gender role stereotype moderate the relationship between employee gender and recommended development, but not promotability. When raters had strong implicit associations between the male gender role stereotype and attributes that were considered highly characteristic of an ideal worker in Research Question 1 but that were not suggested by theory or previous research, raters recommended more development for female than male employees, opposite of my hypothesis. Table 1 provides a summary of all of the research questions and hypotheses across the studies.

To begin investigating these research questions, the next section describes the methodology I used to examine Research Question 1: what are the attributes of the ideal worker? 


\section{Table 1. Proposed Hypotheses for Each Research Question}

Research Question

RQ1: What are the attributes of the ideal worker?

RQ2: Are these attributes gendered masculine?
Hypotheses

No hypotheses developed.

Hypothesis 1: The attributes of an ideal worker will be more associated with the attributes of the male than the female gender role stereotype.

RQ3: Does the extent to which employees exemplify ideal worker attributes predict ratings of promotability and development recommended for them?

Hypothesis 2: Individuals will rate male employees higher on a) promotability and $b$ ) recommended development than female employees.
Hypothesis 3: Raters will rate male employees higher than female employees on the extent to which they exemplify ideal worker attributes.

Hypothesis 4: Ratings of the extent to which an employee exemplifies ideal worker attributes will predict a) promotability and $b$ ) recommended development.

Hypothesis 5: Ratings of the extent to which an employee exemplifies ideal worker attributes will partially mediate the relationship between employee gender and a) promotability and $b$ ) recommended development.

Hypothesis 6: Raters' sexism beliefs will moderate the relationship between employee gender and ideal worker attributes such that individuals with higher scores on the a) benevolent sexism and b) modern sexism scales will be more likely to perceive male employees as fulfilling ideal worker attributes than female employees.

Hypothesis 7: Raters' sexism beliefs (benevolent and modern sexism) will moderate the relationship between employee gender and a) promotability and $b$ ) recommended development such that individuals with higher scores on the sexism scales will be more likely to give male employees higher promotability ratings and more development than female employees. 


\begin{tabular}{ll}
\hline $\begin{array}{l}\text { RQ5: Do implicit associations } \\
\text { between the ideal worker } \\
\text { stereotype and gender role } \\
\text { stereotypes predict } \\
\text { promotability and }\end{array}$ & $\begin{array}{l}\text { Hypothesis } 8: \text { Ideal worker attributes will be more } \\
\text { implicitly associated with the male than the female } \\
\text { gender role stereotype. }\end{array}$ \\
$\begin{array}{l}\text { for male and female } \\
\text { employees? }\end{array}$ & $\begin{array}{l}\text { Hypothesis 9: Implicit associations between the ideal } \\
\text { worker stereotype and gender role stereotypes will } \\
\text { moderate the relationship between employee gender } \\
\text { and a) promotability and b) recommended } \\
\text { development such that individuals with a stronger } \\
\text { implicit association between ideal worker attributes } \\
\text { and the male gender role stereotype will rate female, } \\
\text { but not male, employees lower in promotability and } \\
\text { recommend less development to female employees } \\
\text { than individuals with a weak or no association. }\end{array}$
\end{tabular}




\section{Research Question 1 Method}

\section{Participants}

To answer Research Question 1 about what the attributes of the ideal worker are, I used four samples. Three of the four samples included students from an introductory management class at a large Midwestern university who completed an online survey. In the first sample, 242 students attempted the survey but only 237 passed the data quality checks (i.e. no straightlining of responses). Most were business majors ( $n=131,56.2 \%)$, male $(n=122,52.1 \%)$, and white $(n=196,84.8 \%)$ with a mean age of 20.5 years. Participants had an average of 3.7 years of work experience and a little more than a quarter $(n=65,27.4 \%)$ had leadership experience at work. In the second sample, of the 63 participants (out of the 66 who started the survey and whose data passed quality checks), most were male $(n=39,61.9 \%)$, white $(n=54,85.7 \%)$, and non-business majors $(n=39,61.9 \%)$ with a mean age of 20.7 years. On average, participants had 4.8 years of work experience, and 60.3\% $(n=38)$ had some leadership experience at work. In the third sample, of the 227 students who attempted the survey, 214 completed it and their data passed quality checks. A little over half were male $(n=113,52.7 \%)$, the majority were white $(n=156,72.7 \%)$, and most were either non-business $(n=68$, $31.4 \%)$ or finance $(n=59,27.6 \%)$ majors. The mean age of students was 21.3 years, with 4.3 years of experience on average, and just over half $(n=112,52.5 \%)$ had some supervisory experience.

The fourth sample included current employees in different organizations across the United States. Participants came from Amazon Mechanical Turk. To be eligible for the survey, participants had to be at least 18 years old, currently 
employed, living in the United States, and had already completed over 1,000 HITs (tasks) on Amazon Mechanical Turk. Participants received a small incentive for participating in the study. Data from 318 individuals (of the 352 who started the survey) was used after data quality checks (i.e. no straightlined responses and most items on the survey rated). Of those whose data passed screening, $64.5 \%(n=205)$ were female with a mean age of 39.4 years. Most respondents were white $(n=223,70.1 \%)$, although $12.5 \%(n=40)$ were African-American. Most respondents had some college education ( $n=73,23.0 \%)$ or a bachelor's degree $(n=119,37.4 \%)$; nearly half of respondents $(n=155,48.7 \%)$ were married or in a domestic partnership, and 35.8\% $(n=114)$ were single. About threequarters of participants $(n=241,75.8 \%)$ had some supervisory experience. Table 2 provides a summary of the samples used to address Research Question 1. 
Table 2. Description of Samples and Procedures for All Research Questions

\begin{tabular}{|c|c|c|c|c|c|}
\hline Sample & $n$ & Participants & $\begin{array}{l}\text { Ideal Worker } \\
\text { Description }\end{array}$ & Procedures & $\begin{array}{l}\text { Research } \\
\text { Question }\end{array}$ \\
\hline 1 & 237 & $\begin{array}{l}\text { Students from an } \\
\text { introductory } \\
\text { management class in a } \\
\text { large Midwestern } \\
\text { university }\end{array}$ & $\begin{array}{l}\text { Ideal worker as you } \\
\text { understand the concept } \\
\text { (no definition given) }\end{array}$ & $\begin{array}{l}\text { List } 20 \text { descriptors of an ideal worker and } \\
\text { rate } 181 \text { of items on how characteristic or } \\
\text { uncharacteristic they are of an ideal worker }\end{array}$ & 1 \\
\hline 2 & 63 & $\begin{array}{l}\text { Introductory } \\
\text { management class } \\
\text { students }\end{array}$ & $\begin{array}{l}\text { Employee you would } \\
\text { want to support and } \\
\text { develop by promoting } \\
\text { them to another position }\end{array}$ & $\begin{array}{l}\text { List } 20 \text { descriptors of an ideal worker and } \\
\text { rate } 191 \text { of items on how characteristic or } \\
\text { uncharacteristic they are of an ideal worker }\end{array}$ & 1 \\
\hline 3 & 214 & $\begin{array}{l}\text { Introductory } \\
\text { management class } \\
\text { students }\end{array}$ & $\begin{array}{l}\text { Employee who has the } \\
\text { desire and ability to } \\
\text { reach the highest levels } \\
\text { in the organization }\end{array}$ & $\begin{array}{l}\text { Rate } 153 \text { of items on how characteristic } \\
\text { they are of an ideal worker }\end{array}$ & 1,2 \\
\hline 4 & 318 & $\begin{array}{l}\text { Employees from } \\
\text { different U.S. } \\
\text { organizations on } \\
\text { Amazon Mechanical } \\
\text { Turk }\end{array}$ & $\begin{array}{l}\text { Employee you would } \\
\text { want to support and } \\
\text { develop by promoting } \\
\text { them to another position }\end{array}$ & $\begin{array}{l}\text { Rate } 153 \text { of items on how characteristic } \\
\text { they are of an ideal worker }\end{array}$ & 1,2 \\
\hline 5 & 220 & $\begin{array}{l}\text { Employees from } \\
\text { different U.S. } \\
\text { organizations on } \\
\text { Amazon Mechanical } \\
\text { Turk }\end{array}$ & No description given & $\begin{array}{l}\text { Rate a male or female employee for } \\
\text { promotability, development } \\
\text { recommendations, ideal worker rating and } \\
\text { complete Benevolent Sexism and Modern } \\
\text { Sexism scales }\end{array}$ & 3,4 \\
\hline
\end{tabular}


organizations on

promotability and complete an Implicit

Association Test

Amazon Mechanical

Turk 


\section{Procedure}

For each sample, I used a different prompt to describe the ideal worker to participants to investigate whether different definitions of the ideal worker elicited different attributes to describe the ideal worker stereotype. In the first student sample, participants were asked to describe an ideal worker as they understood the concept, without a definition. In the second (students) and fourth (employee) samples, I described a promotable ideal worker as someone participants would want to promote to support and develop the employee. For the third sample (students), I asked participants to rate an employee who has the desire and ability to reach the highest levels in the organization. See Table 2 for the descriptions of an ideal worker used across all four samples for Research Question 1.

Samples 1 and 2 completed two tasks. In the first task, to collect a list of attributes, I asked participants to freely list descriptors of an ideal worker. For the second task, participants rated items that could describe employees and people generally. Because item ratings yielded substantially more results than asking participants to freely describe an ideal worker, I asked participants in Samples 3 and 4 to rate items but did not ask them to freely list descriptors of an ideal worker. Finally, participants completed demographic questions. Please see Appendix I for the instructions and measures used in this study.

\section{Measures}

Participant-Generated Ideal Worker Descriptors. Participants were asked to list 20 attributes of the ideal worker. This procedure is similar to the technique that Lord et al. (1984) used to generate attributes of different kinds of leaders. Lord and colleagues 
used a 30\% cutoff to assess the characteristics of a leader. I used the same cutoff so that if at least $30 \%$ of participants in a sample mentioned a descriptor, I included it as an attribute of an ideal worker in later studies.

Ideal Worker Item Ratings. Participants rated items on a 5-point scale for how characteristic or uncharacteristic the attributes are of an ideal worker, with 1 meaning 'Extremely uncharacteristic' and 5 meaning 'Extremely characteristic' for Samples 1 and 2 and 1 meaning 'Not at all characteristic' and 5 meaning 'Extremely characteristic' for Samples 3 and 4. Items were based on suggested attributes from research about the ideal worker (Kelly et al., 2010; Reid, 2015; Sallee, 2012) and the theory of gendered organizations (Acker, 1990, 1992) - works long hours, travels and relocates for work, visibly busy at work, and dedicated to work. I included additional items that came from organizational citizenship behavior scales (e.g., Morrison, 1994; Smith et al., 1983; Van Scotter \& Motowidlo, 1996) to measure behaviors that may characterize an ideal worker outside of the scope of an individual's job role. I also included items from scales related to job callings (Wrzesniewski et al., 1997), multiple roles (Kreiner, 2006; Rothbard et al., 2005), and work engagement (Banihani et al., 2013) that described behaviors and attitudes beneficial in the workplace. Some items also came from the Schein Descriptive Index (Duehr \& Bono, 2006, developed by Schein, 1973). The revised Schein Descriptive Index includes 111 adjectives: 92 items from the original index developed by Schein (1973) to describe people generally and 19 items related to relationship orientation and transformational leadership from Duehr and Bono (2006).

To assess which items were attributes of an ideal worker, I used two criteria. To include attributes characteristic of an ideal worker in later studies, I kept items with a 
mean of 4.0 ('Somewhat Characteristic') or above across all four samples. The inclusion rule for attributes that were considered uncharacteristic of an ideal worker was that items had to have a mean of 2.0 ('Somewhat Uncharacteristic') or below.

Demographic Characteristics. Participants were asked about their demographic characteristics. Students were asked about their sex, age, race, major, number of years of work experience, and whether they had supervisory experience or not. Employees were asked about their sex, age, race, highest level of education, and whether they had supervisory experience or not.

\section{Research Question 1 Results}

\section{Participant-Generated Ideal Worker Descriptors}

Participants provided adjectives or phrases that described an ideal worker. To analyze these descriptors, I counted the number of times each word or phrase was mentioned by participants. When misspelled words were easy to identify, I included the misspelled words in the count. Then, I identified the words and phrases that met the inclusion criterion: the word or phrase had to be mentioned by 30 percent of the sample (at least 71 participants in Sample 1 and 19 participants in Sample 2).

Participants provided 678 different words and phrases, of which only 14 met the inclusion criteria. Table 3 includes all the descriptors and their frequencies for Samples 1 and 2. Most of these descriptors describe the ideal worker's work ethic, integrity, ambition, and positive attitude, with "hardworking" being the descriptor most mentioned by both samples. Thus, based on the $30 \%$ agreement rule, participants could agree on some of the 
attributes of an ideal worker; these attributes are broader than those suggested by theory (Acker, 1990, 1992) and in research focused on ideal workers (Kelly et al., 2010; Reid, 2015; Sallee; 2012).

Table 3. Participant-Generated Ideal Worker Descriptors from Samples 1 and 2 (in Order of Number of Mentions)

\begin{tabular}{lcc}
\hline \multicolumn{1}{c}{ Descriptor } & $\begin{array}{c}\text { Sample 1 } \\
(n=237)\end{array}$ & $\begin{array}{c}\text { Sample 2 } \\
(n=63)\end{array}$ \\
\hline Hardworking & $184(77.6 \%)$ & $26(41.3 \%)$ \\
Honest & $117(79.4 \%)$ & \\
Confident & $95(40.1 \%)$ & \\
Positive & $93(39.2 \%)$ & \\
Respectful & $83(35.0 \%)$ & \\
Responsible & $83(35.0 \%)$ & \\
Passionate & $81(34.2 \%)$ & \\
Smart & $80(33.8 \%)$ & \\
Creative & $76(32.1 \%)$ & $21(33.3 \%)$ \\
Driven & $74(31.2 \%)$ & \\
Reliable & $74(31.2 \%)$ & \\
Motivated & $72(30.4 \%)$ & \\
Humble & $71(30.0 \%)$ & \\
Leader & $71(30.0 \%)$ & \\
\hline
\end{tabular}

Note: To be included in later studies, descriptors had to be mentioned by at least $30 \%$ of the sample $(n=$ 71 for Sample 1 and $n=19$ for Sample 2).

\section{Ideal Worker Item Ratings}

As noted above, for items that participants rated on how characteristic or uncharacteristic they were of an ideal worker, items met the inclusion criteria for future studies if they had a mean of 4.0 or above (for items considered 'somewhat characteristic' in Samples 1 and 2 and 'very characteristic' of an ideal worker in Samples 3 and 4) or a mean 2.0 or below (for items considered 'somewhat uncharacteristic' of an ideal worker in Samples 1 and 2) for all samples that rated the item. Appendix II includes the means and standard deviations for all 289 items asked across the four samples. As Appendix II shows, 88 items met the 4.0 or above ('somewhat' or 'very characteristic' attributes) inclusion criteria and four items met the 2.0 or below 
('somewhat uncharacteristic' attributes) inclusion criteria for future studies. To summarize the most characteristic attributes of an ideal worker, Table 4 includes the 32 items with means of 4.25 and above across all samples.

Overall, of the four theoretical constructs of the ideal worker (available to work, travels and relocates for work, visibly busy at work, and committed to work), some items about the availability to work, specifically those related to taking the time to finish tasks at work as well as items describing commitment to work, met the inclusion criteria. Items about traveling and relocating for work as well as being visibly busy at work did not meet the inclusion criteria, contrary to past studies of the ideal worker. In addition to the attributes suggested in the theory of gendered organizations (Acker, 1990,1992) and research on the ideal worker (Kelly et al., 2010; Reid, 2015; Sallee, 2012), other attributes were also considered characteristic of an ideal worker based on item ratings. Because so many items were included in the surveys, items have been grouped by attribute in Appendix II. I grouped items based on their face validity - what does the item appear to measure? These groupings were used for selecting items for later studies. Items related to learning and using feedback, handling difficult situations, being a critical thinker, showing potential and being successful at work, being a team player, bringing out the best in others, easily adapting to change, having the ability to maintain performance into the future, and insightfulness were among the highest rated. Descriptors about how an employee does their work were also considered characteristic of an ideal worker. These attributes included having leadership ability and being competent and intelligent, 
consistent, a good listener, well informed, encouraging, emotionally stable, and sincere.

Table 4. Ideal Worker Rated Items with Means of 4.25 and Above across All Four Samples Ranked by Mean (Ordered by Mean of Sample 4, then Sample 3)

\begin{tabular}{|c|c|c|c|c|}
\hline Item & $\begin{array}{l}\text { Sample } 1 \\
\text { (Students) } \\
(n=237)\end{array}$ & $\begin{array}{c}\text { Sample } 2 \\
\text { (Students) } \\
(n=63)\end{array}$ & $\begin{array}{l}\text { Sample } 3 \\
\text { (Students) } \\
(n=214)\end{array}$ & $\begin{array}{c}\text { Sample } 4 \\
(\text { Employees }) \\
(n=318)\end{array}$ \\
\hline \multirow{2}{*}{ 1. Is competent } & 4.17 & 4.11 & 4.42 & 4.50 \\
\hline & $(.85)$ & $(.95)$ & $(.75)$ & $(.86)$ \\
\hline \multirow{2}{*}{ 2. Is intelligent } & 4.40 & 4.49 & 4.45 & 4.42 \\
\hline & $(.78)$ & $(.76)$ & $(.75)$ & $(.75)$ \\
\hline \multirow{2}{*}{$\begin{array}{l}\text { 3. Seeks opportunities to } \\
\text { learn }\end{array}$} & & 4.54 & 4.53 & 4.40 \\
\hline & & $(.62)$ & $(.72)$ & $(.79)$ \\
\hline \multirow{2}{*}{$\begin{array}{l}\text { 4. Can handle difficult } \\
\text { situations at work }\end{array}$} & & & 4.57 & 4.39 \\
\hline & & & $(.62)$ & $(.84)$ \\
\hline \multirow{2}{*}{ 5. Has leadership ability } & 4.42 & 4.57 & 4.67 & 4.38 \\
\hline & $(.76)$ & $(.59)$ & $(.56)$ & $(.90)$ \\
\hline \multirow[t]{2}{*}{ 6. Is a critical thinker } & & 4.41 & 4.58 & 4.37 \\
\hline & & $(.82)$ & $(.60)$ & $(.80)$ \\
\hline \multirow[t]{2}{*}{ 7. Is resourceful } & & 4.58 & 4.43 & 4.37 \\
\hline & & (.64) & $(.66)$ & $(.78)$ \\
\hline \multirow[t]{2}{*}{ 8. Learns from experience } & & 4.58 & 4.57 & 4.36 \\
\hline & & $(.76)$ & $(.64)$ & $(.87)$ \\
\hline \multirow[t]{2}{*}{ 9. Shows potential } & & 4.55 & 4.46 & 4.36 \\
\hline & & $(.69)$ & $(.71)$ & $(.80)$ \\
\hline \multirow[t]{2}{*}{ 10. Is fully engaged at work } & & 4.47 & 4.51 & 4.35 \\
\hline & & $(.65)$ & $(.64)$ & $(.84)$ \\
\hline \multirow[t]{2}{*}{ 11. Is a team player } & & 4.63 & 4.44 & 4.35 \\
\hline & & (.68) & $(.72)$ & $(.80)$ \\
\hline \multirow{2}{*}{$\begin{array}{l}\text { 12. Can persist through } \\
\text { difficulties at work }\end{array}$} & & & 4.54 & 4.33 \\
\hline & & & $(.54)$ & $(.83)$ \\
\hline \multirow{2}{*}{$\begin{array}{l}\text { 13. Has shown the ability to } \\
\text { be successful }\end{array}$} & & & 4.50 & 4.33 \\
\hline & & & $(.66)$ & $(.82)$ \\
\hline \multirow{2}{*}{ 14. Is consistent } & 4.26 & 4.48 & 4.48 & 4.33 \\
\hline & $(.83)$ & (.69) & (.69) & $(.85)$ \\
\hline \multirow{2}{*}{$\begin{array}{l}\text { 15. Brings out the best in } \\
\text { people }\end{array}$} & & 4.62 & 4.44 & 4.31 \\
\hline & & $(.66)$ & $(.77)$ & $(.87)$ \\
\hline \multirow{2}{*}{ 16. Is a good listener } & 4.32 & 4.59 & 4.50 & 4.30 \\
\hline & $(.82)$ & (.96) & $(.68)$ & $(.84)$ \\
\hline \multirow{2}{*}{$\begin{array}{l}\text { 17. Is committed to their } \\
\text { work }\end{array}$} & 4.28 & 4.40 & 4.52 & 4.29 \\
\hline & $(.82)$ & $(.78)$ & $(.62)$ & $(.85)$ \\
\hline \multirow{2}{*}{ 18. Is logical } & 4.28 & 4.38 & 4.46 & 4.29 \\
\hline & $(.80)$ & $(.71)$ & $(.68)$ & $(.85)$ \\
\hline \multirow{2}{*}{ 19. Is cooperative } & 4.33 & 4.33 & 4.42 & 4.29 \\
\hline & $(.81)$ & $(.88)$ & $(.75)$ & $(.88)$ \\
\hline
\end{tabular}




\begin{tabular}{|c|c|c|c|c|}
\hline 20. Is open-minded & $\begin{array}{l}4.38 \\
(.78)\end{array}$ & $\begin{array}{l}4.41 \\
(.73)\end{array}$ & $\begin{array}{l}4.41 \\
(.74)\end{array}$ & $\begin{array}{l}4.29 \\
(.83)\end{array}$ \\
\hline \multirow[b]{2}{*}{ 21. Is well informed } & 4.29 & 4.42 & 4.40 & 4.29 \\
\hline & $(.78)$ & $(.84)$ & $(.73)$ & $(.84)$ \\
\hline \multirow{2}{*}{$\begin{array}{l}\text { 22. Uses reason to solve } \\
\text { work problems }\end{array}$} & & 4.43 & 4.39 & 4.29 \\
\hline & & $(.62)$ & $(.73)$ & $(.87)$ \\
\hline \multirow[t]{2}{*}{ 23. Uses feedback } & & 4.61 & 4.57 & 4.28 \\
\hline & & (.64) & $(.68)$ & $(.86)$ \\
\hline \multirow[t]{2}{*}{ 24. Easily adapts to change } & & 4.43 & 4.44 & 4.28 \\
\hline & & $(.73)$ & $(.72)$ & $(.82)$ \\
\hline \multirow{2}{*}{ 25. Is emotionally stable } & 4.10 & 4.37 & 4.41 & 4.28 \\
\hline & $(.83)$ & (.93) & $(.76)$ & $(.86)$ \\
\hline \multirow{2}{*}{ 26. Is helpful } & 4.36 & 4.49 & 4.32 & 4.28 \\
\hline & $(.78)$ & (.67) & $(.77)$ & $(.84)$ \\
\hline \multirow[t]{2}{*}{ 27. Is committed to success } & & 4.54 & 4.56 & 4.26 \\
\hline & & $(.62)$ & $(.62)$ & $(.89)$ \\
\hline \multirow{2}{*}{$\begin{array}{l}\text { 28. Cares about the fate of } \\
\text { their organization }\end{array}$} & & 4.54 & 4.54 & 4.25 \\
\hline & & (.64) & $(.65)$ & $(.84)$ \\
\hline \multirow{3}{*}{$\begin{array}{l}\text { 29. Can control their } \\
\text { emotions when } \\
\text { receiving feedback from } \\
\text { others }\end{array}$} & & & 4.49 & 4.25 \\
\hline & & & $(.63)$ & $(.89)$ \\
\hline & & & & \\
\hline \multirow{2}{*}{$\begin{array}{l}\text { 30. Can maintain their level } \\
\text { of performance in the } \\
\text { future }\end{array}$} & & & 4.46 & 4.25 \\
\hline & & & (.68) & $(.92)$ \\
\hline \multirow{2}{*}{ 31. Considers others' ideas } & 4.33 & 4.29 & 4.42 & 4.25 \\
\hline & $(.79)$ & (.87) & (.69) & $(.88)$ \\
\hline \multirow{2}{*}{ 32. Is prompt } & 4.11 & 4.14 & 4.33 & 4.25 \\
\hline & $(.88)$ & $(.88)$ & $(.78)$ & $(.92)$ \\
\hline
\end{tabular}

Few items met the inclusion criteria for attributes uncharacteristic of an ideal worker. This low number was due partially to presenting only attributes that would be characteristic of the ideal worker to Samples 3 and 4 (rather than including both characteristic and uncharacteristic items of an ideal worker in all data collections). Having negative feelings toward their organization, being a dawdler or procrastinator, being bitter, and being selfish were the four attributes considered uncharacteristic of an ideal worker from the set of items presented to Samples 1 and 2. 


\section{Additional Analyses}

Across my samples, I found some differences in mean ratings for different groups of participants. These differences are important to understand so that later studies include only those items that were rated as attributes characteristic of an ideal worker by all participants. The first difference I found was between students and employees. Students tended to rate more attributes as characteristic of an ideal worker compared to the employee sample. For example, having a strong work ethic was considered characteristic of an ideal worker for the students but not for the employee sample. This same pattern occurred for other items that describe an ideal worker's integrity, having aspirations to advance in the organization, having influence over others at work, seeking out opportunities to develop their career and having clear career goals, being able to make tough decisions at work, being someone that other leaders would like to spend time with, spotting a good opportunity long before others can, and asking for challenging work assignments. Students were also more likely to rate being grateful, curious, competitive, direct, sociable, and energetic as more characteristic of an ideal worker than the employee sample did. These attributes can be categorized two ways. One group of attributes are attitudes such as a good work ethic, integrity, and being social. The second group includes behaviors that show dedication to an employee's career such as aspiring to advance in the organization, seeking out opportunities to develop their career, and asking for challenging work assignments. Employees did not view these as important attributes of an ideal worker potentially because they do not differentiate employees well (e.g., most employees are perceived to have a good work ethic) or because they are outside of an employee's control (e.g., making tough decisions at work). Thus, 
employees' work experience may narrow their definition of an ideal worker compared to university students' perceptions.

Second, since Acker $(1990,1992)$ theorized that the ideal worker was masculine, I also wanted to investigate differences in attribute ratings between male and female participants to ensure that I chose items for later studies that characterized the ideal worker for both men and women. Male and female participants mostly agreed on the attributes characteristic of an ideal worker, but for a few items they differed. Appendix IV shows differences between male and female participants in Samples 3 (students) and 4 (employees), with stars indicating significant differences between male and female participants (based on an alpha level $<.001$ due to the large number of $t$-tests run on the data (312 tests total on 156 items over two samples)). As Table 5 shows, only three items were rated significantly differently between male and female participants, and these ratings were only significantly different within the student sample: 1) has goals and values consistent with those of their organization, 2) is open to criticism, and 3) seeks feedback. For all these items, female participants rated these attributes as more characteristic of an ideal worker than male participants, even though both male and female participants rated these attributes as 'somewhat' or 'very characteristic' of an ideal worker in Samples 1 and 2 or Samples 3 and 4, respectively (means above 4.0 for each item). Thus, as with gender role stereotypes (Rudman et al., 2012), male and female raters tended to agree on the attributes of an ideal worker. 
Table 5. Significant Differences in Ideal Worker Ratings by Gender for Samples 3 and 4

\begin{tabular}{|c|c|c|c|c|}
\hline \multirow[b]{2}{*}{ Item } & \multicolumn{2}{|c|}{ Sample 3 (Students) } & \multicolumn{2}{|c|}{ Sample 4 (Employees) } \\
\hline & $\begin{array}{l}\text { Mean for } \\
\text { Male } \\
\text { Participants } \\
(n=126) \\
\end{array}$ & $\begin{array}{l}\text { Mean for } \\
\text { Female } \\
\text { Participants } \\
(n=112) \\
\end{array}$ & $\begin{array}{c}\text { Mean for } \\
\text { Male } \\
\text { Participants } \\
(n=113) \\
\end{array}$ & $\begin{array}{l}\text { Mean for } \\
\text { Female } \\
\text { Participants } \\
(n=205) \\
\end{array}$ \\
\hline $\begin{array}{l}\text { 1. Has goals and } \\
\text { values consistent } \\
\text { with those of their } \\
\text { organization }\end{array}$ & $4.37(.72)^{*}$ & $4.70(.52)$ & $4.11(.89)$ & $4.30(.80)$ \\
\hline $\begin{array}{l}\text { 2. Is open to } \\
\text { criticism }\end{array}$ & $4.32(.70)^{*}$ & $4.62(.57)$ & 4.03 (1.02) & $4.18(.90)$ \\
\hline 3. Seeks feedback & $4.19(.86)^{*}$ & $4.56(.66)$ & $3.96(.95)$ & $3.98(1.00)$ \\
\hline
\end{tabular}

\section{Research Question 1 Discussion}

These studies show that the attributes of the ideal worker are much broader than those discussed by Acker $(1990,1992)$ in the theory of gendered organizations and in past studies of the ideal worker (Kelly et al., 2010; Reid, 2015; Sallee, 2012) Many of the attributes focus on the mental skills of an ideal worker, particularly those that deal with decision making such as being decisive, having good analytical abilities, and being skilled at business matters. Having leadership ability, being ambitious, and focusing on success were also considered important attributes of an ideal worker. In addition, having emotional control, taking initiative at work, and taking a stand on issues also defined an ideal worker. Traditionally, these attributes have been considered more masculine. However, some traditionally feminine attributes were also considered characteristic of an ideal worker, particularly those related to being a good team player and a good colleague. 
Of the four attributes described in the theory of gendered organizations (Acker, 1990, 1992) and in research on the ideal worker (Kelly et al., 2010; Reid, 2015; Sallee, 2012), only working long hours and being committed to work were considered attributes of an ideal worker. In fact, being able to put in the hours needed to complete tasks and handle additional work responsibilities were the only items characteristic of an ideal worker in terms of working long hours that met the inclusion criteria (mean of 4.0 or above). Additionally, it appears that the different ways that employees show their commitment to their work - including to their organization, their job, and particularly to their careers - are important for being perceived as an ideal worker.

However, items about traveling and relocating for work as well as being visibly busy at work were not considered attributes of the ideal worker, contrary to past research (Kelly et al., 2010; Reid, 2015; Sallee, 2012). The theory of gendered organizations was developed by Acker in the 1990s, when technology was just beginning to allow employees to work outside of their offices. It may be that due to technology, having to travel for work, relocate for work, or being visibly busy at work are no longer important attributes of an ideal worker. Now, remote working is common for employees, so having to be physically present in a far-flung office or even working regularly in one's workplace is often not necessary for employees to successfully finish their work tasks. Thus, it may be that the attributes of an ideal worker have evolved as technology changes the way individuals work in organizations. 
Employees and students tended to view attributes similarly, but students perceived more attributes as characteristic of an ideal worker than employees did. Although this study did not investigate why students and employees may perceive the attributes of an ideal worker differently, it may be that employees, with their more extensive work experience, have a slightly different, narrower conception of the ideal worker. One reason may be that employees understand that to maintain their employment, all employees have to meet certain criteria such as having a good work ethic, being concerned about the fate of the organization (and their own future employment), and asking for opportunities to develop their careers - all items that were rated 'somewhat' (in Samples 1 and 2) or 'very characteristic' (in Samples 3 and 4) of an ideal worker by the student samples but not by the employee sample. Thus, these attitudes and behaviors may not distinguish ideal workers from other employees.

It may also be that employees are better able to differentiate between the attributes that describe an ideal worker from those that describe an ideal leader. Many of the items that were rated as characteristic by students but not by employees are related to attributes of a leader such as those about influencing others to gain buy-in for tough decisions, not backing down, and aspiring to a leadership role in the organization. Employees may perceive an ideal worker as someone who could be a good leader in the future, but not necessarily someone who desires to be a leader or who already possesses those qualities. Because later studies only use attributes rated 4.0 or above by all samples, I only include items that both employees and students rated as attributes of an ideal worker. 
Similarly, male and female participants tended to agree on the attributes of an ideal worker, but a few items had significant differences between male and female participant ratings. When male and female participants perceived the attributes of an ideal worker differently, the female participants rated the attribute as more characteristic of an ideal worker than male participants did. Female raters may perceive that they are held to a higher standard at work, which affects their ratings of an ideal worker. The literature on shifting standards may explain some of this difference in ratings. According to the theory of shifting standards, individuals from social groups with less status in society are held to a higher standard when compared to members of social groups with more status in society (Biernat \& Kobrynowicz, 1997; Biernat \& Manis, 1994; Uhlmann \& Cohen, 2005). Because of these differing standards, it can be difficult for lower status group members to be rated as highly as higher status group members on attributes that are important and help groups gain status in society. In the workplace, men tend to have more status than women (Ridgeway, 2001). Thus, it can be difficult for women to be rated as highly as men on attributes that are considered important in the workplace. Female employees likely perceive that they are held to a higher standard, which means that to be perceived as an ideal worker, they may have to work harder than their male colleagues. This difference in the required effort to be perceived as an ideal worker may change how men and women describe the ideal worker.

Overall, for Research Question 1, I discovered that the attributes of the ideal worker are broad. Like other stereotypes, male and female participants 
tended to agree on the attributes of the ideal worker, though employees had a narrower perception of what attributes described an ideal worker compared to students. Thus, my later studies use the attributes that all samples rated as characteristic of an ideal worker. With a better understanding of the attributes of an ideal worker, I focus my second research question on whether the attributes of the ideal worker are gendered, and if so, whether they are more associated with the male gender role stereotype than the female gender role stereotype as suggested by the theory of gendered organizations. In my next section, I describe how I tested this research question. 


\section{Research Question 2 Method}

\section{Participants and Design}

To address Research Question 2, about whether ideal worker attributes are more associated with the male than the female gender role stereotype, I used data from Samples 3 (students from an introductory management class at a large Midwestern university) and 4 (employees from organizations across the United States) used to study Research Question 1.

\section{Procedure}

Participants completed two tasks as part of the online survey. First, participants read a description of an ideal worker and rated how characteristic a list of words and phrases were of an ideal worker. Next, participants rated the same list of words and phrases for how characteristic they were of a typical man or a typical woman. Whether a participant rated a typical man or woman was randomly assigned. See Appendix III for the instructions and measures used to address Research Question 2.

\section{Measures}

Ideal Worker Attributes. Participants rated 153 items that could be considered characteristic of an ideal worker. Sample 3 (students) was asked to rate these items for "an employee who has the desire and ability to reach the highest levels in the organization" and Sample 4 (employees) was asked to rate the same items for "an employee you would want to support and develop by promoting them to another position." Participants rated how characteristic each word or phrase was of an ideal worker on a 5-point scale, where 1 signified 'Not at all characteristic' and 5 'Extremely characteristic' of an ideal worker. 
Typical Male Attributes. Using the same list of attributes, participants rated how characteristic each attribute was for a typical man. Participants completed ratings using a 5-point scale where 1 meant 'Not at all characteristic' and 5 'Extremely characteristic of a typical man.' Whether a participant rated a typical man or a typical woman on the list of worker attributes was randomly assigned.

Typical Female Attributes. Participants rated how characteristic the same attributes were for a typical woman using a 5-point scale of 1 "Not at all characteristic' and 5 'Extremely characteristic of a typical woman.'

Demographic Information. Student participants were asked about their sex, age, race, major, number of years of work experience, and whether they had supervisory experience or not. Employee participants were asked about their sex, age, race, highest level of education, number of years of work experience, and whether they had supervisory experience or not.

\section{Research Question 2 Results}

To test Hypothesis 1, that the ideal worker stereotype is gendered masculine, I compared the ratings of ideal worker attributes to the ratings of attributes of the typical man and typical woman using intraclass correlation coefficients (ICCs; Hays, 1963) for the items in the study. Intraclass correlation coefficients have been calculated in past studies of the Schein Descriptive Index (which was used to study Research Question 1) (Brenner et al., 1989; Gupta et al., 2009; Schein, 1973; Schein et al., 1996). For example, Duehr and Bono (2006) asked raters to use a revised version of the Schein Descriptive Index to rate managers and then to rate either a typical man or woman. In these studies, to compare a concept such as 'manager' with male and female gender role stereotypes 
researchers calculated intraclass correlation coefficients for the index to compare the concept 'manager' with a typical man and typical woman, which represented gender role stereotypes.

The study contained three classes of items: ratings for an ideal worker, a typical man, and a typical woman. I calculated the mean rating for all 153 items within each class. I then calculated the correlation between the mean rating of an ideal worker with that of a typical man and between the mean rating of an ideal worker and the typical woman. The formula for the intraclass correlation between two groups (the ideal worker and either the typical man or typical woman) is:

$$
\hat{\rho}=\frac{M S_{\text {btwn sub }}-M S_{\text {residual }}}{M S_{\text {btwn sub }}+(k-1) M S_{\text {residual }}}
$$

The higher the ICC, the stronger the relationship between ideal worker attributes and those of the typical man or the typical woman. The ICCs were calculated for the student and employee samples separately in three ways: 1) all of the items included in Samples 3 and 4,2 ) only the items considered 'very characteristic' of the ideal worker (as determined by the inclusion rules to address Research Question 1), and 3) theoretical attributes of the ideal worker that were suggested by the theory of gendered organizations and previous research on the ideal worker (works long hours, travels and relocates for work, visibly busy at work, and dedicated to work). Because correlations are standardized coefficients, I conducted $z$-tests to test for significant differences between the correlation of the ideal worker attributes with those of a typical man and the correlation of ideal worker attributes with those of a typical woman.

As Table 6 shows, the ICCs for the student and employee samples led to different results. For all three groups of items (all items, 'very characteristic' 
attributes, and theoretical attributes), the student sample rated the ideal worker attributes as significantly more like those of a typical woman than a typical man. That is, participants perceived that the ideal worker attributes were more related to the female than the male gender role stereotype. However, for the employee sample, none of the comparisons resulted in a significant difference between the ratings of the ideal worker and the typical woman or typical man. Therefore, I find no support for Hypothesis 1 as the student sample showed results opposite of those hypothesized and the employee sample showed ideal worker attributes as equally related to the male and female gender role stereotypes.

Table 6. Intraclass Correlation Coefficient Comparisons for Hypothesis 1

\begin{tabular}{lccc}
\hline Items Included in Analysis & $z$-test & $\begin{array}{c}\text { Correlation } \\
\text { Ideal Worker- } \\
\text { Typical Woman }\end{array}$ & $\begin{array}{c}\text { Correlation } \\
\text { Ideal Worker- } \\
\text { Typical Man }\end{array}$ \\
\hline Student Sample $(n=238)$ & $z=2.75$, & $r(119)=.57$, & $r(118)=.28$, \\
All items & $(p=.01)$ & $(p<.001)$ & $(p<.01)$ \\
Very Characteristic Attributes & $z=2.39$, & $r(119)=.52$, & $r(118)=.25$, \\
& $(p=.02)$ & $(p<.001)$ & $(p<.01)$ \\
Theoretical Attributes & $z=-1.96$, & $r(119)=.47$, & $r(118)=.25$, \\
& $(p<.05)$ & $(p<.001)$ & $(p<.01)$ \\
\hline Employee Sample $(n=318)$ & & & \\
\hline All items & $z=1.35$, & $r(155)=.63$, & $r(159)=.53$, \\
Very Characteristic Attributes & $(p=.16)$ & $(p<.001)$ & $(p<.001)$ \\
Theoretical Attributes & $z=1.29$, & $r(155)=.56$, & $r(159)=.46$, \\
& $(p=.19)$ & $(p<.001)$ & $(p<.001)$ \\
& $z=1.04$, & $r(155)=.58$, & $r(159)=.49$, \\
& $(p=.30)$ & $(p<.001)$ & $(p<.001)$ \\
\hline
\end{tabular}

*Significant difference in $z$-test comparing the correlations of the ideal worker with the typical woman and the typical man at the .05 alpha level.

\section{Research Question 2 Discussion}

This study addressed my second research question about whether the ideal worker attributes are gendered by testing the association of ideal worker attributes to the 
attributes associated with the male and female gender role stereotypes. I hypothesized that ideal worker attributes would be gendered masculine - they would be more correlated with the typical man than the typical woman. However, my analysis did not support this hypothesis. For the student sample, the attributes of the ideal worker were more associated with the female gender role stereotype (more feminine) based on the intraclass correlation coefficients. For the employee sample, the ideal worker was not more related to one gender role stereotype than the other (gender neutral).

The student results may be explained by recent research on gender role stereotypes. Street et al. (1995) found that when rating an ideal woman and an ideal man, college students tended to prefer an androgynous ideal woman (someone who displays both feminine and masculine attributes). Whereas female students also preferred an androgynous man, male students preferred a masculine ideal man (who displays primarily masculine attributes). The attributes of an ideal worker in Research Question 1 included attributes that are generally considered masculine (e.g., independent and work-oriented) and feminine (e.g., understands others, is a team player). This inclusion of both masculine and feminine attributes is characterized as 'androgynous' by Street et al. (1995). Thus, it makes sense that if college students perceive women as more androgynous than men, women may be perceived as having attributes more like an ideal worker, who is also perceived as androgynous, than men do.

The employee results are consistent with recent research on gender role stereotypes in adults. Eagly et al. (2019) used representative poll data from 1950 
to 2018 to investigate whether stereotypes about men and women had changed since the mid- $20^{\text {th }}$ century. Through a meta-analysis of polls, they found that the public has come to perceive women as more competent and more intelligent than in the past such that now men and women generally are rated equal in competence and intelligence. Eagly and her colleagues explain these changes through the dramatic increase of women in the workforce since the 1970s. According to social role theory, as the public began to see more women in professional roles, the typical social role of women may have changed to include employee, a social role that had been mostly limited to men in earlier decades. These social role changes may also explain why women are perceived as more competent and intelligent in 2018 than in 1950.

Additionally, full-time employment may change employees' stereotypes about what an ideal worker is like, especially if they observe ideal employees working in different job roles, across different organizations, and possibly across different industries. These changes in perceiving men and women at work have been found in studies on leadership, which has been traditionally perceived as masculine. Zenger and Folkman (2019) have found that the differences between ratings of men and women on leadership skills has converged over the last few years. Using 360-degree reviews from women in leadership across different organizations, Zenger and Folkman found that although men used to be rated higher on most of the leadership capabilities measured in their research, women score similarly to men on 17 of the 19 capabilities. The biggest differences are found in taking initiative, resilience, practicing self-development, and driving for results. Most of these leadership capabilities are more closely associated with the male gender role stereotype. Thus, their research has found that leadership capabilities align with both 
male and female gender role stereotypes and that perceptions of male and female leadership are not much different from one another. Although my research is focused on the ideal worker rather than on leaders, changes in gender role stereotypes in the workplace may affect the ideal worker stereotype as they have leadership stereotypes such that the ideal worker is perceived as less masculine today than when Acker created the theory of gendered organizations in 1990.

Although I did not find support for my hypothesis that ideal worker attributes would be perceived as masculine as students associated the attributes more with the female gender role stereotype and employees associated ideal worker attributes equally with the male and female gender role stereotypes, my research so far has not addressed whether the attributes of the ideal worker are important for employee outcomes at work. In the next section, I test my third research question: does the extent to which employees exemplify ideal worker attributes predict promotability and development recommended for them? 


\section{Research Question 3 Method}

\section{Participants}

Participants were recruited from Amazon Mechanical Turk. The survey began with screening questions to ensure that participants were current employees in the United States. To ensure the quality of participants, I limited participation to those who had already completed over 1,000 tasks (HITs) on Amazon Mechanical Turk. For completing the survey, participants received a $\$ 2$ incentive. After completing the screening questions, participants were randomly assigned to complete the Research Question 3 or Research Question 5 experimental conditions. Of the 695 participants who started the survey, 550 completed it. I analyzed the demographic characteristics of those who did and did not complete the survey, and I found several significant differences. Those who did not complete the survey were more likely to be male $(\mathrm{t}(580)=2.06, p=.04)$, nonwhite $(t(581)=2.70, p=.01)$, and younger $(t(579)=2.72, p=.01)$. Participants whose data were not included in the final analysis also differed in terms of their experimental condition. Those whose data were not used were more likely to be in the Research Question 5 experimental condition $(t(580)=7.35, p<.001)$. (See Research Question 5 for an explanation as to why participants assigned to the Research Question 5 experimental condition may have been more likely to drop out of the study.) Table 7 shows the significant differences between the participants whose data were included and were not included in the data analysis. 
Table 7. Differences between Participants Whose Data Were Included and Not Included in Analysis

\begin{tabular}{lccccc}
\hline Variable & $n$ & $\begin{array}{c}\text { Mean } \\
\text { Included }\end{array}$ & $\begin{array}{c}\text { Mean Not } \\
\text { Included }\end{array}$ & $\begin{array}{c}t- \\
\text { test }\end{array}$ & $\begin{array}{c}p \text { - } \\
\text { value }\end{array}$ \\
\hline Gender $(1=$ Female $)$ & 582 & .65 & .47 & 2.06 & .04 \\
Race $(1=$ White $)$ & 583 & .81 & .62 & 2.70 & .01 \\
Age & 581 & 39.26 & 33.52 & 2.72 & .01 \\
$\begin{array}{l}\text { Experimental Condition } \\
(1=\text { Research Question }\end{array}$ & 695 & .60 & & & \\
$5)$ & & & .91 & 7.35 & $<.001$ \\
\hline
\end{tabular}

Note: $n=695$

Of the 550 participants who completed the survey, most were full-time employees $(n=452,82.2 \%)$, female $(n=352,64.0 \%)$, white $(n=445,80.9 \%)$, had a bachelor's degree or more education $(n=313,56.9 \%)$, were evenly split between partnered $(n=$ $268,48.7 \%)$ and not $(n=282,51.3 \%)$, and had an average age of 39.3 years old. The average organizational tenure was 7.2 years and the average job tenure was 6.4 years; a little more than half of the participants currently worked in a managerial role in their firm $(n=305,55.5 \%)$.

As noted above, these 550 participants were randomly assigned to complete the survey for Research Question 3 or Research Question 5. The participants who were randomly assigned to the Research Question 3 experimental condition ( $n=220,40 \%$ of the 550 total participants) were mostly female $(n=132,60 \%)$, had a bachelor's degree or more education $(n=123,55.9 \%)$, were married $(n=111,50.5 \%)$, were white $(n=180$, $81.8 \%$ ), and had a mean age of 37.6 years. Most were employed full-time $(n=185$, $84.1 \%$ ) with 6.1 years in their job and 7.3 years in their organization. The majority also had positions at some leadership level in their organization $(n=53,24.1 \%$ at entry-level management; $n=68,30.9 \%$ at middle-level management; and $n=9,4.1 \%$ at senior-level management). 


\section{Procedure}

The design of this study was an experimental design in which participants were presented with performance information for an employee whose gender was randomly assigned to each participant at the beginning of the study. Participants were told that they were testing how people process different ways of presenting employee performance information for managerial decision making. Participants read a performance evaluation table with ratings for an employee. Participants were randomly assigned to read information about either a male or female employee, with gender identified by the employee's name and pronouns used throughout the employee performance table and the accompanying items. After reading the information, participants rated the employee on promotability and developmental opportunity recommendations. For participants who were randomly assigned to the experimental condition for Research Question 3, they also rated the employee's attributes on a list of ideal worker items from the previous studies, completed two measures about their sexism beliefs, and answered questions about their work experience and demographic information to conclude the survey. Appendix V shows the employee information presented to participants along with the measures used to address Research Question 3.

Stimulus Materials. The employee was an operations research analyst. Participants began by reading a brief description about what operations research analysts do, the employee's educational and work background, as well as the career path for highpotential operations research analysts. Operations research analyst was selected as the employee's job because, according to the U.S. Bureau of Labor Statistics (2019), nearly 50 percent of workers in this job category are women. After reading a brief description 
of the job, participants reviewed a table with a performance rating for each of the seven main tasks of an operations research analyst, according to O*Net (2019). The performance scale had 5 points, and the employee had earned very good scores ( 4 out of 5) for four aspects of the job and excellent scores (5 out of 5) for the other three aspects of the job. Appendix V provides a description of the stimulus materials and measures. Participants rated Jessica or Bradley Miller, with the gender of the employee randomly assigned to each participant. Because the employee was at the beginning of their career, first and last names were chosen based on what was popular when the employee would have been born. First names were chosen based on the 200 most popular baby names in the 1990s (U.S. Social Security Administration, 2019), and last names were chosen based on the most popular last names in the United States in 1990 (U.S. Census Bureau, 2014).

\section{Variables}

Promotability Rating. Before participants were randomly assigned to the Research Question 3 or Research Question 5 experimental conditions, all rated the promotability of the employee with four questions. To measure whether the employee should be promoted to the next level of the organizational hierarchy, the first question asked whether the participant would recommend the employee for a promotion to senior operations analyst (the next position up on the organizational hierarchy). To measure the employee's potential ability to move up to the top levels of the organization over their career, participants answered three questions about the employee's executive potential. Participants rated the employee on a 6-point scale, where 1 meant 'Strongly disagree' and 
6 'Strongly agree.' The mean of all four items was calculated to create a rating for each employee. Cronbach's alpha was .82 .

Recommended Development. Before being assigned to the Research Question 3 or Research Question 5 experimental conditions, participants rated whether they would oppose or recommend the employee on 10 developmental opportunities. The 10 opportunities were based on McCauley's (1999) 10 components of developmental jobs: taking on new responsibilities, making strategic changes, fixing problems created by others, managing difficult subordinates, working high-stakes positions, tackling large tasks, dealing with external pressure, exercising influence without authority, interacting with people from different cultures, and supervising a diverse group. The developmental jobs were divided into five categories: 1) experiencing a job transition, 2) creating change, 3) managing at high levels of responsibility, 4) managing boundaries, and 5) dealing with diversity.

The items used in this study were adapted by King et al. (2012). For each of the 10 developmental tasks, participants rated the employee on a 7-point scale, where 1 meant 'Strongly oppose' and 7 meant 'Strongly recommend' the employee for the opportunity. King and colleagues (2012) intended for the 10 developmental opportunity items to be a one-factor scale. A confirmatory factor analysis of the data for this study shows that a one-factor solution is the best fit, so I calculated the mean of all of 10 developmental opportunities to create a scale score. The Cronbach's alpha for the recommended development scale was .90 .

Ideal Worker Attribute Rating. Participants randomly assigned to the Research Question 3 experimental condition rated the employee on 45 attributes of an ideal worker, 
based on attributes considered 'very characteristic' of an ideal worker in the previous two studies. These 45 items were chosen to represent the top-rated attributes of the ideal worker from Research Question 1. Participants used a 5-point scale, where 1 meant 'Not at all characteristic' and 5 'Extremely characteristic' of the employee. The mean for all the items was used to create a rating for the employee. The Cronbach's alpha for the scale was .97 .

Demographic Information. Participants were asked about their demographic characteristics, including sex, age, race, education level, marital status, and their partner's sex and work status. They also answered questions about their work experience, including the industry they work in, tenure with their current organization and in their current role, their current leadership level in their organization, and how much supervisory experience they had during their career.

\section{Research Question 3 Results}

Table 8 provides the correlations among the variables used to test Hypothesis 2. Employee promotability was significantly and positively related to recommended development $(r=.65, p<.01)$. Rater gender was also significantly and positively correlated with employee gender $(r=.08, p<.05)$. This correlation is due to the differences between those whose data were included and those whose data were not. As Table 7 shows, those whose data were included in the analysis were more likely to be female, which was coded as gender $=1$. Because more female participants' data were included, I find a small positive but significant correlation between participant gender and employee gender. Rater age was significantly correlated with employee gender ( $r=$ $.12, p<.01)$, rater gender $(r=.09, p=.04)$, and rater race $(r=.18, p<.001)$ due to the 
characteristics of those who completed the survey and those who did not. Older

participants were more likely to be female and white and were more likely to rate a

female employee.

Table 8. Means, Standard Deviations, and Correlations of Variables for Hypothesis 2

\begin{tabular}{|c|c|c|c|c|c|c|c|c|c|c|}
\hline & Variable & Mean & SD & 1 & 2 & 3 & 4 & 5 & 6 & 7 \\
\hline 1 & Promotability & 5.23 & .64 & $(.81)$ & & & & & & \\
\hline 2 & $\begin{array}{l}\text { Recommended } \\
\text { Development }\end{array}$ & 4.96 & .60 & $.65 * *$ & $(.89)$ & & & & & \\
\hline 3 & $\begin{array}{l}\text { Employee Gender } \\
(\text { female }=1)\end{array}$ & .49 & .50 & .01 & 0 & - & & & & \\
\hline 4 & $\begin{array}{l}\text { Rater Gender (female } \\
=1 \text { ) }\end{array}$ & .65 & .49 & .06 & .03 & $.08 *$ & - & & & \\
\hline 5 & $\begin{array}{l}\text { Rater Leadership } \\
\text { Level }\end{array}$ & .93 & .95 & -.07 & -.04 & -.03 & -.07 & - & & \\
\hline 6 & $\begin{array}{l}\text { Rater Race (white }= \\
\text { 1) }\end{array}$ & .81 & .39 & .06 & .03 & -.02 & .01 & .01 & - & \\
\hline 7 & Rater Age & 39.25 & 11.86 & .04 & .03 & $.12 * *$ & $.09 *$ & .03 & $.18 * *$ & - \\
\hline
\end{tabular}

** and * Significant at the $p<.01$ and $p<.05$ level, respectively.

Notes: $n=550$. Promotability was rated on a 6-point scale and recommended development on a 7-point scale. For employee and rater gender, 0 signifies male and 1 female. Rater leadership level was measured at 4 levels: $0=$ non-leader, $1=$ entry-level management, $2=$ middle-level management, and $3=$ upperlevel management. Rater race was coded as $0=$ non-white and $1=$ white.

To analyze Hypothesis 2, that raters will rate the male employee higher on promotability and recommended development than the female employee, I conducted an analysis of variance (ANOVA) comparing the average promotability rating and recommended development for the male and female employee. Because the analysis of variance model assumes that the data has a normal distribution and homogeneity of variance between groups, I tested these assumptions before running my models. The Shapiro-Wilks test for normality showed that both promotability $(W(550)=.90, p<.001)$ and recommended development $(W(550)=.97, p<.001)$ were not normally distributed. However, the test of homogeneity of variances showed no differences between employee 
gender for promotability, $W(1,548)=.001, p=.97$, and recommended development, $W(1,548)=.005, p=.95$. To account for the non-normal distribution of my data, I ran the Kruskal-Wallis $H$-test, which does not assume normality. Table 9 provides the mean ratings for the male and female employee. The Kruskal-Wallis $H$-test $(n=550)$ was not significant for either promotability, $X^{2}(1)=.13, p=.72$, or recommended development, $X^{2}(1)=.01, p=.92 .^{1}$ Thus, I find no support for Hypothesis 2 .

Table 9. Means and Standard Deviations of Employee Outcomes by Employee Gender for Hypothesis 2

\begin{tabular}{lcc}
\hline & Male $(n=282)$ & Female $(n=268)$ \\
\hline Promotability & 5.22 & 5.24 \\
& $(.63)$ & $(.65)$ \\
\hline Recommended & 4.96 & 4.96 \\
Development & $(.60)$ & $(.61)$ \\
\hline
\end{tabular}

For Hypothesis 3, because only participants randomly assigned to the Research Question 3 experimental condition completed the measures, Table 10 provides the means, standard deviations, and correlations among the variables for Hypotheses 3 and 4.

Promotability and recommended development are significantly and positively correlated $(r=.64, p<.001)$, and ideal worker rating is significantly and positively correlated to both $(r=.65, p<.001$ with promotability and $r=.65, p<.001$ for recommended development). Rater leadership level was significantly and negatively correlated with promotability $(r=-.15, p=.03)$. The higher up in leadership the rater was in their current job, the lower the promotability rating they gave the employee.

\footnotetext{
${ }^{1}$ Because the results from Research Question 2 showed that female raters gave higher ratings to female employees than male raters did, I conducted a Kruskal-Wallis $H$-test on the interaction of rater gender with employee gender on promotability and recommended development. I found no significant interaction effect. I also tested whether the rater's leadership level in their current job role affected their ratings of male and female employees since those in leadership may have more experience with the experimental task (rating employees) but found no significant interaction effect.
} 
Table 10. Means, Standard Deviations, and Correlations of Variables for Hypotheses 3 and 4

\begin{tabular}{|c|c|c|c|c|c|c|c|c|c|c|c|}
\hline & Variable & Mean & SD & 1 & 2 & 3 & 4 & 5 & 6 & 7 & 8 \\
\hline 1 & Promotability & 5.17 & .66 & $(.82)$ & & & & & & & \\
\hline 2 & $\begin{array}{l}\text { Recommended } \\
\text { Development }\end{array}$ & 4.89 & .63 & $.64 * *$ & $(.90)$ & & & & & & \\
\hline 3 & Ideal Worker Rating & 3.98 & .51 & $.65^{* *}$ & $.65^{* *}$ & $(.97)$ & & & & & \\
\hline 4 & $\begin{array}{l}\text { Employee Gender } \\
(\text { female }=1)\end{array}$ & .49 & .50 & .05 & .02 & .02 & - & & & & \\
\hline 5 & $\begin{array}{l}\text { Rater Gender } \\
(\text { female }=1)\end{array}$ & .61 & .50 & .09 & .07 & .13 & .02 & - & & & \\
\hline 6 & $\begin{array}{l}\text { Rater Leadership } \\
\text { Level }\end{array}$ & .98 & .94 & $-.15^{*}$ & -.08 & -.12 & -.03 & $\begin{array}{c}- \\
.05\end{array}$ & - & & \\
\hline 7 & $\begin{array}{l}\text { Rater Race } \\
(\text { white }=1)\end{array}$ & .82 & .34 & -.01 & -.03 & 0 & .11 & $\begin{array}{c}- \\
.02\end{array}$ & .02 & - & \\
\hline 8 & Rater Age & 37.59 & 11.99 & -.02 & .05 & .06 & .01 & .02 & .02 & $.17 *$ & - \\
\hline
\end{tabular}

Notes: $n=220$. Promotability was rated on a 6-point scale, recommended development on a 7 -point scale, and ideal worker rating on a 5-point scale. For employee and rater gender, 0 signifies male and 1 female. Rater leadership level was measured at 4 levels: $0=$ non-leader, $1=$ entry-level management, $2=$ middlelevel management, and $3=$ upper-level management. Rater race was coded as $0=$ non-white and $1=$ white.

To analyze Hypothesis 3 that individuals will rate male employees higher on ideal worker attributes than female employees, I conducted an analysis of variance comparing the ideal worker rating score of the male and female employee. I tested the normality of the data and the homogeneity of variances between the employee gender groups. The Shapiro-Wilk test for normality showed that the ideal worker rating data violates the assumption of normality, $W(220)=.98, p=.006$. However, the Leven's test of homogeneity shows no heterogeneity in variance between male and female employee groups, $W(1,218)=.01, p=.92$. Because the data violates the assumption of normality, I used a Kruskal-Wallis $H$-test. The test showed no difference in ideal worker ratings for male and female employees, $X^{2}(1,219)=.04, p=.84 .^{2}$ Table 11 shows the means and

\footnotetext{
${ }^{2}$ Because rater gender and rater leadership level were correlated with employee gender (see Table 8) and promotability (see Table 10), respectively, I tested whether rater gender or rater leadership level interacted with employee gender to predict ideal worker rating. I found no significant interaction effects.
} 
standard deviations in ideal worker ratings for the male and female employee; the ideal worker rating for the male and female employee is not significantly different. Therefore, I find no support for Hypothesis 3.

Table 11. Means and Standard Deviations of Ideal Worker Rating by Employee Gender for Hypotheses 3

\begin{tabular}{lcc}
\hline & $\begin{array}{c}\text { Male Employee } \\
(n=112)\end{array}$ & $\begin{array}{c}\text { Female Employee } \\
(n=108)\end{array}$ \\
\hline Ideal Worker Rating & 3.97 & 3.99 \\
& $(.50)$ & $(.51)$ \\
\hline
\end{tabular}

To test Hypothesis 4 about whether the ideal worker rating predicts promotability and recommended development, I conducted a linear regression in which ideal worker rating predicts promotability and recommended development. Because rater gender, leadership level, race, and age were related to whose data was included and whose was not in Research Questions 3, 4, and 5, I control for these rater characteristics across the three research questions. Table 12 shows the results of the regressions predicting promotability and recommended development. Because rater gender and leadership level were correlated with the outcomes, and because rater race and age were related to the experimental condition participants completed, I included these rater attributes as controls in my regression models. As Table 12 shows, the employee's ideal worker rating is a significant predictor of their promotability, $b=.84, t=12.23, p<.001$. Likewise, the employee's ideal worker rating predicts development recommended for the employee, $b=.81, t=12.38, p<.001$. Thus, I find support for Hypothesis 4 that the ideal worker rating predicts promotability and recommended development. 


\section{Table 12. Regression Results for Hypothesis 4}

\begin{tabular}{lcc}
\hline & Promotability & Recommended Development \\
\hline Intercept & $1.98^{* *}$ & $1.69 * *$ \\
& $(.30)$ & $(.29)$ \\
Ideal Worker Rating & $.84 * *$ & $.81 * *$ \\
& $(.07)$ & $(.07)$ \\
Rater Gender & .01 & -.03 \\
Rater Leadership Level & $(.07)$ & $(.07)$ \\
& -.05 & 0 \\
Rater Race & $.04)$ & $(.04)$ \\
& 0 & -.04 \\
Rater Age & $(.09)$ & $(.09)$ \\
& 0 & 0 \\
R-square for Full Model & .43 & $(0)$ \\
$* *$ and $*$ Significant at the $p<.01$ and $p<.05$ level, respectively. \\
Note: $n=220$.
\end{tabular}

To test Hypotheses 5a and 5b about whether ideal worker ratings mediate the relationship between employee gender and promotability (Hypothesis 5a) and employee gender and recommended development (Hypothesis 5b), I calculated a mediation model using Hayes's PROCESS model (Hayes, 2018). Figure 2 shows the mediation model and Table 13 provides the results of the mediation analysis. Based on 10,000 bootstrap samples, for promotability, the indirect effect of X on $\mathrm{Y}(a b=.01)$ was not significant, with a confidence interval including $0(-.11, .12)$. Thus, I find no support for Hypothesis 5a. Ideal worker rating does not mediate the relationship between employee gender and promotability. 
Figure 2. Mediation Model for Hypothesis 5a

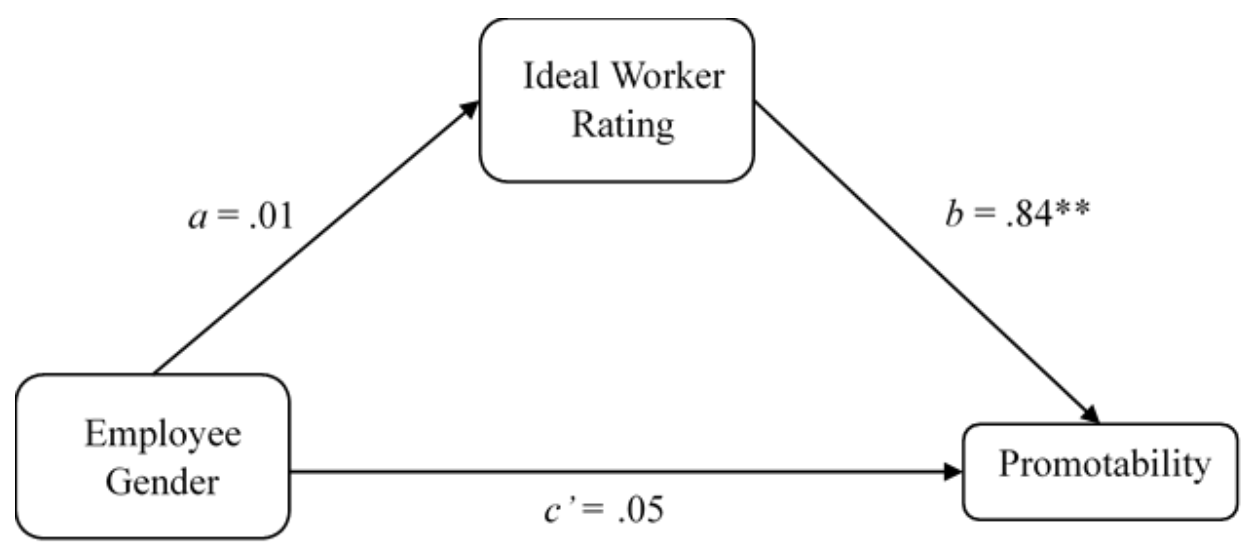

Table 13. Mediation Analysis Results for Hypothesis 5a

\begin{tabular}{|c|c|c|c|c|c|c|c|c|}
\hline \multirow[b]{3}{*}{ Antecedent } & & \multicolumn{7}{|c|}{ Consequent } \\
\hline & & \multicolumn{4}{|c|}{ M (Ideal Worker Rating) } & \multicolumn{3}{|c|}{ Y (Promotability) } \\
\hline & & Coefficient & $S E$ & $p$ & & Coefficient & $S E$ & $p$ \\
\hline Employee Gender & $a$ & .01 & .07 & .84 & $c^{\prime}$ & .05 & .07 & .45 \\
\hline Ideal Worker Rating & & -- & -- & -- & $b$ & .84 & .07 & $<.001$ \\
\hline Rater Gender & & .12 & .07 & .07 & & .01 & .07 & .94 \\
\hline Rater Leadership & & -.06 & .04 & .10 & & -.05 & .04 & .20 \\
\hline \multicolumn{9}{|l|}{ Level } \\
\hline Rater Race & & -.02 & .09 & .85 & & 0 & .09 & .97 \\
\hline Rater Age & & .01 & .09 & .36 & & 0 & 0 & .31 \\
\hline \multirow[t]{2}{*}{ Constant } & $i_{M}$ & 3.87 & .14 & $<$ & $i_{Y}$ & 1.96 & .30 & $<.001$ \\
\hline & & \multicolumn{3}{|c|}{$\begin{array}{c}R^{2}=.03 \\
\mathrm{~F}(5,214)=1.47, p= \\
.20\end{array}$} & & \multicolumn{3}{|c|}{$\begin{aligned} & R^{2}=.43 \\
& \mathrm{~F}(6,213)=26.78, p< \\
& .001\end{aligned}$} \\
\hline
\end{tabular}

Note: $n=220$. All independent variables were mean-centered.

I also calculated a mediation model to test Hypothesis $5 \mathrm{~b}$ that ideal worker rating mediates the relationship between employee gender and recommended development. Figure 3 shows a model of the hypothesized mediation and Table 14 provides the results of the mediation analysis. The indirect effect of ideal worker rating $(a b=.01)$ was not significant as the confidence interval for the indirect effect contained $0(-.16, .19)$, based on 10,000 bootstrap samples. Therefore, I find no support for Hypothesis 5b. Ideal 
worker rating does not mediate the relationship between employee gender and recommended development.

Figure 3. Mediation Model for Hypothesis 5b

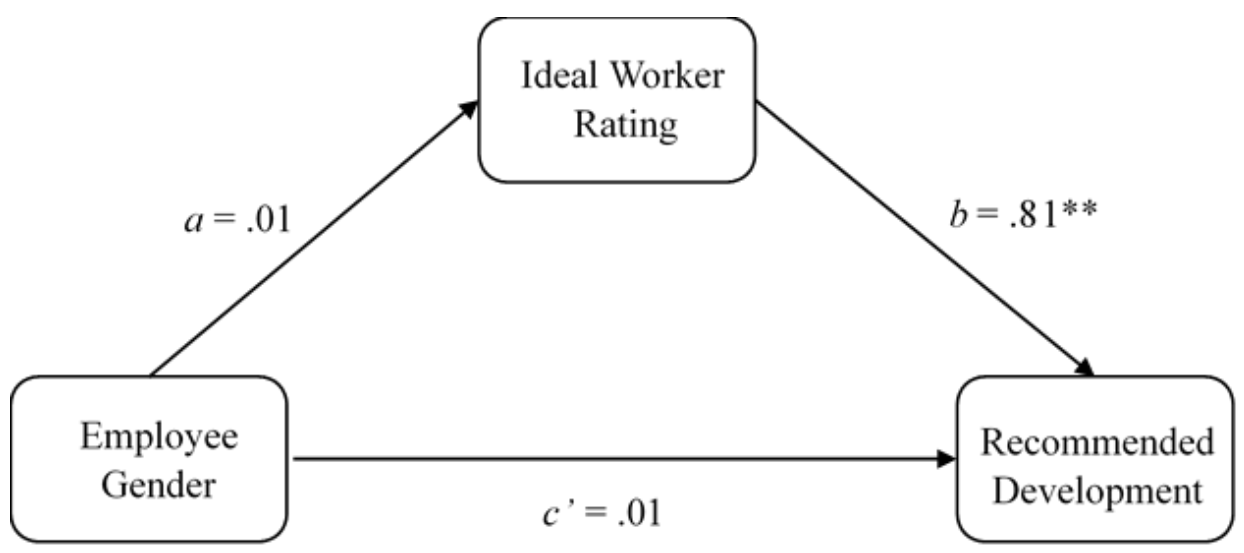

Table 14. Mediation Analysis Results for Hypothesis $5 b$

\begin{tabular}{|c|c|c|c|c|c|c|c|c|}
\hline \multirow[b]{3}{*}{ Antecedent } & & \multicolumn{7}{|c|}{ Consequent } \\
\hline & & \multicolumn{3}{|c|}{ Ideal Worker Rating } & & \multicolumn{3}{|c|}{$\begin{array}{l}\text { Recommended } \\
\text { Development }\end{array}$} \\
\hline & & Coefficient & $S E$ & $p$ & & Coefficient & $S E$ & $p$ \\
\hline Employee Gender & \multirow[t]{7}{*}{$a$} & .01 & .07 & .84 & $c^{\prime}$ & .01 & .07 & .90 \\
\hline Ideal Worker Rating & & -- & -- & -- & $b$ & .81 & .07 & $<.001$ \\
\hline Rater Gender & & .12 & .07 & .07 & & -.03 & .07 & .70 \\
\hline Rater Leadership & & -.06 & .04 & .10 & & 0 & .04 & .95 \\
\hline Level & & & & & & & & \\
\hline Rater Race & & -.02 & .09 & .85 & & -.04 & .09 & .63 \\
\hline Rater Age & & 0 & 0 & .36 & & 0 & 0 & .76 \\
\hline \multirow[t]{3}{*}{ Constant } & $i_{M}$ & 3.87 & .14 & $<$ & $i_{Y}$ & 1.69 & .29 & $<.001$ \\
\hline & & & & .001 & & & & \\
\hline & \multicolumn{4}{|c|}{$R^{2}=.03$} & & \multicolumn{3}{|c|}{$R^{2}=.42$} \\
\hline
\end{tabular}

Note: $n=220$. All independent variables were mean-centered.

\section{Research Question 3 Discussion}

In Research Question 3, I found no differences in terms of promotability, recommended development, and ideal worker ratings between the male and female employee, and thus, no support for Hypotheses 2 and 3. However, I did find that the 
ideal worker rating was a significant predictor of both promotability and recommended development (H4), but I found no support that ideal worker rating mediates the relationship between employee gender and either of the outcomes (promotability and recommended development) (H5a and $\mathrm{H} 5 \mathrm{~b})$.

Despite not finding ideal worker rating as a mediator between employee gender and the outcomes studied (promotability and recommended development), such results indicate that the attributes of the ideal worker provide important information to raters about employees. More specifically, when employees are perceived to have more of the behaviors and attitudes of an ideal worker, raters reward them with higher promotability and more development. Although supervisors may provide all employees with some development to improve performance in the future, promotability may help supervisors give the best developmental opportunities to a select group: those who best exemplify ideal worker attributes at work. High promotability ratings among these employees may also lead to higher promotions and other benefits in the future as promotability is an important outcome for employees (Finkelstein et al., 2017).

One interesting finding is that participant leadership level was related to promotability ratings, which was an unexpected finding. The higher the leadership role in the participant's current job, the lower promotability ratings they gave to employees, but I did not find the same relationship for recommended development. As promotion decisions depend on the promotability rating given to an employee by their supervisor (Breaugh, 2011; London \& Stumpf, 1983; Ng et al., 2005; Stumpf \& London, 1981; Van Scotter et al., 2000), this finding has important impacts for employees. For example, if employees at the same level of the organizational hierarchy have supervisors at different 
levels of the organizational hierarchy, whether an employee receives a high promotability rating or a promotion may not depend solely on the employee's performance. Those employees who have supervisors with more leadership experience may receive lower promotability ratings, making it difficult for those employees to receive promotions and other rewards that have an impact on their career (Harris et al., 2006). Differences in performance evaluation ratings not due to differences in employee performance have been shown to lead employees to perceive the performance appraisal system as unjust (Erdogan et al., 2001). One reason may be that raters with a higher leadership position in their organization perceive promotability ratings as zero-sum decisions in which only one person earns the promotion. Promotions are usually zero-sum decisions for organizations since they often have only one or a limited number of positions open for internal promotion. Although promotability on its face is not a zero-sum decision - many employees can have high promotability ratings - raters with leadership experience may understand that decisions linked to promotability are zero-sum, and thus, want more information and may be stricter in rating employee promotability. Future research should explore how supervisors think about the relationship between promotability and promotions and how that relationship affects decisions around male and female employee promotability ratings and promotions.

What this research leaves out are important individual differences among raters that affect how they differentially perceive male and female employees, particularly for employees with similar performance. These differences may affect the association that ideal worker ratings have with promotability and recommended development. In the next 
section, I investigate Research Question 4 about whether and how sexism beliefs affect the way that raters perceive male and female employees. 


\section{Research Question 4 Method}

\section{Participants and Procedure}

Participants were recruited from Amazon Mechanical Turk and were the same participants used to test Hypotheses 3 and 4. See the Method section for Research Question 3 (above) for a description of the sample, the procedure, and variables used, and Appendix V for the items used in the survey.

\section{Measures}

Promotability Rating. Participants rated the promotability of the employee with the same four questions as used in Research Question 3. Participants rated the employee on a 6-point scale, where 1 meant 'Strongly disagree' and 6 'Strongly agree.' The Cronbach's alpha for promotability rating in this study was .82.

Recommended Development. Participants rated whether they would oppose or recommend the employee on 10 developmental opportunities as described in Research Question 3. For each developmental task, participants rated the employee on a 7-point scale, where 1 meant 'Strongly oppose' and 7 meant 'Strongly recommend' the employee for the opportunity. The Cronbach's alpha for the recommended development scale was 90 .

Ideal Worker Attribute Rating. Participants rated the employee on 45 attributes of an ideal worker, as described in Research Question 3. Participants used a 5-point scale, where 1 meant 'Not at all characteristic' and 5 'Extremely characteristic' of the employee. The Cronbach's alpha for the full scale was .97.

Benevolent Sexism Inventory. Participants completed the 11-item Benevolent Sexism Inventory (Rollero et al., 2014, based on Glick \& Fiske, 1996). For each item, 
participants rated how much they agreed or disagreed with the statement on a 6-point scale, where 1 meant 'Strongly disagree' and 6 meant 'Strongly agree.' The Cronbach's alpha for the Benevolent Sexism Inventory in this study was .86 .

Modern Sexism Scale. Participants completed the Modern Sexism Scale, developed by Swim et al. (1995) and based on the Modern Racism Scale from McConahay (1986). The Modern Sexism Scale contains eight items. Participants rated the items on a 6-point scale, where 1 signified "Completely Disagree" and 6 "Completely Agree." The Cronbach's alpha for the Modern Sexism Scale was .87.

Demographic Information. Participants were asked the same demographic questions as in Research Question 3.

\section{Research Question 4 Results}

Table 15 provides the means, standard deviations, and correlations for the scales used to test Hypotheses 6 (that raters with higher sexism beliefs will give higher ideal worker ratings to male than female employees) and 7 (that raters with higher sexism beliefs will give higher promotability ratings and recommend more development to male than female employees). Promotability, recommended development, and ideal worker rating are highly and positively correlated with each other. Promotability, but not recommended development, is also significantly and negatively correlated with benevolent sexism $(r=-.16, p=.02)$ and modern sexism $(r=-.21, p<.01)$, which are highly and positively correlated with each other $(r=.40, p<.001)$. Benevolent sexism is significantly and negatively related to employee gender $(r=-.15, p=.03)$, rater gender $(r$ $=-.19, p<.01)$, and rater race $(r=-.19, p<.01)$, and positively correlated with rater leadership level $(r=.18, p<.01)$. Raters who read about a female employee, were 
female, were minority, or who were non-leaders or at lower levels of leadership in their current job tended to have lower benevolent sexism ratings. 
Table 15. Means, Standard Deviations, and Correlations of Variables for Hypotheses 5 and 6

\begin{tabular}{|c|c|c|c|c|c|c|c|c|c|c|c|c|c|}
\hline & Variable & Mean & SD & 1 & 2 & 3 & 4 & 5 & 6 & 7 & 8 & 9 & 10 \\
\hline 1 & Ideal Worker Rating & 3.98 & .51 & $(.97)$ & & & & & & & & & \\
\hline 2 & Promotability & 5.17 & .66 & $.65 * *$ & $(.82)$ & & & & & & & & \\
\hline 3 & Recommended Development & 4.89 & .63 & $.65 * *$ & $.64 * *$ & $(.90)$ & & & & & & & \\
\hline 4 & Employee Gender (female = 1) & .49 & .50 & .02 & .05 & .01 & - & & & & & & \\
\hline 5 & Benevolent Sexism & 3.29 & .97 & .05 & $-.16^{*}$ & -.09 & $-.15^{*}$ & $(.88)$ & & & & & \\
\hline 6 & Modern Sexism & 2.85 & 1.07 & -.07 & $-.21 * *$ & -.05 & -.13 & $.41 * *$ & $(.87)$ & & & & \\
\hline 7 & Rater Gender (female $=1)$ & .61 & .50 & .13 & .09 & .07 & .02 & $-.19 * *$ & $-.24 * *$ & - & & & \\
\hline 8 & Rater Leadership Level & .98 & .94 & -.12 & $-.15^{*}$ & -.08 & -.03 & $.18 * *$ & .09 & -.05 & - & & \\
\hline 9 & Rater Race (white $=1$ ) & .82 & .39 & 0 & -.01 & -.03 & .11 & $-.19 * *$ & -.07 & -.02 & .02 & - & \\
\hline 10 & Rater Age & 37.59 & 11.99 & .06 & -.02 & .05 & .01 & 0.4 & -.04 & .02 & .02 & $.17 *$ & \\
\hline
\end{tabular}

** and * Significant at the $p<.01$ and $p<.05$ level, respectively.

Notes: $n=220$. Ideal worker rating, promotability, benevolent sexism, and modern sexism were rated on a 6-point scale. Recommended development was rated on a 7-point scale and ideal worker rating on a 5-point scale. For employee and rater gender, 0 signifies male and 1 female. Rater leadership level was measured at 4 levels: $0=$ non-leader, $1=$ entry-level management, $2=$ middle-level management, and $3=$ upper-level management. Rater race was coded as $0=$ non-white and $1=$ white. 
To analyze Hypotheses $6 \mathrm{a}$ and $6 \mathrm{~b}$, that those with higher sexism beliefs will rate the male employee higher than the female employee on ideal worker attributes, I used regression models with interactions to test the hypotheses; see Table 16 for analysis results (Hayes, 2018). For Hypothesis 6a, the results in Model 1 show that the interaction between the employee's gender and the rater's benevolent sexism beliefs was significant and negative in predicting ideal worker rating, $b=-.19, p<.01$. Figure 4 shows the interaction. A rater's benevolent sexism beliefs do not significantly affect male employees' ideal worker ratings, but those beliefs do affect female employees' ideal worker ratings. When raters had lower benevolent sexism beliefs, they perceived female employees as exemplifying the attributes of the ideal worker more than male employees, but when raters had higher benevolent sexism beliefs, they perceived female employees as less likely to exemplify ideal worker attributes than male employees. 
Table 16. Regression Results for Hypotheses 5 and 6

\begin{tabular}{|c|c|c|c|c|c|c|}
\hline & \multicolumn{2}{|c|}{$\begin{array}{l}\text { Ideal Worker } \\
\text { Rating }\end{array}$} & \multicolumn{2}{|c|}{ Promotability } & \multicolumn{2}{|c|}{$\begin{array}{c}\text { Recommended } \\
\text { Development }\end{array}$} \\
\hline & Model & Model & Model & Model & Model & Model \\
\hline & 1 & 2 & 3 & 4 & 5 & 6 \\
\hline Intercept & $\begin{array}{c}3.86^{* *} \\
(.14)\end{array}$ & $\begin{array}{c}3.89 * * \\
(.14)\end{array}$ & $\begin{array}{c}5.26 * * \\
(.18)\end{array}$ & $\begin{array}{c}5.29 * * \\
(.18)\end{array}$ & $\begin{array}{c}4.83 * * \\
(.17)\end{array}$ & $\begin{array}{r}4.85^{* *} \\
(.17)\end{array}$ \\
\hline Employee Gender & $\begin{array}{l}.02 \\
(.07)\end{array}$ & $\begin{array}{c}.01 \\
(.07)\end{array}$ & $\begin{array}{l}.04 \\
(.09)\end{array}$ & $\begin{array}{c}.03 \\
(.09)\end{array}$ & $\begin{array}{l}.01 \\
(.09)\end{array}$ & $\begin{array}{l}.01 \\
(.08)\end{array}$ \\
\hline Rater Benevolent Sexism & $\begin{array}{l}.05 \\
(.04)\end{array}$ & & $\begin{array}{l}-.09 \dagger \\
(.05)\end{array}$ & & $\begin{array}{l}-.05 \\
(.05)\end{array}$ & \\
\hline $\begin{array}{l}\text { Emp. Gender x Ben. } \\
\text { Sexism }\end{array}$ & $\begin{array}{c}-.19 * * \\
(.07)\end{array}$ & & $\begin{array}{l}-.03 \\
(.09)\end{array}$ & & $\begin{array}{l}-.19^{*} \\
(.09)\end{array}$ & \\
\hline Rater Modern Sexism & & $\begin{array}{l}-.01 \\
(.03)\end{array}$ & & $\begin{array}{c}-.12 * * \\
(.04)\end{array}$ & & $\begin{array}{l}-.02 \\
(.04)\end{array}$ \\
\hline $\begin{array}{l}\text { Emp. Gender x Modern } \\
\text { Sexism }\end{array}$ & & $\begin{array}{l}-.15^{*} \\
(.06)\end{array}$ & & $\begin{array}{l}-.12 \\
(.08)\end{array}$ & & $\begin{array}{r}-.28 * * \\
(.08)\end{array}$ \\
\hline Rater Gender & $\begin{array}{l}.16^{*} \\
(.07)\end{array}$ & $\begin{array}{l}.11 \\
(.07)\end{array}$ & $\begin{array}{l}.08 \\
(.09)\end{array}$ & $\begin{array}{l}.05 \\
(.09)\end{array}$ & $\begin{array}{l}.07 \\
(.09)\end{array}$ & $\begin{array}{l}.05 \\
(.09)\end{array}$ \\
\hline Rater Leadership Level & $\begin{array}{l}-.07 \dagger \\
(.04)\end{array}$ & $\begin{array}{l}-.06 \\
(.04)\end{array}$ & $\begin{array}{l}-.08 \dagger \\
(.05)\end{array}$ & $\begin{array}{l}-.09 \dagger \\
(.05)\end{array}$ & $\begin{array}{l}-.04 \\
(.05)\end{array}$ & $\begin{array}{l}-.05 \\
(.04)\end{array}$ \\
\hline Rater Race & $\begin{array}{c}.01 \\
(.09)\end{array}$ & $\begin{array}{c}.01 \\
(.09)\end{array}$ & $\begin{array}{l}-.07 \\
(.12)\end{array}$ & $\begin{array}{l}-.01 \\
(.12)\end{array}$ & $\begin{array}{l}-.08 \\
(.11)\end{array}$ & $\begin{array}{l}-.01 \\
(.11)\end{array}$ \\
\hline Rater Age & $\begin{array}{c}0 \\
(0)\end{array}$ & $\begin{array}{c}0 \\
(0)\end{array}$ & $\begin{array}{c}0 \\
(0)\end{array}$ & $\begin{array}{c}0 \\
(0)\end{array}$ & $\begin{array}{c}0 \\
(0)\end{array}$ & $\begin{array}{c}0 \\
(0)\end{array}$ \\
\hline $\mathrm{N}$ & 220 & 220 & 220 & 220 & 220 & 220 \\
\hline $\mathrm{R}$-square & $.07 *$ & $.06 \dagger$ & .05 & $.07 *$ & .04 & $.07 *$ \\
\hline
\end{tabular}


Figure 4. Two-Way Interaction between Employee Gender and Rater's Benevolent Sexism Beliefs Predicting Ideal Worker Rating (Hypothesis 6a)

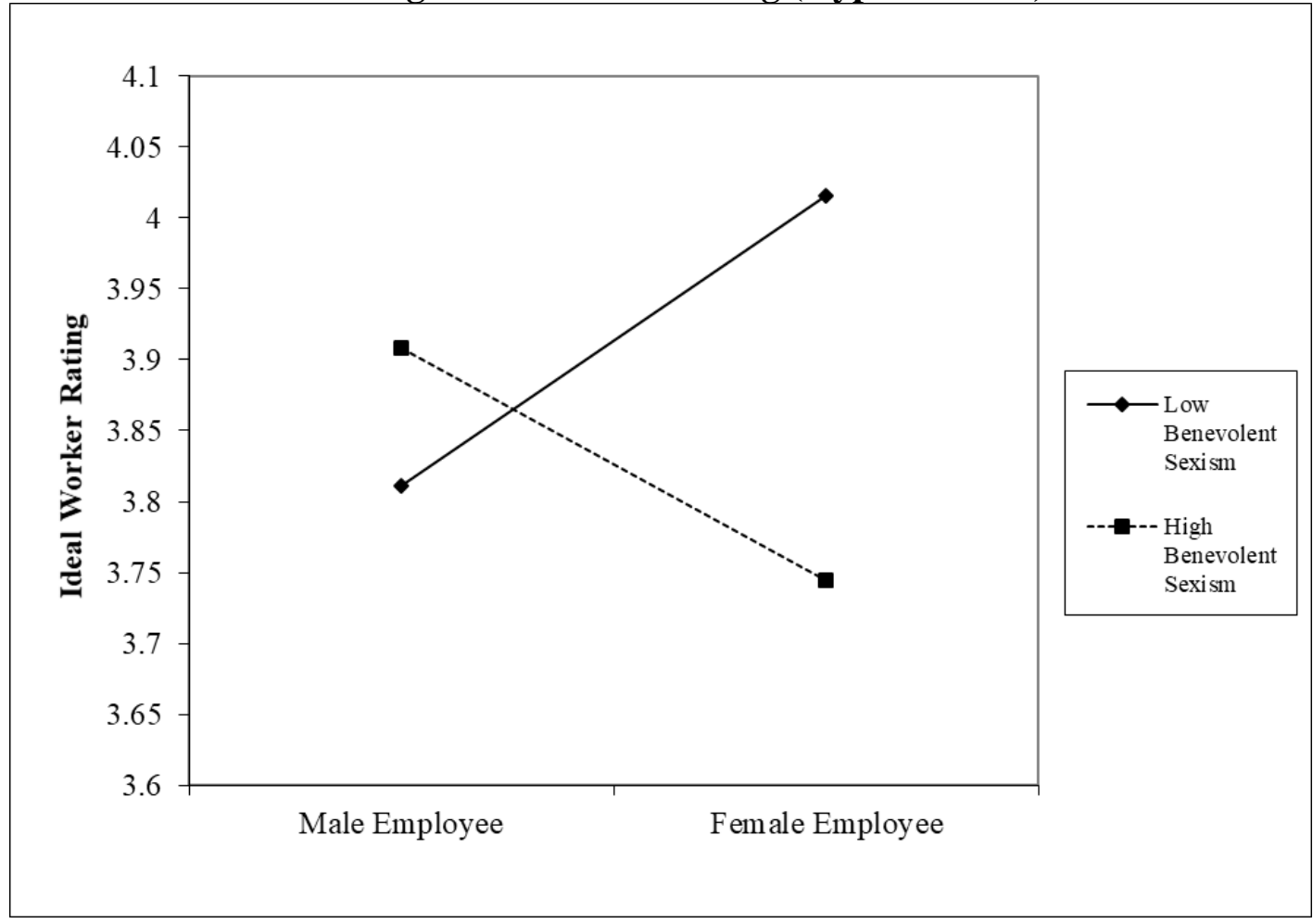

Note: $n=220$. High and low benevolent sexism are represented by $+/$ - one standard deviation of the mean, respectively.

I analyzed Hypothesis $6 \mathrm{~b}$ using the rater's modern sexism beliefs as a moderator of the relationship between the employee's gender and their ideal worker rating. Model 2 in Table 16 shows that the interaction between the employee's gender and the rater's modern sexism beliefs significantly and negatively affects the ideal worker rating, $b=-$ $.15, p=.02$. Figure 5 illustrates the interaction. Like benevolent sexism, male employees' ideal worker ratings are unaffected but female employee's ideal worker ratings are affected by raters' modern sexism beliefs. When a rater's modern sexism beliefs are low, female employees receive higher ideal worker ratings; but when a rater's modern sexism beliefs are high, female employees receive lower ideal worker ratings than male employees. Thus, Hypothesis 6 is supported for both benevolent and modern sexism. 
Figure 5. Two-Way Interaction between Employee Gender and Rater's Modern Sexism Beliefs Predicting Ideal Worker Rating (Hypothesis 6b)

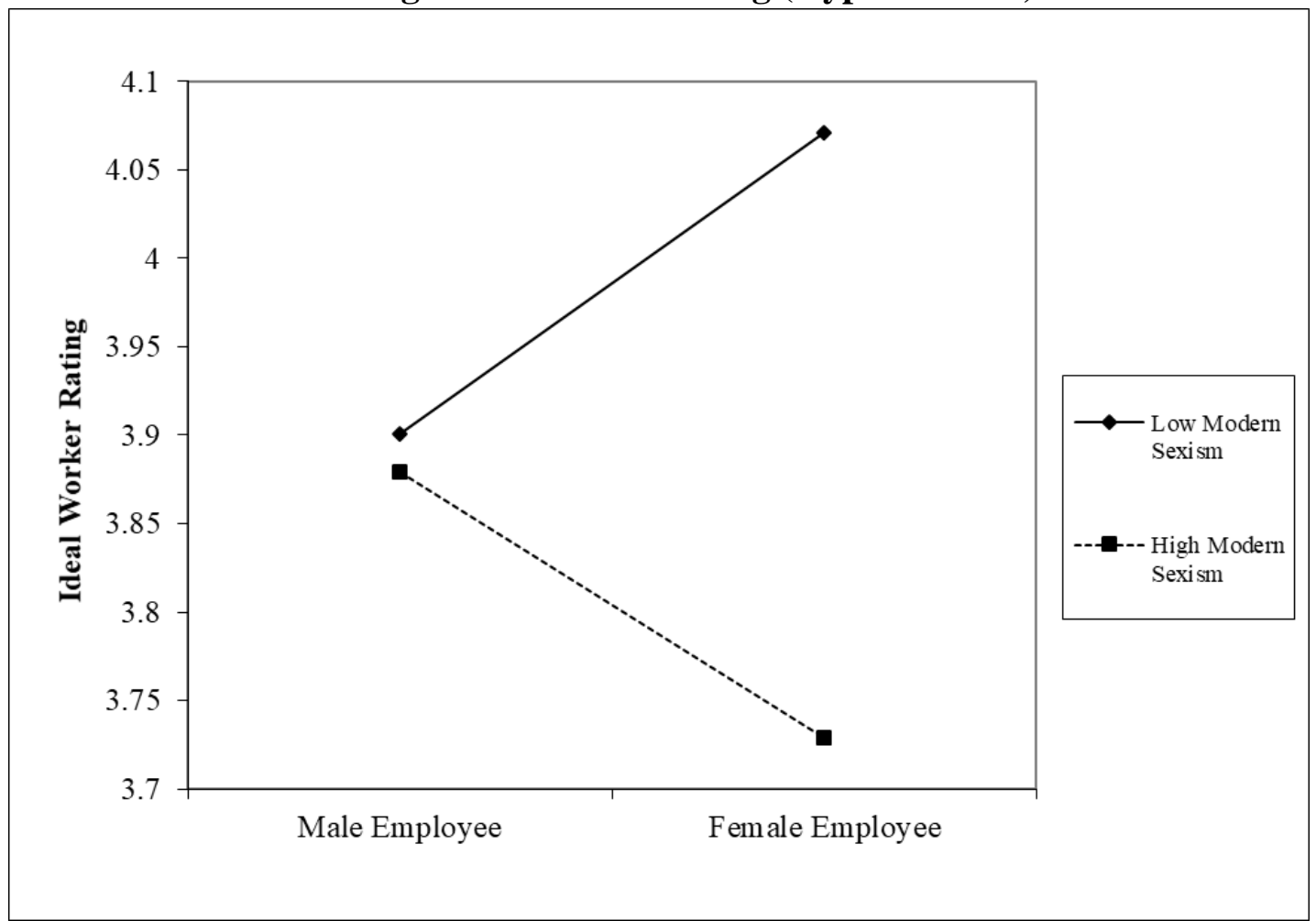

Note: $n=220$. High and low modern sexism are represented by $+/$ - one standard deviation of the mean, respectively.

To test Hypothesis 7, that the rater's sexism beliefs will moderate the relationship between the employee's gender and a) promotability and b) recommended development, I ran linear regression models with interactions (Hayes, 2018). As Models 3 and 4 in Table 16 show, neither raters' benevolent sexism $(b=-.03, p=.76)$ nor their modern sexism beliefs $(b=-.12, p=.16)$ interact with employee gender to significantly affect ratings of promotability. For recommended development, Models 5 and 6 in Table 16 show that benevolent sexism significantly and negatively interacts with employee gender $(b=-.19, p=.03)$ as does modern $\operatorname{sexism}(b=-.28, p<.001)$. Figures 6 and 7 illustrate the interaction effects for benevolent and modern sexism, respectively. For both benevolent and modern sexism, male employees are unaffected by raters' sexism beliefs. 
But for female employees, when raters have low sexism beliefs, they recommend more development, and when raters have high sexism beliefs, they recommend less development. Thus, I find partial support for Hypothesis 7 as both benevolent and modern sexism moderated the relationship between employee gender and recommended development but not the relationship between employee gender and promotability.

Figure 6. Two-Way Interaction between Employee Gender and Rater's Benevolent Sexism Beliefs Predicting Recommended Development (Hypothesis 7b)

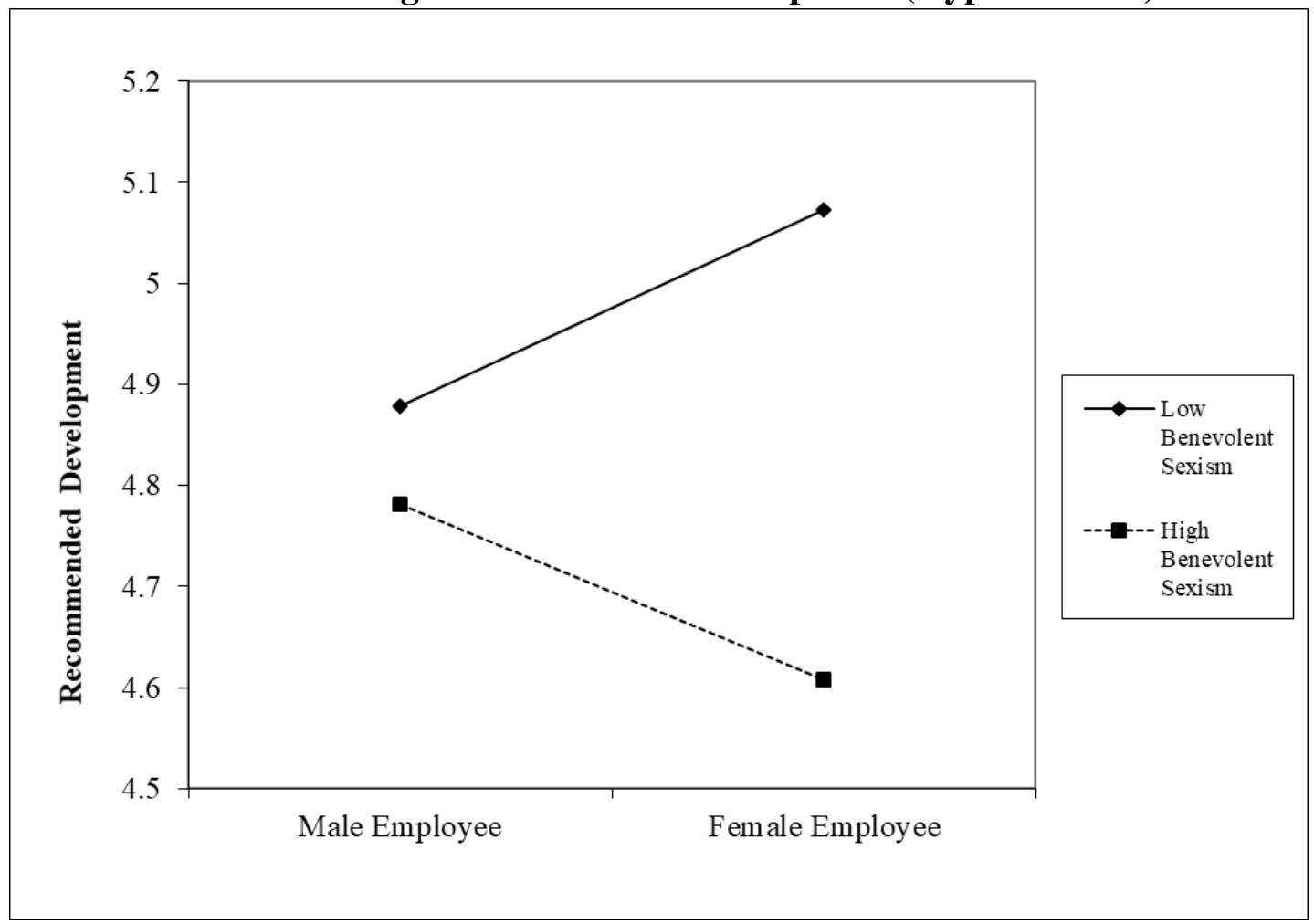

Note: $n=220$. High and low benevolent sexism are represented by $+/$ - one standard deviation of the mean, respectively. 
Figure 7. Two-Way Interaction between Employee Gender and Rater's Modern Sexism Beliefs Predicting Recommended Development (Hypothesis 7b)

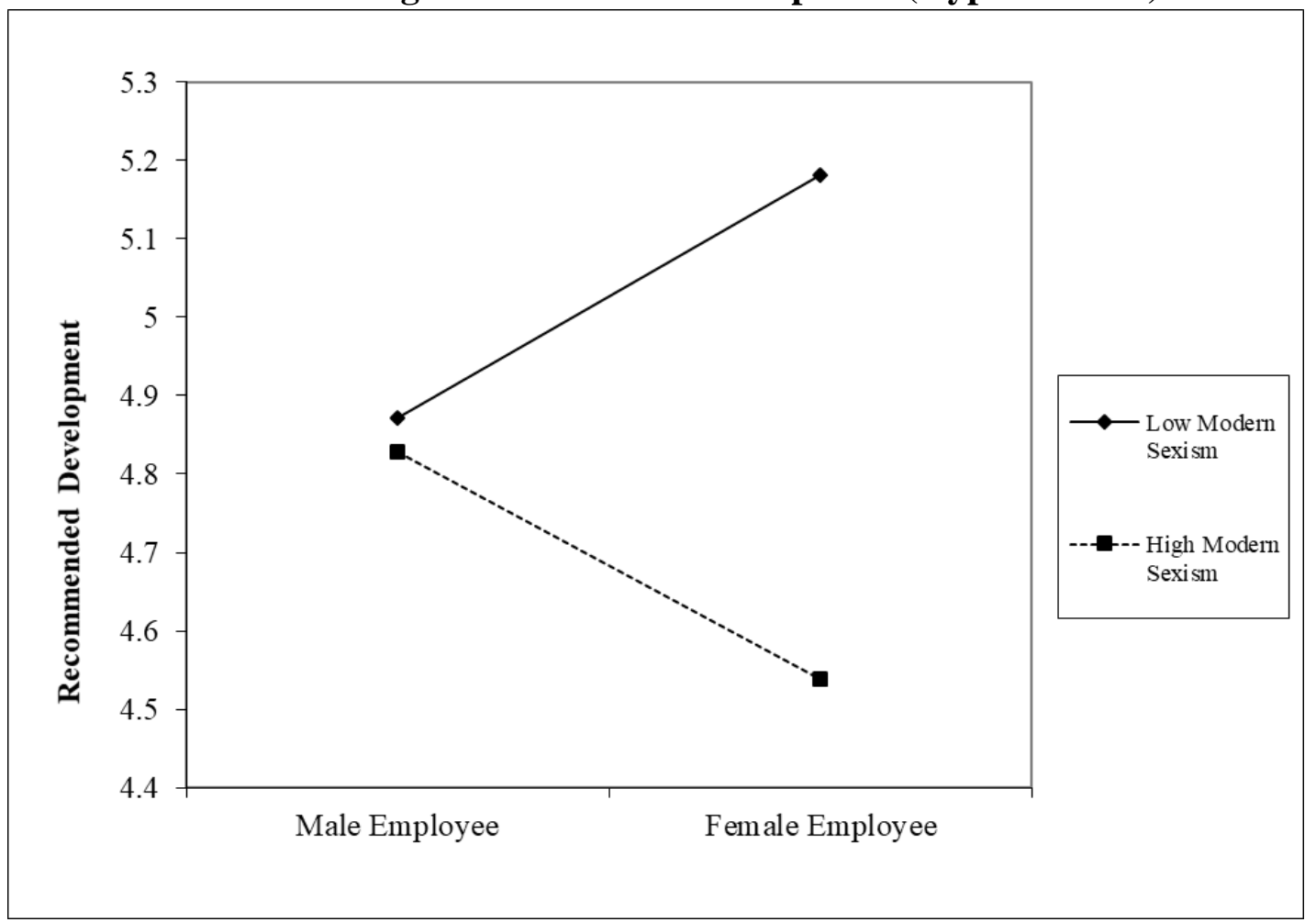

Note: $n=220$. High and low modern sexism are represented by $+/$ - one standard deviation of the mean, respectively.

\section{Research Question 4 Discussion}

In Research Question 4, I investigated whether and how raters' gender role beliefs, as measured by benevolent and modern sexism, moderate the relationship between employee gender and employee outcomes (promotability and recommended development). I found that both benevolent and modern sexism beliefs affect female employees' but not male employees' ideal worker ratings and recommended development but not promotability. When raters were low in benevolent or modern sexism, they were more likely to give female employees higher ideal worker ratings and more development recommendations, but when raters were high in sexism beliefs, they gave female employees lower ideal worker ratings and less development. 
Raters' sexism beliefs may explain why I found no main effect of employee gender on ideal worker ratings and recommended development in Research Question 3. Differences in raters' sexism beliefs may have masked the relationship of employee gender to ideal worker ratings and recommended development such that those with high sexism beliefs offset the ratings of those with low sexism beliefs. These individual differences in sexism beliefs only mattered for female employees' ratings, not male employees' ratings. Thus, although the results for Research Question 3 indicate no main effect of employee gender on ratings, results for Research Question 4 indicate that raters' sexism beliefs matter for how male and female employees are rated.

To this point, my research questions have focused on the conscious aspects of the ideal worker stereotype. One problem with the conscious component of a stereotype is that participants can control how they respond to questions about the stereotype such that they may answer in a way that is socially desirable. Additionally, the theory of gendered organizations (Acker, 1990, 1992) as well as other research on how gender role stereotypes affect individuals in organizations (Lewis \& Simpson, 2012) suggests that gender role stereotypes often operate at an unconscious level. To address these concerns, my next study focuses on the unconscious component of the ideal worker stereotype. In the next study, I address Research Question 5 about whether and how implicit (unconscious) associations between the ideal worker stereotype and gender role stereotypes affect promotability and development recommendations for male and female employees. 


\section{Research Question 5 Method}

\section{Participants}

Participants were recruited from Amazon Mechanical Turk and were either randomly assigned to complete the survey for Research Question 3 or Research Question 5. See Research Question 3 for a description of the screening questions used for this study. Although 462 participants were assigned to the Research Question 5 experimental condition and started the survey, only 330 completed the survey and passed data quality checks as described below. The survey for Research Question 5 included a program that runs on Java and required participants to use a computer with a keyboard to complete the survey. Of the 462 participants who were randomly assigned to the experimental condition for Research Question 5, 329 completed the survey, 10 reported by email to the researcher that they had problems with the Java program when they were working on the survey, and 123 did not attempt the Java program within the survey. Likely most of these 123 participants, if not all, were not using a computer with a keyboard as required by the survey. Although the Java program usually includes an automatic check for the type of device a participant is using before they begin the survey, this check was disabled due to the number of randomizations required for the survey (including a randomization into the study for Research Question 3 (that did not require a computer with a keyboard) or Research Question 5 (that required a computer with a keyboard). Thus, participants who were not on a computer with a keyboard were able to continue the survey, even though the consent form stated that they should not complete the survey without the technology needed. 
Of the 330 participants whose data were used in this study, most were female $(n=$ $220,66.7 \%)$, white $(n=265,80.3 \%)$, not married $(n=173,52.4 \%)$, worked full-time $(n$ $=267,80.9 \%)$, had a bachelor's or graduate degree $(n=184,55.8 \%)$, and had an average age of 37.6 years. The average job tenure was 6.1 years and organizational tenure was 7.3 years; more than half $(n=175,53.0 \%)$ had a leadership role in their organization.

\section{Procedure}

The design of this study was an experimental design in which participants were presented with performance information for an employee whose gender was randomly assigned to each participant at the beginning of the study. Participants read a performance evaluation table with ratings for an employee, the same information used in Research Questions 3 and 4. See Appendix VII for the full survey. After reading the information, participants rated the employee on promotability and recommended development. Participants then completed the Implicit Association Test (IAT), which was described to participants as a measure of short-term memory but really measures the implicit association between the attributes of the ideal worker stereotype and gender role stereotypes. In the IAT, participants matched male and female names with words characteristic of employees high in executive potential and those low in executive potential. Finally, participants completed questions about their work experience and demographic information to conclude the survey.

\section{Variables}

Promotability Rating. Participants rated the promotability of the employee with the same four questions as in Research Questions 3 and 4. Participants rated the 
employee on a 6-point scale, where 1 meant 'Strongly disagree' and 6 'Strongly agree.' The Cronbach's alpha for the promotability rating was .81 .

Recommended Development. Participants rated whether they opposed or recommended the employee on 10 challenging tasks, the same set of developmental opportunities asked about in Research Questions 3 and 4. Participants rated the employee on a 7-point scale, where 1 meant 'Strongly oppose' and 7 meant 'Strongly recommend' the employee for the opportunity. The Cronbach's alpha for the recommended development scale was .88 .

Implicit Association Test (IAT). For this study, I developed two ideal worker stereotype implicit association tests (IATs) to measure whether participants associated the attributes of the ideal worker stereotype with those of the male and female gender role stereotypes. I divided the attributes into two sets because the IAT presents the same few words or phrases a limited number of times. If an IAT set has too many words or phrases, it is possible that participants do not see all combinations of words or phrases for categorization during the IAT. I named one IAT set the 'Theoretical IAT' because the set included items suggested by the theory of gendered organizations (Acker, 1990, 1992) or found to be characteristic of an ideal worker in previous research (Kelly et al., 2010; Reed, 2015; Sallee, 2012). I named the other IAT set the 'Highly Characteristic IAT' as this set included items rated as 'very characteristic' of an ideal worker in Research Question 1 but were attributes not suggested in the theory of gendered organizations or previous research on the ideal worker.

The goal of the IAT sets was to measure the unconscious or implicit associations that participants have between attributes of the ideal worker stereotype and gender role 
stereotypes. In an implicit association test, participants are asked to categorize words or phrases into two groups. For the IAT sets I developed, participants grouped words that described an employee with 'high executive potential' (to represent ideal worker attributes) and 'low executive potential' (to represent the opposite of an ideal worker) as well as male and female names (to represent gender role stereotypes). The IAT measures the speed with which individuals associate two concepts; participants take less time to assign a stimulus to a category for a pre-existing association than when no association exists (Greenwald, Nosek, \& Banaji, 2003). For example, if ideal worker stereotype attributes are gendered masculine, then participants should be faster at categorizing attributes describing employees with high executive potential and male names than categorizing those same attributes and female names.

Because the IAT I used in this study was new, I pre-tested each set with a sample of participants (separate from those who participated in Research Question 5). The IAT shows the same few words multiple times to measure how long it takes participants to categorize these words, so the number of different words in an IAT is small. The first Theoretical IAT set contained 17 attributes (8 characteristic of a high executive potential employee, based on the theory of the ideal worker, and 9 characteristic of a low executive potential employee), and the Highly Characteristic IAT set contained 21 attributes (12 characteristic of a high executive potential employee, rated 'very characteristic' of an ideal employee from Research Question 1, and 9 characteristic of a low executive potential employee, the same used for the Theoretical IAT set). See Appendix VIII for a list of the attributes and names used in each IAT set. 
Because 'ideal worker' may not be a familiar term for many participants (based on my results in Research Question 1 where I used many different prompts to describe an ideal worker), I used the term 'high executive potential' in this study instead. To test that 'high executive potential' was descriptive of an ideal worker, I asked participants to rate the attributes proposed for the IAT sets on the extent to which they characterized an employee with high or low executive potential. Participants rated 31 attribute words and phrases on a 5-point scale, where 1 meant 'Very much describes an employee with low executive potential' and 5 meant 'Very much describes an employee with high executive potential.' I chose attributes that were representative of the different kinds of attributes of an ideal worker and that were no longer than three words so that participants could quickly read them when the words were flashed on the screen during the IAT task. Because these words and phrases derive from Research Question 1 but are not exactly the same as the items in those studies, these additional ratings of the IAT attributes provide content validation for each attribute included in the IAT (that it describes an employee with either high or low executive potential, as intended).

I also wanted to ensure that the IAT would lead to variability in response times for participants. Variability in response times shows different implicit associations between the attributes of the ideal worker and gender role stereotypes for different participants. For example, if the words and phrases used in the IAT are too long to read quickly when they flash on the screen, participants may have trouble categorizing words leading to errors in measuring implicit associations using the IAT. Thus, to ensure the IAT worked as intended, each participant completed an IAT with one of the two IAT sets created for this study. To account for possible priming effects of these tasks (rating the 
descriptors for the IAT and completing the IAT), the task order for the pretest was randomly assigned for each participant.

I found that all but two of the items included as ideal worker attributes were considered 'very characteristic' of an ideal worker (mean 4.0 or above). The two attributes not considered very characteristic of an ideal worker were travels for work and relocates for work. These attributes were included in the set suggested by the theory of gendered organizations (Acker, 1990, 1992) and research on the ideal worker (Kelly et al., 2010; Reed, 2015; Sallee, 2012) but were not found to be very characteristic of an ideal worker in Research Question 1. Because these two items did not meet the inclusion criteria for the IAT, they were dropped from the study. All items considered 'very uncharacteristic' of an ideal worker from Research Question 1 received mean ratings of 2.0 or below in the IAT pre-test. Thus, all these items were included in the final IAT sets used.

For Research Question 5, the IAT included seven sequences following Nosek et al. (2005) and were created using the iatgen Shiny Web Applet online (Carpenter et al., 2019). I used the scoring methods recommended by Greenwald et al. (2003), which provide best practices for ensuring high quality data such as deleting responses slower than 10,000 milliseconds. Significant positive $D$-scores mean that participants took more time in the incongruent pairing sequences (high executive potential - female names) than the congruent pairing sequences (high executive potential - male names), indicating an association between high executive potential attributes and the male gender role stereotype. Likewise, negative $D$-scores indicate an association between high executive potential attributes and the female gender role stereotype, while $D$-scores close to 0 
indicate no association between high or low executive potential attributes and gender role stereotypes.

Demographic Information. Participants were asked about their demographic characteristics, including sex, age, race, education level, marital status, and their partner's sex and work status. They were also asked about their work experience, including the industry they work in, tenure with their current organization and in their current role, and at what leadership level their current position is in their organization.

\section{Research Question 5 Results}

Table 17 shows the means, standard deviations, and correlations for the study variables. Promotability and recommended development were positively and significantly correlated $(r=.67, p<.001)$. Employee gender was positively and significantly related to the theoretical IAT $D$-score $(r=.18, p=.02)$. Those who rated a female employee were more likely to associate ideal worker attributes on the Theoretical IAT with the male gender role stereotype than those who rated a male employee. This relationship may be due to a priming effect of rating a male or female employee before completing the Theoretical IAT task. Rater gender was also significantly and positively related to the Theoretical IAT $(r=.43, p<.001)$ and to the Highly Characteristic IAT $D$ scores $(r=.54, p<.001)$. Female raters were more likely to have implicit associations between ideal worker attributes and the male gender role stereotype than male raters. Rater race was also significantly and positively correlated with promotability $(r=12, p=$ .03). White raters tended to give employees higher promotability ratings than non-white raters. 
Table 17. Means, Standard Deviations, and Correlations of Variables for Hypotheses 8 and 9

\begin{tabular}{|c|c|c|c|c|c|c|c|c|c|c|c|c|}
\hline & Variable & Mean & SD & 1 & 2 & 3 & 4 & 5 & 6 & 7 & 8 & 9 \\
\hline 1 & Promotability & 5.27 & .62 & $(.81)$ & & & & & & & & \\
\hline 2 & $\begin{array}{l}\text { Recommended } \\
\text { Development }\end{array}$ & 5.01 & .58 & $.67 * *$ & $(.88)$ & & & & & & & \\
\hline 3 & $\begin{array}{l}\text { Employee Gender } \\
(\text { female }=1)\end{array}$ & .48 & .50 & -.01 & -.02 & - & & & & & & \\
\hline 4 & $\begin{array}{l}\text { Theoretical IAT } \\
(n=169)\end{array}$ & .09 & .38 & -.04 & -.13 & $.18^{*}$ & - & & & & & \\
\hline 5 & $\begin{array}{l}\text { High. Char. IAT } \\
(n=161)\end{array}$ & .04 & .38 & .03 & .03 & .14 & a & - & & & & \\
\hline 6 & $\begin{array}{l}\text { Rater Gender } \\
(\text { female }=1)\end{array}$ & .67 & .47 & .03 & -.02 & $.12^{*}$ & $.43^{* *}$ & $.54 * *$ & - & & & \\
\hline 7 & $\begin{array}{l}\text { Rater Leadership } \\
\text { Level }\end{array}$ & .89 & .96 & 0 & 0 & -.04 & .03 & -.04 & .06 & - & & \\
\hline 8 & Rater Race & .80 & .40 & $.12 *$ & .06 & -.02 & -.09 & .06 & .05 & 0 & - & \\
\hline 9 & Rater Age & 40.36 & 11.66 & .06 & 0 & -.08 & 0 & .02 & $.13^{*}$ & .05 & $.19 * *$ & - \\
\hline
\end{tabular}

** and $*$ Significant at the $p<.01$ and $p<.05$-level, respectively.

${ }^{a}$ A correlation cannot be computed for the Theoretical IAT and Highly Characteristic IAT because participants were randomly assigned to one of the two IATs. Thus, no participant completed both IATs. Notes: $n=330$. Ideal worker rating, promotability, benevolent sexism, and modern sexism were rated on a 6-point scale, while recommended development was rated on a 7-point scale. For employee and rater gender, 0 signifies male and 1 female. Rater leadership level was measured at 4 levels: $0=$ non-leader, $1=$ entry-level management, $2=$ middle-level management, and $3=$ upper-level management. Rater race was coded as $0=$ non-white and $1=$ white.

To test Hypothesis 8, that the attributes of the ideal worker will be more implicitly associated with the male than the female gender role stereotype, I compared the mean $D$ scores for each of the IAT sets to 0. If the attributes are more associated with the male gender role stereotypes, then participants will have positive $D$-scores that are significantly different from 0 , but if they are associated with the female gender role stereotype, $D$-scores will be negative and significantly different from $0 . D$-scores that are not significantly different from 0 indicate that participants did not implicitly associate the attributes of the ideal worker with one gender role stereotype over the other.

For the Theoretical IAT, the mean for the sample was $M=.09(S D=.38)$, which was significantly different from $0, t(168)=2.89, p=.004$. Participants, on average, associated the attributes of the ideal worker (attributes suggested by the theory of 
gendered organizations and research on the ideal worker) with the male gender role stereotype (a masculine implicit association). This was not the case for the Highly Characteristic IAT, those attributes I found highly characteristic of an ideal worker in Research Question 1 but that were not suggested by theory or research. The mean implicit association test score was $M=.04(S D=.38)$, which was not significantly different from $0, t(160)=1.30, p=.20$. Participants did not associate the highly characteristic attributes of the ideal worker more with either gender role stereotype (no implicit association). Thus, Hypothesis 8 was partially supported as the theoretical attributes of the ideal worker were significantly associated with the male gender role stereotype, but the highly characteristic attributes were not.

Hypothesis 9 addresses whether implicit associations between ideal worker attributes and gender role stereotypes moderate the relationship between employee gender and employee outcomes (promotability and recommended development). Table 18 shows the linear regression for Hypothesis 9a for promotability. As Model 1 shows, the interaction between employee gender and Theoretical IAT $D$-scores is not a significant predictor of promotability, $b=-.29, p=.25$. Likewise, Model 2 shows no interaction between employee gender and Highly Characteristic IAT $D$-scores, $b=.35, p$ $=.19$. Therefore, I find no support for Hypothesis 9a for either IAT set. 
Table 18. Regression Results for Hypotheses 9a and 9b

\begin{tabular}{lcccc}
\hline & \multicolumn{2}{c}{ Promotability } & \multicolumn{2}{c}{$\begin{array}{c}\text { Recommended } \\
\text { Development }\end{array}$} \\
\hline & $\begin{array}{c}\text { Model } \\
1\end{array}$ & $\begin{array}{c}\text { Model } \\
\text { Model } 3\end{array}$ & Model 4 \\
\hline Intercept & $5.05^{* *}$ & $4.98^{* *}$ & $5.00^{* *}$ & $4.98^{* *}$ \\
& $(.20)$ & $(.21)$ & $(.20)$ & $(.17)$ \\
Employee Gender & 0 & -.04 & -.08 & .08 \\
& $(.10)$ & $(.10)$ & $(.10)$ & $(.09)$ \\
Theoretical IAT & -.08 & & 0 & \\
& $(.14)$ & & $(.19)$ & \\
Employee Gender x Theoretical IAT & -.29 & & .41 & \\
& $(.25)$ & .03 & & .09 \\
Highly Characteristic IAT & & $(.16)$ & & $(.13)$ \\
& & .35 & & $.48^{*}$ \\
Employee Gender x Highly & & $(.27)$ & & $(.22)$ \\
Characteristic IAT & & & .08 & -.07 \\
& .08 & .02 & .08 \\
Rater Gender & $.11)$ & $(.13)$ & $(.12)$ & $(.11)$ \\
Rater Leadership Level & .03 & -.05 & .02 & -.04 \\
& $(.05)$ & $(.05)$ & $(.05)$ & $(.05)$ \\
Rater Race & .15 & .18 & .13 & -.01 \\
& $(.12)$ & $(.13)$ & $(.12)$ & $(.11)$ \\
Rater Age & 0 & .01 & -.01 & 0 \\
& $(0)$ & $(0)$ & $(0)$ & $(0)$ \\
N & & & & \\
R-square & 169 & 161 & 169 & 161 \\
\hline
\end{tabular}

** and $*$ Significant at the $p<.01$ and $p<.05$-level, respectively.

Note: $n=330$. All independent variables were mean-centered.

I conducted the same moderation analyses predicting recommended development (Hypothesis 9b). In Table 18, Model 3 shows no interaction between Theoretical IAT $D$ scores and employee gender for predicting recommended development, $b=-.41, p=.11$. However, for the Highly Characteristic IAT, Model 4 shows that $D$-scores interact with employee gender, $b=.48, p=.03$. Figure 8 illustrates this interaction. Male employees' recommended development is unaffected but female employee's recommended development is affected by raters' Highly Characteristic IAT $D$-scores. When raters have 
masculine implicit associations (positive $D$-scores), they give female employees more recommended development than male employees, but when they have no implicit associations ( $D$-scores near 0$)$, raters recommended similar amounts of development for male and female employees. Based on these results, I find no support for Hypothesis $9 \mathrm{~b}$ as I found that Theoretical IAT $D$-scores did not moderate the relationship between employee gender and either outcome, and Highly Characteristic IAT $D$-scores moderated the employee gender-recommended development relationship such that those with higher $D$-scores recommended more development for female employees, the opposite of my hypothesis.

Figure 8. Two-Way Interaction of Employee Gender and Highly Characteristic IAT D-Score Predicting Recommended Development (Hypothesis 9b)

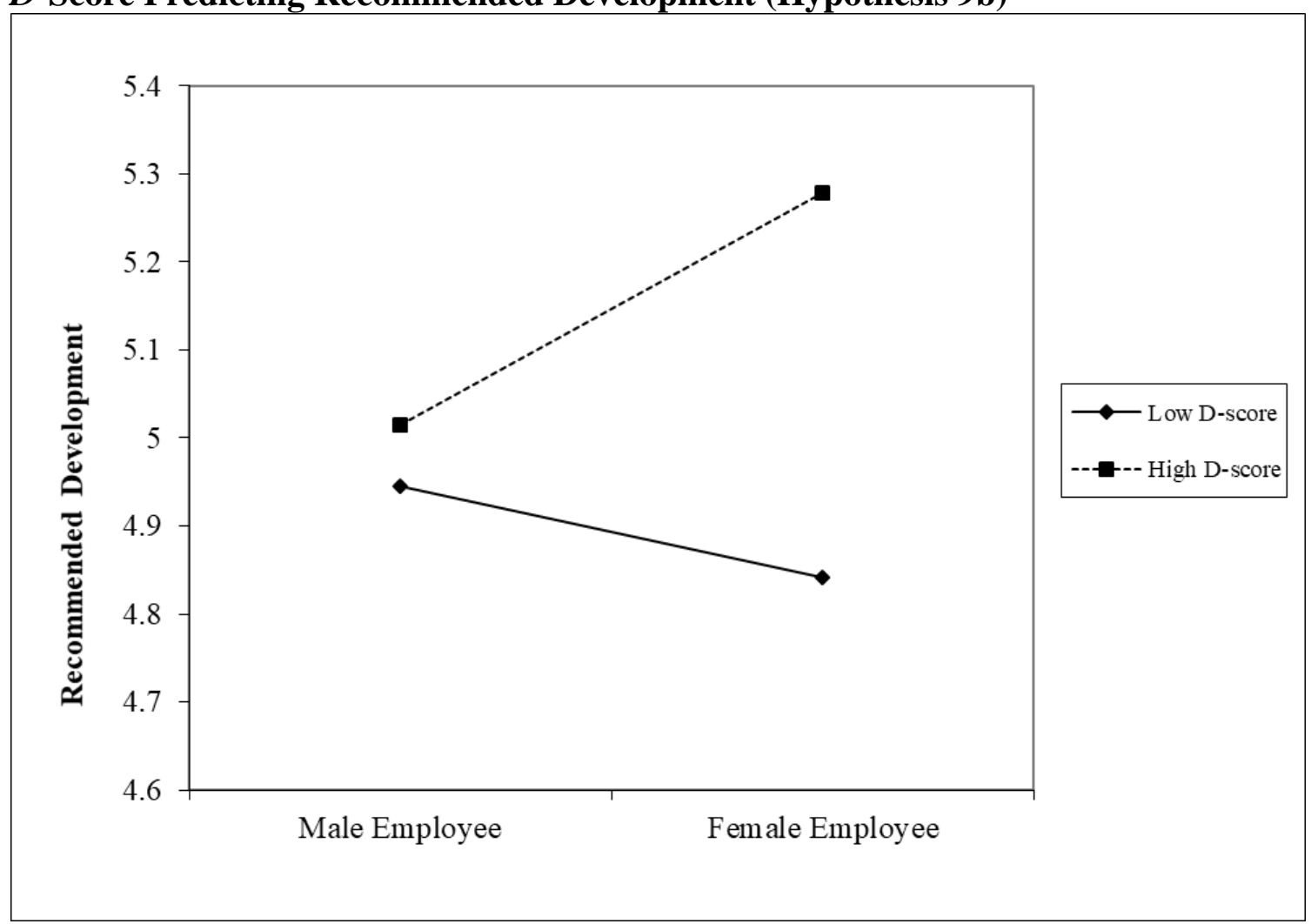

Note: $n=161$. High and low Highly Characteristic IAT D-score are represented by $+/$ - one standard deviation of the mean, respectively. 


\section{Research Question 5 Discussion}

The focus of Research Question 5 was to investigate the implicit associations of ideal worker attributes with gender role stereotypes and how those implicit associations impact ratings of employee promotability and recommended development. Hypothesis 8 addressed whether and how ideal worker attributes were gendered. The theory of gendered organizations posits that the ideal worker is masculine (Acker, 1990, 1992), however my results only found this to be true for the theoretical attributes of the ideal worker (works long hours, visibly busy at work, and committed to work). The highly characteristic attributes of the ideal worker had no implicit associations with either gender role stereotype.

In testing Hypothesis 9a, I found no support that implicit associations moderated the relationship between employee gender and promotability. For Hypothesis 9b, although implicit associations between theoretical ideal worker attributes and gender role stereotypes did not moderate the employee gender-recommended development relationship, implicit associations for highly characteristic ideal worker attributes positively moderated this relationship. When raters had strong masculine implicit associations, they gave female employees more development than male employees, but raters gave similar amounts of development to male and female employees when they had no implicit association.

These analyses highlight that implicit associations matter for the ratings of female employees but not male employees. Male employees received similar development recommendations regardless of the rater's implicit associations, but female employee's recommended development varied based on their rater's implicit associations. This 
finding is important for female employees because their development may be influenced by their raters' implicit associations, which may introduce bias in decision making about female but not male employees.

Raters may have perceived the attributes in these two IAT sets differently. The attributes in the theoretical IAT set have traditionally been considered masculine (works long hours, visibly busy at work, and dedicated to work) based on the male gender role stereotype that men are more focused on work. The attributes in the highly characteristic IAT set were both masculine (e.g., takes initiative, confident) and feminine (e.g., encouraging, helpful) based on traditional male and female gender role stereotypes. For the theoretical attributes of the ideal worker, raters assessed male and female employees similarly in terms of promotability and recommended development, regardless of raters' implicit associations. For the highly characteristic ideal worker attributes, although promotability ratings were unaffected by raters' implicit associations, raters with masculine implicit associations were inclined to give female employees more development. Perhaps raters with masculine implicit associations believe that female employees need more developmental opportunities to develop the ability to exemplify the attributes of the ideal worker. Why implicit associations differed between the IAT sets and why they had different interactions with employee gender in predicting recommended development is a question for future research. 


\section{General Discussion}

I began this research with a problem that has plagued management scholars for decades: why do women receive fewer promotions and developmental opportunities than men? Research has suggested several reasons including lower performance evaluations and greater perceived conflicts between work and family for female employees. But contrary to these explanations, research finds that women receive similar or better performance evaluations (Roth et al., 2012) and report experiencing fewer work-family conflicts (Hoobler et al., 2009) than their male colleagues. Despite these findings, women continue to receive fewer promotions and less development than men. In addition to those reasons, I proposed that the ideal worker stereotype, which describes employees that meet their supervisor's expectations and who have the potential to move to the top level of their organizations over their careers, plays a role in how male and female employees are perceived at work.

The goal of this research was to uncover the attributes of the ideal worker stereotype and investigate whether and how the ideal worker stereotype may impact employees' promotability and development. Table 19 presents my five research questions along with the hypotheses and results that I tested for each research question. In Research Question 1, I focused on learning what the attributes of the ideal worker are, and I found the attributes to be much broader than Acker $(1990,1992)$ proposed in the theory of gendered organizations and those suggested by research on ideal workers (Kelly et al., 2010; Reid, 2015; Sallee, 2012). The theory of gendered organizations suggests that the ideal worker is masculine, which I tested in Hypothesis 1 in Research Question 2. Contrary to my hypothesis, the attributes of the ideal worker were equally related to male 
and female gender role stereotypes (gender neutral) for employees, although the attributes were considered more associated with the female gender role stereotype (gendered feminine) for students.

In Research Question 3, I found that, contrary to past research (e.g., Roth et al., 2012) and my hypothesis, raters did not rate male or female employees differently on promotability (Hypothesis 2a) or recommended development (Hypothesis 2b). In addition, raters perceived male and female employees similarly on the extent to which they exemplified the attributes of the ideal worker (Hypothesis 3), even though I hypothesized that male employees would be rated higher than female employees. The extent to which employees exemplified the attributes of the ideal worker, the ideal worker rating, was a significant predictor of promotability and recommended development, consistent with Hypotheses 4a and 4b. However, when I tested whether ideal worker rating mediated the employee gender-promotability relationship and the employee gender-recommended development relationship for Hypotheses 5a and 5b, I found no significant mediation effect.

Despite finding no main effects of gender on promotability, recommended development, or ideal worker rating in Research Question 3, I found benevolent and modern sexism moderated the relationship between employee gender and some of these outcomes in Research Question 4. Benevolent and modern sexism moderated the relationship between employee gender and ideal worker rating (Hypothesis 6) and recommended development (Hypothesis 7b), as hypothesized, such that when raters had higher sexism beliefs, they gave lower ideal worker ratings and recommended less development for female employees. Male employees' ideal worker ratings and 
recommended development were unaffected by raters' sexism beliefs. I found no moderation effect for benevolent or modern sexism on the employee genderpromotability relationship (Hypothesis 7a).

Research Question 5 investigated the implicit association of ideal worker attributes with gender role stereotypes. I divided the attributes I tested into those that were suggested by the theory of gendered organizations (Acker, 1990,1992) and research on the ideal worker (Kelly et al., 2010; Reid, 2015; Sallee, 2012) (the Theoretical IAT) and another set of attributes that were rated as very characteristic of an ideal worker in Research Question 1 but that were not suggested by theory or research (Highly Characteristic IAT). For Hypothesis 8, I tested whether the ideal worker attributes were related to the male gender role stereotype, as suggested by the theory of gendered organizations (Acker, 1990, 1992, 1998). I found that the theoretical attributes were implicitly associated with the male gender role stereotype, in support of the theory, but the highly characteristic attributes were not implicitly associated with either gender role stereotype, contrary to my hypothesis. Hypothesis 9 tested whether these implicit associations moderated the relationship between employee gender and promotability (Hypothesis 9a) and recommended development (Hypothesis 9b). Implicit associations did not moderate the relationship between employee gender and promotability, contrary to my hypothesis. Likewise, implicit associations for the theoretical attributes did not moderate the employee gender-recommended development relationship but implicit associations for highly characteristic ideal worker attributes did. When raters had masculine implicit associations, they recommended more development for female employees than male employees, opposite of my hypothesis. 


\title{
Table 19. Hypotheses and Results for Each of the Research Questions
}

\author{
Hypothesis Results
}

RQ1: What are the attributes of the ideal worker?

No hypotheses

The ideal worker stereotype attributes are broad and include attributes that have been traditionally considered feminine, masculine, and gender neutral.

RQ2: Are these attributes gendered masculine?

Hypothesis 1: The attributes of an ideal worker will be more associated with the attributes of the male than the female gender role stereotype.
No support: Students perceived the ideal worker stereotype to be more like the female gender role stereotype; employees perceived the ideal worker stereotype to be equally related to the male and female gender role stereotypes.

RQ3: Does the extent to which employees exemplify ideal worker attributes predict ratings of promotability and development recommended for them?

Hypothesis 2: Individuals will rate male employees higher on a) promotability and b) recommended development than female employees.

Hypothesis 3: Raters will rate male employees higher than female employees on the extent to which they exemplify ideal worker attributes.

Hypothesis 4: Ratings of the extent to which an employee exemplifies ideal worker attributes will predict a) promotability and b) recommended development.

Hypothesis 5: Ratings of the extent to which an employee exemplifies ideal worker attributes will partially mediate the relationship between employee gender and $a$ ) promotability and $b$ ) recommended development.
No support: I found no difference between male and female employees for either a) promotability or b) recommended development.

No support: I found no difference between male and female employees' ideal worker ratings.

Supported: Ideal worker rating positively predicts both a) promotability and b) recommended development.

No support: Ideal worker rating does not significantly mediate either the a) employee gender-promotability or b) employee gender-recommended development relationship. 
RQ4: Do individual differences in rater sexism beliefs moderate the relationship between employee gender and employee outcomes (ideal worker rating, promotability, and recommended development) for male and female employees?

Hypothesis 6: Raters' sexism beliefs will moderate the relationship between employee gender and ideal worker attributes such that individuals with higher scores on the a) benevolent sexism and b) modern sexism scales will be more likely to perceive male employees as fulfilling ideal worker attributes than female employees.

Hypothesis 7: Raters' sexism beliefs (benevolent and modern sexism) will moderate the relationship between employee gender and a) promotability and b) recommended development such that individuals with higher scores on the sexism scales will be more likely to give male employees higher promotability ratings and more development than female employees.
Supported: For both benevolent and modern sexism: Female employees receive lower ideal worker ratings when sexism is high; male employees' ratings are unaffected by rater sexism beliefs.
Partial support: Benevolent and modern sexism did not moderate the employee gender-promotability relationship, but they did moderate the employee genderrecommended development relationship. When sexism is high, female employees receive less development; male employees are unaffected by rater sexism.

RQ5: Do implicit associations between the ideal worker stereotype and gender role stereotypes predict promotability and development recommended for male and female employees?

Hypothesis 8: Ideal worker attributes will be more implicitly associated with the male than the female gender role stereotype.

Hypothesis 9: Implicit associations between the ideal worker stereotype and gender role stereotypes will moderate the relationship between employee gender and a) promotability and b) recommended development such that individuals with a stronger implicit association between ideal worker attributes and the male gender role stereotype will rate female, but not male, employees, lower in
Partial support: Theoretical IAT attributes were significantly implicitly associated with the male gender role stereotype, but the highly characteristic attributes were not implicitly associated with either gender role stereotype.

No support: Neither the Theoretical nor the Highly Characteristic IAT moderated the employee gender-promotability relationship. The employee genderrecommended development relationship was moderated by the Highly Characteristic IAT but not the Theoretical IAT. When raters had masculine implicit associations for the highly characteristic ideal worker attributes, they 
promotability and recommend less development for female employees than individuals with a weak or no association. recommended more development for female employees than male employees, contrary to my hypothesis.

The Ideal Worker as a Stereotype. This research demonstrates that what employees need to do to be perceived as an ideal worker is much broader than theory and research have suggested (Acker, 1990, 1992; Kelly et al., 2010; Reid, 2015; Sallee, 2012). I found that the ideal worker stereotype includes many more attributes and that the attributes-associated with ideal workers are related to both the male and female gender role stereotypes. For example, being productive, having career ambitions, having emotional control in difficult situations, seeing things in a new way, and having good social skills are some of the attributes that describe an ideal worker. On their face, many of these attributes are masculine (e.g., having career ambitions), but some are gender neutral (e.g., seeing things in a new way) or considered feminine (e.g., having good social skills). The variety of attributes that describe the ideal worker based on my research and the varied relationships of those attributes with gender role stereotypes may explain why some participants tended to rate the typical female as embodying the attributes of the ideal worker more than the typical male. If most or all these attributes were masculine, it might be difficult for individuals to perceive women as being an ideal worker because of expectations that women display feminine attributes and the backlash that would result from women displaying masculine attributes (Eagly \& Karau, 2002).

Because of the variety of attributes included in the ideal worker stereotype, and their different relationships to gender role stereotype, an important question for future research is whether all these attributes are valued equally by supervisors and valued equally for male and female employees. For example, although raters may have 
perceived the typical woman as possessing more of the attributes of the ideal worker than the typical man, the attributes for which the typical man and typical woman scored similarly (e.g., seeks more responsibility) may be more important in rating promotability and making development recommendations than the attributes for which the typical woman scored higher than the typical man (e.g., being a good team player). It may also be that supervisors perceive that some attributes of the ideal worker are rare, and thus, are useful for identifying ideal workers. Ranking ideal worker attributes by their importance and rarity may help future researchers to understand how supervisors and other raters perceive employees as ideal workers. Raters may use a heuristic to determine which employees are ideal workers. For instance, raters may consider employees who do not exemplify the most important attributes of the ideal worker stereotype (rather than all of the attributes of the ideal worker) as not worthy to be designated as an ideal worker. Thus, knowing the importance or priority of ideal worker attributes may inform how raters use these attributes to determine which employees are deemed ideal workers.

In addition, a more comprehensive examination of these attributes could lead to the development of an ideal worker scale. As most scales associated with measuring stereotypes assume that each attribute has the same weight, knowledge of the ranking or importance of ideal worker attributes would be helpful in producing a more accurate scale for future research. If we understand more about the ideal worker stereotype, scholars could also learn more about how this stereotype affects other employee outcomes at work, such as hiring decisions and high-potential designations.

Since my research did not ask participants to rank or rate the most important ideal worker attributes, my results may hide potential gendering of the ideal worker attributes. 
Acker $(1990,1992,1998)$ proposed that organizations are developed and managed through the perspective of men who lead the organization. If masculine attributes are the ones most valued and used for determining which employees are ideal workers, this ranking of attributes may show a masculine gendering of the organization through the valuing of masculine attributes in employees. It may be that male leaders may value masculine attributes more in ideal workers when considering who deserves promotions or how to distribute development opportunities across employees. This affinity for masculine attributes may be due to similarity-attraction; male leaders may like and promote those who are most like them, in this case, employees who display masculine attributes. It may also be that male leaders felt pressure to conform to masculine expectations as they moved up the organizational hierarchy, so they expect more junior employees to do the same if they want promotions and other rewards.

Additionally, we know little about the importance of ideal worker attributes across job roles and industries, particularly male-dominated and female-dominated industries. Like leadership stereotypes (Lord et al., 1984), it may be that the ideal worker stereotype has different levels of specificity such that a general ideal worker stereotype exists, but that we also have more specific ideal worker stereotypes for industries and job roles. Some evidence suggests that adherence to the ideal worker stereotype increases as employees move up in the hierarchy (Bailyn, 1993), so the attributes of the ideal worker that supervisors value may change as an employee moves from non-leader to the top leadership levels in their organization. Distinguishing these stereotypes may help future research to home in on the effect of employee gender on different employee outcomes, including promotability and recommended development, in more specific settings such as 
STEM (i.e. science, technology, engineering, and math), where the different rate of male and female promotions is much higher than other fields (Barber, 1995; National Science Foundation, 2009; Sonnert \& Holton, 1996).

\section{Unconscious Associations between Ideal Worker and Gender Role}

Stereotypes. My results provide some support for Acker's $(1990,1992)$ claim that the masculine gendering of organizations is difficult for individuals to recognize because the processes and structure of the organization are presented as gender neutral. When rating an ideal worker and a typical male or female, I found employees associated the attributes equally to the male and female gender role stereotypes. Thus, the conscious component of the ideal worker stereotype was perceived as gender neutral. However, the implicit associations were not. Raters had masculine implicit associations for the theoretical ideal worker attributes, consistent with the theory of gendered organizations (Acker, 1990, 1992). But the highly characteristic ideal worker attributes had no implicit associations, similar to the (conscious) ratings provided by employees but contrary to the theory of gendered organizations, which posits that the attributes are masculine. Thus, I found some support for Acker's proposal, but only for some attributes of the ideal worker.

I divided attributes into two different IAT sets due to constraints in the number of items presented to participants during the IAT. I found different relationships of these sets of implicit associations with recommended development (e.g., implicit associations for the theoretical attributes did not moderate the employee gender-recommended development relationship, but the implicit associations for the highly characteristic attributes did such that those with more masculine implicit associations recommended more development for female employees than their male counterparts). If researchers 
could test a broader range of attributes, or test those that are most important to supervisors who decide employee outcomes, we may better understand how conscious and unconscious components of the ideal worker stereotype impact male and female employees across a variety of outcomes.

Individual Differences and the Ideal Worker Stereotype. Although I found no main effect of employee gender on different work outcomes, I did find that sexism beliefs moderated some of these relationships. When raters had high benevolent or modern sexism beliefs, they rated female employees lower than male employees on the extent to which they exemplified the attributes of the ideal worker and on recommended development. These sexism beliefs are consistent with gender essentialism, which is the idea that "differences between males and females are stable, unchanging, fixed at birth, and due to biological differences rather than environmental factors" (Smiler \& Gelman, 2008, p. 864). Research has shown a link between sexism and gender essentialism beliefs (Morton et al., 2009). Raters with high sexism beliefs may believe that female employees are inherently not like ideal workers and that no matter how much help and support female employees receive, they can never be like ideal workers. These individual beliefs may explain why supervisors assign less challenging developmental opportunities to female employees compared to male employees. Research shows that the kind of opportunities that male and female employees receive are different. Men are more likely to receive opportunities that are more visible to top management (Kilian et al, 2005) and more related to firm strategy, the kinds of opportunities that often lead directly to the top executive positions in the organization (De Pater et al., 2010). Meanwhile, women are less likely to receive challenging assignments and other important 
developmental opportunities that help prepare an employee to move up in the organizational hierarchy (King et al., 2012; Lyness \& Schrader, 2006; Meier 2017). Ultimately, these beliefs leave female employees in a bind and hurt female employees in the short term and over their careers. No matter how hard female employees try, if raters have high sexism beliefs, they may not perceive female employees as ideal workers. Because raters may not perceive female employees as having the ability to ever be ideal workers, female employees may not receive the development to help them acquire the skills and knowledge needed to be an ideal worker.

The results from these studies show that leaders within organizations may give different employee ratings and have different levels of sexism than employees in lower levels of leadership. I found a significant negative relationship between leadership level and promotability. Raters at a higher leadership level in their current jobs gave lower promotability ratings to employees than leaders at lower levels of leadership or in nonleadership positions in their current job role. Additionally, a rater's leadership level in their current job role was positively and significantly correlated with their benevolent sexism beliefs. When a rater had a higher level of leadership in their current job, they were more likely to have high benevolent sexism beliefs. Although the literature on sexism notes that sexism beliefs tend to be higher in older men (Hammond et al., 2018), I found no relationship between age and leadership level nor between age and benevolent or modern sexism beliefs in my sample. Thus, future research may want to study why leaders have higher benevolent sexism beliefs than non-leaders. Do people with higher sexism beliefs receive more promotions, or is it that individuals develop more benevolent sexism beliefs as they move up the organizational hierarchy? Different theories suggest 
different reasons for the leadership-benevolent sexism relationship. For example, similarity-attraction theory (Byrne, 1971) proposes that those who are in leadership positions, who are likely to have high sexism beliefs based on my results, are likely to promote and develop employees that are like them, which may be those who are male and also have high sexism beliefs. It may also be that leaders, as they move up in the organizational hierarchy, take on the characteristics of paternalistic leadership. Farh and Cheng (2001) define paternalistic leadership as combining "strong discipline and authority with fatherly benevolence" (p. 91). That fatherly benevolence may be directed more toward female than male employees for those who have high benevolent sexism beliefs.

The relationship between leadership level and benevolent sexism is an important question for future research because it may be one reason why women are less likely to be promoted to the top levels of their organizations. As employees move up the organizational hierarchy, their supervisors are more likely to be at higher levels of leadership in the firm and, based on the results from my research, more likely to have higher sexism beliefs. Leader sexism beliefs may strengthen leader perceptions that upper-level management positions are masculine (as leadership research suggests (Koenig et al., 2011)) and may create a self-fulfilling prophecy: as mostly or only men are promoted, organizational leaders may perceive that only male employees can be successful at the top leadership levels of the organization This self-fulfilling prophecy may justify protecting women from the challenges top leaders in the organization face (benevolent sexism). Thus, understanding the relationship between leadership and sexism beliefs is an important question for future research to study. 
For organizations, the fairness of the evaluation system may depend not only on the process but also on who assesses employees. In firms where leadership changes often or without a formal organizational hierarchy in which employees at one level are the supervisors for employees at the next level below, employees at the same lateral level may have supervisors at different horizontal levels of the hierarchy. Future research may want to study why leaders at higher levels give different ratings and have higher sexism beliefs than leaders at lower levels of the organization. Do organizational cultures promote sexism beliefs, leading to the promotion of individuals with those same beliefs? Do leaders learn to have stricter standards for evaluation as they move up the organizational hierarchy? To avoid these problems, organizations should consider multiple raters for employee performance evaluations as well as promotion and development decision making. Multiple raters, particularly at different levels of the organization, such as in 360-degree feedback evaluation systems, may give female employees a fairer chance at high evaluation scores, more promotions, and more valuable development over their careers.

Finally, we know little about how the ideal worker stereotype affects male and female employees in organizations and throughout their careers. Research on the differential outcomes between men and women at work is important because even small effects, like those I found in my study, can have long-lasting effects on employees' careers and detrimental effects for organizations that rely on their human capital to succeed (Agars, 2004). Compared to experimental conditions, supervisors may face different conditions in rating employees in the workplace. For example, one difference between the evaluation process in organizations and my research are the tasks that raters 
complete. In organizations, raters have much more information about employees, they may rate multiple employees, and they may rate employees using multiple raters (e.g., 360-degree feedback). These differences may make gender role stereotypes less influential in decision processes (Wilson \& Jones, 2008). However, we also know that gender role stereotypes influence the kinds of information that individuals remember such that people tend to remember information that is consistent with gender role stereotypes (Bodenhausen \& Wyer, 1985). Thus, supervisors may be more likely to remember situations in which female employees displayed feminine attributes and male employees displayed masculine attributes. How does the information about employees that supervisors have inform their perceptions of the extent to which their employees exemplify the attributes of the ideal worker? Does an employee's ideal worker rating predict promotability ratings and recommended development as well in a real-world context as it did in the controlled experiment in this research? Research shows that promotability ratings generally differ between men and women at work (Hoobler et al., 2009; Lyness \& Heilman, 2006; Post et al., 2009; Roth et al., 2012) but not in my study, which suggests that testing these relationships in the field is important to better understand how the influence of the ideal worker stereotype may differ in an organizational context.

\section{Limitations and Future Research Directions}

I conducted several studies to learn about the attributes of the ideal worker and investigate how those attributes are related to promotability and recommended development, two outcomes important to employees' careers. Despite the different ways 
that I investigated the ideal worker stereotype, my studies have limitations that open the door for further research on this topic.

First, I used several samples to collect attributes of the ideal worker stereotype for later studies, but I did not gather information on which attributes were the most important, best differentiated ideal workers from other employees, or were considered rare among employees. Knowing how these attributes rate in priority is important to understanding the complexity of the stereotype, including whether it differs across job roles, management levels, and industries, as well as the relationship to other employee outcomes that I did not study in this research, such as hiring decisions and identifying high-potential employees. It is also important to understand how this stereotype may differ across different raters. I found differences between students and employees for the conscious component of the stereotype, so it may be that such variations exist in organizations across different raters with different backgrounds (e.g., a new supervisor with little leadership experience vs. a senior-level executive who has evaluated employees for decades).

Second, because I did not test these stereotypes in the field, I also lack information about how organizational culture, national culture, and other contextual variables may affect the value of ideal worker attributes for raters as well as their perceptions that male and female employees exemplify these attributes. Future research could, for example, have supervisors rate the importance of each of the ideal worker attributes and use a weighted calculation for determining employee ideal worker ratings. A weighted rating may reveal differences in how important different attributes are and the extent to which male and female employees are perceived to display those attributes 
at work. Researchers may also study whether and how organizational culture relates to the importance of different ideal worker attributes and whether and how ideal worker ratings differ between male and female employees in different organizational cultures such as those with many women leaders (vs. those who do not) as research shows that experience with female leaders can weaken the association between leadership (those who are promoted) and the male gender role stereotype (Duehr, \& Bono, 2006). These relationships may also differ based on the national culture in which the organization operates. For instance, paternalistic leadership may be more common in some national cultures than others (Pellegrini \& Scandura, 2008), which may change the relationship of employee gender to work outcomes such as promotability and recommended development.

Third, measuring the associations between ideal worker attributes and gender role stereotypes in different ways may help researchers to understand whether individuals perceive the ideal worker stereotype as gendered. For instance, I asked participants to rate an ideal worker and either a typical man or a typical woman on the same attributes. However, because perceptions about women are changing such that they are considered as competent and intelligent as men (Eagly et al., 2019), these ratings may have made it difficult to differentiate whether participants regarded the attributes of the ideal worker as masculine, feminine, or gender neutral. One way that future researchers could study the gendering of these attributes is by asking participants to rate how feminine or masculine each attribute is. Along with information about the importance of each attribute in assessing which employees are ideal workers, different ways of measuring the association 
of ideal worker attributes and gender role stereotypes may help clarify how the stereotype is gendered, if at all.

Additionally, in measuring implicit associations, I used a limited number of attributes, which may not have represented all the important attributes of the ideal worker stereotype. I also asked participants to rate a male or female employee before completing the implicit association test. Having participants rate a male or female employee for promotability and recommended development kept the order of tasks the same for Research Question 3 and Research Question 5. This task order may also have reduced the influence of the IAT on the employee rating task as participants may have figured out during the IAT that the study was about gender since they had to categorize words by male and female names. The difference in implicit associations between those who rated a female employee (masculine implicit associations) and those who rated a male employee (with no implicit associations) suggests that gender role stereotypes may have been primed for those rating a female employee but perhaps not for those who rated a male employee. Research on implicit associations has found that priming can affect the results of implicit association measures (Mellott, 2003). Future researchers should counterbalance tasks in their study to investigate the role of social desirability bias on conscious associations and priming gender role stereotypes on implicit associations. Researchers may also want to consider how counterbalancing tasks may affect male and female employee ratings in the field. As these limitations show, we need more research to understand the ideal worker stereotype and its impact on employees at work. 


\section{Conclusion}

I focused on five different research questions to explore the ideal worker stereotype in organizations. I discovered that individuals perceive the ideal worker to have a broad array of attributes such as being a good decision maker, leader, and team player at work. For students, these attributes tended to be more associated with the female gender role stereotype, but for employees, the attributes were equally related to the male and female gender role stereotypes. Thus, unlike the theory of gendered organizations suggests (Acker, 1990, 1992), I did not find that the attributes of the ideal worker were masculine. Similarly, unlike past research, I found no differences in ratings of promotability or recommended development for male and female employees, nor did I find a difference in the extent to which raters perceived male and female employees to exemplify the attributes of the ideal worker. But I did find that the ideal worker rating was a significant and positive predictor of promotability and recommended development. Although I found no main effect of employee gender on ideal worker ratings or recommended development, rater sexism beliefs moderated these relationships such that female employees received lower ideal worker ratings and were recommended less development when raters had high sexism beliefs, as hypothesized. Male employees were unaffected by rater sexism beliefs. Finally, I found that implicit associations between ideal worker attributes and gender role stereotypes did not moderate the employee gender-promotability relationship and implicit associations with the theoretical attributes of the ideal worker did not moderate the employee gender-recommended development relationship. But implicit associations with the highly characteristic ideal worker attributes did. When raters had masculine implicit associations for highly 
characteristic attributes, raters recommended more development for female employees than male employees, contrary to my hypothesis. Thus, my research contributes to the theory of gendered organizations by describing the ideal worker stereotype more fully and examining how this stereotype impacts employees in terms of important work outcomes. I also open the way for future research to study these relationships across different work contexts to more fully understand why the attributes of the ideal worker may lead to different outcomes between men and women at work. 


\section{References}

Acker, J. (1990). Hierarchies, jobs, bodies: A theory of gendered organizations. Gender \& Society, 4(2), 139-158.

Acker, J. (1992). Gendering organizational theory. In A. J. Mills \& P. Tancred (Eds.), Gendering organizational analysis (pp. 248-260). Newbury Park, CA: Sage.

Acker, J. (1998). The future of 'gender and organizations': Connections and boundaries. Gender, Work \& Organization, 5(4), 195-206.

Agars, M. D. (2004). Reconsidering the impact of gender stereotypes on the advancement of women in organizations. Psychology of Women Quarterly, 28(2), 103-111.

Altman, Y., \& Shortland, S. (2008). Women and international assignments: Taking stock - a 25-year review. Human Resource Management, 47(2), 199-216.

Bailyn, L. (1993). Breaking the mold: Women, men, and time in the new corporate world. New York: Free Press.

Bailyn, L. (2006). Breaking the mold: Redesigning work for productive and satisfying lives. Ithaca, NY: Cornell University Press.

Banaji, M. R., \& Hardin, C. D. (1996). Automatic stereotyping. Psychological Science, 7(3), 136-141.

Banaji, M. R., Hardin, C., \& Rothman, A. J. (1993). Implicit stereotyping in person judgment. Journal of Personality and Social Psychology, 65(2), 272-281.

Banihani, M., Lewis, P., \& Syed, J. (2013). Is work engagement gendered? Gender in Management: An International Journal, 28(7), 400-423.

Barber, L. A. (1995). US women in science and engineering, 1960-1990: Progress toward equity? The Journal of Higher Education, 66(2), 213-234.

Biemann, T., \& Braakmann, N. (2013). The impact of international experience on objective and subjective career success in early careers. The International Journal of Human Resource Management, 24(18), 3438-3456.

Biernat, M., \& Fuegen, K. (2001). Shifting standards and the evaluation of competence: Complexity in gender-based judgment and decision making. Journal of Social Issues, 57(4), 707-724.

Biernat, M., \& Kobrynowicz, D. (1997). Gender-and race-based standards of competence: Lower minimum standards but higher ability standards for devalued groups. Journal of Personality and Social Psychology, 72(3), 544-557.

Biernat, M., \& Manis, M. (1994). Shifting standards and stereotype-based judgments. Journal of Personality and Social Psychology, 66(1), 5-20.

Boak, G., \& Crabbe, S. (2019). Experiences that develop leadership capabilities. Leadership \& Organization Development Journal, 40(1), 97-106.

Bodenhausen, G. V., \& Wyer, R. S. (1985). Effects of stereotypes in decision making and information-processing strategies. Journal of Personality and Social Psychology, 48(2), 267-282.

Breaugh, J. A. (2011). Modeling the managerial promotion process. Journal of Managerial Psychology, 26(4), 264-277.

Brenner, O. C., Tomkiewicz, J., \& Schein, V. E. (1989). The relationship between sex role stereotypes and requisite management characteristics revisited. Academy of Management Journal, 32(3), 662-669. 
Brewer, M. B. (1988). A dual process model of impression formation. In R. Wyer \& T. Srull (Eds.), Advances in social cognition (Vol. 1, pp. 1-36). Hilldale, NJ: Lawrence Erlbaum.

Byrne, D. E. (1971). The attraction paradigm. New York: Academic Press.

Campbell, B., Schellenberg, E. G., \& Senn, C. Y. (1997). Evaluating measures of contemporary sexism. Psychology of Women Quarterly, 21(1), 89-102.

Carpenter, T., Pogacar, R., Pullig, C., Kouril, M., Aguilar, S., LaBouff, J. P., Isenberg., N., \& Chakroff, A. (2019). Survey-software implicit association tests: A methodological and empirical analysis. Behavior Research Methods, 51(5), 21942208.

Carter, N. M., \& Silva, C. (2011). The myth of the ideal worker: Does doing all the right things really get women ahead? New York: Catalyst.

Catalyst. (7 Aug 2019). Women in management: Quick take. Retrieved from https://www.catalyst.org/knowledge/women-management

Correll, S. J. (2004). Constraints into preferences: Gender, status, and emerging career aspirations. American Sociological Review, 69(1), 93-113.

Correll, S. J., Benard, S., \& Paik, I. (2007). Getting a job: Is there a motherhood penalty? American Journal of Sociology, 112(5), 1297-1338.

Cuddy, A. J., Fiske, S. T., \& Glick, P. (2004). When professionals become mothers, warmth doesn't cut the ice. Journal of Social issues, 60(4), 701-718.

Day, D. V. (2000). Leadership development: A review in context. The Leadership Quarterly, 11(4), 581-613.

De Pater, I. E., Van Vianen, A. E., Bechtoldt, M. N., \& Klehe, U. C. (2009). Employees' challenging job experiences and supervisors' evaluations of promotability. Personnel Psychology, 62(2), 297-325.

DeSilver, D. (30 Apr 2018). Women scarce at top of U.S. business - and in the job that lead there. Pew Research Center. Retrieved from https://www.pewresearch.org/fact-tank/2018/04/30/women-scarce-at-top-of-u-sbusiness-and-in-the-jobs-that-lead-there/

Devine, P. G. (1989). Stereotypes and prejudice: Their automatic and controlled components. Journal of Personality and Social Psychology, 56(1), 5-18.

Diekman, A. B., \& Eagly, A. H. (2000). Stereotypes as dynamic constructs: Women and men of the past, present, and future. Personality and Social Psychology Bulletin, 26(10), 1171-1188.

Dragoni, L., Oh, I. S., Tesluk, P. E., Moore, O. A., VanKatwyk, P., \& Hazucha, J. (2014). Developing leaders' strategic thinking through global work experience: The moderating role of cultural distance. Journal of Applied Psychology, 99(5), 867882.

Duehr, E. E., \& Bono, J. E. (2006). Men, women, and managers: Are stereotypes finally changing? Personnel Psychology, 59(4), 815-846.

Eagly, A. H. (1987). Sex differences in social behavior: A social role interpretation. Hillsdale, NJ: Erlbaum.

Eagly, A. H., \& Carli, L. L. (2003a). The female leadership advantage: An evaluation of the evidence. The Leadership Quarterly, 14(6), 807-834. 
Eagly, A. H., \& Carli, L. L. (2003b). Finding gender advantage and disadvantage: Systematic research integration is the solution. The Leadership Quarterly, 14(6), 851-859.

Eagly, A. H., \& Crowley, M. (1986). Gender and helping behavior: A meta-analytic review of the social psychological literature. Psychological Bulletin, 100(3), 283308.

Eagly, A. H., \& Karau, S. J. (2002). Role congruity theory of prejudice toward female leaders. Psychological Review, 109(3), 573-598.

Eagly, A. H., Makhijani, M. G., \& Klonsky, B. G. (1992). Gender and the evaluation of leaders: A meta-analysis. Psychological Bulletin, 111(1), 3-22.

Eagly, A. H., Nater, C., Miller, D. I., Kaufmann, M., \& Sczesny, S. (2019). Gender stereotypes have changed: A cross-temporal meta-analysis of US public opinion polls from 1946 to 2018. American Psychologist, 1-15.

Ely, R. J., \& Meyerson, D. E. (2000). Theories of gender in organizations: A new approach to organizational analysis and change. Research in Organizational Behavior, 22, 103-151.

Erdogan, B., Kraimer, M. L., \& Liden, R. C. (2001). Procedural justice as a twodimensional construct: An examination in the performance appraisal context. The Journal of Applied Behavioral Science, 37(2), 205-222.

Etaugh, C., \& Folger, D. (1998). Perceptions of parents whose work and parenting behaviors deviate from role expectations. Sex Roles, 39(3-4), 215-223.

Farh, J. L., \& Cheng, B. S. (2000). A cultural analysis of paternalistic leadership in Chinese organizations. In J. T. Li, A. S. Tsui, \& E. Weldon (Eds.), Management and organizations in the Chinese context (pp. 84-127). London: Palgrave Macmillan.

Fazio, R. H., \& Olson, M. A. (2003). Implicit measures in social cognition research: Their meaning and use. Annual Review of Psychology, 54(1), 297-327.

Finkelstein, L. M., Costanza, D. P., \& Goodwin, G. F. (2018). Do your high potentials have potential? The impact of individual differences and designation on leader success. Personnel Psychology, 71(1), 3-22.

Fiske, S. T. (1998). Stereotyping, prejudice, and discrimination. In D. T. Gilbert, S. T. Fiske, \& G. Lindzey (Eds.), The handbook of social psychology (pp. 357-411). New York: McGraw-Hill.

Fiske, A. P., Haslam, N., \& Fiske, S. T. (1991). Confusing one person with another: What errors reveal about the elementary forms of social relations. Journal of Personality and Social Psychology, 60(5), 656-674.

Foschi, M. (2000). Double standards for competence: Theory and research. Annual Review of Sociology, 26(1), 21-42.

Fuegen, K., Biernat, M., Haines, E., \& Deaux, K. (2004). Mothers and fathers in the workplace: How gender and parental status influence judgments of job-related competence. Journal of Social Issues, 60(4), 737-754.

Fuhrmans, V. (6 Feb 2020). Where are all the women CEOs? Wall Street Journal. Retrieved from https://www.wsj.com/articles/why-so-few-ceos-are-women-youcan-have-a-seat-at-the-table-and-not-be-a-player-11581003276

Garman, A. N., \& Glawe, J. (2004). Succession planning. Consulting Psychology Journal: Practice and Research, 56(2), 119-128. 
Glick, P., \& Fiske, S. T. (1996). The ambivalent sexism inventory: Differentiating hostile and benevolent sexism. Journal of Personality and Social Psychology, 70(3), 491512.

Glick, P., \& Fiske, S. T. (2001). An ambivalent alliance: Hostile and benevolent sexism as complementary justifications for gender inequality. American Psychologist, 56(2), 109-118.

Greenhaus, J. H., Parasuraman, S., \& Wormley, W. M. (1990). Effects of race on organizational experiences, job performance evaluations, and career outcomes. Academy of Management Journal, 33(1), 64-86.

Greenwald, A. G., Nosek, B. A., \& Banaji, M. R. (2003). Understanding and using the implicit association test: I. An improved scoring algorithm. Journal of Personality and Social Psychology, 85(2), 197-216.

Gupta, V. K., Turban, D. B., Wasti, S. A., \& Sikdar, A. (2009). The role of gender stereotypes in perceptions of entrepreneurs and intentions to become an entrepreneur. Entrepreneurship Theory and Practice, 33(2), 397-417.

Gurbuz, S., Habiboglu, O. S., \& Bingol, D. (2016). Who is being judged promotable: Good actors, high performers, highly committed or birds of a feather? International Journal of Selection and Assessment, 24(2), 197-208.

Hammond, M. D., Milojev, P., Huang, Y., \& Sibley, C. G. (2018). Benevolent sexism and hostile sexism across the ages. Social Psychological and Personality Science, 9(7), 863-874.

Harris, K. J., Kacmar, K. M., \& Carlson, D. S. (2006). An examination of temporal variables and relationship quality on promotability ratings. Group \& Organization Management, 31(6), 677-699.

Hayes, A. F. (2018). Introduction to mediation, moderation, and conditional process analysis: A regression-based approach ( $2^{\text {nd }}$ ed.). New York: Guilford Press.

Hays, W. L. (1963). Statistics for psychologists. New York: Holt, Rinehart, and Winston.

Heilman, M. E. (1983). Sex bias in work settings: The lack of fit model. Research in Organizational Behavior, 5, 269-298.

Heilman, M. E. (2001). Description and prescription: How gender stereotypes prevent women's ascent up the organizational ladder. Journal of Social Issues, 57(4), 657674.

Heilman, M. E., \& Okimoto, T. G. (2008). Motherhood: A potential source of bias in employment decisions. Journal of Applied Psychology, 93(1), 189-198.

Heilman, M. E., \& Parks-Stamm, E. J. (2007). Gender stereotypes in the workplace: Obstacles to women's career progress. In S. J. Correll (Ed.), Social psychology of gender: Advances in group processes (Vol. 24, pp. 47-77). Oxford, England: Elsevier.

Heilman, M. E., Wallen, A. S., Fuchs, D., \& Tamkins, M. M. (2004). Penalties for success: Reactions to women who succeed at male gender-typed tasks. Journal of Applied Psychology, 89(3), 416-427.

Hezlett, S. A. (2016). Enhancing experience-driven leadership development. Advances in Developing Human Resources, 18(3), 369-389.

Hilton, J. L., \& Von Hippel, W. (1996). Stereotypes. Annual Review of Psychology, 47(1), 237-271. 
Hoobler, J. M., Wayne, S. J., \& Lemmon, G. (2009). Bosses' perceptions of family-work conflict and women's promotability: Glass ceiling effects. Academy of Management Journal, 52(5), 939-957.

Hrebiniak, L. G., \& Alutto, J. A. (1973). A comparative organizational study of performance and size correlates in impatient psychiatric departments. Administrative Science Quarterly, 18(3), 365-382.

Ibarra, H., Carter, N. M., \& Silva, C. (2010). Why men still get more promotions than women. Harvard Business Review, 88(9), 80-85.

Iles, P. (1997). Sustainable high-potential career development: A resource-based view. Career Development International, 2(7), 347-353.

Jarman, J., Blackburn, R. M., \& Racko, G. (2012). The dimensions of occupational gender segregation in industrial countries. Sociology, 46(6), 1003-1019.

Jones, E. E., \& McGillis, D. (1976). Correspondent inferences and the attribution cube: A comparative reappraisal. New Directions in Attribution Research, 1, 389-420.

Joshi, A. (2014). By whom and when is women's expertise recognized? The interactive effects of gender and education in science and engineering teams. Administrative Science Quarterly, 59(2), 202-239.

Joshi, A., Son, J., \& Roh, H. (2015). When can women close the gap? A meta-analytic test of sex differences in performance and rewards. Academy of Management Journal, 58(5), 1516-1545.

Kelly, E. L., Ammons, S. K., Chermack, K., \& Moen, P. (2010). Gendered challenge, gendered response: Confronting the ideal worker norm in a white-collar organization. Gender \& Society, 24(3), 281-303.

Kilian, C.M., Hukai, D. and McCarty, C.E. (2005). Building diversity in the pipeline to corporate leadership, Journal of Management Development, 24(2), 155-168.

King, E. B., Botsford, W., Hebl, M. R., Kazama, S., Dawson, J. F., \& Perkins, A. (2012). Benevolent sexism at work: Gender differences in the distribution of challenging developmental experiences. Journal of Management, 38(6), 1835-1866.

Kmec, J. A. (2011). Are motherhood penalties and fatherhood bonuses warranted? Comparing pro-work behaviors and conditions of mothers, fathers, and nonparents. Social Science Research, 40(2), 444-459.

Koenig, A. M., Eagly, A. H., Mitchell, A. A., \& Ristikari, T. (2011). Are leader stereotypes masculine? A meta-analysis of three research paradigms.

Psychological Bulletin, 137(4), 616.

Kreiner, G. E. (2006). Consequences of work-home segmentation or integration: A person-environment fit perspective. Journal of Organizational Behavior: The International Journal of Industrial, Occupational and Organizational Psychology and Behavior, 27(4), 485-507.

Kuchynka, S. L., Bosson, J. K., Vandello, J. A., \& Puryear, C. (2018). Zero-sum thinking and the masculinity contest: Perceived intergroup competition and workplace gender bias. Journal of Social Issues, 74(3), 529-550.

Landau, J. C., Shamir, B., \& Arthur, M. B. (1992). Predictors of willingness to relocate for managerial and professional employees. Journal of Organizational Behavior, 13(7), 667-680.

Lewis, P., \& Simpson, R. (2012). Kanter revisited: Gender, power and (in)visibility. International Journal of Management Reviews, 14(2), 141-158. 
London, M., \& Stumpf, S. A. (1983). Effects of candidate characteristics on management promotion decisions: An experimental study. Personnel Psychology, 36(2), 241259.

Lord, R. G., Foti, R. J., \& De Vader, C. L. (1984). A test of leadership categorization theory: Internal structure, information processing, and leadership perceptions. Organizational Behavior and Human Performance, 34(3), 343-378.

Lyness, K. S., \& Heilman, M. E. (2006). When fit is fundamental: Performance evaluations and promotions of upper-level female and male managers. Journal of Applied Psychology, 91(4), 777-785.

Lyness, K. S., \& Schrader, C. A. (2006). Moving ahead or just moving? An examination of gender differences in senior corporate management appointments. Group \& Organization Management, 31(6), 651-676.

Maccoby, E. E. (1988). Gender as a social category. Developmental Psychology, 24(6), 755-765.

Macrae, C. N., Bodenhausen, G. V., Milne, A. B., \& Jetten, J. (1994). Out of mind but back in sight: Stereotypes on the rebound. Journal of Personality and Social Psychology, 67(5), 808-817.

Mandel, H. (2013). Up the down staircase: Women's upward mobility and the wage penalty for occupational feminization, 1970-2007. Social Forces, 91(4), 11831207.

Marsiglio, W., Amato, P., Day, R. D., \& Lamb, M. E. (2000). Scholarship on fatherhood in the 1990s and beyond. Journal of Marriage and Family, 62(4), 1173-1191.

McConahay, J. B. (1986). Modern racism, ambivalence, and the Modern Racism Scale. In J. F. Dovidio \& S. L. Gaertner (Eds.), Prejudice, discrimination, and racism (p. 91-125). Cambridge, MA: Academic Press.

McCauley, C. D. (1999). Learning from work experience: Job challenge profile. San Francisco, CA: John Wiley.

Meier, O. (2017). The path to diversity: Women on assignment. Retrieved from https://mobilityexchange.mercer.com/Insights/article/The-Path-to-DiversityWomen-on-Assignment

Mellott, D. S. (2003). Measuring implicit attitudes and stereotypes: Increasing internal consistency reveals the convergent validity of IAT and priming measures. Dissertation Abstracts International: Section B: The Sciences and Engineering, 64(5-B), 2442.

Morrison, E. W. (1994). Role definitions and organizational citizenship behavior: The importance of the employee's perspective. Academy of Management Journal, 37(6), 1543-1567.

Morton, T. A., Postmes, T., Haslam, S. A., \& Hornsey, M. J. (2009). Theorizing gender in the face of social change: Is there anything essential about essentialism? Journal of Personality and Social Psychology, 96(3), 653-664.

Mowday, R. T., Steers, R. M., \& Porter, L. W. (1979). The measurement of organizational commitment. Journal of Vocational Behavior, 14(2), 224-247.

National Science Foundation, Division of Science Resources Statistics. (2009). Women, minorities, and persons with disabilities in science and engineering: 2009. NSF 09-305. Arlington, VA: National Science Foundation. 
Ng, T. W., Eby, L. T., Sorensen, K. L., \& Feldman, D. C. (2005). Predictors of objective and subjective career success: A meta-analysis. Personnel Psychology, 58(2), 367-408.

Noe, R. A., \& Barber, A. E. (1993). Willingness to accept mobility opportunities: Destination makes a difference. Journal of Organizational Behavior, 14(2), 159175.

Nosek, B. A., Greenwald, A. G., \& Banaji, M. R. (2005). Understanding and using the Implicit Association Test: II. Method variables and construct validity. Personality and Social Psychology Bulletin, 31(2), 166-180.

O*Net Online. (2019, December 12). Summary report for: 15-2031.00 Operations research analysts. Retrieved from https://www.onetonline.org/link/summary/152031.00.

Okimoto, T. G., \& Heilman, M. E. (2012). The "bad parent” assumption: How gender stereotypes affect reactions to working mothers. Journal of Social Issues, 68(4), 704-724.

Paustian-Underdahl, S. C., Halbesleben, J. R., Carlson, D. S., \& Kacmar, K. M. (2016). The work-family interface and promotability: Boundary integration as a doubleedged sword. Journal of Management, 42(4), 960-981.

Pazy, A., \& Oron, I. (2001). Sex proportion and performance evaluation among highranking military officers. Journal of Organizational Behavior: The International Journal of Industrial, Occupational and Organizational Psychology and Behavior, 22(6), 689-702.

Pearce, J., \& Gregersen, H. B. (1991). Task interdependence and extrarole behavior: A test of the mediating effects of felt responsibility. Journal of Applied Psychology, $76,838-844$.

Pellegrini, E. K., \& Scandura, T. A. (2008). Paternalistic leadership: A review and agenda for future research. Journal of Management, 34(3), 566-593.

Phelan, J. E., Moss-Racusin, C. A., \& Rudman, L. A. (2008). Competent yet out in the cold: Shifting criteria for hiring reflect backlash toward agentic women. Psychology of Women Quarterly, 32(4), 406-413.

Phelan, J. E., \& Rudman, L. A. (2010). Prejudice toward female leaders: Backlash effects and women's impression management dilemma. Social and Personality Psychology Compass, 4(10), 807-820.

Post, C., DiTomaso, N., Lowe, S. R., Farris, G. F., \& Cordero, R. (2009). A few good women: Gender differences in evaluations of promotability in industrial research and development. Journal of Managerial Psychology, 24(4), 348-371.

Prentice, D. A., \& Carranza, E. (2002). What women and men should be, shouldn't be, are allowed to be, and don't have to be: The contents of prescriptive gender stereotypes. Psychology of Women Quarterly, 26(4), 269-281.

Ramsey, R., Lassk, F.G., \& Marshall, G.W. (1995). A critical evaluation of a measure of job involvement: The use of the Lodahl and Kejner (1965) scale with salespeople. Journal of Personal Selling \& Sales Management, 15(3): 65-74.

Reid, E. (2015). Embracing, passing, revealing, and the ideal worker image: How people navigate expected and experienced professional identities. Organization Science, 26(4), 997-1017. 
Rhode, D. L. (2003). The difference" difference" makes: Women and leadership. Stanford, CA: Stanford University Press.

Ridgeway, C. L. (2001). Gender, status, and leadership. Journal of Social Issues, 57(4), 637-655.

Rollero, C., Glick, P., \& Tartaglia, S. (2014). Psychometric properties of short versions of the Ambivalent Sexism Inventory and Ambivalence toward Men Inventory. TPM:

Testing, Psychometrics, Methodology in Applied Psychology, 21(2), 149-159.

Roth, P. L., Purvis, K. L., \& Bobko, P. (2012). A meta-analysis of gender group differences for measures of job performance in field studies. Journal of Management, 38(2), 719-739.

Rothbard, N. P., Phillips, K. W., \& Dumas, T. L. (2005). Managing multiple roles: Workfamily policies and individuals' desires for segmentation. Organization Science, 16(3), 243-258.

Rudman, L. A., Moss-Racusin, C. A., Phelan, J. E., \& Nauts, S. (2012). Status incongruity and backlash effects: Defending the gender hierarchy motivates prejudice against female leaders. Journal of Experimental Social Psychology, 48(1), 165-179.

Sallee, M. W. (2012). The ideal worker or the ideal father: Organizational structures and culture in the gendered university. Research in Higher Education, 53(7), 782-802.

Schein, V. E. (1973). The relationship between sex role stereotypes and requisite management characteristics. Journal of Applied Psychology, 57(2), 95-100.

Schein, V. E., Mueller, R., Lituchy, T., \& Liu, J. (1996). Think manager - think male: A global phenomenon? Journal of Organizational Behavior, 17(1), 33-41.

Shondrick, S. J., Dinh, J. E., \& Lord, R. G. (2010). Developments in implicit leadership theory and cognitive science: Applications to improving measurement and understanding alternatives to hierarchical leadership. The Leadership Quarterly, 21(6), 959-978.

Shore, L. M., Barksdale, K., \& Shore, T. H. (1995). Managerial perceptions of employee commitment to the organization. Academy of Management Journal, 38(6), 15931615.

Smiler, A. P., \& Gelman, S. A. (2008). Determinants of gender essentialism in college students. Sex Roles, 58(11-12), 864-874.

Smith, C. A., Organ, D. W., \& Near, J. P. (1983). Organizational citizenship behavior: Its nature and antecedents. Journal of Applied Psychology, 68(4), 653-663.

Smith-Lovin, L., \& Brody, C. (1989). Interruptions in group discussions: The effects of gender and group composition. American Sociological Review, 54(3), 424-435.

Sonnert, G., \& Holton, G. (1996). Career patterns of women and men in the sciences. American Scientist, 84(1), 63-71.

Stephan, W. G. (1989). A cognitive approach to stereotyping. In D. Bar-Tal, C. F. Graumann, A. W. Kruglanski, \& W. Stroebe (Eds.), Stereotyping and prejudice (pp. 37-57). New York: Springer.

Street, S., Kimmel, E. B., \& Kromrey, J. D. (1995). Revisiting university student gender role perceptions. Sex Roles, 33(3-4), 183-201.

Stumpf, S. A., \& London, M. (1981). Capturing rater policies in evaluating candidates for promotion. Academy of Management Journal, 24(4), 752-766. 
Swim, J. K., Aikin, K. J., Hall, W. S., \& Hunter, B. A. (1995). Sexism and racism: Oldfashioned and modern prejudices. Journal of Personality and Social Psychology, 68(2), 199-214.

Swim, J. K., \& Cohen, L. L. (1997). Overt, covert, and subtle sexism: A comparison between the attitudes toward women and modern sexism scales. Psychology of Women Quarterly, 21(1), 103-118.

Swim, J. K., Mallett, R., Russo-Devosa, Y., \& Stangor, C. (2005). Judgments of sexism: A comparison of the subtlety of sexism measures and sources of variability in judgments of sexism. Psychology of Women Quarterly, 29(4), 406-411.

Thacker, R. A., \& Wayne, S. J. (1995). An examination of the relationship between upward influence tactics and assessments of promotability. Journal of Management, 21(4), 739-756.

Thomas, R., Cooper, M., Konar, E., Rooney, M., Noble-Tolla, M., Bohrer, A., Yee, L., Krivkovich, A., Starikova, I., Robinson, K., Nadeau, M. C., \& Robinson, N. (2018). Women in the Workplace: 2018. Retrieved from https://womenintheworkplace.com/Women_in_the_Workplace_2018.pdf

Uhlmann, E. L., \& Cohen, G. L. (2005). Constructed criteria: Redefining merit to justify discrimination. Psychological Science, 16(6), 474-480.

U.S. Bureau of Labor Statistics. (2019, Jan 18). Labor force statistics from the Current Population Survey. Retrieved from https://www.bls.gov/cps/cpsaat11.htm.

U.S. Census Bureau. (2014, Sept 15). Frequently occurring surnames from the 1990 census. Retrieved from https://www.census.gov/topics/population/genealogy/data/1990_census.html.

U.S. Social Security Administration. (2019 Mar). Top names of the 1990s. Retrieved from https://www.ssa.gov/oact/babynames/decades/names1990s.html.

Van Scotter, J. R., \& Motowidlo, S. J. (1996). Interpersonal facilitation and job dedication as separate facets of contextual performance. Journal of Applied Psychology, 81(5), 525-531.

Van Scotter, J., Motowidlo, S. J., \& Cross, T. C. (2000). Effects of task performance and contextual performance on systemic rewards. Journal of Applied Psychology, 85(4), 526-535.

Wayne, S. J., Liden, R. C., Kraimer, M. L., \& Graf, I. K. (1999). The role of human capital, motivation and supervisor sponsorship in predicting career success. Journal of Organizational Behavior, 20(5), 577-595.

Wilson, K. Y., \& Jones, R. G. (2008). Reducing job-irrelevant bias in performance appraisals: Compliance and beyond. Journal of General Management, 34(2), 5770.

Wrzesniewski, A., McCauley, C., Rozin, P., \& Schwartz, B. (1997). Jobs, careers, and callings: People's relations to their work. Journal of Research in Personality, 31(1), 21-33.

Yavorsky, J. E., Kamp Dush, C. M., \& Schoppe-Sullivan, S. J. (2015). The production of inequality: The gender division of labor across the transition to parenthood. Journal of Marriage and Family, 77(3), 662-679.

Yoder, J. D., \& McDonald, T. W. (1997). The generalizability and construct validity of the Modern Sexism Scale: Some cautionary notes. Sex Roles, 36(9-10), 655-663. 
Zarya, V. (2018, May 21). The share of female CEOs in the Fortune 500 dropped by $25 \%$ in 2018. Fortune. Retrieved from http://fortune.com/2018/05/21/women-fortune500-2018

Zenger, J., \& Folkman, J. (2019). Research: Women score higher than men in most leadership skills. Harvard Business Review. 


\section{Appendix I: Research Question 1 Survey (Sample 1)}

\section{Part 1: Ideal Worker Idea Generation}

Many managers and academics talk about "ideal workers" but currently no consensus exists about what is meant by an "ideal worker." We would like to know what you think an ideal worker is like. Please list 20 attributes of an ideal worker. You may describe the attitudes or behaviors of an ideal worker using any words and phrases that come to mind. You may write more than 20 attributes if you think of more.

[Participants will see a list numbered 1-20 where they can free write words and phrases]

\section{Part 2: Ideal Worker Attributes Questionnaire (Full Version)}

The following list are characteristics that may or may not describe an ideal worker. Please rate what you think an ideal worker is like on the following attributes, where 1 means "Extremely uncharacteristic of an ideal worker" and 5 means "Extremely characteristic of an ideal worker."

[Respondents did not see information in parentheses. Items were randomly ordered.]

\section{Availability to Work}

\begin{tabular}{|c|c|c|c|c|c|}
\hline & $\begin{array}{c}1=\text { Extremely } \\
\text { Uncharacteristic } \\
\text { of an Ideal } \\
\text { Worker }\end{array}$ & $\begin{array}{c}2=\text { Somewhat } \\
\text { Uncharacteristic } \\
\text { of an Ideal } \\
\text { Worker }\end{array}$ & $\begin{array}{c}3=\text { Neither } \\
\text { Characteristic } \\
\text { nor } \\
\text { Uncharacteristic } \\
\text { of an Ideal } \\
\text { Worker }\end{array}$ & $\begin{array}{c}4= \\
\text { Somewhat } \\
\text { Characteristic } \\
\text { of an Ideal } \\
\text { Worker }\end{array}$ & $\begin{array}{c}5=\text { Extremely } \\
\text { Characteristic } \\
\text { of an Ideal } \\
\text { Worker }\end{array}$ \\
\hline $\begin{array}{l}\text { 1. Ideal } \\
\text { workers are } \\
\text { available to } \\
\text { work } \\
\text { beyond } \\
\text { regular } \\
\text { work hours. }\end{array}$ & & & & & \\
\hline $\begin{array}{l}\text { 2. Ideal } \\
\text { workers } \\
\text { tend to } \\
\text { come to } \\
\text { work before } \\
\text { the boss and } \\
\text { leave after } \\
\text { the boss. }\end{array}$ & & & & & \\
\hline $\begin{array}{l}\text { 3. Ideal } \\
\text { workers } \\
\text { drop } \\
\text { everything } \\
\text { to take care }\end{array}$ & & & & & \\
\hline
\end{tabular}




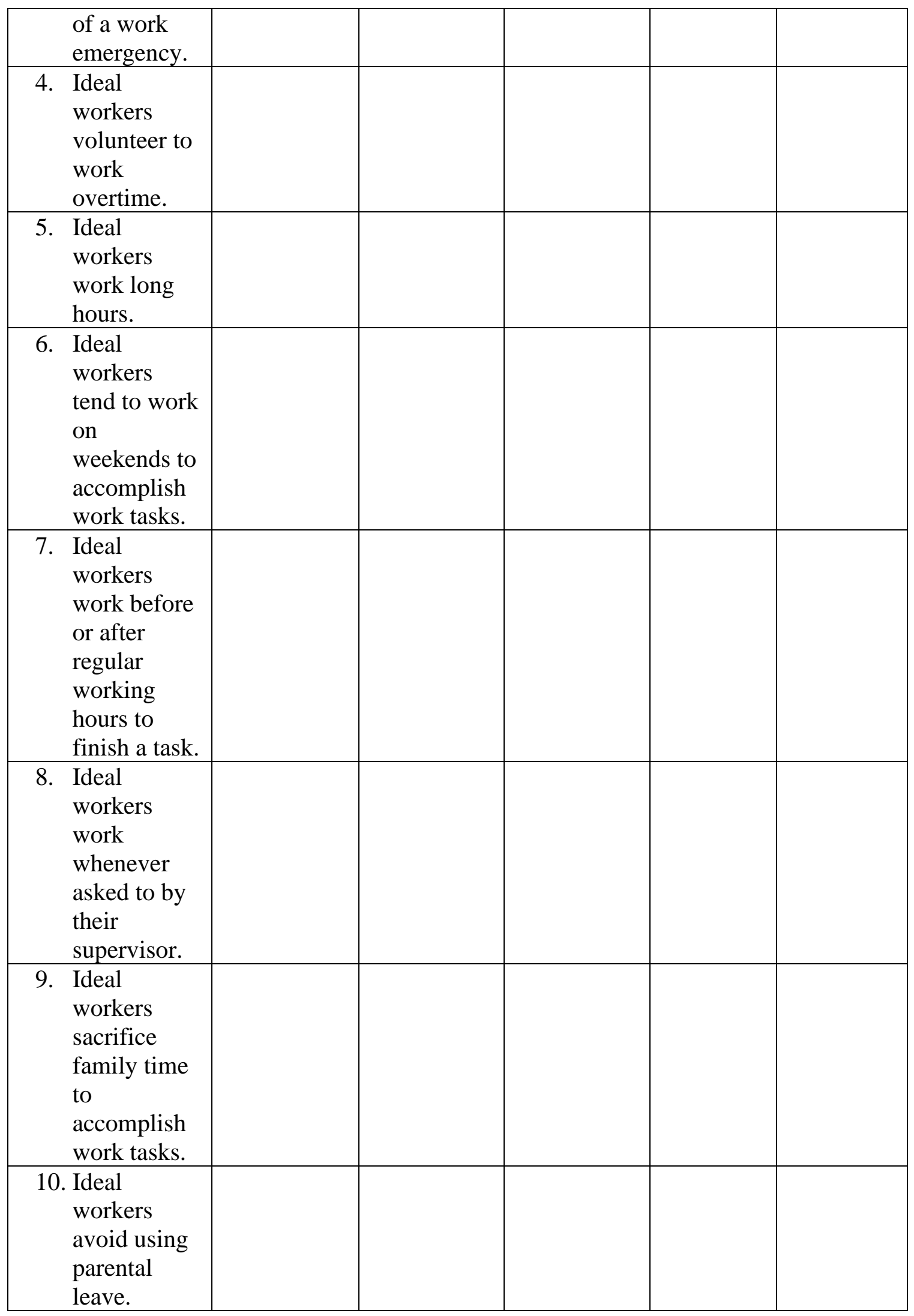




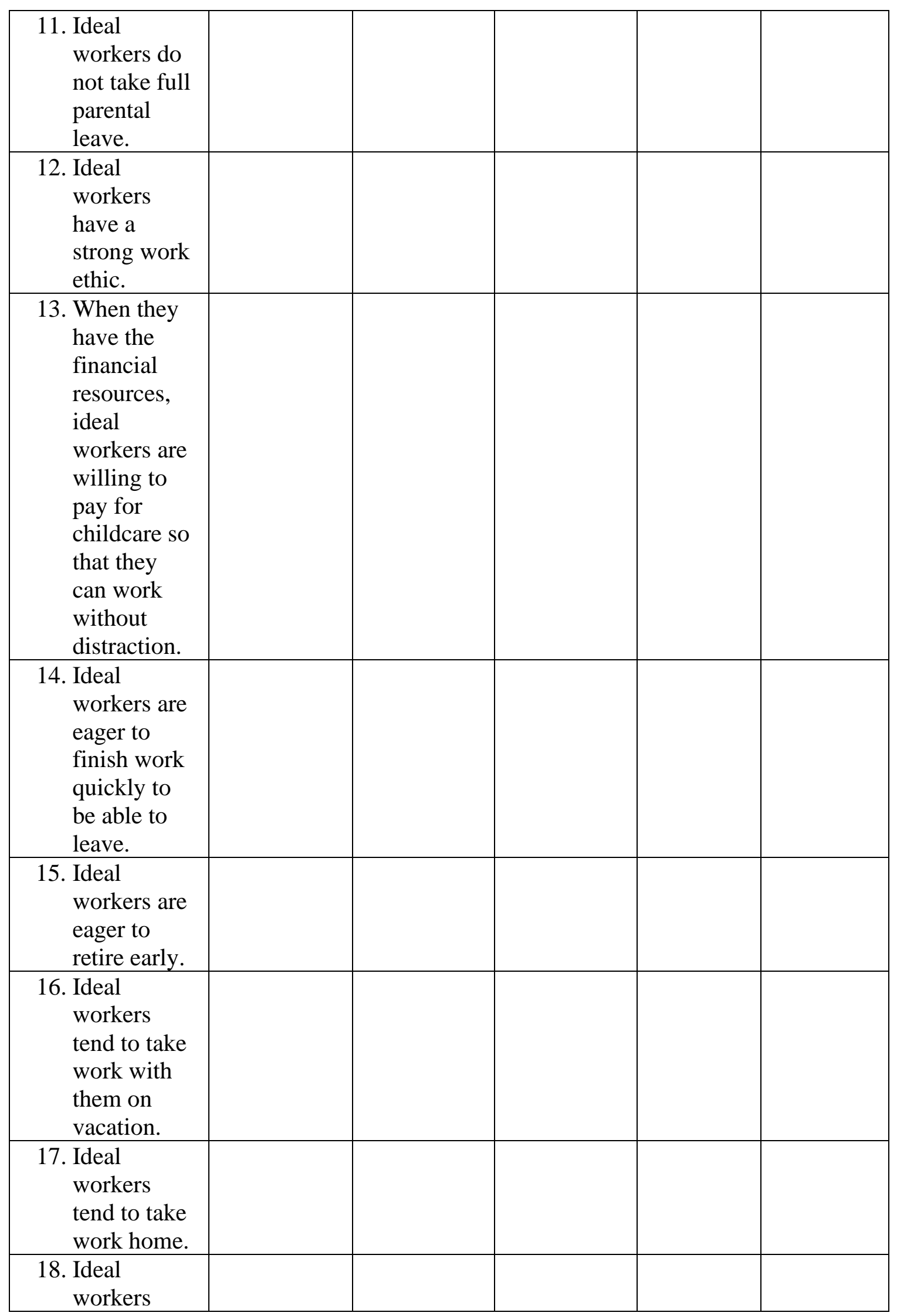




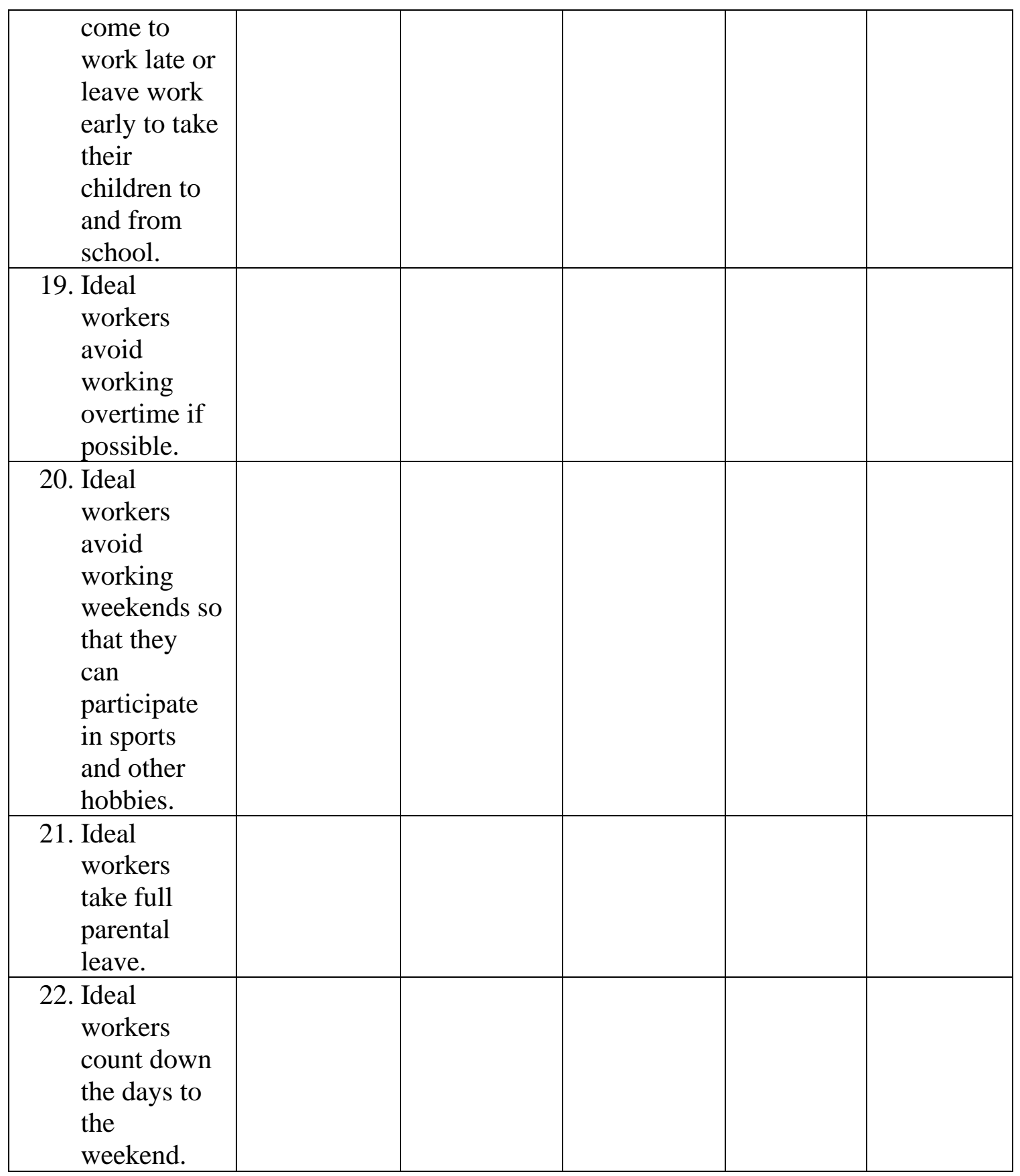

\section{Willingness to Travel and Move for Work}

\begin{tabular}{|c|c|c|c|c|c|}
\hline & $\begin{array}{c}1=\text { Extremely } \\
\text { Uncharacteristi } \\
\text { c of an Ideal } \\
\text { Worker }\end{array}$ & $\begin{array}{c}2=\text { Somewhat } \\
\text { Uncharacteristi } \\
\text { c of an Ideal } \\
\text { Worker }\end{array}$ & $\begin{array}{c}3=\text { Neither } \\
\text { Characteristic } \\
\text { nor } \\
\text { Uncharacteristi } \\
\text { c of an Ideal } \\
\text { Worker }\end{array}$ & $\begin{array}{c}4= \\
\text { Somewhat } \\
\text { Characteristi } \\
\text { c of an Ideal } \\
\text { Worker }\end{array}$ & $\begin{array}{c}\text { Extremely } \\
\text { Characteristi } \\
\text { c of an Ideal } \\
\text { Worker }\end{array}$ \\
\hline $\begin{array}{c}\text { 23. Ideal workers } \\
\text { travel for }\end{array}$ & & & & & \\
\hline
\end{tabular}




\begin{tabular}{|l|l|l|l|l|}
\hline $\begin{array}{l}\text { work, when } \\
\text { needed. }\end{array}$ & & & & \\
\hline $\begin{array}{l}\text { 24. Ideal workers } \\
\text { are willing to } \\
\text { travel } \\
\text { internationall } \\
\text { y for work. }\end{array}$ & & & & \\
\hline $\begin{array}{l}\text { 25. Ideal workers } \\
\text { are willing to } \\
\text { relocate for } \\
\text { work. }\end{array}$ & & & & \\
\hline $\begin{array}{l}\text { 26. Ideal workers } \\
\text { are willing to } \\
\text { relocate } \\
\text { internationall } \\
\text { y for work. }\end{array}$ & & & & \\
\hline $\begin{array}{l}\text { 27. Ideal workers } \\
\text { are willing to } \\
\text { move their } \\
\text { family for } \\
\text { work. }\end{array}$ & & & & \\
\hline $\begin{array}{l}\text { 28. Ideal workers } \\
\text { are available } \\
\text { to travel at } \\
\text { any time for } \\
\text { work. }\end{array}$ & & & & \\
\hline $\begin{array}{l}\text { 29. Ideal workers } \\
\text { are willing to } \\
\text { maintain } \\
\text { long-distance } \\
\text { relationships } \\
\text { for work. }\end{array}$ & & & & \\
\hline $\begin{array}{l}\text { 30. Ideal workers } \\
\text { are willing to } \\
\text { live far from } \\
\text { extended } \\
\text { family for } \\
\text { work. }\end{array}$ & & & & \\
\hline $\begin{array}{l}\text { 31. Ideal workers } \\
\text { try to keep } \\
\text { travel for } \\
\text { work to a } \\
\text { minimum. }\end{array}$ & & & & \\
\hline
\end{tabular}




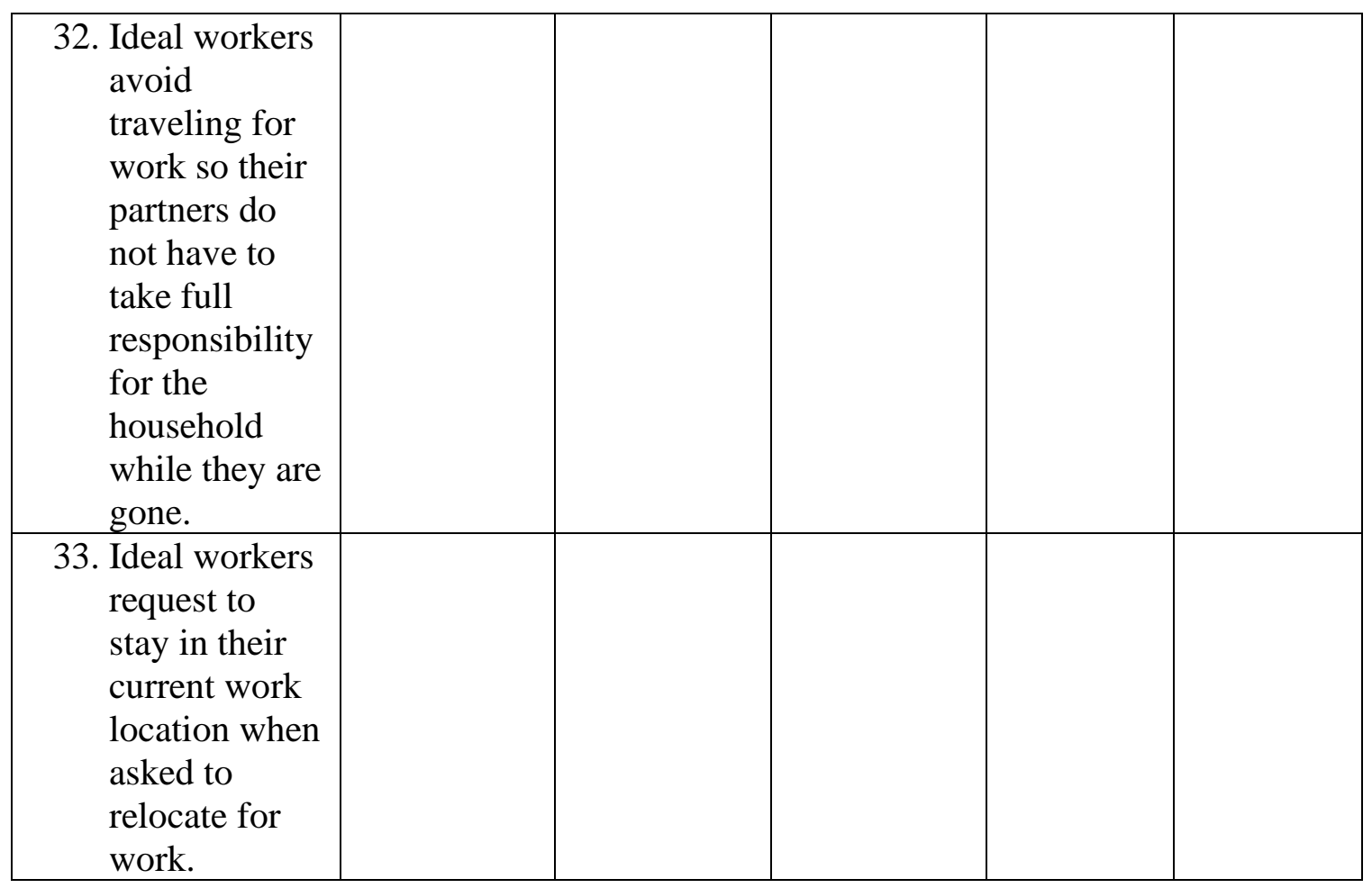

\section{Visibility at Work}

\begin{tabular}{|c|c|c|c|c|c|}
\hline & $\begin{array}{c}1 \text { = Extremely } \\
\text { Uncharacteristi } \\
\text { c of an Ideal } \\
\text { Worker }\end{array}$ & $\begin{array}{c}2=\text { Somewhat } \\
\text { Uncharacteristi } \\
\text { c of an Ideal } \\
\text { Worker }\end{array}$ & $\begin{array}{c}3=\text { Neither } \\
\text { Characteristic } \\
\text { nor } \\
\text { Uncharacteristi } \\
\text { c of an Ideal } \\
\text { Worker }\end{array}$ & $\begin{array}{c}4= \\
\text { Somewhat } \\
\text { Characteristi } \\
\text { c of an Ideal } \\
\text { Worker }\end{array}$ & $\begin{array}{c}5= \\
\text { Extremely } \\
\text { Characteristi } \\
\text { c of an Ideal } \\
\text { Worker }\end{array}$ \\
\hline $\begin{array}{l}\text { 34. Ideal workers } \\
\text { are visibly busy } \\
\text { at work. }\end{array}$ & & & & & \\
\hline $\begin{array}{l}\text { 35. The } \\
\text { accomplishmen } \\
\text { ts of ideal } \\
\text { workers are } \\
\text { visible to } \\
\text { management. }\end{array}$ & & & & & \\
\hline $\begin{array}{l}\text { 36. Ideal workers } \\
\text { ensure that their } \\
\text { colleagues see } \\
\text { the products of } \\
\text { their work. }\end{array}$ & & & & & \\
\hline $\begin{array}{l}\text { 37. Ideal workers } \\
\text { only engage in } \\
\text { work-related } \\
\text { talk. }\end{array}$ & & & & & \\
\hline
\end{tabular}




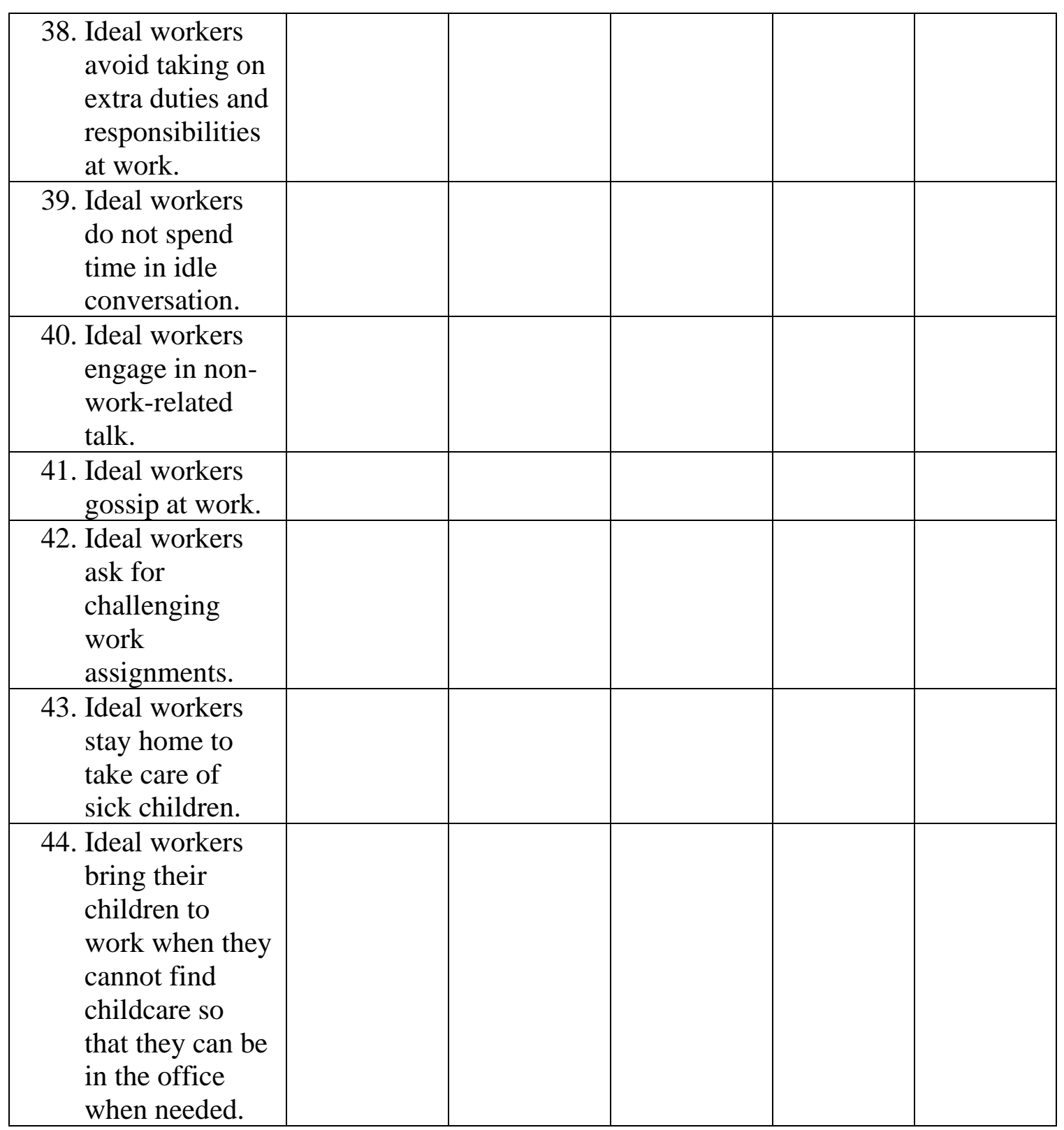

\section{Commitment to Work}

\begin{tabular}{|c|c|c|c|c|c|}
\hline & $\begin{array}{c}1=\text { Extremely } \\
\text { Uncharacteristic } \\
\text { of an Ideal } \\
\text { Worker }\end{array}$ & $\begin{array}{c}2=\text { Somewhat } \\
\text { Uncharacteristic } \\
\text { of an Ideal } \\
\text { Worker }\end{array}$ & $\begin{array}{c}3=\text { Neither } \\
\text { Characteristic } \\
\text { nor } \\
\text { Uncharacteristic } \\
\text { of an Ideal } \\
\text { Worker }\end{array}$ & $\begin{array}{c}4= \\
\text { Somewhat } \\
\text { Characteristic } \\
\text { of an Ideal } \\
\text { Worker }\end{array}$ & $\begin{array}{c}5= \\
\text { Extremely } \\
\text { Characteristic } \\
\text { of an Ideal } \\
\text { Worker }\end{array}$ \\
\hline $\begin{array}{l}\text { 45. Ideal } \\
\text { workers } \\
\text { have } \\
\text { positive } \\
\text { feelings }\end{array}$ & & & & & \\
\hline
\end{tabular}




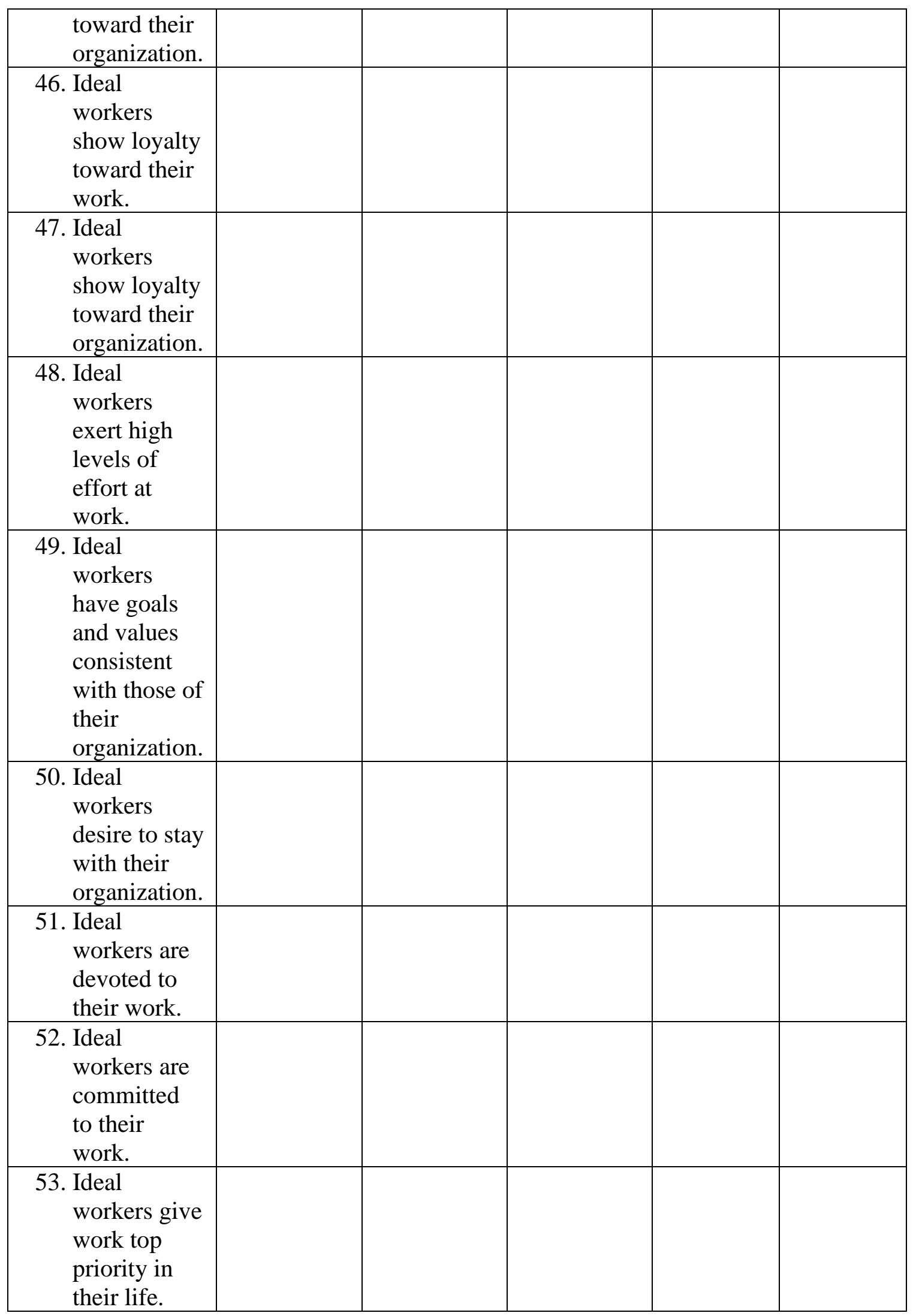




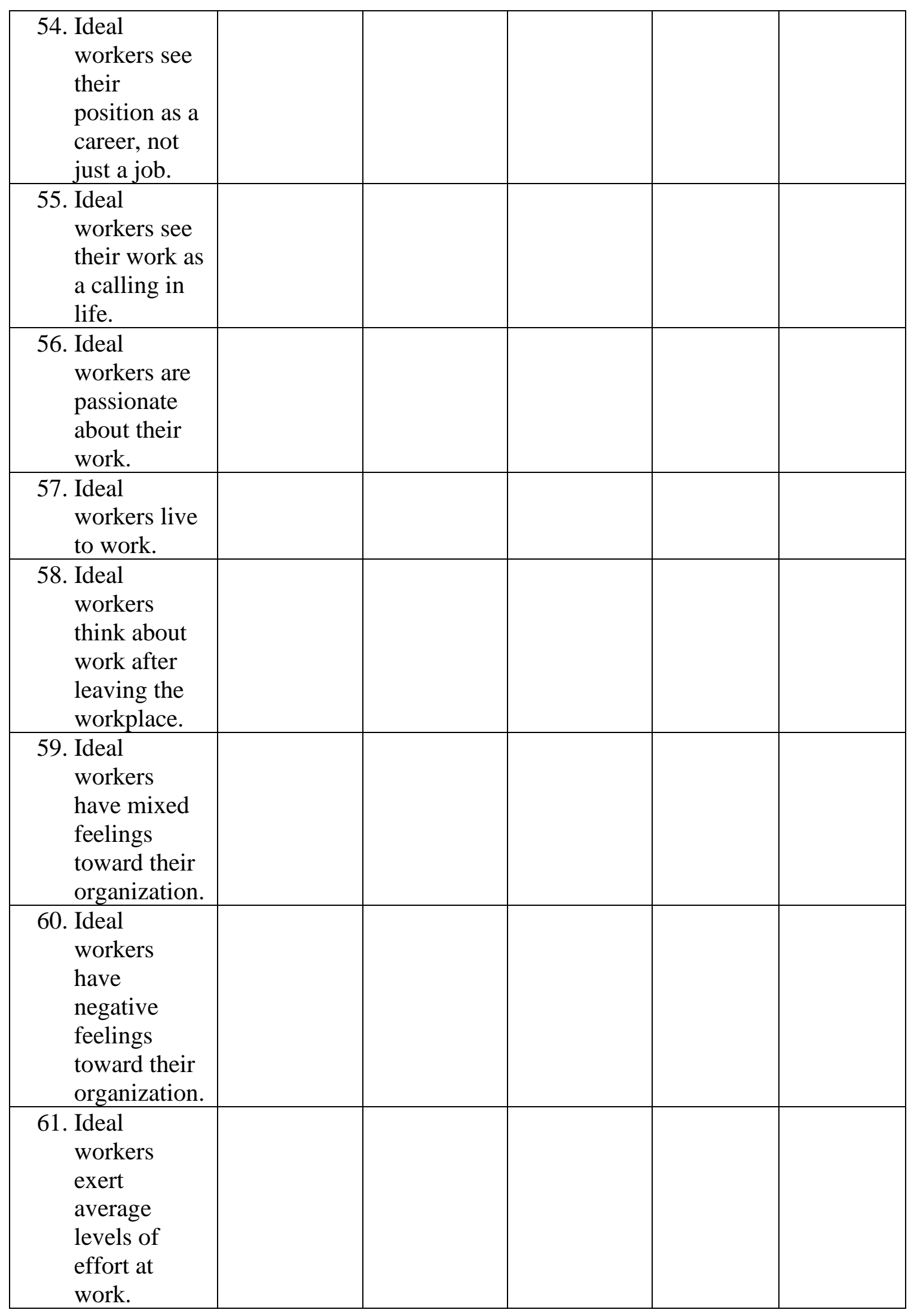




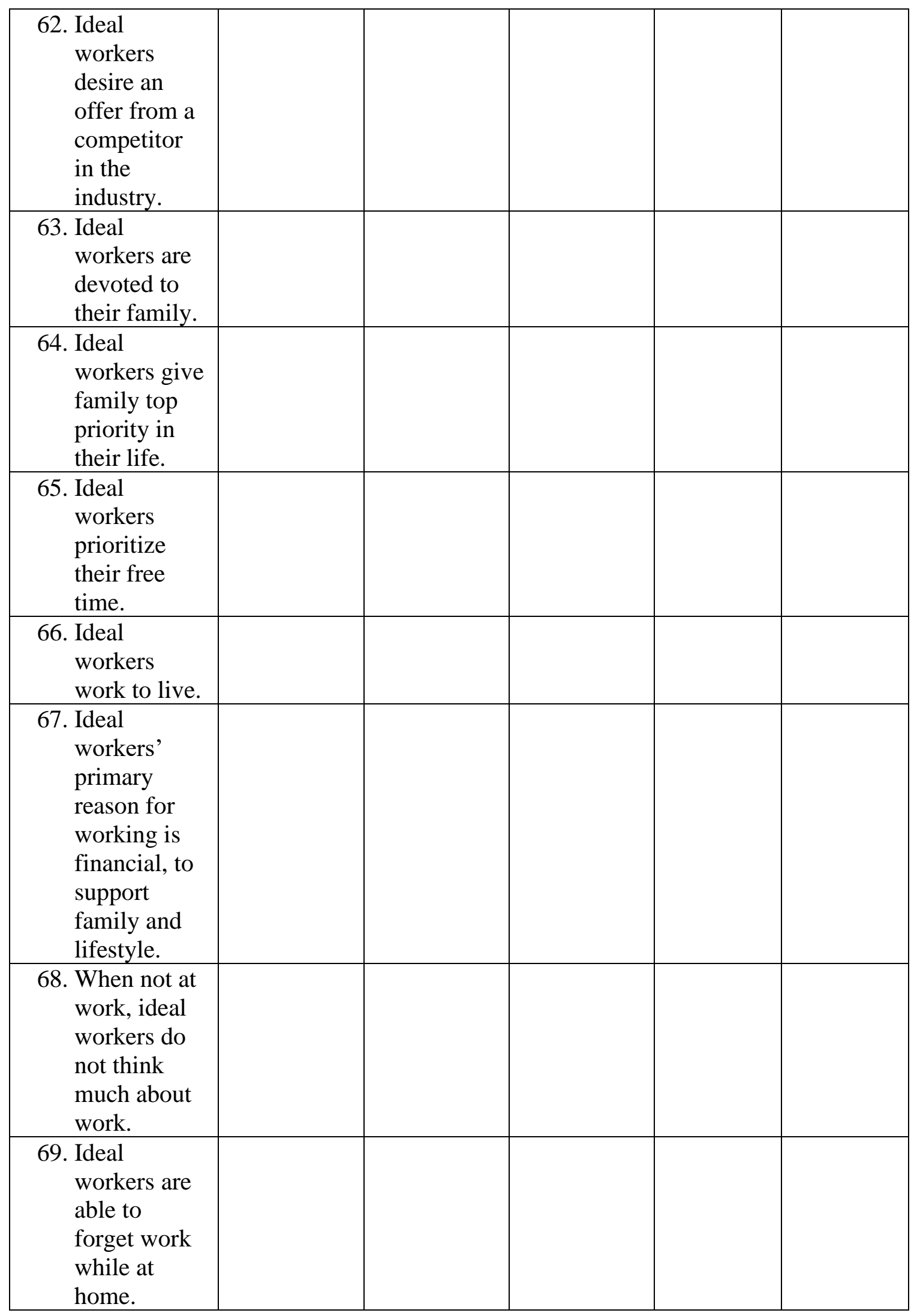


70. Ideal

workers

keep work

life at work.

\section{Schein Descriptive Index}

\begin{tabular}{|c|c|c|c|c|c|}
\hline & $\begin{array}{c}1=\text { Not at All } \\
\text { Characteristic } \\
\text { of an Ideal } \\
\text { Worker }\end{array}$ & $\begin{array}{c}2=\text { Slightly } \\
\text { Characteristic } \\
\text { of an Ideal } \\
\text { Worker }\end{array}$ & $\begin{array}{c}3= \\
\text { Moderately } \\
\text { Characteristic } \\
\text { of an Ideal } \\
\text { Worker }\end{array}$ & $\begin{array}{c}4=\text { Very } \\
\text { Characteristic } \\
\text { of an Ideal } \\
\text { Worker }\end{array}$ & $\begin{array}{c}5=\text { Extremely } \\
\text { Characteristic } \\
\text { of an Ideal } \\
\text { Worker }\end{array}$ \\
\hline 1. Selfish & & & & & \\
\hline $\begin{array}{l}\text { 2. Skilled in } \\
\text { business matters }\end{array}$ & & & & & \\
\hline $\begin{array}{l}\text { 3. High need for } \\
\text { power }\end{array}$ & & & & & \\
\hline $\begin{array}{l}\text { 4. Speedy recovery } \\
\text { from emotional } \\
\text { disturbance }\end{array}$ & & & & & \\
\hline 5. Self-confident & & & & & \\
\hline 6. Modest & & & & & \\
\hline 7. Bitter & & & & & \\
\hline 8. Independent & & & & & \\
\hline 9. Sympathetic & & & & & \\
\hline $\begin{array}{l}\text { 10. High need for } \\
\text { autonomy }\end{array}$ & & & & & \\
\hline 11. Self-reliant & & & & & \\
\hline 12. Shy & & & & & \\
\hline 13. Frank & & & & & \\
\hline $\begin{array}{l}\text { 14. Leadership } \\
\text { ability }\end{array}$ & & & & & \\
\hline 15. Self-controlled & & & & & \\
\hline 16. Devious & & & & & \\
\hline 17. Tactful & & & & & \\
\hline 18. Firm & & & & & \\
\hline 19. Cheerful & & & & & \\
\hline 20. Forceful & & & & & \\
\hline 21. Assertive & & & & & \\
\hline 22. Timid & & & & & \\
\hline 23. Prompt & & & & & \\
\hline $\begin{array}{l}\text { 24. Not } \\
\text { uncomfortable } \\
\text { about being } \\
\text { aggressive }\end{array}$ & & & & & \\
\hline 25. Courteous & & & & & \\
\hline
\end{tabular}




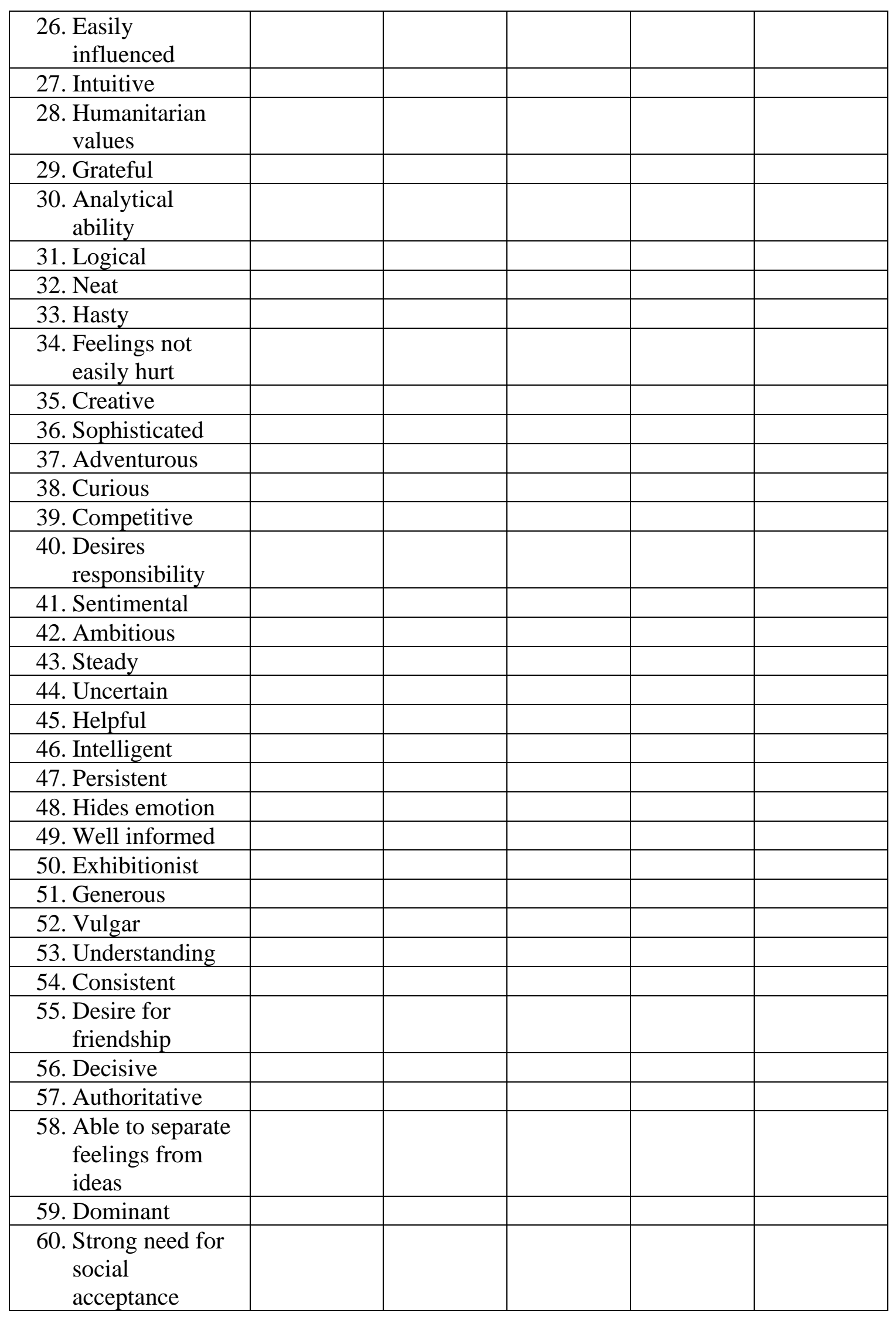




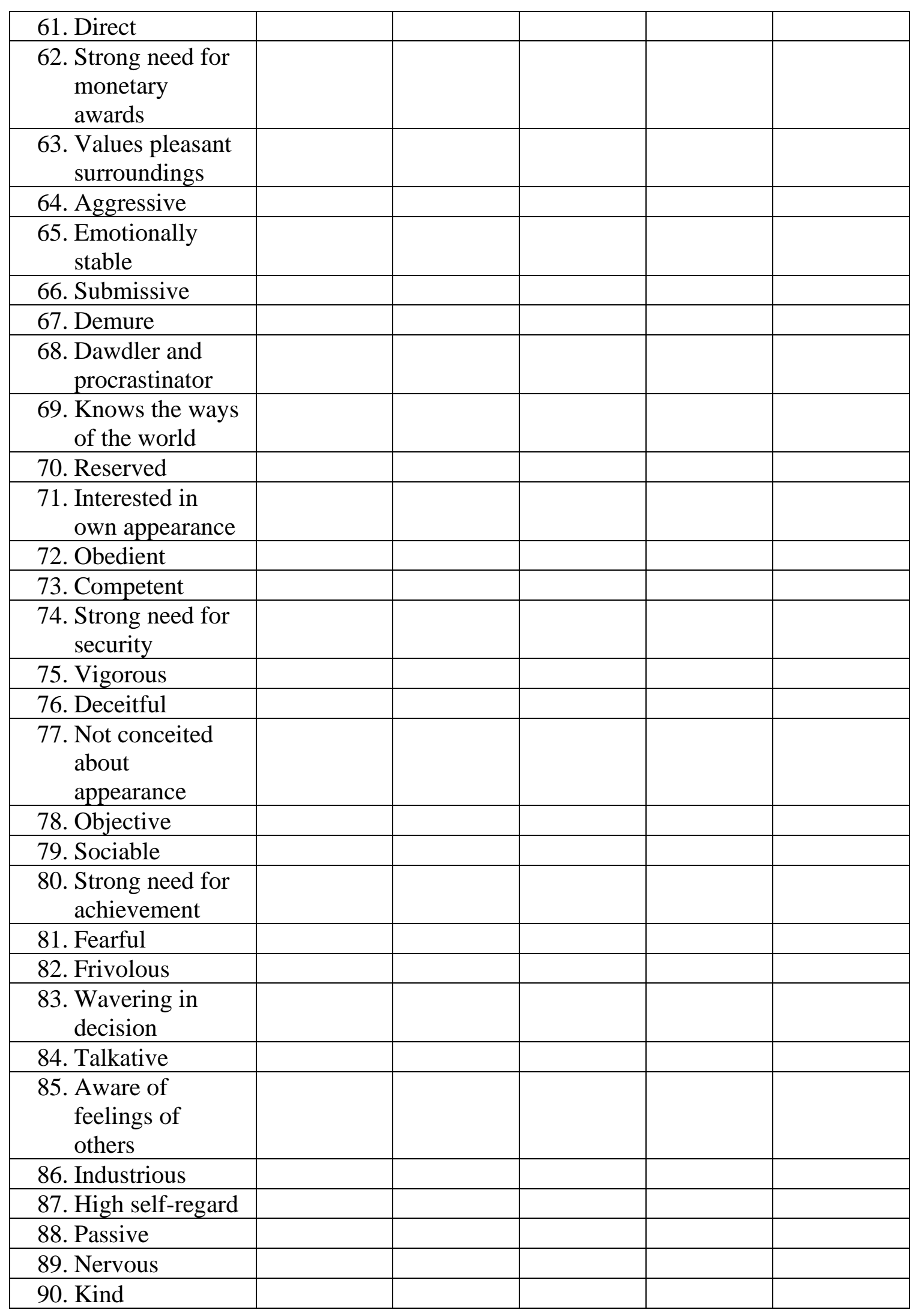




\begin{tabular}{|l|l|l|l|l|l|}
\hline $\begin{array}{c}\text { 91. Desire to avoid } \\
\text { controversy }\end{array}$ & & & & & \\
\hline 92. Quarrelsome & & & & & \\
\hline 93. Compassionate & & & & & \\
\hline 94. Cooperative & & & & & \\
\hline 95. Fair & & & & & \\
\hline 96. Good listener & & & & & \\
\hline 97. Inclusive & & & & & \\
\hline $\begin{array}{c}\text { 98. Shows } \\
\text { appreciation }\end{array}$ & & & & & \\
\hline $\begin{array}{c}\text { 99. Attends to the } \\
\text { needs of others }\end{array}$ & & & & & \\
\hline 100. Considerate & & & & & \\
\hline $\begin{array}{c}\text { 101. Considers } \\
\text { others' ideas }\end{array}$ & & & & & \\
\hline 102. Encouraging & & & & & \\
\hline 103. Energetic & & & & & \\
\hline 104. Enthusiastic & & & & & \\
\hline 105. Inspiring & & & & & \\
\hline 106. Open-minded & & & & & \\
\hline 107. Optimistic & & & & & \\
\hline $\begin{array}{c}\text { 108. Sense of } \\
\text { purpose }\end{array}$ & & & & & \\
\hline 109. Sincere & & & & & \\
\hline 110. Supportive & & & & & \\
\hline 111. Trustworthy & & & & & \\
\hline
\end{tabular}

\section{Demographic Information}

What is your gender? [Male, Female, Other]

What is your age (in years)?

What is your race? Please select all that apply. [American Indian or Alaska Native, Asian, Black or African American, Native Hawaiian or Other Pacific Islander, White]

What is your major? [Accounting, Finance, Management, Marketing, Non-business major]

How much work experience, either part-time or full-time, do you have in years?

Do you have any leadership experience at work? Yes, No 


\section{Appendix II: Research Question 1 Results for Ideal Worker Item Ratings}

\begin{tabular}{|c|c|c|c|c|}
\hline Item & $\begin{array}{l}\text { Sample 1 } \\
\text { (Students) } \\
(n=237)\end{array}$ & $\begin{array}{l}\text { Sample } 2 \\
\text { (Students) } \\
(n=63)\end{array}$ & $\begin{array}{l}\text { Sample } 3 \\
\text { (Students) } \\
(n=214)\end{array}$ & $\begin{array}{c}\text { Sample } 4 \\
\text { (Employees) } \\
(n=318)\end{array}$ \\
\hline \multicolumn{5}{|c|}{ Availability to Work (from Theory) } \\
\hline 33. Has a strong work ethic & $\begin{array}{l}4.45 \\
(.89)\end{array}$ & $\begin{array}{l}4.69 \\
(.62)\end{array}$ & $\begin{array}{l}4.71 \\
(.50)\end{array}$ & $\begin{array}{l}3.91 \\
(.93)\end{array}$ \\
\hline $\begin{array}{l}\text { 34. Works beyond regular } \\
\text { work hours }\end{array}$ & $\begin{array}{l}3.69 \\
(.92)\end{array}$ & $\begin{array}{c}3.60 \\
(1.28)\end{array}$ & $\begin{array}{c}3.77 \\
(1.05)\end{array}$ & $\begin{array}{c}3.25 \\
(1.18)\end{array}$ \\
\hline $\begin{array}{l}\text { 35. Works before or after } \\
\text { regular work hours to } \\
\text { finish a task } \\
\text { (Pearce \& Gregerson, } \\
\text { 1991) }\end{array}$ & $\begin{array}{c}3.61 \\
(1.02)\end{array}$ & $\begin{array}{c}3.70 \\
(1.13)\end{array}$ & $\begin{array}{l}3.86 \\
(1.00)\end{array}$ & $\begin{array}{c}3.39 \\
(1.19)\end{array}$ \\
\hline $\begin{array}{l}\text { 36. Comes to work before the } \\
\text { boss and leaves after the } \\
\text { boss }\end{array}$ & $\begin{array}{l}3.50 \\
(.98)\end{array}$ & $\begin{array}{c}3.62 \\
(1.31)\end{array}$ & $\begin{array}{c}3.45 \\
(1.21)\end{array}$ & $\begin{array}{c}2.91 \\
(1.28)\end{array}$ \\
\hline $\begin{array}{l}\text { 37. Volunteers to work } \\
\text { overtime }\end{array}$ & $\begin{array}{l}3.63 \\
(.93)\end{array}$ & $\begin{array}{c}3.81 \\
(1.12)\end{array}$ & $\begin{array}{c}3.73 \\
(1.06)\end{array}$ & $\begin{array}{c}3.32 \\
(1.16)\end{array}$ \\
\hline 38. Works long hours & $\begin{array}{l}3.36 \\
(.97)\end{array}$ & $\begin{array}{c}3.44 \\
(1.18)\end{array}$ & $\begin{array}{c}3.63 \\
(1.01)\end{array}$ & $\begin{array}{c}3.13 \\
(1.19)\end{array}$ \\
\hline $\begin{array}{l}\text { 39. Works on weekends to } \\
\text { accomplish work tasks }\end{array}$ & $\begin{array}{l}3.40 \\
(.99)\end{array}$ & $\begin{array}{l}3.51 \\
(1.16)\end{array}$ & $\begin{array}{c}3.67 \\
(1.07)\end{array}$ & $\begin{array}{c}3.00 \\
(1.22)\end{array}$ \\
\hline $\begin{array}{l}\text { 40. Prioritizes finishing tasks } \\
\text { over watching the clock* }\end{array}$ & & & $\begin{array}{l}4.29 \\
(.87)\end{array}$ & $\begin{array}{l}4.16 \\
(.99)\end{array}$ \\
\hline $\begin{array}{l}\text { 41. Can put in the time at work } \\
\text { to finish a task * }\end{array}$ & & & $\begin{array}{l}4.39 \\
(.68)\end{array}$ & $\begin{array}{l}4.12 \\
(.88)\end{array}$ \\
\hline $\begin{array}{l}\text { 42. Has the time to take on } \\
\text { new assignments }\end{array}$ & & & $\begin{array}{l}3.99 \\
(.87)\end{array}$ & $\begin{array}{c}3.79 \\
(1.05)\end{array}$ \\
\hline $\begin{array}{l}\text { 43. Can handle additional } \\
\text { work responsibilities * }\end{array}$ & & & $\begin{array}{l}4.41 \\
(.64)\end{array}$ & $\begin{array}{l}4.23 \\
(.90)\end{array}$ \\
\hline $\begin{array}{l}\text { 44. Drops everything to take } \\
\text { care of a work emergency }\end{array}$ & & $\begin{array}{c}3.45 \\
(1.13)\end{array}$ & $\begin{array}{c}3.58 \\
(1.04)\end{array}$ & $\begin{array}{c}3.56 \\
(1.13)\end{array}$ \\
\hline $\begin{array}{l}\text { 45. Works whenever asked by } \\
\text { their supervisor }\end{array}$ & $\begin{array}{c}3.57 \\
(1.09)\end{array}$ & & & \\
\hline $\begin{array}{l}\text { 46. Sacrifices family time to } \\
\text { accomplish work tasks }\end{array}$ & $\begin{array}{c}2.91 \\
(1.11)\end{array}$ & $\begin{array}{c}2.73 \\
(1.31)\end{array}$ & & \\
\hline $\begin{array}{l}\text { 47. Willing to pay for } \\
\text { childcare so that they can } \\
\text { work without distraction }\end{array}$ & $\begin{array}{l}3.47 \\
(.96)\end{array}$ & $\begin{array}{c}2.92 \\
(1.36)\end{array}$ & & \\
\hline $\begin{array}{l}\text { 48. Avoids using parental } \\
\text { leave }\end{array}$ & $\begin{array}{c}2.66 \\
(1.01)\end{array}$ & & & \\
\hline $\begin{array}{l}\text { 49. Does not take full parental } \\
\text { leave }\end{array}$ & $\begin{array}{c}2.66 \\
(1.06)\end{array}$ & & & \\
\hline $\begin{array}{l}\text { 50. Comes to work late or } \\
\text { leaves work early to take }\end{array}$ & $\begin{array}{c}2.55 \\
(1.10)\end{array}$ & & & \\
\hline
\end{tabular}


their children to and from school

51. Takes full parental leave $\quad 3.06$

52. Stays home to take care of $\quad 3.28$ sick children

53. Brings their children to work when they cannot

find childcare so that they can be in the office when needed

54. Is eager to finish work quickly to be able to leave (Wrzesniewski et al., 1997)

55 . Is eager to retire early (Wrzesniewski et al., 1997)

56. Takes work with them on

vacation

(Wrzesniewski et al., 1997)

57. Takes work home

(Rothbard et al., 2005;

Wrzesniewski et al., 1997)

58. Avoids working overtime if possible

59. Avoids working weekends so that they can participate in sports and other hobbies

60. Counts down the days to the weekend (Wrzesniewski et al., 1997)

61. Prioritizes their free time

Willingness to Travel and Move for Work (from Theory)

\begin{tabular}{|c|c|c|c|c|}
\hline $\begin{array}{l}\text { 62. Is willing to travel for } \\
\text { work }\end{array}$ & $\begin{array}{l}3.93 \\
(.85)\end{array}$ & $\begin{array}{c}3.84 \\
(1.00)\end{array}$ & $\begin{array}{c}3.64 \\
(1.06)\end{array}$ & $\begin{array}{c}3.21 \\
(1.22)\end{array}$ \\
\hline $\begin{array}{l}\text { 63. Is willing to travel abroad } \\
\text { for work }\end{array}$ & & & $\begin{array}{c}3.56 \\
(1.05)\end{array}$ & $\begin{array}{l}2.85 \\
(1.23)\end{array}$ \\
\hline $\begin{array}{l}\text { 64. Is willing to travel long } \\
\text { distances for work }\end{array}$ & & & $\begin{array}{c}3.53 \\
(1.08)\end{array}$ & $\begin{array}{c}2.97 \\
(1.23)\end{array}$ \\
\hline $\begin{array}{l}\text { 65. Is willing to travel } \\
\text { internationally for work }\end{array}$ & $\begin{array}{l}3.80 \\
(.89)\end{array}$ & $\begin{array}{c}3.56 \\
(1.15)\end{array}$ & $\begin{array}{c}3.46 \\
(1.09)\end{array}$ & $\begin{array}{c}2.81 \\
(1.23)\end{array}$ \\
\hline $\begin{array}{l}\text { 66. Is available to travel at any } \\
\text { time for work }\end{array}$ & $\begin{array}{l}3.49 \\
(.94)\end{array}$ & $\begin{array}{c}3.52 \\
(1.16)\end{array}$ & $\begin{array}{c}3.53 \\
(1.05)\end{array}$ & $\begin{array}{l}2.96 \\
(1.21)\end{array}$ \\
\hline $\begin{array}{l}\text { 67. Can travel last-minute for } \\
\text { work }\end{array}$ & & & $\begin{array}{c}3.44 \\
(1.09)\end{array}$ & $\begin{array}{r}3.00 \\
(1.22)\end{array}$ \\
\hline
\end{tabular}


68. Is willing to travel for

several days at a time for

(1.06)

work

69. Keeps travel for work to a

2.70

minimum

(.87)

70. Avoids traveling for work

2.64

so their partners do not

(.93)

have to take full

responsibility for the

household while they are

gone

71. Willing to relocate for

work

(.87)

(1.16)

72. Willing to relocate

3.31

3.31

internationally for work

(.99)

(1.30)

73. Requests to stay in their

2.86 current work location when asked to relocate for work

74. Willing to move their

3.40

3.42

family for work

(.91)

(1.28)

75. Willing to maintain long-

3.30

2.90

distance relationships for

(.98)

(1.34)

work

76. Willing to live far away

3.15

3.06

from extended family for

(.99)

(1.27) work

\begin{tabular}{|c|c|c|c|c|}
\hline \multicolumn{5}{|c|}{ Visibility at Work (from Theory) } \\
\hline 77. Is visibly busy at work & $\begin{array}{l}3.94 \\
(.86)\end{array}$ & $\begin{array}{l}3.98 \\
(.92)\end{array}$ & $\begin{array}{c}3.71 \\
(1.00)\end{array}$ & $\begin{array}{c}3.60 \\
(1.16)\end{array}$ \\
\hline $\begin{array}{l}\text { 78. Makes sure } \\
\text { accomplishment are visible } \\
\text { to management }\end{array}$ & $\begin{array}{l}4.01 \\
(.89)\end{array}$ & $\begin{array}{c}3.56 \\
(1.28)\end{array}$ & $\begin{array}{c}3.79 \\
(1.09)\end{array}$ & $\begin{array}{c}3.27 \\
(1.22)\end{array}$ \\
\hline $\begin{array}{l}\text { 79. Makes sure that their } \\
\text { colleagues see the products } \\
\text { of their work }\end{array}$ & $\begin{array}{c}3.38 \\
(1.01)\end{array}$ & $\begin{array}{c}3.48 \\
(1.32)\end{array}$ & $\begin{array}{c}3.71 \\
(1.00)\end{array}$ & $\begin{array}{c}3.40 \\
(1.24)\end{array}$ \\
\hline $\begin{array}{l}\text { 80. Only engages in work- } \\
\text { related talk (based on } \\
\text { Morrison, 1994) }\end{array}$ & $\begin{array}{c}2.67 \\
(1.08)\end{array}$ & $\begin{array}{c}2.52 \\
(1.27)\end{array}$ & & \\
\hline $\begin{array}{l}\text { 81. Engages in non-work- } \\
\text { related talk (Morrison, } \\
\text { 1994) }\end{array}$ & $\begin{array}{l}3.20 \\
(.93)\end{array}$ & & & \\
\hline $\begin{array}{l}\text { 82. Does not spend time in idle } \\
\text { conversation } \\
\text { (Smith, Organ, \& Near, } \\
\text { 1983) }\end{array}$ & $\begin{array}{c}3.09 \\
(1.01)\end{array}$ & & & \\
\hline
\end{tabular}


83. Gossips at work 1.98

84. Avoids taking on extra 2.27

duties and responsibilities

for work (Ramsey et al., 1995)

85. Asks for challenging work

3.94

4.34

4.22

3.89

assignments

(.92)

(.81)

(.85)

(.96)

(Van Scotter \&

Motowidlo, 1996)

\begin{tabular}{|c|c|c|c|c|}
\hline \multicolumn{5}{|c|}{ Commitment to Work (from Theory) } \\
\hline 86. Shows loyalty toward their & 4.28 & 4.51 & 4.47 & 4.12 \\
\hline organization $*$ & $(.92)$ & $(.67)$ & $(.68)$ & $(.93)$ \\
\hline 87. Cares about the fate of & & 4.54 & 4.54 & 4.25 \\
\hline their organization $*$ & & $(.64)$ & $(.65)$ & $(.84)$ \\
\hline 88. Has goals and values & 4.21 & 4.52 & 4.52 & 4.23 \\
\hline $\begin{array}{l}\text { consistent with those of } \\
\text { their organization } *\end{array}$ & $(.88)$ & $(.72)$ & $(.66)$ & $(.84)$ \\
\hline 89. Values work as much as & & & 4.26 & 4.05 \\
\hline $\begin{array}{l}\text { others do in the } \\
\text { organization } *\end{array}$ & & & $(.84)$ & $(.94)$ \\
\hline 90. Grows with the company * & & & $\begin{array}{l}4.48 \\
(.70)\end{array}$ & $\begin{array}{l}4.16 \\
(.87)\end{array}$ \\
\hline 91. Desires to stay with their & 4.01 & 4.50 & 4.33 & 4.11 \\
\hline organization $*$ & $(.89)$ & $(.70)$ & $(.80)$ & $(.97)$ \\
\hline 92. Views the organization's & & 3.89 & 4.08 & 3.73 \\
\hline problems as their own & & $(.99)$ & $(.88)$ & $(.98)$ \\
\hline 93. Has positive feelings & 4.30 & 4.34 & & \\
\hline toward their organization $*$ & $(.87)$ & $(.75)$ & & \\
\hline 94. Exerts high levels of effort & 4.38 & 4.53 & 4.57 & 4.19 \\
\hline at work * & $(.85)$ & $(.72)$ & $(.64)$ & $(.90)$ \\
\hline 95. Is fully engaged at work $*$ & & 4.47 & 4.51 & 4.35 \\
\hline & & $(.65)$ & $(.64)$ & $(.84)$ \\
\hline 96. Experiences & & 4.35 & 4.34 & 3.93 \\
\hline $\begin{array}{l}\text { meaningfulness from their } \\
\text { work }\end{array}$ & & $(.75)$ & $(.78)$ & $(.96)$ \\
\hline 97. Is passionate about their & 4.25 & 4.49 & 4.62 & 4.24 \\
\hline work $*$ & $(.98)$ & $(.69)$ & $(.62)$ & $(.90)$ \\
\hline 98. Is committed to their work & 4.28 & 4.40 & 4.52 & 4.29 \\
\hline$*$ & $(.82)$ & $(.78)$ & $(.62)$ & $(.85)$ \\
\hline 99. Shows loyalty toward their & 4.21 & 4.60 & 4.46 & 4.18 \\
\hline work * & $(.87)$ & $(.59)$ & $(.66)$ & $(.89)$ \\
\hline 100. Is interested in & & & 4.42 & 4.10 \\
\hline developing their career & & & $(.71)$ & $(.91)$ \\
\hline
\end{tabular}


101. Is devoted to their work *

102. Sees their position as a career, not just a job *

103. Plans on working until retirement

104. Asks for opportunities to develop their career

105. Has a clear idea of career goals

106. Sees their work as a calling in life

107. Gives work top priority in their life

108. Thinks about work after leaving the workplace (Rothbard et al., 2005)

109. Lives to work

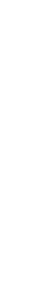

110. Has mixed feelings toward their organization

111. Has negative feelings toward their organization **

112. Exerts average levels of effort at work

113. Desires an offer from a competitor in the industry

114. Is devoted to their family

115. Gives family top priority in their life

116. Works to live

117. Primary reason for working is financial, to support family and lifestyle (Wrzesniewski et al., 1997)

118. When not at work, does not think much about work (Wrzesniewski et al., 1997)

119 . Is able to forget work while at home (Kreiner, 2006; Rothbard et al., 2005)

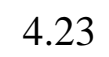

(.81)

4.10

(.97)

3.82

(.89)

3.23

(.99)

3.21

(.93)

3.01

(1.08)

(1.22) 
120. Keeps work life at work 3.51 (Kreiner, 2006)

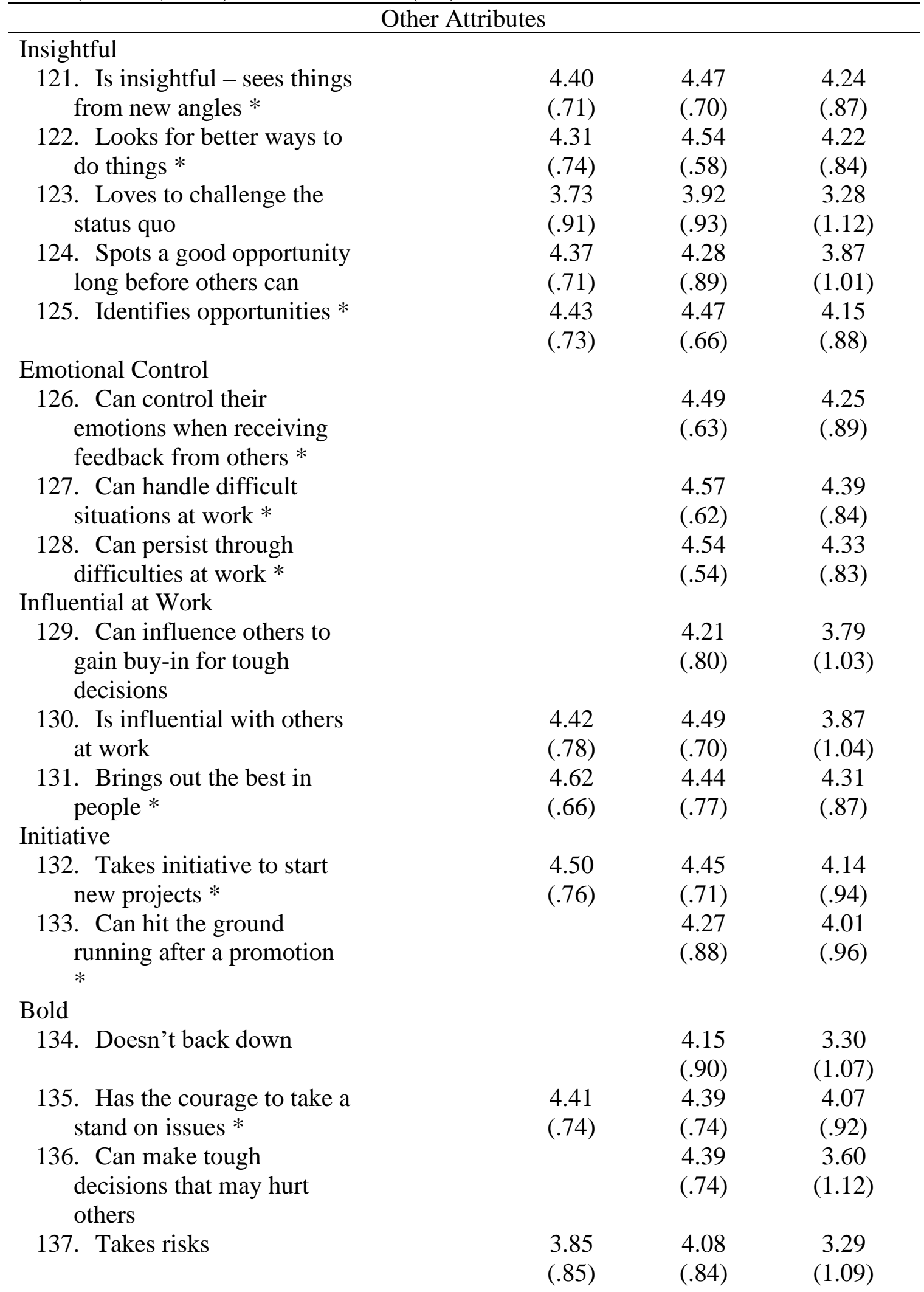


Authenticity

138. Is able to show their true self at work

Ambitious

139. Is interested in being an executive in the future

140. Has realistic career goals *

141. Expresses a desire for promotion

142. Has high aspirations for advancing in the organization

143. Has requested to be considered for promotions in the organization

144. Has aspirations for management

Successful

145. Is committed to success $*$

146. Will do whatever it takes to be successful

147. Has shown the ability to be successful *

148. Shows potential *

149. Outperforms their colleagues

150. Has what it takes to be the best $*$

Friendly

151. Seems like someone who gets along with managers

152. Other leaders would like to spend time with this employee

153. Is a good example of the kind of friends I would like to make

154. Has an effective relationship with their supervisor *

155. Gets along with leaders *

\begin{tabular}{|c|c|c|}
\hline $\begin{array}{l}4.30 \\
(.90)\end{array}$ & $\begin{array}{l}4.05 \\
(.98)\end{array}$ & $\begin{array}{c}3.72 \\
(1.12)\end{array}$ \\
\hline & $\begin{array}{l}4.29 \\
(.84) \\
4.18 \\
(.89)\end{array}$ & $\begin{array}{c}3.55 \\
(1.15) \\
4.01 \\
(.99)\end{array}$ \\
\hline 3.94 & 4.07 & 3.70 \\
\hline$(1.08)$ & $(.96)$ & $(1.06)$ \\
\hline 4.34 & 4.53 & 3.88 \\
\hline$(.92)$ & $(.65)$ & $(1.01)$ \\
\hline $\begin{array}{c}3.77 \\
(1.05)\end{array}$ & $\begin{array}{c}3.84 \\
(1.02)\end{array}$ & $\begin{array}{c}3.55 \\
(1.12)\end{array}$ \\
\hline $\begin{array}{l}4.29 \\
(.97)\end{array}$ & $\begin{array}{l}4.31 \\
(.78)\end{array}$ & $\begin{array}{c}3.82 \\
(1.05)\end{array}$ \\
\hline 4.54 & 4.56 & 4.26 \\
\hline$(.62)$ & $\begin{array}{l}(.62) \\
4.10\end{array}$ & $\begin{array}{l}(.89) \\
3.40\end{array}$ \\
\hline & (1.01) & $(1.20)$ \\
\hline & 4.50 & 4.33 \\
\hline & $(.66)$ & $(.82)$ \\
\hline 4.55 & 4.46 & 4.36 \\
\hline (.69) & $(.71)$ & $(.80)$ \\
\hline & 4.08 & 3.87 \\
\hline & $(.90)$ & (.98) \\
\hline & 4.43 & 4.07 \\
\hline & $(.75)$ & $(.92)$ \\
\hline
\end{tabular}

$4.14 \quad 3.82$
$(.83)$

(.83) $\quad(.99)$

$4.33 \quad 3.64$

(.70) (1.07)

$\begin{array}{lll}3.94 & 3.83 & 3.36\end{array}$

(1.00) (1.12) (1.22)

$\begin{array}{lll}4.34 & 4.26 & 4.03\end{array}$

(.77) (.79) (.93)

$4.43 \quad 4.13$

(.71) (.90) 
Manager-Like

156. Seems like managers in the firm

157. Can work like managers

158. Values work as much as managers do *

Good Investment for

Organization

159. Worthwhile to invest in this employee *

160. Is the best person to get things done $*$

161. Is the best candidate for

162. Can maintain their level future *

Good Thinker

163. Uses reason to solve work problems *

164. Is a critical thinker*

165. Is resourceful $*$

166. Is "in-the-know" at work

167. Is rational (in Banihani

Team Player

168. Has credibility with peers $*$

169. Is a team player $*$

170. Gets along most easily

Learning-Oriented

171. Is open to criticism *

172. Seeks feedback

173. Uses feedback *

174. Learns from experience 


\begin{tabular}{|c|c|c|c|c|}
\hline \multicolumn{2}{|l|}{$\begin{array}{l}\text { 175. Seeks opportunities to } \\
\text { learn * }\end{array}$} & $\begin{array}{l}4.54 \\
(.62)\end{array}$ & $\begin{array}{l}4.53 \\
(.72)\end{array}$ & $\begin{array}{l}4.40 \\
(.79)\end{array}$ \\
\hline \multicolumn{5}{|l|}{ Integrity } \\
\hline \multicolumn{2}{|l|}{ 176. Acts with integrity } & $\begin{array}{l}4.56 \\
(.74)\end{array}$ & $\begin{array}{l}4.54 \\
(.68)\end{array}$ & $\begin{array}{c}3.25 \\
(1.07)\end{array}$ \\
\hline \multicolumn{5}{|l|}{ Adaptability } \\
\hline \multicolumn{2}{|l|}{ 177. Easily adapts to change * } & $\begin{array}{l}4.43 \\
(.73)\end{array}$ & $\begin{array}{l}4.44 \\
(.72)\end{array}$ & $\begin{array}{l}4.28 \\
(.82)\end{array}$ \\
\hline \multicolumn{2}{|l|}{$\begin{array}{l}\text { 178. Changes themselves to } \\
\text { fit in at work } \\
\text { (Banihani et al., 2013) }\end{array}$} & $\begin{array}{c}2.79 \\
(1.39)\end{array}$ & & \\
\hline \multicolumn{5}{|c|}{ Schein Descriptive Index } \\
\hline 179. Is selfish $* *$ & $\begin{array}{c}1.89 \\
(1.14)\end{array}$ & $\begin{array}{c}1.71 \\
(1.17)\end{array}$ & & \\
\hline $\begin{array}{l}\text { 180. Is skilled in business } \\
\text { matters * }\end{array}$ & $\begin{array}{l}4.28 \\
(.84)\end{array}$ & $\begin{array}{l}4.45 \\
(.76)\end{array}$ & $\begin{array}{l}4.43 \\
(.72)\end{array}$ & $\begin{array}{l}4.13 \\
(.86)\end{array}$ \\
\hline 181. Has high need for power & $\begin{array}{c}3.06 \\
(1.07)\end{array}$ & $\begin{array}{c}2.52 \\
(1.23)\end{array}$ & & \\
\hline $\begin{array}{l}\text { 182. Has speedy recovery } \\
\text { from emotional } \\
\text { disturbance }\end{array}$ & $\begin{array}{c}3.47 \\
(1.06)\end{array}$ & $\begin{array}{l}3.68 \\
(1.08)\end{array}$ & & \\
\hline 183. Is self-confident $*$ & $\begin{array}{l}4.31 \\
(.77)\end{array}$ & $\begin{array}{l}4.24 \\
(.78)\end{array}$ & $\begin{array}{l}4.56 \\
(.66)\end{array}$ & $\begin{array}{l}4.14 \\
(.87)\end{array}$ \\
\hline 184. Is modest & $\begin{array}{c}3.68 \\
(1.02)\end{array}$ & $\begin{array}{c}3.75 \\
(1.16)\end{array}$ & & \\
\hline 185. Is bitter $* *$ & $\begin{array}{c}1.93 \\
(1.19)\end{array}$ & $\begin{array}{c}1.74 \\
(1.20)\end{array}$ & & \\
\hline 186. Is independent $*$ & $\begin{array}{l}4.00 \\
(.87)\end{array}$ & $\begin{array}{c}4.03 \\
(1.08)\end{array}$ & $\begin{array}{l}4.04 \\
(.95)\end{array}$ & $\begin{array}{l}4.18 \\
(.85)\end{array}$ \\
\hline 187. Is sympathetic & $\begin{array}{l}3.96 \\
(.87)\end{array}$ & $\begin{array}{c}3.92 \\
(1.00)\end{array}$ & & \\
\hline $\begin{array}{l}\text { 188. Has high need for } \\
\text { autonomy }\end{array}$ & $\begin{array}{c}3.32 \\
(1.05)\end{array}$ & $\begin{array}{c}2.95 \\
(1.18)\end{array}$ & & \\
\hline 189. Is self-reliant & $\begin{array}{l}4.08 \\
(.90)\end{array}$ & $\begin{array}{c}3.92 \\
(1.08)\end{array}$ & & \\
\hline 190. Is shy & $\begin{array}{l}2.27 \\
(1.04)\end{array}$ & $\begin{array}{c}2.02 \\
(1.14)\end{array}$ & & \\
\hline 191. Is frank & $\begin{array}{l}3.21 \\
(1.10)\end{array}$ & $\begin{array}{c}3.11 \\
(1.06)\end{array}$ & & \\
\hline 192. Has leadership ability * & $\begin{array}{l}4.42 \\
(.76)\end{array}$ & $\begin{array}{l}4.57 \\
(.59)\end{array}$ & $\begin{array}{l}4.67 \\
(.56)\end{array}$ & $\begin{array}{l}4.38 \\
(.90)\end{array}$ \\
\hline 193. Is self-controlled $*$ & $\begin{array}{l}4.13 \\
(.88)\end{array}$ & $\begin{array}{c}4.07 \\
(1.02)\end{array}$ & $\begin{array}{l}4.40 \\
(.72)\end{array}$ & $\begin{array}{l}4.18 \\
(.87)\end{array}$ \\
\hline 194. Is devious & $\begin{array}{c}2.02 \\
(1.21)\end{array}$ & $\begin{array}{c}1.95 \\
(1.30)\end{array}$ & & \\
\hline
\end{tabular}




\begin{tabular}{|c|c|c|c|c|}
\hline 195. Is tactful & $\begin{array}{l}3.88 \\
(.97)\end{array}$ & $\begin{array}{c}3.83 \\
(1.13)\end{array}$ & & \\
\hline 196. Is firm & $\begin{array}{l}3.70 \\
(.96)\end{array}$ & $\begin{array}{c}3.62 \\
(1.17)\end{array}$ & & \\
\hline 197. Is cheerful & $\begin{array}{l}4.07 \\
(.83)\end{array}$ & $\begin{array}{l}4.10 \\
(.96)\end{array}$ & $\begin{array}{l}3.98 \\
(.92)\end{array}$ & $\begin{array}{c}3.74 \\
(1.02)\end{array}$ \\
\hline 198. Is forceful & $\begin{array}{c}2.79 \\
(1.20)\end{array}$ & $\begin{array}{c}2.44 \\
(1.17)\end{array}$ & & \\
\hline 199. Is assertive & $\begin{array}{l}3.84 \\
(.91)\end{array}$ & $\begin{array}{c}3.77 \\
(1.10)\end{array}$ & & \\
\hline 200. Is timid & $\begin{array}{c}2.23 \\
(1.14)\end{array}$ & $\begin{array}{c}2.10 \\
(1.11)\end{array}$ & & \\
\hline 201. Is prompt $*$ & $\begin{array}{l}4.11 \\
(.88)\end{array}$ & $\begin{array}{l}4.14 \\
(.88)\end{array}$ & $\begin{array}{l}4.33 \\
(.78)\end{array}$ & $\begin{array}{l}4.25 \\
(.92)\end{array}$ \\
\hline $\begin{array}{l}\text { 202. Is not uncomfortable } \\
\text { about being aggressive }\end{array}$ & $\begin{array}{c}3.10 \\
(1.08)\end{array}$ & $\begin{array}{l}3.00 \\
(1.19)\end{array}$ & & \\
\hline 203. Is courteous $*$ & $\begin{array}{l}4.19 \\
(.84)\end{array}$ & $\begin{array}{l}4.23 \\
(.95)\end{array}$ & $\begin{array}{l}4.14 \\
(.81)\end{array}$ & $\begin{array}{l}4.08 \\
(.92)\end{array}$ \\
\hline 204. Is easily influenced & $\begin{array}{c}2.70 \\
(1.16)\end{array}$ & $\begin{array}{c}2.44 \\
(1.12)\end{array}$ & & \\
\hline 205. Is intuitive * & $\begin{array}{l}4.09 \\
(.94)\end{array}$ & $\begin{array}{l}4.26 \\
(.84)\end{array}$ & $\begin{array}{l}4.41 \\
(.64)\end{array}$ & $\begin{array}{l}4.09 \\
(.89)\end{array}$ \\
\hline 206. Has humanitarian values & $\begin{array}{l}3.89 \\
(.98)\end{array}$ & $\begin{array}{c}3.81 \\
(1.00)\end{array}$ & & \\
\hline 207. Is grateful & $\begin{array}{l}4.14 \\
(.88)\end{array}$ & $\begin{array}{l}4.10 \\
(.89)\end{array}$ & $\begin{array}{l}4.24 \\
(.84)\end{array}$ & $\begin{array}{l}3.80 \\
(1.07)\end{array}$ \\
\hline 208. Has analytical ability $*$ & $\begin{array}{l}4.19 \\
(.84)\end{array}$ & $\begin{array}{l}4.16 \\
(.98)\end{array}$ & $\begin{array}{l}4.40 \\
(.70)\end{array}$ & $\begin{array}{l}4.20 \\
(.88)\end{array}$ \\
\hline 209. Is logical * & $\begin{array}{l}4.28 \\
(.80)\end{array}$ & $\begin{array}{l}4.38 \\
(.71)\end{array}$ & $\begin{array}{l}4.46 \\
(.68)\end{array}$ & $\begin{array}{l}4.29 \\
(.85)\end{array}$ \\
\hline 210. Is neat & $\begin{array}{l}4.00 \\
(.85)\end{array}$ & $\begin{array}{l}4.06 \\
(.94)\end{array}$ & $\begin{array}{c}3.73 \\
(1.03)\end{array}$ & $\begin{array}{c}3.54 \\
(1.09)\end{array}$ \\
\hline 211. Is hasty & $\begin{array}{c}2.27 \\
(1.14)\end{array}$ & $\begin{array}{c}2.21 \\
(1.30)\end{array}$ & & \\
\hline 212. Feelings not easily hurt & $\begin{array}{l}3.71 \\
(.99)\end{array}$ & $\begin{array}{c}3.81 \\
(1.05)\end{array}$ & & \\
\hline 213. Is creative * & $\begin{array}{l}4.22 \\
(.88)\end{array}$ & $\begin{array}{l}4.51 \\
(.74)\end{array}$ & $\begin{array}{l}4.26 \\
(.85)\end{array}$ & $\begin{array}{l}4.09 \\
(.89)\end{array}$ \\
\hline 214. Is sophisticated & $\begin{array}{l}3.93 \\
(.94)\end{array}$ & $\begin{array}{c}4.00 \\
(1.03)\end{array}$ & $\begin{array}{l}3.97 \\
(.94)\end{array}$ & $\begin{array}{c}3.27 \\
(1.13)\end{array}$ \\
\hline 215. Is adventurous & $\begin{array}{l}4.00 \\
(.84)\end{array}$ & $\begin{array}{l}3.97 \\
(.95)\end{array}$ & & \\
\hline 216. Is curious & $\begin{array}{l}4.03 \\
(.88)\end{array}$ & $\begin{array}{l}4.21 \\
(.83)\end{array}$ & $\begin{array}{l}4.12 \\
(.80)\end{array}$ & $\begin{array}{c}3.45 \\
(1.15)\end{array}$ \\
\hline 217. Is competitive & $\begin{array}{l}4.02 \\
(.85)\end{array}$ & $\begin{array}{l}4.17 \\
(.91)\end{array}$ & $\begin{array}{l}4.28 \\
(.84)\end{array}$ & $\begin{array}{c}3.50 \\
(1.09)\end{array}$ \\
\hline
\end{tabular}




\begin{tabular}{|c|c|c|c|c|}
\hline 218. Desires responsibility* & $\begin{array}{l}4.20 \\
(.86)\end{array}$ & $\begin{array}{l}4.16 \\
(.88)\end{array}$ & $\begin{array}{l}4.38 \\
(.75)\end{array}$ & $\begin{array}{l}4.16 \\
(.86)\end{array}$ \\
\hline 219. Is sentimental & $\begin{array}{c}3.28 \\
(1.05)\end{array}$ & $\begin{array}{c}3.41 \\
(1.04)\end{array}$ & & \\
\hline 220. Is ambitious * & $\begin{array}{l}4.37 \\
(.79)\end{array}$ & $\begin{array}{l}4.30 \\
(.93)\end{array}$ & $\begin{array}{l}4.53 \\
(.66)\end{array}$ & $\begin{array}{l}4.06 \\
(.94)\end{array}$ \\
\hline 221. Is steady * & $\begin{array}{l}4.03 \\
(.92)\end{array}$ & $\begin{array}{l}4.17 \\
(.91)\end{array}$ & $\begin{array}{l}4.17 \\
(.89)\end{array}$ & $\begin{array}{l}4.22 \\
(.82)\end{array}$ \\
\hline 222. Is uncertain & $\begin{array}{c}2.04 \\
(1.10)\end{array}$ & $\begin{array}{c}1.71 \\
(1.05)\end{array}$ & & \\
\hline 223. Is helpful * & $\begin{array}{l}4.36 \\
(.78)\end{array}$ & $\begin{array}{l}4.49 \\
(.67)\end{array}$ & $\begin{array}{l}4.32 \\
(.77)\end{array}$ & $\begin{array}{l}4.28 \\
(.84)\end{array}$ \\
\hline 224. Is intelligent* & $\begin{array}{l}4.40 \\
(.78)\end{array}$ & $\begin{array}{l}4.49 \\
(.76)\end{array}$ & $\begin{array}{l}4.45 \\
(.75)\end{array}$ & $\begin{array}{l}4.42 \\
(.75)\end{array}$ \\
\hline 225. Is persistent $*$ & $\begin{array}{l}4.09 \\
(.96)\end{array}$ & $\begin{array}{l}4.16 \\
(.89)\end{array}$ & $\begin{array}{l}4.39 \\
(.70)\end{array}$ & $\begin{array}{l}4.09 \\
(.95)\end{array}$ \\
\hline 226. Hides emotion & $\begin{array}{c}2.75 \\
(1.01)\end{array}$ & $\begin{array}{c}2.68 \\
(1.16)\end{array}$ & & \\
\hline 227. Is well informed $*$ & $\begin{array}{l}4.29 \\
(.78)\end{array}$ & $\begin{array}{l}4.42 \\
(.84)\end{array}$ & $\begin{array}{l}4.40 \\
(.73)\end{array}$ & $\begin{array}{l}4.29 \\
(.84)\end{array}$ \\
\hline 228. Is an exhibitionist & $\begin{array}{l}3.25 \\
(1.11)\end{array}$ & $\begin{array}{c}3.21 \\
(1.22)\end{array}$ & & \\
\hline 229. Is generous & $\begin{array}{l}4.08 \\
(.78)\end{array}$ & $\begin{array}{l}4.10 \\
(.98)\end{array}$ & $\begin{array}{l}4.00 \\
(.97)\end{array}$ & $\begin{array}{c}3.67 \\
(1.05)\end{array}$ \\
\hline 230. Is vulgar & $\begin{array}{c}1.97 \\
(1.23)\end{array}$ & $\begin{array}{c}1.71 \\
(1.10)\end{array}$ & & \\
\hline 231. Is understanding $*$ & $\begin{array}{l}4.33 \\
(.76)\end{array}$ & $\begin{array}{l}4.32 \\
(.80)\end{array}$ & $\begin{array}{l}4.32 \\
(.82)\end{array}$ & $\begin{array}{l}4.15 \\
(.91)\end{array}$ \\
\hline 232. Is consistent $*$ & $\begin{array}{l}4.26 \\
(.83)\end{array}$ & $\begin{array}{l}4.48 \\
(.69)\end{array}$ & $\begin{array}{l}4.48 \\
(.69)\end{array}$ & $\begin{array}{l}4.33 \\
(.85)\end{array}$ \\
\hline 233. Desires friendship & $\begin{array}{l}3.70 \\
(.92)\end{array}$ & $\begin{array}{c}3.49 \\
(1.06)\end{array}$ & & \\
\hline 234. Is decisive * & $\begin{array}{l}4.08 \\
(.88)\end{array}$ & $\begin{array}{c}4.21 \\
(1.01)\end{array}$ & $\begin{array}{l}4.43 \\
(.75)\end{array}$ & $\begin{array}{l}4.14 \\
(.94)\end{array}$ \\
\hline 235. Is authoritative & $\begin{array}{l}3.66 \\
(.98)\end{array}$ & $\begin{array}{c}3.45 \\
(1.16)\end{array}$ & & \\
\hline $\begin{array}{l}\text { 236. Is able to separate } \\
\text { feelings from ideas }\end{array}$ & $\begin{array}{l}4.10 \\
(.86)\end{array}$ & $\begin{array}{l}3.97 \\
(.91)\end{array}$ & & \\
\hline 237. Is dominant & $\begin{array}{c}3.20 \\
(1.08)\end{array}$ & $\begin{array}{c}3.14 \\
(1.01)\end{array}$ & & \\
\hline $\begin{array}{l}\text { 238. Has a strong need for } \\
\text { social acceptance }\end{array}$ & $\begin{array}{c}2.89 \\
(1.04)\end{array}$ & $\begin{array}{l}2.37 \\
(1.27)\end{array}$ & & \\
\hline 239. Is direct & $\begin{array}{l}4.01 \\
(.87)\end{array}$ & $\begin{array}{l}4.02 \\
(.84)\end{array}$ & $\begin{array}{l}4.26 \\
(.77)\end{array}$ & $\begin{array}{l}3.88 \\
(.95)\end{array}$ \\
\hline $\begin{array}{l}\text { 240. Has a strong need for } \\
\text { monetary awards }\end{array}$ & $\begin{array}{c}2.92 \\
(1.08)\end{array}$ & $\begin{array}{c}2.54 \\
(1.20)\end{array}$ & & \\
\hline
\end{tabular}




\begin{tabular}{|c|c|c|c|c|}
\hline $\begin{array}{l}\text { 241. Values pleasant } \\
\text { surroundings }\end{array}$ & $\begin{array}{l}3.84 \\
(.86)\end{array}$ & $\begin{array}{c}3.66 \\
(1.14)\end{array}$ & & \\
\hline $\begin{array}{l}\text { 242. Aggressive (in Banihani } \\
\text { et al., 2013) }\end{array}$ & $\begin{array}{c}2.59 \\
(1.21)\end{array}$ & $\begin{array}{c}2.70 \\
(1.13)\end{array}$ & & \\
\hline 243. Is emotionally stable * & $\begin{array}{l}4.10 \\
(.83)\end{array}$ & $\begin{array}{l}4.37 \\
(.93)\end{array}$ & $\begin{array}{l}4.41 \\
(.76)\end{array}$ & $\begin{array}{l}4.28 \\
(.86)\end{array}$ \\
\hline 244. Is submissive & $\begin{array}{l}2.45 \\
(1.13)\end{array}$ & $\begin{array}{l}2.05 \\
(1.14)\end{array}$ & & \\
\hline 245. Is demure & $\begin{array}{c}2.79 \\
(1.13)\end{array}$ & $\begin{array}{l}2.56 \\
(1.13)\end{array}$ & & \\
\hline $\begin{array}{l}\text { 246. Is a dawdler and } \\
\text { procrastinator } * *\end{array}$ & $\begin{array}{l}1.93 \\
(1.24)\end{array}$ & $\begin{array}{c}1.74 \\
(1.25)\end{array}$ & & \\
\hline $\begin{array}{l}\text { 247. Knows the ways of the } \\
\text { world }\end{array}$ & $\begin{array}{l}4.00 \\
(.92)\end{array}$ & $\begin{array}{l}4.10 \\
(.78)\end{array}$ & $\begin{array}{l}3.96 \\
(.91)\end{array}$ & $\begin{array}{c}3.50 \\
(1.07)\end{array}$ \\
\hline 248. Is reserved & $\begin{array}{c}2.82 \\
(1.15)\end{array}$ & $\begin{array}{c}2.67 \\
(1.16)\end{array}$ & & \\
\hline $\begin{array}{l}\text { 249. Is interested in their own } \\
\text { appearance }\end{array}$ & $\begin{array}{c}3.22 \\
(1.06)\end{array}$ & $\begin{array}{l}3.03 \\
(1.34)\end{array}$ & & \\
\hline 250. Is obedient & $\begin{array}{l}3.74 \\
(.96)\end{array}$ & $\begin{array}{l}3.73 \\
(1.08)\end{array}$ & & \\
\hline 251. Is competent $*$ & $\begin{array}{l}4.17 \\
(.85)\end{array}$ & $\begin{array}{l}4.11 \\
(.95)\end{array}$ & $\begin{array}{l}4.42 \\
(.75)\end{array}$ & $\begin{array}{l}4.50 \\
(.86)\end{array}$ \\
\hline $\begin{array}{l}\text { 252. Has a strong need for } \\
\text { security }\end{array}$ & $\begin{array}{c}3.31 \\
(1.07)\end{array}$ & $\begin{array}{c}2.78 \\
(1.08)\end{array}$ & & \\
\hline 253. Is vigorous & $\begin{array}{c}3.32 \\
(1.14)\end{array}$ & $\begin{array}{c}3.52 \\
(1.28)\end{array}$ & & \\
\hline 254. Is deceitful & $\begin{array}{c}2.07 \\
(1.30)\end{array}$ & $\begin{array}{c}2.02 \\
(1.36)\end{array}$ & & \\
\hline $\begin{array}{l}\text { 255. Is not conceited about } \\
\text { their appearance }\end{array}$ & $\begin{array}{l}3.33 \\
(1.09)\end{array}$ & $\begin{array}{c}3.43 \\
(1.28)\end{array}$ & & \\
\hline 256. Is objective & $\begin{array}{l}3.86 \\
(.89)\end{array}$ & $\begin{array}{c}3.92 \\
(1.04)\end{array}$ & & \\
\hline 257. Is sociable & $\begin{array}{l}4.09 \\
(.83)\end{array}$ & $\begin{array}{l}4.17 \\
(.85)\end{array}$ & $\begin{array}{l}4.39 \\
(.73)\end{array}$ & $\begin{array}{l}3.70 \\
(.97)\end{array}$ \\
\hline $\begin{array}{l}\text { 258. Has a high need for } \\
\text { achievement }\end{array}$ & $\begin{array}{l}4.06 \\
(.94)\end{array}$ & $\begin{array}{l}4.08 \\
(.95)\end{array}$ & $\begin{array}{l}4.43 \\
(.73)\end{array}$ & $\begin{array}{c}3.69 \\
(1.06)\end{array}$ \\
\hline 259. Is fearful & $\begin{array}{c}2.15 \\
(1.17)\end{array}$ & $\begin{array}{l}1.89 \\
(1.15)\end{array}$ & & \\
\hline 260. Is frivolous & $\begin{array}{l}2.66 \\
(1.17)\end{array}$ & $\begin{array}{l}2.71 \\
(1.35)\end{array}$ & & \\
\hline 261. Wavers in decisions & $\begin{array}{l}2.49 \\
(1.21)\end{array}$ & $\begin{array}{l}2.44 \\
(1.22)\end{array}$ & & \\
\hline 262. Is talkative & $\begin{array}{c}3.51 \\
(1.02)\end{array}$ & $\begin{array}{l}3.35 \\
(1.02)\end{array}$ & & \\
\hline $\begin{array}{l}\text { 263. Aware of the feelings of } \\
\text { others * }\end{array}$ & $\begin{array}{l}4.18 \\
(.80)\end{array}$ & $\begin{array}{l}4.24 \\
(.73)\end{array}$ & $\begin{array}{l}4.20 \\
(.89)\end{array}$ & $\begin{array}{l}4.09 \\
(.88)\end{array}$ \\
\hline
\end{tabular}




\begin{tabular}{|c|c|c|c|c|}
\hline 264. Is industrious & $\begin{array}{c}3.74 \\
(1.03)\end{array}$ & $\begin{array}{c}3.68 \\
(1.04)\end{array}$ & & \\
\hline 265. Has high self-regard & $\begin{array}{c}3.61 \\
(1.09)\end{array}$ & $\begin{array}{c}3.48 \\
(1.26)\end{array}$ & & \\
\hline 266. Is passive & $\begin{array}{c}2.45 \\
(1.21)\end{array}$ & $\begin{array}{c}2.33 \\
(1.30)\end{array}$ & & \\
\hline 267. Is nervous & $\begin{array}{c}2.20 \\
(1.09)\end{array}$ & $\begin{array}{l}1.90 \\
(.98)\end{array}$ & & \\
\hline 268. Is kind & $\begin{array}{l}4.21 \\
(.83)\end{array}$ & $\begin{array}{l}4.37 \\
(.81)\end{array}$ & $\begin{array}{c}4.08 \\
(1.04)\end{array}$ & $\begin{array}{l}3.98 \\
(.96)\end{array}$ \\
\hline $\begin{array}{l}\text { 269. Has desire to avoid } \\
\text { controversy }\end{array}$ & $\begin{array}{c}3.26 \\
(1.13)\end{array}$ & $\begin{array}{l}3.10 \\
(1.16)\end{array}$ & & \\
\hline 270. Is quarrelsome & $\begin{array}{c}2.38 \\
(1.24)\end{array}$ & $\begin{array}{l}2.39 \\
(1.31)\end{array}$ & & \\
\hline 271. Is compassionate & $\begin{array}{l}4.20 \\
(.85)\end{array}$ & $\begin{array}{l}4.34 \\
(.81)\end{array}$ & $\begin{array}{l}4.11 \\
(.93)\end{array}$ & $\begin{array}{c}3.94 \\
(1.00)\end{array}$ \\
\hline 272. Is cooperative * & $\begin{array}{l}4.33 \\
(.81)\end{array}$ & $\begin{array}{l}4.33 \\
(.88)\end{array}$ & $\begin{array}{l}4.42 \\
(.75)\end{array}$ & $\begin{array}{l}4.29 \\
(.88)\end{array}$ \\
\hline 273. Is fair & $\begin{array}{l}4.20 \\
(.89)\end{array}$ & $\begin{array}{l}4.24 \\
(.94)\end{array}$ & $\begin{array}{l}4.24 \\
(.88)\end{array}$ & $\begin{array}{c}3.87 \\
(1.03)\end{array}$ \\
\hline 274. Is a good listener * & $\begin{array}{l}4.32 \\
(.82)\end{array}$ & $\begin{array}{l}4.59 \\
(.96)\end{array}$ & $\begin{array}{l}4.50 \\
(.68)\end{array}$ & $\begin{array}{l}4.30 \\
(.84)\end{array}$ \\
\hline 275. Is inclusive & $\begin{array}{c}4.01 \\
(1.03)\end{array}$ & $\begin{array}{c}3.92 \\
(1.12)\end{array}$ & & \\
\hline 276. Shows appreciation & $\begin{array}{l}4.25 \\
(.81)\end{array}$ & $\begin{array}{l}4.43 \\
(.73)\end{array}$ & $\begin{array}{l}4.37 \\
(.76)\end{array}$ & $\begin{array}{c}3.99 \\
(1.00)\end{array}$ \\
\hline $\begin{array}{l}\text { 277. Attends to the needs of } \\
\text { others }\end{array}$ & $\begin{array}{l}4.00 \\
(.88)\end{array}$ & $\begin{array}{l}4.05 \\
(.91)\end{array}$ & $\begin{array}{l}4.09 \\
(.87)\end{array}$ & $\begin{array}{l}3.96 \\
(.93)\end{array}$ \\
\hline 278. Is considerate $*$ & $\begin{array}{l}4.31 \\
(.75)\end{array}$ & $\begin{array}{l}4.40 \\
(.71)\end{array}$ & $\begin{array}{l}4.20 \\
(.88)\end{array}$ & $\begin{array}{l}4.11 \\
(.93)\end{array}$ \\
\hline 279. Considers others' ideas * & $\begin{array}{l}4.33 \\
(.79)\end{array}$ & $\begin{array}{l}4.29 \\
(.87)\end{array}$ & $\begin{array}{l}4.42 \\
(.69)\end{array}$ & $\begin{array}{l}4.25 \\
(.88)\end{array}$ \\
\hline 280. Is encouraging * & $\begin{array}{l}4.35 \\
(.77)\end{array}$ & $\begin{array}{l}4.49 \\
(.64)\end{array}$ & $\begin{array}{l}4.42 \\
(.72)\end{array}$ & $\begin{array}{l}4.18 \\
(.86)\end{array}$ \\
\hline 281. Is energetic & $\begin{array}{l}4.20 \\
(.84)\end{array}$ & $\begin{array}{l}4.35 \\
(.68)\end{array}$ & $\begin{array}{l}4.33 \\
(.72)\end{array}$ & $\begin{array}{l}3.88 \\
(.94)\end{array}$ \\
\hline 282. Is enthusiastic * & $\begin{array}{l}4.24 \\
(.80)\end{array}$ & $\begin{array}{l}4.43 \\
(.71)\end{array}$ & $\begin{array}{l}4.38 \\
(.74)\end{array}$ & $\begin{array}{l}4.03 \\
(.94)\end{array}$ \\
\hline 283. Is inspiring * & $\begin{array}{l}4.24 \\
(.76)\end{array}$ & $\begin{array}{l}4.40 \\
(.79)\end{array}$ & $\begin{array}{l}4.37 \\
(.73)\end{array}$ & $\begin{array}{l}4.02 \\
(.97)\end{array}$ \\
\hline 284. Is open-minded $*$ & $\begin{array}{l}4.38 \\
(.78)\end{array}$ & $\begin{array}{l}4.41 \\
(.73)\end{array}$ & $\begin{array}{l}4.41 \\
(.74)\end{array}$ & $\begin{array}{l}4.29 \\
(.83)\end{array}$ \\
\hline 285. Is optimistic $*$ & $\begin{array}{l}4.27 \\
(.85)\end{array}$ & $\begin{array}{l}4.35 \\
(.74)\end{array}$ & $\begin{array}{l}4.33 \\
(.82)\end{array}$ & $\begin{array}{l}4.07 \\
(.92)\end{array}$ \\
\hline 286. Has a sense of purpose $*$ & $\begin{array}{l}4.28 \\
(.77)\end{array}$ & $\begin{array}{l}4.30 \\
(.80)\end{array}$ & $\begin{array}{l}4.43 \\
(.68)\end{array}$ & $\begin{array}{l}4.11 \\
(.88)\end{array}$ \\
\hline
\end{tabular}


287. Is sincere *

288. Is supportive *

289. Is trustworthy
$4.14 \quad 4.40$

(.87) (.74)

$\begin{array}{ll}4.31 & 4.40\end{array}$

(.76)

4.41

(.79)
(.74)

4.57

(.86)
4.17

(.91)

4.31

(.80)

4.63

(.64)
4.25

(.88)

4.19

(.90)

3.67

(.98)

*Signifies that the item met the requirement of mean $\geq 4.0$ (Very characteristic of an ideal worker) across all data collections

$* *$ Signifies that the item met the requirement of mean $\leq 2.0$ (Very uncharacteristic of an ideal worker) across all data collections 


\section{Appendix II: Research Question 2 Survey (Sample 4)}

\section{Comparing the Attributes of a Promotable Ideal Worker to Gender Role Stereotypes}

One of the responsibilities of a supervisor is to make promotion decisions. Promotions include moving up to leadership roles with more responsibilities that also allow development of competencies important for executive success (i.e., at much higher levels of the organization). Leaders use promotions to reward employees for good work, and to develop and grow high-potential employees that can serve in the highest levels of the firm.

Despite a lot of research on promotions, scientists know little about what managers look for in employees whose career trajectories they would like to support through promotions within the organization. If you were a manager who made promotion decisions, what characteristics would you look for in an employee you want to support and develop by promoting them to another position?

\section{Ideal Worker Attributes}

Please rate what you think an employee you would like to promote is like on the following attributes, where 1 means "Extremely uncharacteristic of an employee I would like to promote" and 5 means "Extremely characteristic of an employee I would like to promote."

[Participants did not see the headings in bold. Items were randomly ordered.]

\begin{tabular}{|c|c|c|c|c|c|}
\hline & $\begin{array}{c}1=\text { Not at All } \\
\text { Characteristic } \\
\text { of an } \\
\text { Employee I } \\
\text { Would Like to } \\
\text { Promote }\end{array}$ & $\begin{array}{c}2=\text { Slightly } \\
\text { Characteristic } \\
\text { of an } \\
\text { Employee I } \\
\text { Would Like to } \\
\text { Promote }\end{array}$ & $\begin{array}{c}3= \\
\text { Moderately } \\
\text { Characteristic } \\
\text { of an } \\
\text { Employee I } \\
\text { Would Like to } \\
\text { Promote }\end{array}$ & $\begin{array}{c}4=\text { Very } \\
\text { Characteristic } \\
\text { of an } \\
\text { Employee I } \\
\text { Would Like to } \\
\text { Promote }\end{array}$ & $\begin{array}{c}5=\text { Extremely } \\
\text { Characteristic } \\
\text { of an } \\
\text { Employee I } \\
\text { Would Like to } \\
\text { Promote }\end{array}$ \\
\hline $\begin{array}{l}\text { Relationship to } \\
\text { Organization }\end{array}$ & & & & & \\
\hline $\begin{array}{l}\text { 1. Shows loyalty } \\
\text { toward their } \\
\text { organization }\end{array}$ & & & & & \\
\hline $\begin{array}{l}\text { 2. Cares about the } \\
\text { fate of the } \\
\text { organization }\end{array}$ & & & & & \\
\hline $\begin{array}{l}\text { 3. Has goals and } \\
\text { values consistent } \\
\text { with those of } \\
\text { their organization }\end{array}$ & & & & & \\
\hline $\begin{array}{l}\text { 4. Values work as } \\
\text { much as others } \\
\text { do in the } \\
\text { organization }\end{array}$ & & & & & \\
\hline
\end{tabular}




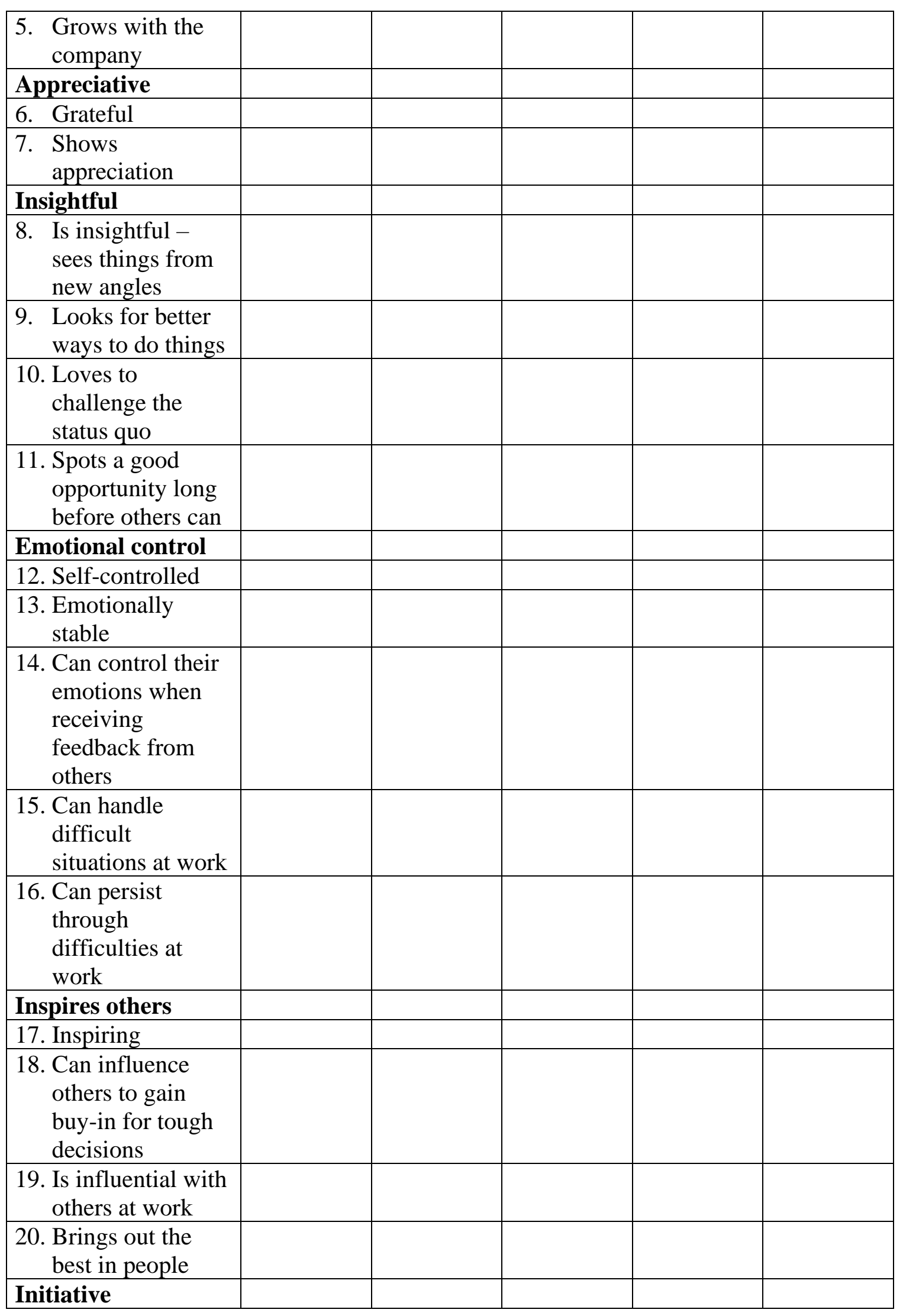




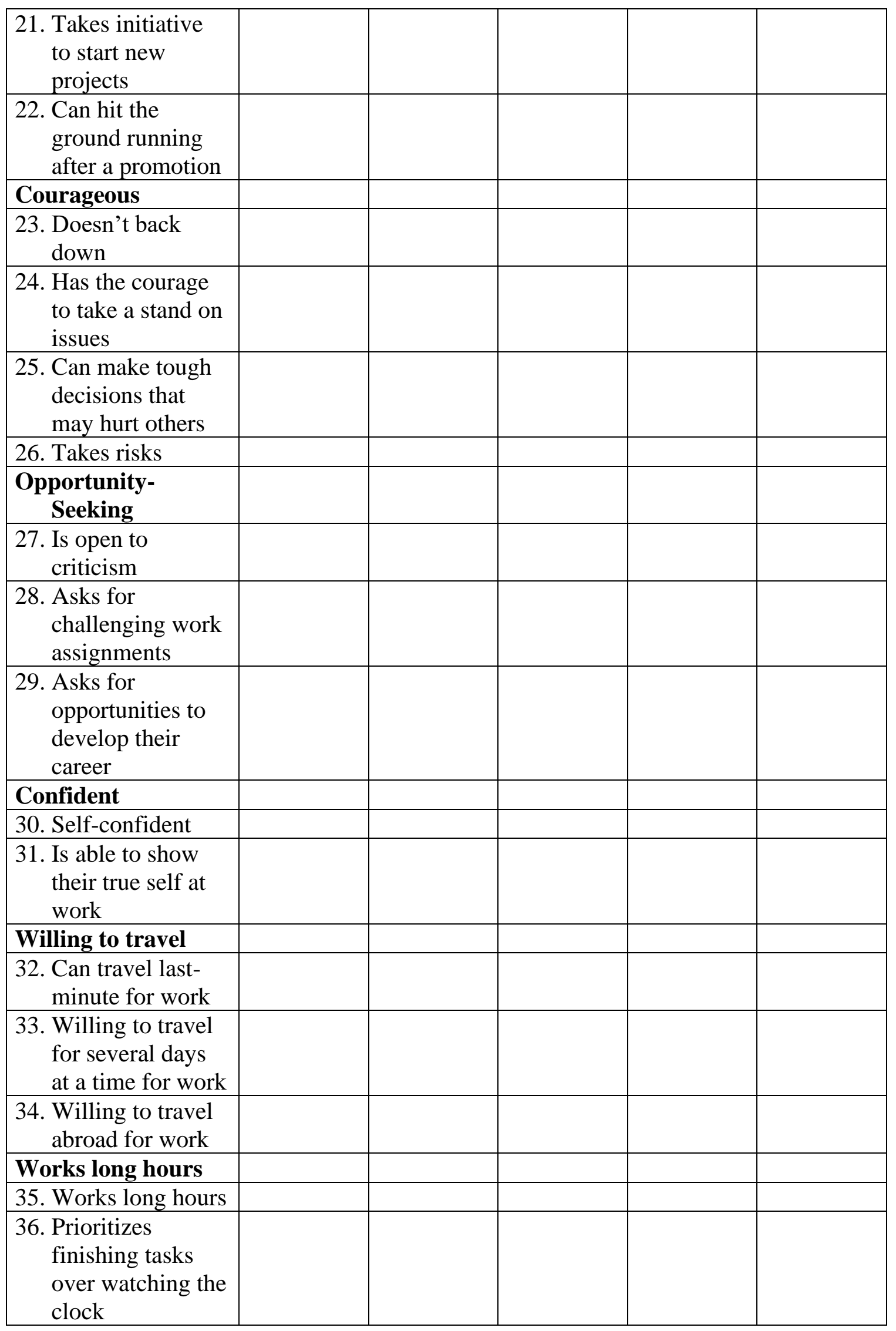




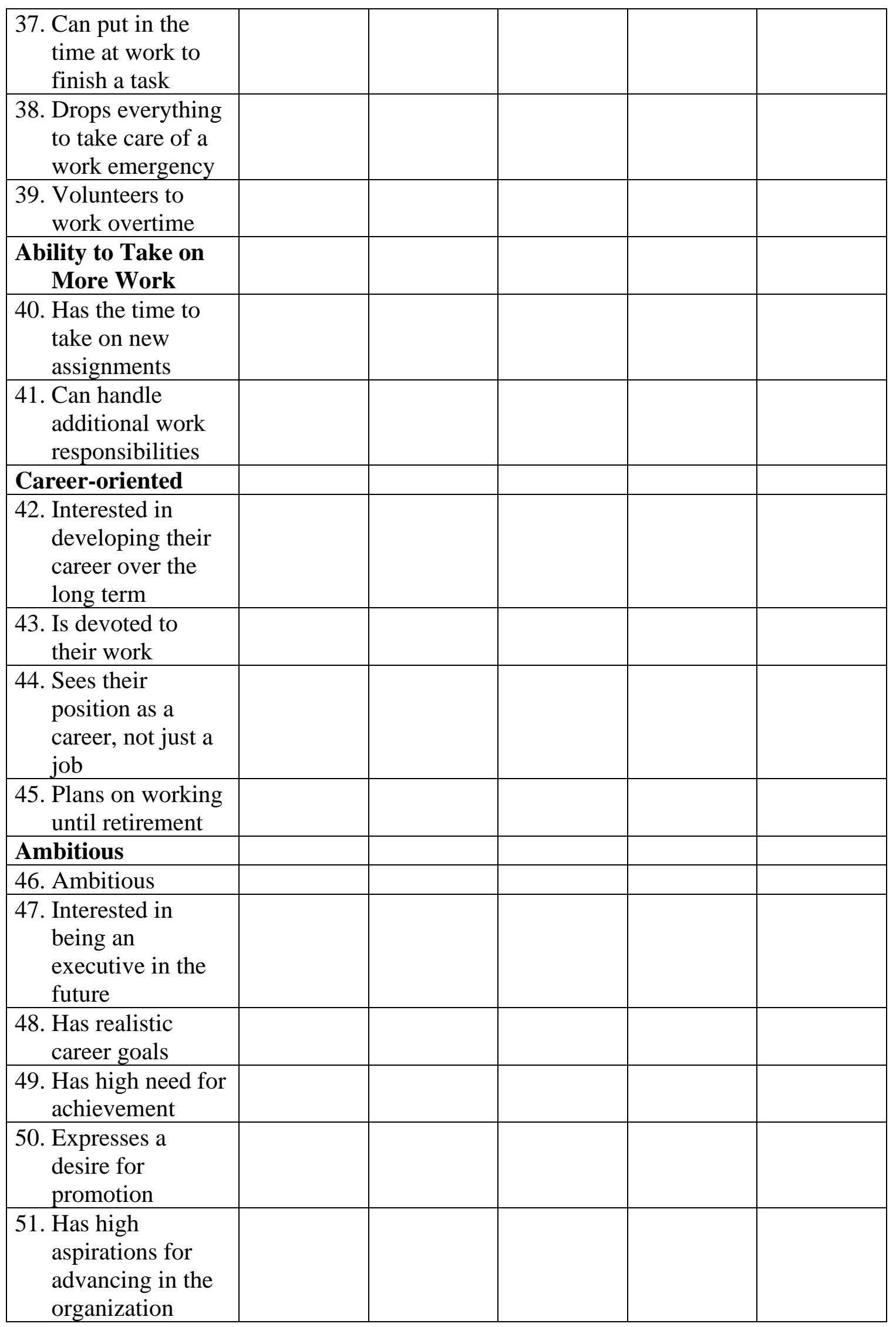




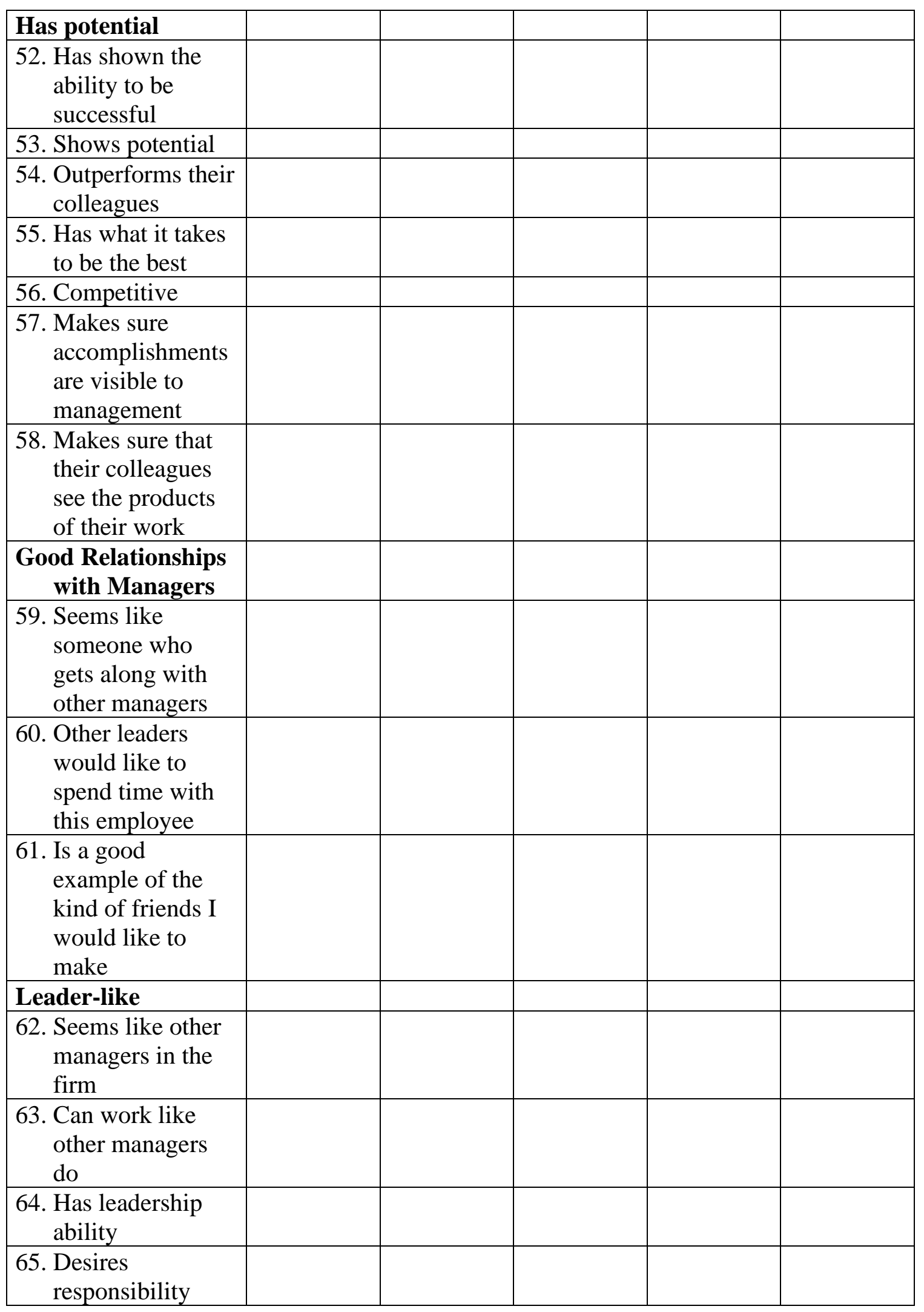




\begin{tabular}{|l|l|l|l|l|l|}
\hline $\begin{array}{l}\text { 66. Values work as } \\
\text { much as other } \\
\text { managers do }\end{array}$ & & & & & \\
\hline Best Choice & & & & & \\
\hline $\begin{array}{l}\text { 67. Worthwhile to } \\
\text { invest in this } \\
\text { employee }\end{array}$ & & & & & \\
\hline $\begin{array}{l}\text { 68. Is the best person } \\
\text { to get things done }\end{array}$ & & & & & \\
\hline $\begin{array}{l}\text { 69. Is the best } \\
\text { candidate for } \\
\text { management }\end{array}$ & & & & & \\
\hline
\end{tabular}

\section{Typical Man Attributes Measure}

Please rate what you think a typical man is like on the following attributes, where 1 means "Extremely uncharacteristic" and 5 means "Extremely characteristic of a typical man."

[Participants rated the typical man on the same items as listed above for the ideal worker.]

\section{Typical Woman Attributes Measure}

Please rate what you think a typical woman is like on the following attributes, where 1 means "Extremely uncharacteristic" and 5 means "Extremely characteristic of a typical woman."

[Participants rated the typical woman on the same items as listed above for the ideal worker.]

\section{Demographic Information}

We would like to know a little bit more about you. The questions below will be used to classify your responses; your answers to these questions will be kept confidential and will be used only for classification.

What is your gender? [Male, Female, Other]

What is your age (in years)?

What is your race? Please select all that apply. [American Indian or Alaska Native,

Asian, Black or African American, Hispanic, Native Hawaiian or Other Pacific Islander, White]

What is your highest level of education? [Less than a high school diploma, High school degree or equivalent (e.g., GED), Some college but no degree, Associate degree, Bachelor degree, Master degree, Professional degree, Doctorate]

What is your marital status? [Single, Married or in a domestic partnership, Widowed, or Divorced, Separated]

How much work experience do you have in years?

Do you have any leadership experience at work? Yes No 
Appendix IV: Research Question 2 Results for Ideal Worker Item Ratings

\begin{tabular}{|c|c|c|c|c|}
\hline \multirow[b]{2}{*}{ Item } & \multicolumn{2}{|c|}{ Sample 3 (Students) } & \multicolumn{2}{|c|}{ Sample 4 (Employees) } \\
\hline & $\begin{array}{l}\text { Mean Male } \\
\text { Participants } \\
(\mathrm{n}=126)\end{array}$ & $\begin{array}{c}\text { Mean } \\
\text { Female } \\
\text { Participants } \\
(\mathrm{n}=112)\end{array}$ & $\begin{array}{l}\text { Mean Male } \\
\text { Participants } \\
(\mathrm{n}=113)\end{array}$ & $\begin{array}{c}\text { Mean } \\
\text { Female } \\
\text { Participants } \\
(\mathrm{n}=205)\end{array}$ \\
\hline $\begin{array}{l}\text { 1. Shows loyalty } \\
\text { toward the } \\
\text { organization }\end{array}$ & $4.40(.72)$ & $4.57(.65)$ & $3.95(.99)$ & $4.21(.88)$ \\
\hline $\begin{array}{l}\text { 2. Cares about the fate } \\
\text { of the organization }\end{array}$ & $4.45(.70)$ & $4.66(.53)$ & $4.18(.90)$ & $4.29(.80)$ \\
\hline $\begin{array}{l}\text { 3. Has goals and values } \\
\text { consistent with those } \\
\text { of their organization }\end{array}$ & $4.37(.72)^{*}$ & $4.70(.52)$ & $4.11(.89)$ & $4.30(.80)$ \\
\hline $\begin{array}{l}\text { 4. Values work as } \\
\text { much as others do in } \\
\text { the organization }\end{array}$ & $4.19(.84)$ & $4.36(.80)$ & $4.00(1.00)$ & $4.07(.91)$ \\
\hline $\begin{array}{l}\text { 5. Grows with the } \\
\text { company }\end{array}$ & $4.37(.76)$ & $4.64(.57)$ & $4.13(.84)$ & $4.18(.89)$ \\
\hline $\begin{array}{l}\text { 6. Desires to stay with } \\
\text { their organization }\end{array}$ & $4.28(.85)$ & $4.40(.74)$ & $4.04(.95)$ & $4.14(.99)$ \\
\hline $\begin{array}{l}\text { 7. Views the } \\
\text { organization's } \\
\text { problems as their } \\
\text { own }\end{array}$ & $4.11(.83)$ & $4.13(.87)$ & $3.76(.103)$ & $3.71(.96)$ \\
\hline $\begin{array}{l}\text { 8. Can travel last- } \\
\text { minute for work }\end{array}$ & $3.50(1.10)$ & $3.37(1.07)$ & $3.19(1.18)$ & $2.90(1.23)$ \\
\hline $\begin{array}{l}\text { 9. Is willing to travel } \\
\text { for several days at a } \\
\text { time for work }\end{array}$ & $3.56(1.08)$ & $3.66(1.01)$ & $3.14(1.19)$ & $2.95(1.22)$ \\
\hline $\begin{array}{l}\text { 10. Is willing to travel } \\
\text { abroad for work }\end{array}$ & $3.55(1.05)$ & $3.63(1.03)$ & $3.05(1.23)$ & $2.73(1.22)$ \\
\hline $\begin{array}{l}\text { 11. Is willing to travel } \\
\text { long distances for } \\
\text { work }\end{array}$ & $3.47(1.04)$ & $3.58(1.09)$ & $3.12(1.23)$ & $2.89(1.23)$ \\
\hline $\begin{array}{l}\text { 12. Is willing to travel } \\
\text { for work }\end{array}$ & $3.62(1.07)$ & $3.69(1.01)$ & $3.29(1.19)$ & $3.17(1.23)$ \\
\hline $\begin{array}{l}\text { 13. Is willing to travel } \\
\text { internationally for } \\
\text { work }\end{array}$ & $3.48(1.11)$ & $3.48(1.04)$ & $2.98(1.23)$ & $2.71(1.23)$ \\
\hline $\begin{array}{l}\text { 14. Is available to travel } \\
\text { at any time for work }\end{array}$ & $3.60(1.07)$ & $3.55(.99)$ & $3.15(1.15)$ & $2.86(1.24)$ \\
\hline 15. Works long hours & $3.69(.97)$ & $3.54(1.04)$ & $3.19(1.18)$ & $3.10(1.19)$ \\
\hline
\end{tabular}




\begin{tabular}{|c|c|c|c|c|}
\hline $\begin{array}{l}\text { 16. Prioritizes finishing } \\
\text { tasks over watching } \\
\text { the clock }\end{array}$ & $4.33(.84)$ & $4.29(.92)$ & $4.10(1.07)$ & $4.20(.94)$ \\
\hline $\begin{array}{l}\text { 17. Can put in the time } \\
\text { at work to finish a } \\
\text { task }\end{array}$ & $4.29(.67)$ & $4.53(.64)$ & $4.20(.86)$ & $4.07(.90)$ \\
\hline $\begin{array}{l}\text { 18. Drops everything to } \\
\text { take care of a work } \\
\text { emergency }\end{array}$ & $3.56(1.05)$ & $3.67(1.03)$ & $3.53(1.13)$ & $3.58(1.14)$ \\
\hline $\begin{array}{l}\text { 19. Volunteers to work } \\
\text { overtime }\end{array}$ & $3.71(1.11)$ & $3.81(.99)$ & $3.35(1.16)$ & $3.30(1.16)$ \\
\hline $\begin{array}{l}\text { 20. Works on weekends } \\
\text { to accomplish work } \\
\text { tasks }\end{array}$ & $3.80(1.03)$ & $3.60(1.08)$ & $3.11(1.26)$ & $2.95(1.20)$ \\
\hline $\begin{array}{l}\text { 21. Works before or } \\
\text { after regular work } \\
\text { hours to finish a task }\end{array}$ & $4.00(.92)$ & $3.77(1.07)$ & $3.40(1.21)$ & 3.39 (1.19) \\
\hline $\begin{array}{l}\text { 22. Works beyond } \\
\text { regular work hours }\end{array}$ & $3.87(1.00)$ & $3.71(1.07)$ & $3.37(1.14)$ & $3.19(1.19)$ \\
\hline $\begin{array}{l}\text { 23. Comes to work } \\
\text { before the boss and } \\
\text { leaves after the boss }\end{array}$ & $3.50(1.23)$ & $3.40(1.19)$ & $2.93(1.28)$ & $2.89(1.28)$ \\
\hline $\begin{array}{l}\text { 24. Exerts high levels of } \\
\text { effort at work }\end{array}$ & $4.48(.65)$ & $4.69(.60)$ & $4.19(.85)$ & $4.20(.92)$ \\
\hline $\begin{array}{l}\text { 25. Is fully engaged at } \\
\text { work }\end{array}$ & $4.45(.62)$ & $4.50(.65)$ & $4.31(.83)$ & $4.38(.85)$ \\
\hline $\begin{array}{l}\text { 26. Has a sense of } \\
\text { purpose }\end{array}$ & $4.42(.61)$ & $4.39(.75)$ & $4.12(.84)$ & $4.10(.90)$ \\
\hline $\begin{array}{l}\text { 27. Experiences } \\
\text { meaningfulness from } \\
\text { their work }\end{array}$ & $4.25(.81)$ & $4.45(.72)$ & $3.80(1.05)$ & $4.00(.89)$ \\
\hline $\begin{array}{l}\text { 28. Is passionate about } \\
\text { their work }\end{array}$ & $4.52(.69)$ & $4.75(.48)$ & $4.19(.96)$ & $4.26(.87)$ \\
\hline $\begin{array}{l}\text { 29. Is committed to their } \\
\text { work }\end{array}$ & $4.47(.62)$ & $4.59(.62)$ & $4.25(.89)$ & $4.31(.82)$ \\
\hline $\begin{array}{l}\text { 30. Shows loyalty } \\
\text { toward their work }\end{array}$ & $4.40(.67)$ & $4.51(.62)$ & $4.10(1.01)$ & $4.22(.82)$ \\
\hline $\begin{array}{l}\text { 31. Is visibly busy at } \\
\text { work }\end{array}$ & $3.75(.93)$ & $3.67(1.09)$ & $3.48(1.23)$ & $3.66(1.12)$ \\
\hline 32. Is grateful & 4.15 & 4.29 & $3.73(1$ & $3.83(1.04)$ \\
\hline 33. Shows appreciation & $4.25(.84)$ & $4.49(.71)$ & $3.89(1.00)$ & $4.05(.99)$ \\
\hline $\begin{array}{l}\text { 34. Is insightful - sees } \\
\text { things from new } \\
\text { angles }\end{array}$ & $4.37(.70)$ & $4.57(.69)$ & $4.26(.87)$ & $4.23(.87)$ \\
\hline $\begin{array}{l}\text { 35. Looks for better } \\
\text { ways to do things }\end{array}$ & $4.55(.57)$ & $4.56(.57)$ & $4.27(.84)$ & $4.20(.85)$ \\
\hline
\end{tabular}




\begin{tabular}{|c|c|c|c|c|}
\hline $\begin{array}{l}\text { 36. Loves to challenge } \\
\text { the status quo }\end{array}$ & $3.94(.90)$ & $3.94(.91)$ & $3.28(1.13)$ & $3.27(1.11)$ \\
\hline $\begin{array}{l}\text { 37. Spots a good } \\
\text { opportunity long } \\
\text { before others can }\end{array}$ & $4.30(.81)$ & $4.27(.94)$ & $3.88(1.02)$ & $3.86(1.01)$ \\
\hline $\begin{array}{l}\text { 38. Identifies } \\
\text { opportunities }\end{array}$ & $4.36(.70)$ & $4.61(.54)$ & $4.12(.94)$ & $4.16(.85)$ \\
\hline 39. Is open-minded & $4.33(.76)$ & $4.46(.77)$ & $4.28(.85)$ & $4.29(.82)$ \\
\hline 40. Is creative & $4.25(.89)$ & $4.25(.82)$ & $4.00(.99)$ & $4.14(.84)$ \\
\hline 41. Is self-controlled & $4.30(.77)$ & $4.48(.68)$ & $4.16(.87)$ & $4.19(.87)$ \\
\hline 42. Is emotionally stable & $4.39(.80)$ & $4.38(.71)$ & $4.27(.95)$ & $4.29(.81)$ \\
\hline $\begin{array}{l}\text { 43. Can control their } \\
\text { emotions when } \\
\text { receiving feedback } \\
\text { from others }\end{array}$ & $4.44(.65)$ & $4.53(.63)$ & $4.12(.99)$ & $4.32(.83)$ \\
\hline $\begin{array}{l}\text { 44. Can handle difficult } \\
\text { situations at work }\end{array}$ & $4.53(.62)$ & $4.63(.62)$ & $4.38(.91)$ & $4.40(.80)$ \\
\hline $\begin{array}{l}\text { 45. Can persist through } \\
\text { difficulties at work }\end{array}$ & $4.48(.53)$ & $4.64(.54)$ & $4.25(.90)$ & $4.38(.79)$ \\
\hline 46. Is steady & $4.06(.92)$ & $4.24(.90)$ & $4.18(.86)$ & $4.24(.80)$ \\
\hline 47. Is inspiring & $4.33(.76)$ & $4.46(.68)$ & 4.00 & $4.03(.97)$ \\
\hline $\begin{array}{l}\text { 48. Can influence others } \\
\text { to gain buy-in for } \\
\text { tough decisions }\end{array}$ & $4.24(.79)$ & $4.19(.80)$ & $3.89(.97)$ & $3.74(1.07)$ \\
\hline $\begin{array}{l}\text { 49. Is influential with } \\
\text { others at work }\end{array}$ & $4.44(.66)$ & $4.55(.72)$ & $3.88(1.04)$ & $3.87(1.04)$ \\
\hline $\begin{array}{l}\text { 50. Brings out the best in } \\
\text { people }\end{array}$ & $4.41(.82)$ & $4.42(.78)$ & $4.33(.90)$ & $4.30(.85)$ \\
\hline $\begin{array}{l}\text { 51. Takes initiative to } \\
\text { start new projects }\end{array}$ & $4.38(.70)$ & $4.54(.66)$ & $4.15(.90)$ & $4.13(.96)$ \\
\hline $\begin{array}{l}\text { 52. Can hit the ground } \\
\text { running after a } \\
\text { promotion }\end{array}$ & $4.33(.81)$ & $4.24(.89)$ & $3.97(1.02)$ & $4.02(.93)$ \\
\hline 53. Is independent & $3.90(1.02)$ & $4.21(.86)$ & $4.07(.91)$ & $4.24(.80)$ \\
\hline 54. Doesn't back down & $4.26(.82)$ & $4.04(.93)$ & $3.42(1.13)$ & $3.23(1.03)$ \\
\hline $\begin{array}{l}\text { 55. Has the courage to } \\
\text { take a stand on } \\
\text { issues }\end{array}$ & $4.36(.80)$ & $4.41(.65)$ & $3.94(1.03)$ & $4.14(.85)$ \\
\hline $\begin{array}{l}\text { 56. Can make tough } \\
\text { decisions that may } \\
\text { hurt others }\end{array}$ & $4.06(.95)$ & $4.09(.92)$ & 3.70 (1.09) & $3.54(1.14)$ \\
\hline 57. Takes risks & $4.00(.8$ & $4.16(.77)$ & $3.27(1.07)$ & $3.29(1.10)$ \\
\hline 58. Is self-confic & $4.53(.6$ & $4.61(.61)$ & $4.11(.94)$ & $4.15(.84)$ \\
\hline $\begin{array}{l}\text { 59. Is able to show their } \\
\text { true self at work }\end{array}$ & $3.96(.98)$ & $4.09(1.01)$ & $3.69(1.06)$ & $3.74(1.15)$ \\
\hline
\end{tabular}




\begin{tabular}{|c|c|c|c|c|}
\hline $\begin{array}{l}\text { 60. Has the time to take } \\
\text { on new assignments }\end{array}$ & $3.94(.91)$ & $4.06(.82)$ & $3.82(1.06)$ & $3.77(1.05)$ \\
\hline $\begin{array}{l}\text { 61. Can handle } \\
\text { additional work } \\
\text { responsibilities }\end{array}$ & $4.39(.59)$ & $4.43(.69)$ & $4.23(.95)$ & $4.22(.87)$ \\
\hline $\begin{array}{l}\text { 62. Is interested in } \\
\text { developing their } \\
\text { career over the long } \\
\text { term }\end{array}$ & $4.33(.69)$ & $4.52(.74)$ & $4.04(.99)$ & $4.14(.87)$ \\
\hline $\begin{array}{l}\text { 63. Is devoted to their } \\
\text { work }\end{array}$ & $4.36(.70)$ & $4.55(.63)$ & $4.06(.95)$ & $4.09(.94)$ \\
\hline $\begin{array}{l}\text { 64. Sees their position as } \\
\text { a career, not just a } \\
\text { job }\end{array}$ & $4.33(.79)$ & $4.55(.57)$ & $4.15(.97)$ & $4.17(.97)$ \\
\hline $\begin{array}{l}\text { 65. Plans on working } \\
\text { until retirement }\end{array}$ & $3.58(1.13)$ & $3.65(1.13)$ & $3.31(1.29)$ & $3.36(1.24)$ \\
\hline $\begin{array}{l}\text { 66. Asks for } \\
\text { opportunities to } \\
\text { develop their career }\end{array}$ & $4.33(.74)$ & $4.53(.60)$ & $3.92(.93)$ & $4.00(.95)$ \\
\hline $\begin{array}{l}\text { 67. Has a clear idea of } \\
\text { career goals }\end{array}$ & $4.29(.76)$ & $4.39(.72)$ & $3.96(.93)$ & $3.98(.96)$ \\
\hline $\begin{array}{l}\text { 68. Sees their work as a } \\
\text { calling in life }\end{array}$ & $4.07(.94)$ & $4.10(.87)$ & $3.53(1.10)$ & $3.51(1.14)$ \\
\hline 69. Is ambitious & $4.42(.71)$ & $4.68(.54)$ & $4.04(.99)$ & $4.06(.91)$ \\
\hline $\begin{array}{l}\text { 70. Is interested in being } \\
\text { an executive in the } \\
\text { future }\end{array}$ & $4.30(.84)$ & $4.26(.85)$ & $3.55(1.14)$ & $3.55(1.15)$ \\
\hline $\begin{array}{l}\text { 71. Has realistic career } \\
\text { goals }\end{array}$ & $4.08(.94)$ & $4.29(.86)$ & $3.86(1.08)$ & $4.09(.93)$ \\
\hline $\begin{array}{l}\text { 72. Has a high need for } \\
\text { achievement }\end{array}$ & $4.36(.72)$ & $4.50(.71)$ & $3.85(.99)$ & $3.60(1.09)$ \\
\hline $\begin{array}{l}\text { 73. Expresses a desire } \\
\text { for promotion }\end{array}$ & $4.06(.95)$ & $4.06(.96)$ & $3.63(1.11)$ & $3.75(1.04)$ \\
\hline $\begin{array}{l}\text { 74. Has high aspirations } \\
\text { for advancing in the } \\
\text { organization }\end{array}$ & $4.45(.70)$ & $4.63(.57)$ & $3.88(1.02)$ & $3.88(1.01)$ \\
\hline $\begin{array}{l}\text { 75. Has requested to be } \\
\text { considered for } \\
\text { promotions in the } \\
\text { organization }\end{array}$ & $3.67(1.07)$ & $4.00(.99)$ & $3.35(1.16)$ & $3.66(1.08)$ \\
\hline $\begin{array}{l}\text { 76. Has aspirations for } \\
\text { management }\end{array}$ & $4.25(.79)$ & $4.37(.75)$ & $3.77(1.00)$ & $3.84(1.08)$ \\
\hline 77. Is committed to & $4.52(.63)$ & $4.64(.57)$ & $4.22(.89)$ & $4.28(.89)$ \\
\hline
\end{tabular}
success 


\begin{tabular}{|c|c|c|c|c|}
\hline $\begin{array}{l}\text { 78. Will do whatever it } \\
\text { takes to be } \\
\text { successful }\end{array}$ & $4.22(.90)$ & 4.00 (1.09) & $3.49(1.21)$ & $3.36(1.19)$ \\
\hline $\begin{array}{l}\text { 79. Has shown the } \\
\text { ability to be } \\
\text { successful }\end{array}$ & $4.40(.67)$ & $4.63(.60)$ & $4.29(.90)$ & $4.35(.78)$ \\
\hline 80. Shows potential & $4.40(.71)$ & $4.57(.65)$ & $4.18(.84)$ & $4.46(.77)$ \\
\hline $\begin{array}{l}\text { 81. Outperforms their } \\
\text { colleagues }\end{array}$ & $4.21(.85)$ & $3.99(.96)$ & $3.98(.98)$ & $3.81(.97)$ \\
\hline $\begin{array}{l}\text { 82. Has what it takes to } \\
\text { be the best }\end{array}$ & $4.50(.68)$ & $4.35(.82)$ & $4.07(1.01)$ & $4.06(.88)$ \\
\hline 83. Is competitive & $4.42(.70)$ & $4.17(.91)$ & $3.62(1.09)$ & $3.43(1.09)$ \\
\hline $\begin{array}{l}\text { 84. Makes sure } \\
\text { accomplishment are } \\
\text { visible to } \\
\text { management }\end{array}$ & $3.87(1.06)$ & $3.77(1.12)$ & $3.27(1.20)$ & $3.27(1.23)$ \\
\hline $\begin{array}{l}\text { 85. Makes sure that their } \\
\text { colleagues see the } \\
\text { products of their } \\
\text { work }\end{array}$ & $3.71(.94)$ & $3.64(1.06)$ & $3.51(1.14)$ & $3.33(1.29)$ \\
\hline $\begin{array}{l}\text { 86. Seems like someone } \\
\text { who gets along with } \\
\text { managers }\end{array}$ & $4.06(.85)$ & $4.17(.80)$ & $3.79(1.00)$ & $3.84(.99)$ \\
\hline $\begin{array}{l}\text { 87. Other leaders would } \\
\text { like to spend time } \\
\text { with this employee }\end{array}$ & $4.34(.66)$ & $4.29(.76)$ & $3.51(1.08)$ & $3.71(1.06)$ \\
\hline $\begin{array}{l}\text { 88. Is a good example of } \\
\text { the kind of friends I } \\
\text { would like to make }\end{array}$ & $3.73(1.19)$ & $3.88(1.06)$ & $3.29(1.22)$ & $3.40(1.21)$ \\
\hline $\begin{array}{l}\text { 89. Has an effective } \\
\text { relationship with } \\
\text { their supervisor }\end{array}$ & $4.26(.79)$ & $4.31(.75)$ & $3.97(.95)$ & $4.07(.92)$ \\
\hline $\begin{array}{l}\text { 90. Gets along with } \\
\text { leaders }\end{array}$ & $4.40(.73)$ & $4.47(.68)$ & $4.02(.89)$ & $4.19(.90)$ \\
\hline $\begin{array}{l}\text { 91. Seems like managers } \\
\text { in the firm }\end{array}$ & $3.88(.97)$ & $3.93(.98)$ & $3.42(1.08)$ & $3.44(1.16)$ \\
\hline $\begin{array}{l}\text { 92. Can work like } \\
\text { managers do }\end{array}$ & $4.22(.85)$ & $4.39(.72)$ & $3.93(1.02)$ & $4.03(1.00)$ \\
\hline $\begin{array}{l}\text { 93. Has leadership } \\
\text { ability }\end{array}$ & $4.56(.59)$ & $4.79(.49)$ & $4.44(.83)$ & $4.34(.93)$ \\
\hline $\begin{array}{l}\text { 94. Desires } \\
\text { responsibility }\end{array}$ & $4.25(.80)$ & $4.55(.61)$ & $4.11(.92)$ & $4.20(.82)$ \\
\hline $\begin{array}{l}\text { 95. Values work as } \\
\text { much as managers } \\
\text { do }\end{array}$ & $4.21(.76)$ & $4.46(.66)$ & $4.08(1.01)$ & $4.14(.90)$ \\
\hline
\end{tabular}




\begin{tabular}{|c|c|c|c|c|}
\hline $\begin{array}{l}\text { 96. Worthwhile to invest } \\
\text { in this employee }\end{array}$ & $4.30(.79)$ & $4.38(.76)$ & $4.13(.89)$ & $4.29(.87)$ \\
\hline $\begin{array}{l}\text { 97. Is the best person to } \\
\text { get things done }\end{array}$ & $4.44(.68)$ & $4.46(.75)$ & $4.22(.91)$ & $4.20(.86)$ \\
\hline $\begin{array}{l}\text { 98. Is the best candidate } \\
\text { for management }\end{array}$ & $4.37(.71)$ & $4.36(.76)$ & $4.27(.96)$ & $4.19(.97)$ \\
\hline 9. Is helpful & $4.19(.77)$ & $4.45(.76)$ & $4.24(.82)$ & $4.30(.85)$ \\
\hline 100. Is supportive & $4.20(.85)$ & $4.38(.76)$ & $4.12(.92)$ & $4.23(.88)$ \\
\hline $\begin{array}{l}\text { 101. Attends to the } \\
\text { needs of others }\end{array}$ & $3.98(.96)$ & $4.22(.77)$ & $3.96(.98)$ & $3.96(.90)$ \\
\hline $\begin{array}{l}\text { 102. Aware of the } \\
\text { feelings of others }\end{array}$ & $4.14(.94)$ & $4.23(.85)$ & $4.04(.89)$ & $4.12(.88)$ \\
\hline $\begin{array}{l}\text { 103. Considers others' } \\
\text { ideas }\end{array}$ & $4.30(.74)$ & $4.53(.60)$ & $4.09(1.00)$ & $4.35(.80)$ \\
\hline 104. Is a good listener & $4.39(.67)$ & $4.63(.67)$ & $4.17(.91)$ & $4.37(.79)$ \\
\hline 105. Is encouraging & $4.37(.74)$ & $4.46(.70)$ & $4.11(.88)$ & $4.22(.86)$ \\
\hline 106. Is understanding & $4.21(.86)$ & $4.43(.80)$ & $4.13(.91)$ & $4.16(.91)$ \\
\hline 107. Is compassionate & $3.96(1.04)$ & $4.24(.85)$ & $3.83(.93)$ & $4.00(1.02)$ \\
\hline 108. Is generous & $3.87(1.06)$ & $4.16(.88)$ & $3.58(1.08)$ & $3.73(1.03)$ \\
\hline 109. Is decisive & $3.87(1.06)$ & $4.44(.77)$ & $4.04(1.06)$ & $4.19(.86)$ \\
\hline $\begin{array}{l}\text { 110. Uses reason to } \\
\text { solve work problems }\end{array}$ & $4.31(.73)$ & $4.52(.70)$ & $4.27(.95)$ & $4.31(.82)$ \\
\hline 111. Is a critical thinker & $4.60(.57)$ & $4.58(.61)$ & $4.35(.86)$ & $4.39(.76)$ \\
\hline $\begin{array}{l}\text { 112. Has analytical } \\
\text { ability }\end{array}$ & $4.43(.63)$ & $4.38(.76)$ & $4.19(.92)$ & $4.20(.86)$ \\
\hline 113. Is logical & $4.40(.69)$ & $4.52(.63)$ & $4.21(.88)$ & $4.33(.83)$ \\
\hline $\begin{array}{l}\text { 114. Is skilled in } \\
\text { business matters }\end{array}$ & $4.44(.70)$ & $4.45(.72)$ & $4.16(.85)$ & $4.11(.87)$ \\
\hline 115. Is well informed & $4.31(.78)$ & $4.51(.62)$ & $4.25(.82)$ & $4.31(.85)$ \\
\hline $\begin{array}{l}\text { 116. Knows the ways of } \\
\text { the world }\end{array}$ & $3.90(.91)$ & $4.05(.87)$ & $3.56(1.10)$ & $3.46(1.05)$ \\
\hline 117. Is sophisticated & $3.97(.89)$ & $3.97(.99)$ & $3.32(1.11)$ & $3.25(1.14)$ \\
\hline 118. Is intuitive & $4.35(.67)$ & $4.47(.62)$ & $4.11(.90)$ & $4.08(.88)$ \\
\hline 119. Is resourceful & $4.38(.69)$ & $4.47(.64)$ & $4.36(.80)$ & $4.37(.77)$ \\
\hline $\begin{array}{l}\text { 120. Is "in-the-know" at } \\
\text { work }\end{array}$ & $3.95(.93)$ & $4.18(.87)$ & $3.73(1.05)$ & $3.72(1.05)$ \\
\hline 121. Is competent & $4.38(.74)$ & $4.45(.77)$ & $4.40(1.01)$ & $4.55(.76)$ \\
\hline 122. Is intelligent & $4.39(.76)$ & $4.52(.76)$ & $4.30(.83)$ & $4.49(.69)$ \\
\hline $\begin{array}{l}\text { 123. Can maintain their } \\
\text { level of } \\
\text { performance in the } \\
\text { future }\end{array}$ & $4.44(.69)$ & $4.54(.66)$ & $4.10(1.07)$ & $4.33(.82)$ \\
\hline 124. Is consistent & $4.41(.78)$ & $4.55(.60)$ & $4.27(.95)$ & $4.37(.80)$ \\
\hline 125. Is persistent & $4.39(.67)$ & $4.39(.72)$ & $4.15(.96)$ & $4.06(.95)$ \\
\hline 126. Is prompt & $4.26(.79)$ & $4.43(.72)$ & $4.19(.89)$ & $4.28(.93)$ \\
\hline 127. Is sociable & $4.40(.78)$ & $4.39(.66)$ & $3.78(.94)$ & $3.66(.99)$ \\
\hline
\end{tabular}




\begin{tabular}{|c|c|c|c|c|}
\hline $\begin{array}{l}\text { 128. Has credibility } \\
\text { with peers }\end{array}$ & $4.45(.69)$ & $4.59(.61)$ & $4.06(.87)$ & $4.17(.83)$ \\
\hline 129. Is a team player & $4.36(.77)$ & $4.49(.63)$ & $4.29(.82)$ & $4.38(.79)$ \\
\hline 130. Is sincere & $3.99(.99)$ & $4.35(.81)$ & $4.19(.97)$ & $4.28(.83)$ \\
\hline 131. Is considerate & $4.05(.95)$ & $4.36(.76)$ & $4.00(.94)$ & $4.18(.93)$ \\
\hline $\begin{array}{l}\text { 132. Gets along most } \\
\text { easily with other } \\
\text { group members }\end{array}$ & $4.19(.79)$ & $4.31(.70)$ & $3.99(1.00)$ & $4.03(.97)$ \\
\hline 133. Is cooperative & $4.40(.77)$ & $4.41(.75)$ & $4.21(.92)$ & $4.33(.85)$ \\
\hline 134. Is courteous & $3.97(.89)$ & $4.26(.77)$ & $3.88(.93)$ & $4.20(.89)$ \\
\hline 135. Is kind & $3.94(1.11)$ & $4.21(.97)$ & $3.78(1.03)$ & $4.09(.91)$ \\
\hline 136. Is direct & $4.23(.79)$ & $4.30(.73)$ & $3.87(.96)$ & $3.88(.95)$ \\
\hline 137. Is open to criticism & $4.32(.70)^{*}$ & $4.62(.57)$ & $4.03(1.02)$ & $4.18(.90)$ \\
\hline 138. Seeks feedback & $4.19(.86)^{*}$ & $4.56(.66)$ & $3.96(.95)$ & $3.98(1.00)$ \\
\hline 139. Uses feedback & $4.42(.79)$ & $4.73(.52)$ & $4.22(.95)$ & $4.32(.81)$ \\
\hline $\begin{array}{l}\text { 140. Learns from } \\
\text { experience }\end{array}$ & $4.55(.67)$ & $4.65(.58)$ & $4.34(.90)$ & $4.38(.85)$ \\
\hline $\begin{array}{l}\text { 141. Seeks } \\
\text { opportunities to learn }\end{array}$ & $4.43(.76)$ & $4.63(.63)$ & $4.40(.84)$ & $4.40(.76)$ \\
\hline $\begin{array}{l}\text { 142. Asks for } \\
\text { challenging work } \\
\text { assignments }\end{array}$ & $4.17(.88)$ & $4.31(.83)$ & $3.88(.99)$ & $3.90(.95)$ \\
\hline 143. Is curious & $3.99(.80)$ & $4.22(.80)$ & $3.82(1.05)$ & $3.90(1.02)$ \\
\hline 144. Is trustworthy & $4.58(.75)$ & $4.66(.53)$ & $4.46(.87)$ & $4.60(.71)$ \\
\hline 145. Is fair & $4.09(.97)$ & $4.40(.82)$ & $4.25(.84)$ & $4.37(.83)$ \\
\hline 146. Acts with integrity & $4.44(.73)$ & $4.63(.62)$ & $4.39(.87)$ & $4.64(.70)$ \\
\hline $\begin{array}{l}\text { 147. Has a strong work } \\
\text { ethic }\end{array}$ & $4.67(.49)$ & $4.76(.52)$ & $4.54(.79)$ & $4.55(.76)$ \\
\hline 148. Is neat & $3.77(1.01)$ & $3.71(1.04)$ & $3.37(1.17)$ & $3.64(1.02)$ \\
\hline 149. Is cheerful & $3.87(1.00)$ & $4.04(.82)$ & $3.62(1.08)$ & $3.80(.98)$ \\
\hline 150. Is optimistic & $4.21(.86)$ & $4.46(.70)$ & $4.02(.97)$ & $4.10(.89)$ \\
\hline 151. Is energetic & $4.26(.74)$ & $4.39(.68)$ & $3.85(.98)$ & $3.90(.92)$ \\
\hline 152. Is enthusiastic & $4.37(.73)$ & $4.38(.74)$ & $3.92(.97)$ & $4.09(.92)$ \\
\hline $\begin{array}{l}\text { 153. Easily adapts to } \\
\text { change }\end{array}$ & $4.40(.70)$ & $4.54(.71)$ & $4.26(.86)$ & $4.29(.79)$ \\
\hline
\end{tabular}

*Significant difference between male and female raters (within each sample) at the $\leq .001$ alpha level (due to the large number of comparisons in the table). 


\section{Appendix V: Research Questions 3 and 4 Survey}

[Participants were randomly selected to complete this study or the study addressing Research Question 5 (see Appendix IV).]

Thank you for participating in this study. We are studying how people process information in different formats. Managers use information to assess their employees' performance, but the way that information is presented to managers differs across organizations. Information processing scholars have not considered how performance evaluation forms may affect the decisions that managers make in promoting and developing their employees. To study this question, we will show you the performance information for a single employee in either a grid, narrative, or visual scale format. These three types of scales are the most common for employee performance evaluation forms. After reviewing the information, we would like you to answer questions about your likelihood of recommending the employee for different developmental opportunities, assessing their promotability, and describing the characteristics of the employee based on the information provided.

\section{Employee Rating Information}

Imagine that you are part of evaluation team in your company, and your task is to review the performance information for an operations research analyst. Operations research analysts formulate and apply mathematical models to develop and interpret information that managers use for decision making.

Please review the following employee performance information and indicate the extent to which you would oppose or recommend [Jessica/Bradley] in terms of developmental opportunities and then rate [her/his] promotability as well as how you would describe [her/him].

[Each participant will be randomly assigned a female or male employee]

\section{Jessica/Bradley Miller}

[Jessica/Bradley] has worked in the organization for four years. [She/he] has the typical background for an operations research analyst, which includes a bachelor's degree and a summer internship before joining the company. Operations research analyst is the entry-level position on the operations team. Excellent analysts can be promoted to senior operations analyst and eventually can move into technical lead and executive positions if they show potential.

The following grid provides [Jessica's/Bradley's] performance information for each of the seven main tasks of an operations research analyst. These ratings were provided by [Jessica's/Bradley's] supervisor to describe [her/his] performance over the last year. 


\begin{tabular}{|c|c|c|c|c|c|}
\hline \multicolumn{6}{|l|}{ Employee Performance Rating } \\
\hline & Poor & Fair & Good & $\begin{array}{l}\text { Very } \\
\text { Good }\end{array}$ & Excellent \\
\hline Develops Appropriate Models to Solve Client Problems & & & & & - \\
\hline Performs Validation and Testing of Models to Company Standards & & & & - & \\
\hline Collaborates with Client Management and Decision Makers & & & & & - \\
\hline Presents Results of Modeling in a Clear Manner to Clients & & & & - & \\
\hline Provides Justification for Chosen Model to Clients & & & & - & \\
\hline Educates Clients on How to Use Chosen Model for Decision Making & & & & & • \\
\hline $\begin{array}{l}\text { Collaborates with Research Colleagues to Successfully Develop Models for } \\
\text { Clients }\end{array}$ & & & & - & \\
\hline
\end{tabular}

\section{Developmental Opportunities}

We would like to know whether you would recommend or oppose [Jessica/Bradley] for a variety of developmental opportunities your organization offers. For each of the items below, please rate your recommendation on a 7-point scale, where 1 means 'Strongly oppose' and 7 means 'Strongly recommend' [Jessica/Bradley] for the opportunity.

\begin{tabular}{|c|c|c|c|c|c|c|c|}
\hline & $\begin{array}{l}1=\text { Strongly } \\
\text { Oppose }\end{array}$ & $2=$ Oppose & $\begin{array}{l}3=\text { Slightly } \\
\text { Oppose }\end{array}$ & $\begin{array}{l}4=\text { Neither } \\
\text { Oppose nor } \\
\text { Recommend }\end{array}$ & $\begin{array}{l}5=\text { Slightly } \\
\text { Recommend }\end{array}$ & $\begin{array}{c}6= \\
\text { Recommend }\end{array}$ & $\begin{array}{l}7 \text { = Strongly } \\
\text { Recommend }\end{array}$ \\
\hline $\begin{array}{l}\text { 1. A task requiring [Jessica/Bradley] to } \\
\text { learn significantly new or very } \\
\text { unfamiliar responsibilities. }\end{array}$ & & & & & & & \\
\hline $\begin{array}{l}\text { 2. A task requiring [Jessica/Bradley] to } \\
\text { start something radically new in the } \\
\text { organization or make strategic } \\
\text { changes in business. }\end{array}$ & & & & & & & \\
\hline $\begin{array}{l}\text { 3. A task requiring [Jessica/Bradley] to } \\
\text { fix major problems created by a } \\
\text { predecessor. }\end{array}$ & & & & & & & \\
\hline $\begin{array}{l}\text { 4. A challenging task requiring } \\
\text { [Jessica/Bradley] to deal with }\end{array}$ & & & & & & & \\
\hline
\end{tabular}




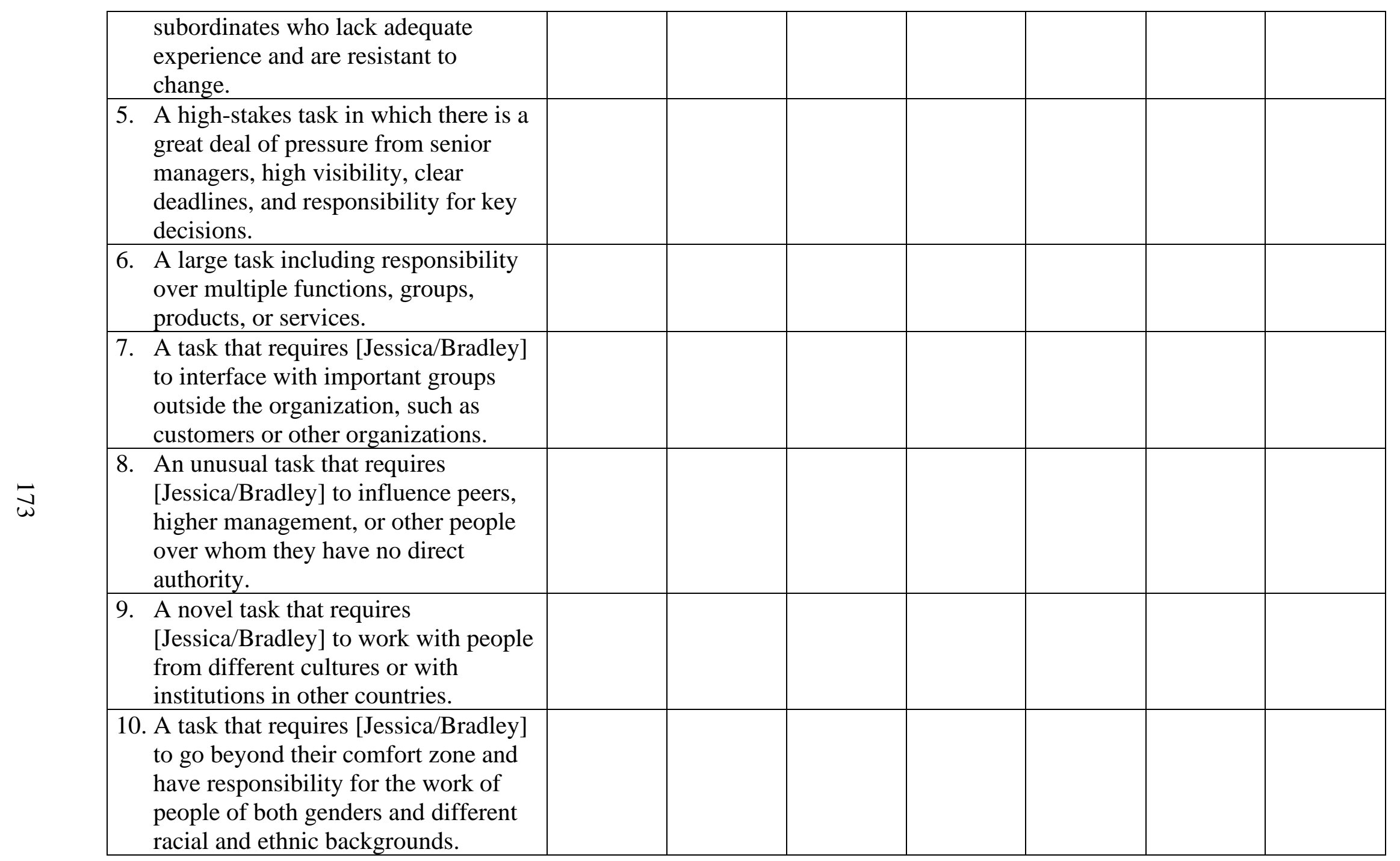

\section{Promotability Scale}

We would like to know how promotable you think [Jessica/Bradley] is. Please rate how much you agree with the following descriptions for on a 6-point scale where 1 means 'Strongly disagree' and 6 means 'Strongly agree.' 


\begin{tabular}{|l|l|l|l|c|c|c|}
\hline & $\begin{array}{c}1=\text { Strongly } \\
\text { Disagree }\end{array}$ & $\begin{array}{c}2= \\
\text { Disagree }\end{array}$ & $\begin{array}{c}3=\text { Slightly } \\
\text { Disagree }\end{array}$ & $\begin{array}{c}4= \\
\text { Slightly } \\
\text { Agree }\end{array}$ & $\begin{array}{c}5= \\
\text { Agree }\end{array}$ & $\begin{array}{c}6= \\
\text { Strongly } \\
\text { Agree }\end{array}$ \\
\hline Ability to Be Promoted to Next Position Up & & & & & & \\
\hline $\begin{array}{l}\text { 1. I would recommend Jessica/Bradley be promoted to } \\
\text { senior operations analyst, the next position up for an } \\
\text { operations research analyst. }\end{array}$ & & & & & & \\
\hline Ability to Be Promoted to Executive Levels & & & & & & \\
\hline 2. I believe [Jessica/Bradley] will have a successful career. & & & & & & \\
\hline $\begin{array}{l}\text { 3. [Jessica/Bradley] the ability to move up to an executive } \\
\text { position over [her/his] career. }\end{array}$ & & & & & & \\
\hline $\begin{array}{l}\text { 4. I would recommend that Jessica/Bradley be designed as } \\
\text { a high-potential employee in the company. }\end{array}$ & & & & & \\
\hline
\end{tabular}

\section{Ideal Worker Attributes}

Past research shows that the way information is presented to us (in a grid, narrative, or visual scale format) can affect the way we perceive others. We would like to know how you would describe [Jessica/Bradley] based on the employee performance information you have received. Although it may be difficult to assess [Jessica/Bradley] on each of these characteristics based on only the performance information you have received, please do your best in describing [her/him]. Please rate each of the following characteristics on a 5-point scale, where 1 means "Not at all characteristic of [Jessica/Bradley]" and 5 means "Extremely characteristic of [Jessica/Bradley]."

[Participants did not see the headings in bold. Items were ordered randomly.]

\begin{tabular}{|l|l|l|l|l|l|}
\hline & $\begin{array}{l}1=\text { Not at all } \\
\text { characteristic }\end{array}$ & $\begin{array}{l}2=\text { Slightly } \\
\text { characteristic }\end{array}$ & $\begin{array}{l}3=\text { Moderately } \\
\text { characteristic }\end{array}$ & $\begin{array}{l}4=\text { Very } \\
\text { characteristic }\end{array}$ & $\begin{array}{l}5=\text { Extremely } \\
\text { characteristic }\end{array}$ \\
\hline Works Long Hours & & & & & \\
\hline $\begin{array}{l}\text { Puts in extra time at work as needed to } \\
\text { finish a task }\end{array}$ & & & & & \\
\hline $\begin{array}{l}\text { Will use personal time to take care of a } \\
\text { work emergency }\end{array}$ & & & & & \\
\hline Is willing to work long hours & & & & \\
\hline
\end{tabular}




\begin{tabular}{|l|l|l|l|l|}
\hline $\begin{array}{l}\text { Can handle additional work } \\
\text { responsibilities }\end{array}$ & & & & \\
\hline $\begin{array}{l}\text { Has the time to take on new } \\
\text { assignments }\end{array}$ & & & & \\
\hline Work Travel and Relocation & & & & \\
\hline Is willing to travel for work & & & & \\
\hline $\begin{array}{l}\text { Is willing to travel for work on short } \\
\text { notice }\end{array}$ & & & & \\
\hline $\begin{array}{l}\text { Is willing to travel for many days at a } \\
\text { time for work }\end{array}$ & & & & \\
\hline Is willing to travel abroad for work & & & & \\
\hline Is willing to move for work & & & & \\
\hline Is willing to relocate overseas for work & & & & \\
\hline Productivity & & & & \\
\hline $\begin{array}{l}\text { Can maintain or increase [her/his] level } \\
\text { of performance in the future }\end{array}$ & & & & \\
\hline $\begin{array}{l}\text { Can hit the ground running after a } \\
\text { promotion }\end{array}$ & & & & \\
\hline Work Engagement & & & & \\
\hline Exerts high levels of effort at work & & & & \\
\hline Is fully engaged at work & & & & \\
\hline Is passionate about their work & & & & \\
\hline Career Ambition & & & & \\
\hline Has ambitious goals for [her/his] career & & & & \\
\hline $\begin{array}{l}\text { Is interested in being an executive in the } \\
\text { future }\end{array}$ & & & & \\
\hline Is career-oriented & & & & \\
\hline $\begin{array}{l}\text { Sees [her/his] position as a career, not } \\
\text { just a job }\end{array}$ & & & & \\
\hline $\begin{array}{l}\text { Not likely to stop working when } \\
\text { [she/he] starts a family }\end{array}$ & & & & \\
\hline $\begin{array}{l}\text { Not likely to work part-time in the } \\
\text { future }\end{array}$ & & & & \\
\hline
\end{tabular}




\begin{tabular}{|l|l|l|l|l|}
\hline $\begin{array}{l}\text { Is interested in advancing [her/his] } \\
\text { career over the long term }\end{array}$ & & & & \\
\hline Emotional Control & & & & \\
\hline Persists through difficulties at work & & & & \\
\hline Is emotionally stable & & & & \\
\hline $\begin{array}{l}\text { Controls [her/his] emotions when } \\
\text { receiving feedback from others }\end{array}$ & & & & \\
\hline Best Choice & & & & \\
\hline Is the best person to get things done & & & & \\
\hline $\begin{array}{l}\text { Is worthwhile for the company to invest } \\
\text { in [Jessica/Bradley] }\end{array}$ & & & & \\
\hline Is the best candidate for management & & & & \\
\hline Has what it takes to be the best & & & & \\
\hline Has Potential & & & & \\
\hline Has shown the ability to be successful & & & & \\
\hline Outperforms [her/his] colleagues & & & & \\
\hline Has leadership ability & & & & \\
\hline Pursues Opportunities & & & & \\
\hline Is independent & & & & \\
\hline Takes initiative to start new projects & & & & \\
\hline $\begin{array}{l}\text { Is decisive about new executive } \\
\text { opportunities for their company }\end{array}$ & & & & \\
\hline $\begin{array}{l}\text { Has the courage to take a stand on } \\
\text { issues }\end{array}$ & & & & \\
\hline $\begin{array}{l}\text { Is insightful - sees things from new } \\
\text { angles }\end{array}$ & & & & \\
\hline Looks for better ways to do things & & & & \\
\hline Identifies opportunities & & & & \\
\hline Social Skills & & & & \\
\hline Has credibility with peers & & & & \\
\hline Has excellent work relationships & & & & \\
\hline Encourages colleagues & & & & \\
\hline
\end{tabular}




\begin{tabular}{|l|l|l|l|l|l|}
\hline Helps develop others at work & & & & \\
\hline Understands others' points-of-view & & & & & \\
\hline
\end{tabular}

\section{Benevolent Sexism Inventory}

How we process information is affected by the way the information is presented to us (for example, in a grid, narrative, or visual scale format) as well as your personal beliefs. In particular, beliefs we have about other people can influence how we interpret information about others as well as how much influence the way that information is presented to us (for example, in a grid, narrative, or visual scale form) has on our decision making. To understand more about your beliefs about others, below are several questions about men and women and their relationship to one another. Please rate how much you agree or disagree with the following statements, where 1 means 'Strongly disagree' and 6 means 'Strongly agree.' There are no right or wrong answers, so please answer as honestly as you can.

[Items were combined with the Modern Sexism Scale (below) and randomly ordered.]

\begin{tabular}{|c|c|c|c|c|c|c|}
\hline & $\begin{array}{c}1=\text { Strongly } \\
\text { Disagree }\end{array}$ & $\begin{array}{c}2= \\
\text { Disagree }\end{array}$ & $\begin{array}{c}\text { 3 = Slightly } \\
\text { Disagree }\end{array}$ & $\begin{array}{c}4=\text { Slightly } \\
\text { Agree }\end{array}$ & $\begin{array}{c}5= \\
\text { Agree }\end{array}$ & $\begin{array}{c}6=\text { Strongly } \\
\text { Agree }\end{array}$ \\
\hline $\begin{array}{l}\text { 1. No matter how accomplished he is, a man is not tru } \\
\text { complete as a person unless he has the love of a } \\
\text { woman. }\end{array}$ & & & & & & \\
\hline $\begin{array}{l}\text { 2. In a disaster, women should not necessarily be } \\
\text { rescued before men. }(\mathrm{R})\end{array}$ & & & & & & \\
\hline $\begin{array}{l}\text { 3. People are often truly happy in life without being } \\
\text { romantically involved with a member of the opposit } \\
\text { sex. (R) }\end{array}$ & & & & & & \\
\hline $\begin{array}{l}\text { 4. Many women have a quality of purity that few men } \\
\text { possess. }\end{array}$ & & & & & & \\
\hline 5. Women should be cherished and protected by men. & & & & & & \\
\hline 6. Every man should have a woman he adores. & & & & & & \\
\hline 7. Men are complete without women (R) & & & & & & \\
\hline $\begin{array}{l}\text { 8. A good woman should be set on a pedestal by her } \\
\text { man. }\end{array}$ & & & & & & \\
\hline $\begin{array}{l}\text { 9. Women, compared to men, tend to have a superior } \\
\text { moral sensibility. }\end{array}$ & & & & & & \\
\hline
\end{tabular}




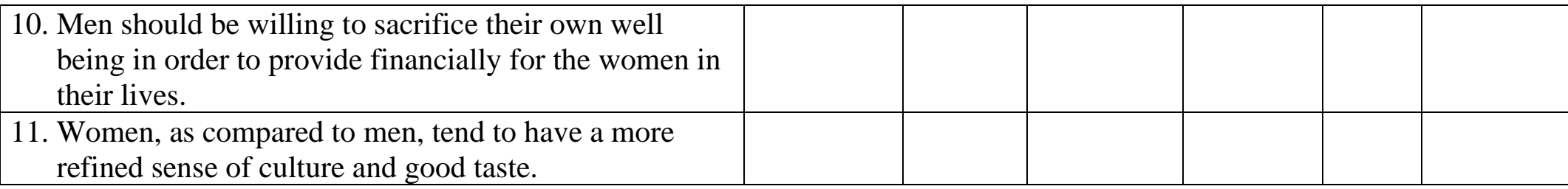

\section{Modern Sexism Scale}

Please rate each of these statements as to how much you agree or disagree on a 6-point scale, where 1 means 'Strongly disagree' and 6 means 'Strongly agree.' There are no right or wrong answers, so please answer as honestly as you can.

[Items were combined with the Benevolent Sexism Inventory (above) and randomly ordered.]

\begin{tabular}{|c|c|c|c|c|c|c|}
\hline & $\begin{array}{c}1= \\
\text { Strongly } \\
\text { Disagree }\end{array}$ & $\begin{array}{c}2= \\
\text { Disagree }\end{array}$ & $\begin{array}{l}3 \text { = Slightly } \\
\text { Disagree }\end{array}$ & $\begin{array}{l}4= \\
\text { Slightly } \\
\text { Agree }\end{array}$ & $\begin{array}{c}5= \\
\text { Agree }\end{array}$ & $\begin{array}{c}6= \\
\text { Strongly } \\
\text { Agree }\end{array}$ \\
\hline $\begin{array}{l}\text { 1. Discrimination against women is no longer a problem in } \\
\text { the United States. }(\mathrm{R})\end{array}$ & & & & & & \\
\hline $\begin{array}{l}\text { 2. Women often miss out on good jobs due to gender } \\
\text { discrimination. }\end{array}$ & & & & & & \\
\hline $\begin{array}{l}\text { 3. It is rare to see women treated in a sexist manner on } \\
\text { television. (R) }\end{array}$ & & & & & & \\
\hline $\begin{array}{l}\text { 4. On average, people in our society treat husbands and wive } \\
\text { equally. }(\mathrm{R})\end{array}$ & & & & & & \\
\hline $\begin{array}{l}\text { 5. Society has reached the point where women and men have } \\
\text { equal opportunities for achievement. (R) }\end{array}$ & & & & & & \\
\hline $\begin{array}{l}\text { 6. It is easy to understand why women's groups are still } \\
\text { concerned about social limitations of women's } \\
\text { opportunities. }\end{array}$ & & & & & & \\
\hline $\begin{array}{l}\text { 7. It is easy to understand the anger of women's groups in } \\
\text { America. }\end{array}$ & & & & & & \\
\hline $\begin{array}{l}\text { 8. Over the past few years, the government and news media } \\
\text { have been showing more concern about the treatment of } \\
\text { women than is warranted by women's actual experiences. } \\
\text { (R) }\end{array}$ & & & & & & \\
\hline
\end{tabular}


To conclude this study, we would like to learn more about you including your background and work experience. The following questions will be used to aggregate the results of this study.

\section{Demographic Information}

We would like to know a little bit more about you. The questions below will be used to classify your responses; your answers to these questions will be kept confidential and will be used only for classification.

What is your gender? [Male, Female, Other]

What is your age (in years)?

What is your race? Please select all that apply. [American Indian or Alaska Native, Asian, Black or African American, Hispanic, Native Hawaiian or Other Pacific Islander, White]

What is your highest level of education? [Less than a high school diploma, High school degree or equivalent (e.g., GED), Some college but no degree, Associate degree, Bachelor degree, Master degree, Professional degree, Doctorate]

What is your marital status? [Single, Married or in a domestic partnership, Widowed, or Divorced, Separated]

[If married or domestic partnership] What gender is your partner? [Male, Female, Other]

[If married or domestic partnership] Does your partner work for pay? [Yes, full-time; Yes, part-time, No]

What field do you work in?

How long have you worked in your current organization (in years)?

How long have you worked in your current role (in years)?

At what level of leadership is your current position in the organization? [Non-leader, Entry-level management, Middle-level management, Senior-level management]

Are you a native English speaker? [Yes, No] 


\section{Appendix VI: Research Question 5 Survey}

[Participants were randomly selected to complete this study or the study for Research Questions 3 and 4 (see Appendix III).]

Thank you for participating in this study. We are studying how people process information in different formats. Managers use information to assess their employees' performance, but the way that information is presented to managers differs across organizations. Information processing scholars have not considered how performance evaluation forms may affect the decisions that managers make in promoting and developing their employees. To study this question, we will show you the performance information for a single employee in either a grid, narrative, or visual scale format. These three types of scales are the most common for employee performance evaluation forms. After reviewing the information, we would like you to answer questions about your likelihood of recommending the employee for different developmental opportunities, assessing their promotability, and describing the characteristics of the employee based on the information provided.

\section{Employee Rating Information}

Imagine that you are part of evaluation team in your company, and your task is to review the performance information for an operations research analyst. Operations research analysts formulate and apply mathematical models to develop and interpret information that managers use for decision making.

Please review the following employee performance information and indicate the extent to which you would oppose or recommend [Jessica/Bradley] in terms of developmental opportunities and then rate [her/his] promotability as well as how you would describe [her/him].

[Each participant will be randomly assigned a female or male employee]

\section{Jessica/Bradley Miller}

[Jessica/Bradley] has worked in the organization for four years. [She/he] has the typical background for an operations research analyst, which includes a bachelor's degree and a summer internship before joining the company. Operations research analyst is the entry-level position on the operations team. Excellent analysts can be promoted to senior operations analyst and eventually can move into technical lead and executive positions if they show potential.

The following grid provides [Jessica's/Bradley's] performance information for each of the seven main tasks of an operations research analyst. These ratings were provided by [Jessica's/Bradley's] supervisor to describe [her/his] performance over the last year. 


\begin{tabular}{|c|c|c|c|c|c|}
\hline \multicolumn{6}{|l|}{ Employee Performance Rating } \\
\hline & Poor & Fair & Good & $\begin{array}{l}\text { Very } \\
\text { Good }\end{array}$ & Excellent \\
\hline Develops Appropriate Models to Solve Client Problems & & & & & • \\
\hline Performs Validation and Testing of Models to Company Standards & & & & • & \\
\hline Collaborates with Client Management and Decision Makers & & & & & - \\
\hline Presents Results of Modeling in a Clear Manner to Clients & & & & • & \\
\hline Provides Justification for Chosen Model to Clients & & & & • & \\
\hline Educates Clients on How to Use Chosen Model for Decision Making & & & & & - \\
\hline $\begin{array}{l}\text { Collaborates with Research Colleagues to Successfully Develop Models for } \\
\text { Clients }\end{array}$ & & & & • & \\
\hline
\end{tabular}

\section{Developmental Opportunities}

We would like to know whether you would recommend or oppose [Jessica/Bradley] for a variety of developmental opportunities your organization offers. For each of the items below, please rate your recommendation on a 7-point scale, where 1 means 'Strongly oppose' and 7 means 'Strongly recommend' [Jessica/Bradley] for the opportunity.

\begin{tabular}{|c|c|c|c|c|c|c|c|}
\hline & $\begin{array}{c}1=\text { Strongly } \\
\text { Oppose }\end{array}$ & $2=$ Oppose & $\begin{array}{c}3=\text { Slightly } \\
\text { Oppose }\end{array}$ & $\begin{array}{l}4=\text { Neither } \\
\text { Oppose nor } \\
\text { Recommend }\end{array}$ & $\begin{array}{l}5=\text { Slightly } \\
\text { Recommend }\end{array}$ & $\begin{array}{c}6= \\
\text { Recommend }\end{array}$ & $\begin{array}{l}7=\text { Strongly } \\
\text { Recommend }\end{array}$ \\
\hline $\begin{array}{l}\text { 1. A task requiring [Jessica/Bradley] to } \\
\text { learn significantly new or very } \\
\text { unfamiliar responsibilities. }\end{array}$ & & & & & & & \\
\hline $\begin{array}{l}\text { 2. A task requiring [Jessica/Bradley] to } \\
\text { start something radically new in the } \\
\text { organization or make strategic } \\
\text { changes in business. }\end{array}$ & & & & & & & \\
\hline $\begin{array}{l}\text { 3. A task requiring [Jessica/Bradley] to } \\
\text { fix major problems created by a } \\
\text { predecessor. }\end{array}$ & & & & & & & \\
\hline
\end{tabular}




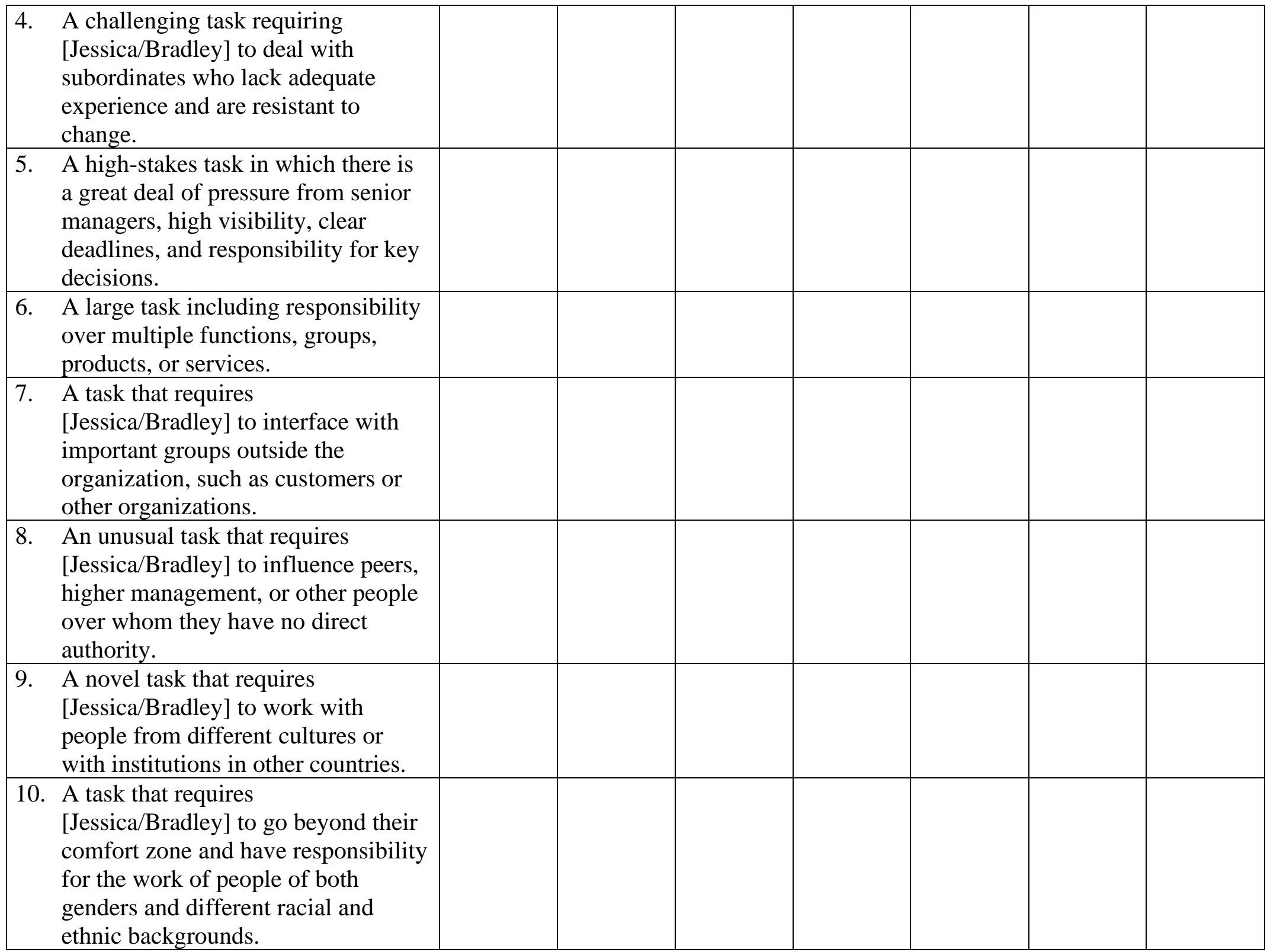




\section{Promotability Scale}

We would like to know how promotable you think [Jessica/Bradley] is. Please rate how much you agree with the following descriptions for on a 6-point scale where 1 means 'Strongly disagree' and 6 means 'Strongly agree.'

\begin{tabular}{|c|c|c|c|c|c|c|}
\hline & $\begin{array}{l}1 \text { = Strongly } \\
\text { Disagree }\end{array}$ & $\begin{array}{c}2= \\
\text { Disagree }\end{array}$ & $\begin{array}{l}3 \text { = Slightly } \\
\text { Disagree }\end{array}$ & $\begin{array}{c}4= \\
\text { Slightly } \\
\text { Agree }\end{array}$ & $\begin{array}{l}5= \\
\text { Agree }\end{array}$ & $\begin{array}{c}6= \\
\text { Strongly } \\
\text { Agree }\end{array}$ \\
\hline Ability to Be Promoted to Next Position Up & & & & & & \\
\hline $\begin{array}{l}\text { 1. I would recommend Jessica/Bradley be promoted to } \\
\text { senior operations analyst, the next position up for an } \\
\text { operations research analyst. }\end{array}$ & & & & & & \\
\hline Ability to Be Promoted to Executive Levels & & & & & & \\
\hline 2. I believe [Jessica/Bradley] will have a successful career. & & & & & & \\
\hline $\begin{array}{l}\text { 3. [Jessica/Bradley] the ability to move up to an executive } \\
\text { position over [her/his] career. }\end{array}$ & & & & & & \\
\hline $\begin{array}{l}\text { 4. I would recommend that Jessica/Bradley be designed as } \\
\text { a high-potential employee in the company. }\end{array}$ & & & & & & \\
\hline
\end{tabular}

\section{Implicit Association Test}

In this next section, we would like to test your short-term memory. Please click forward to the next screen for directions on how to complete this task.

[Instructions provided in the software, which will be integrated into Qualtrics, the survey software. The following tables show how the trials will be organized and the words and phrases shown to participants during the IAT.]

Sequence of Implicit Association Test Presentation
\begin{tabular}{|l|c|c|c|c|c|c|c|}
\hline Sequence & 1 & 3 & 4 & 5 & 6 & 7 \\
\hline Task & $\begin{array}{c}\text { Categorize } \\
\text { Description } \\
\text { stimuli into } \\
\text { categories }\end{array}$ & $\begin{array}{c}\text { Categorize } \\
\text { attribute stimuli } \\
\text { into attribute } \\
\text { categories }\end{array}$ & $\begin{array}{c}\text { First } \\
\text { incongruent } \\
\text { pairing }\end{array}$ & $\begin{array}{c}\text { Second } \\
\text { incongruent } \\
\text { pairing }\end{array}$ & $\begin{array}{c}\text { Reversed } \\
\text { mapping }\end{array}$ & $\begin{array}{c}\text { First } \\
\text { congruent } \\
\text { pairing }\end{array}$ & $\begin{array}{c}\text { Second } \\
\text { congruent } \\
\text { pairing }\end{array}$ \\
\hline
\end{tabular}




\begin{tabular}{|c|c|c|c|c|c|c|c|}
\hline $\begin{array}{l}\text { Task } \\
\text { Instructions }\end{array}$ & $\begin{array}{c}\text { - Female } \\
\text { Male • }\end{array}$ & $\begin{array}{c}\text { - High Executive } \\
\text { Potential } \\
\text { Low Executive } \\
\text { Potential• }\end{array}$ & $\begin{array}{c}\cdot \text { Female } \\
\bullet \text { High } \\
\text { Executive } \\
\text { Potential } \\
\text { Male • } \\
\text { Low } \\
\text { Executive } \\
\text { Potential • }\end{array}$ & $\begin{array}{c}\cdot \text { Female } \\
\text { • High } \\
\text { Executive } \\
\text { Potential } \\
\text { Male • } \\
\text { Low } \\
\text { Executive } \\
\text { Potential • }\end{array}$ & $\begin{array}{l}\text { Female • } \\
\text { - Male }\end{array}$ & $\begin{array}{c}\cdot \text { Female } \\
\text { • Low } \\
\text { Executive } \\
\text { Potential } \\
\text { Male • } \\
\text { High } \\
\text { Executive } \\
\text { Potential • }\end{array}$ & $\begin{array}{c}\cdot \text { Female } \\
\bullet \text { Low } \\
\text { Executive } \\
\text { Potential } \\
\text { Male • } \\
\text { High } \\
\text { Executive } \\
\text { Potential• }\end{array}$ \\
\hline $\begin{array}{l}\text { Number of } \\
\text { Trials }\end{array}$ & 20 & 20 & 20 & 40 & 40 & 20 & 40 \\
\hline
\end{tabular}

The $\operatorname{symbol}$ denotes the correct responses for each step of the Implicit Association Test.

\section{Stimuli for the Implicit Association Test.}

[Participants will complete the IAT set with the High Executive Potential Attributes Based on Theory or Based on Highly Characteristic Attributes of an Ideal Worker]

\begin{tabular}{|c|c|c|c|c|}
\hline $\begin{array}{l}\text { Male } \\
\text { Names }\end{array}$ & $\begin{array}{l}\text { Female } \\
\text { Names }\end{array}$ & $\begin{array}{c}\text { High Executive Potential } \\
\text { Attributes (Based on Theory) }\end{array}$ & $\begin{array}{c}\text { High Executive Potential Attributes } \\
\text { (Based on Highly Characteristic } \\
\text { Attributes of an Ideal Worker) } \\
\end{array}$ & $\begin{array}{c}\text { Low Executive Potential } \\
\text { Attributes }\end{array}$ \\
\hline $\begin{array}{l}\text { Daniel } \\
\text { Christopher } \\
\text { Jason } \\
\text { David } \\
\text { James } \\
\text { John } \\
\text { Robert } \\
\text { Brian } \\
\text { William } \\
\text { Matthew } \\
\text { Andrew } \\
\text { Joseph }\end{array}$ & $\begin{array}{l}\text { Jennifer } \\
\text { Amy } \\
\text { Melissa } \\
\text { Sarah } \\
\text { Lisa } \\
\text { Angela } \\
\text { Heather } \\
\text { Nicole } \\
\text { Emily } \\
\text { Amanda } \\
\text { Megan } \\
\text { Rachel }\end{array}$ & $\begin{array}{l}\text { Works long hours } \\
\text { Hard-working } \\
\text { Productive } \\
\text { Passionate about job } \\
\text { Dedicated } \\
\text { Career-oriented } \\
\text { Prioritizes job } \\
\text { Loyal }\end{array}$ & $\begin{array}{l}\text { Takes initiative } \\
\text { Independent } \\
\text { Determined } \\
\text { Confident } \\
\text { Seeks responsibility } \\
\text { Ambitious } \\
\text { Goal-oriented } \\
\text { High-potential } \\
\text { Encouraging } \\
\text { Helpful } \\
\text { Understands others } \\
\text { Takes a stand }\end{array}$ & $\begin{array}{l}\text { Absent } \\
\text { Devious } \\
\text { Aloof } \\
\text { Lazy } \\
\text { Vulgar } \\
\text { Bitter } \\
\text { Procrastinator } \\
\text { Uncertain } \\
\text { Timid } \\
\text { Anxious }\end{array}$ \\
\hline
\end{tabular}

To conclude this study, we would like to learn more about you including your background and work experience. The following questions will be used to aggregate the results of this study. 


\section{Demographic Information}

We would like to know a little bit more about you. The questions below will be used to classify your responses; your answers to these questions will be kept confidential and will be used only for classification.

What is your gender? [Male, Female, Other]

What is your age (in years)?

What is your race? Please select all that apply. [American Indian or Alaska Native, Asian, Black or African American, Hispanic, Native Hawaiian or Other Pacific Islander, White]

What is your highest level of education? [Less than a high school diploma, High school degree or equivalent (e.g., GED), Some college but no degree, Associate degree, Bachelor degree, Master degree, Professional degree, Doctorate]

What is your marital status? [Single, Married or in a domestic partnership, Widowed, or Divorced, Separated]

[If married or domestic partnership] What gender is your partner? [Male, Female, Other]

[If married or domestic partnership] Does your partner work for pay? [Yes, full-time; Yes, part-time, No]

Are you a native English speaker? [Yes, No]

What field do you work in?

$\vec{\infty} \quad$ How long have you worked in your current organization (in years)?

How long have you worked in your current role (in years)?

At what level of leadership is your current position in the organization? [Non-leader, Entry-level management, Middle-level management, Senior-level management] 


\section{Appendix VII: Research Question 5 Study Implicit Association Pre-test Survey}

\section{Rate High and Low Executive Potential Attributes}

We would like to know how you think about the following attributes. For each attribute, please rate on a scale from 1-5, where 1 means "Very much describes an employee with low executive potential" and 5 means "Very much describes an employee with high executive potential."

[Order of the attributes will be randomized.]

\begin{tabular}{|c|c|c|c|c|c|}
\hline & $\begin{array}{c}1=\text { Very } \\
\text { Much } \\
\text { Describes } \\
\text { an } \\
\text { Employee } \\
\text { with Low } \\
\text { Executive } \\
\text { Potential }\end{array}$ & $\begin{array}{c}2= \\
\text { Somewhat } \\
\text { Describes } \\
\text { an } \\
\text { Employee } \\
\text { with Low } \\
\text { Executive } \\
\text { Potential }\end{array}$ & $\begin{array}{c}3=\text { Does } \\
\text { Not } \\
\text { Describe an } \\
\text { Employee } \\
\text { with Either } \\
\text { Low or } \\
\text { High } \\
\text { Executive } \\
\text { Potential }\end{array}$ & $\begin{array}{c}4= \\
\text { Somewhat } \\
\text { Describes } \\
\text { an } \\
\text { Employee } \\
\text { with High } \\
\text { Executive } \\
\text { Potential }\end{array}$ & $\begin{array}{c}5=\text { Very } \\
\text { Much } \\
\text { Describes } \\
\text { an } \\
\text { Employee } \\
\text { with High } \\
\text { Executive } \\
\text { Potential }\end{array}$ \\
\hline $\begin{array}{l}\text { (High Executive Potential Attributes Based on } \\
\text { Theory) }\end{array}$ & & & & & \\
\hline Works long hours & & & & & \\
\hline Travels for work & & & & & \\
\hline Relocates for work & & & & & \\
\hline Hard-working & & & & & \\
\hline Productive & & & & & \\
\hline Passionate about job & & & & & \\
\hline Dedicated & & & & & \\
\hline Career-oriented & & & & & \\
\hline Prioritizes job & & & & & \\
\hline $\begin{array}{l}\text { ( High Executive Potential Attributes Based on } \\
\text { Highly Characteristic of an Ideal Worker) }\end{array}$ & & & & & \\
\hline Takes initiative & & & & & \\
\hline
\end{tabular}




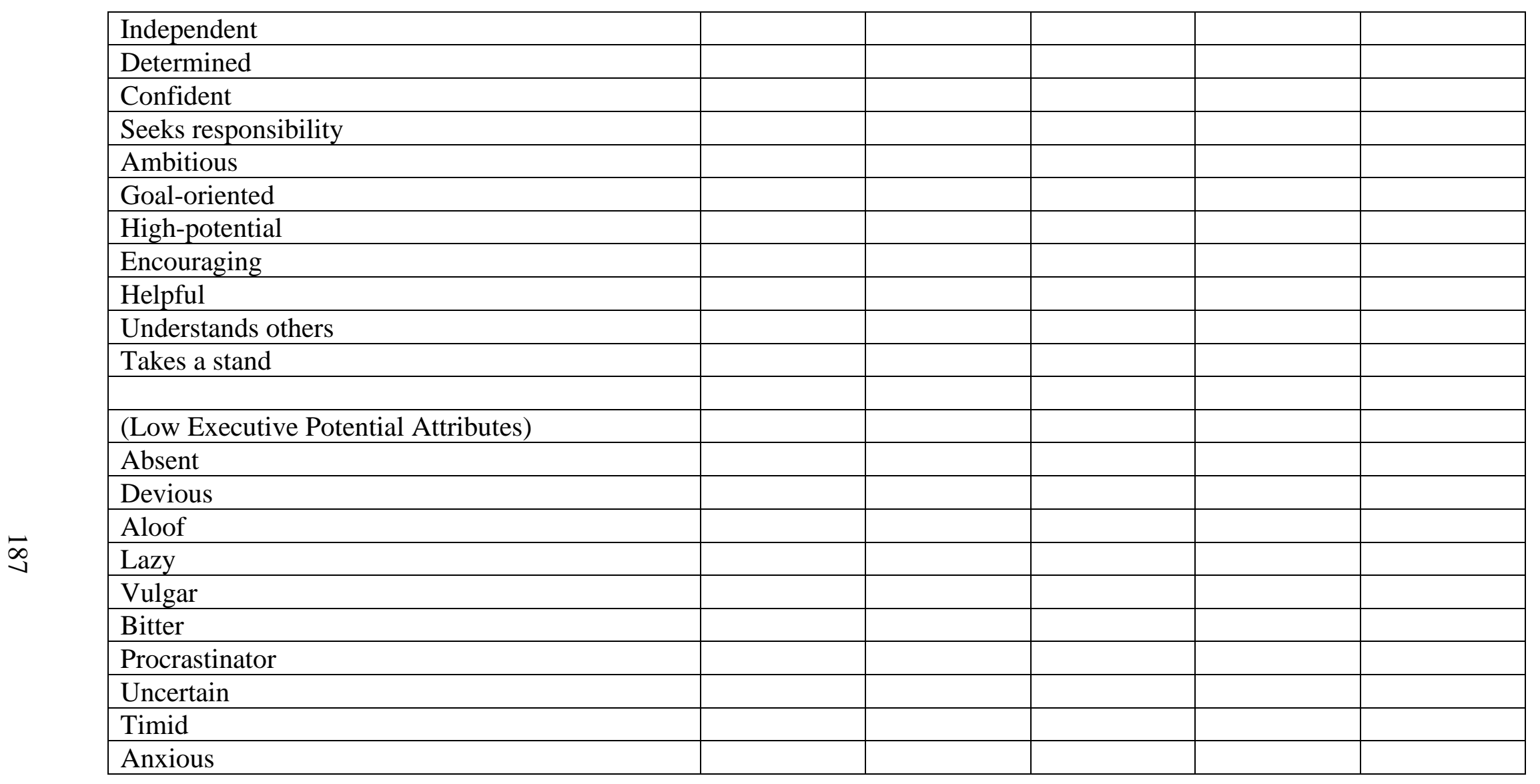

\section{Implicit Association Test}

In this next task, we are validating a few research scales for use in future studies. On the next screen, you will begin one of the validation tests. Instructions will be shown to you and you will have a chance to practice the task. Please press the forward button to begin the task.

[Instructions provided in the software, which will be integrated into Qualtrics, the survey software. The following tables show how the trials will be organized and the words and phrases shown to participants during the IAT.] 
Sequence of Implicit Association Test Presentation

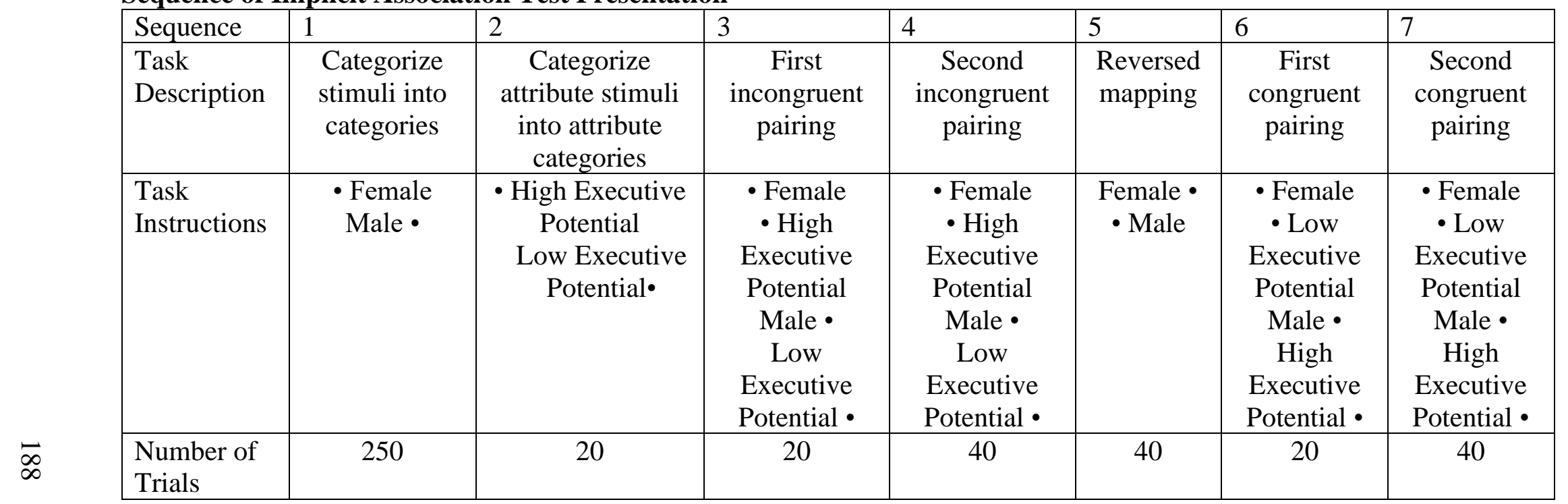

The symbol denotes the correct responses for each step of the Implicit Association Test.

Stimuli for the Implicit Association Test.

[Respondents will be randomly assigned to the High Executive Potential Attributes based on theory or based on highly characteristic attributes of an ideal worker]

\begin{tabular}{|c|c|c|c|c|}
\hline $\begin{array}{l}\text { Male } \\
\text { Names }\end{array}$ & $\begin{array}{l}\text { Female } \\
\text { Names }\end{array}$ & $\begin{array}{c}\text { High Executive Potential } \\
\text { Attributes (Based on Theory) }\end{array}$ & $\begin{array}{l}\text { High Executive Potential Attributes } \\
\text { (Based on Highly Characteristic } \\
\text { Attributes of an Ideal Worker) } \\
\end{array}$ & $\begin{array}{c}\text { Low Executive Potential } \\
\text { Attributes }\end{array}$ \\
\hline Daniel & Jennifer & Works long hours & Takes initiative & Absent \\
\hline Christopher & Amy & Travels for work & Independent & Devious \\
\hline Jason & Melissa & Relocates for work & Determined & Aloof \\
\hline David & Sarah & Hard-working & Confident & Lazy \\
\hline James & Lisa & Productive & Seeks responsibility & Vulgar \\
\hline John & Angela & Passionate about job & Ambitious & Bitter \\
\hline Robert & Heather & Dedicated & Goal-oriented & Procrastinator \\
\hline
\end{tabular}




\begin{tabular}{|c|c|l|l|l|}
\hline Brian & Nicole & Career-oriented & High-potential & Uncertain \\
William & Emily & Prioritizes job & Encouraging & Timid \\
Matthew & Amanda & Loyal & Helpful & Anxious \\
Andrew & Megan & & Understands others & \\
Joseph & Rachel & & Takes a stand & \\
\hline
\end{tabular}

\section{Demographic Information}

We would like to know a little bit more about you. The questions below will be used to classify your responses; your answers to these questions will be kept confidential and will be used only for classification.

What is your gender? [Male, Female, Other]

What is your age (in years)?

What is your race? Please select all that apply. [American Indian or Alaska Native, Asian, Black or African American, Hispanic, Native Hawaiian or Other Pacific Islander, White]

What is your highest level of education? [Less than a high school diploma, High school degree or equivalent (e.g., GED), Some college but no degree, Associate degree, Bachelor degree, Master degree, Professional degree, Doctorate] What is your marital status? [Single, Married or in a domestic partnership, Widowed, or Divorced, Separated] [If married or domestic partnership] What gender is your partner? [Male, Female, Other] [If married or domestic partnership] Does your partner work for pay? [Yes, full-time; Yes, part-time, No] Are you a native English speaker? [Yes, No]

What field do you work in?

How long have you worked in your current organization (in years)?

How long have you worked in your current role (in years)?

At what level of leadership is your current position in the organization? [Non-leader, Entry-level management, Middle-level management, Senior-level management] 


\section{VITA}

Clarissa R. Steele was born in Columbia, Missouri. In sixth grade she moved to Kearney, Nebraska, and graduated from Kearney Senior High School. She attended the University of Nebraska-Lincoln and graduated with a Bachelor of Science in Business Administration (in Management) and a Bachelor of Arts in Spanish and Psychology in May 2004. As an undergraduate student, she studied abroad in Toledo, Spain, at the Fundación Ortega y Gasset in the spring of 2003. After graduation, she pursued a Master of Arts in Spanish from Bowling Green State University in Ohio. She spent the first year of her graduate program studying in Alcalá de Henares, Spain, and completed the degree in May 2006. After completing her master's program, she worked as a Study Abroad Advisor at Texas A\&M University in College Station, Texas, where she specialized in programs in Spanish-speaking countries. She worked in study abroad for a little over a year before returning to the University of Nebraska-Lincoln to pursue a Master of Science in Survey Research and Methodology. She graduated in May 2010. She then worked at the University of Wisconsin-Madison in K-12 education research as a survey specialist before returning to graduate school. She began her doctoral program at the University of Missouri-Columbia in the fall of 2015. As a doctoral candidate at Mizzou, she was a university-wide runner-up of the 3-Minute Thesis competition two years in a row. She earned a Doctor of Philosophy in Business Administration, with a concentration in Management, in May 2020. 